\title{
ENERGY CONSERVATION
}

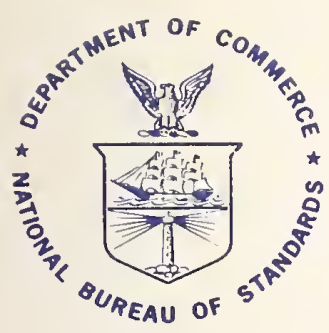

\section{THROUGH EFFECTIVE ENERGY UTILIZATION}

NBS SPECIAL PUBLICATION 403

U.S. DEPARTMENT OF COMMERCE/ National Bureau of Standards

A CONFERENCE SPONSORED BY NATIONAL BUREAU" OF STANDARDS NATIONAL SCIENCE FOUNDATION ENGINEERING FOUNDATION

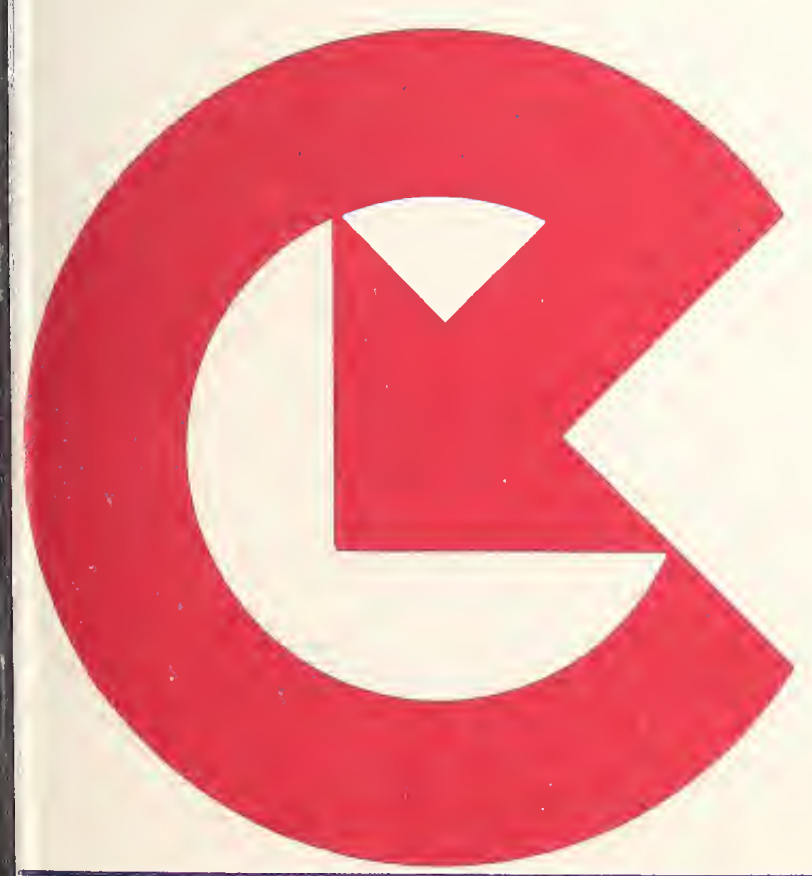


The National Bureau of Standards' was established by an act of Congress March 3, 1901. The Bureau's overall goal is to strengthen and advance the Nation's science and technology and facilitate their effective application for public benefit. To this end, the Bureau conducts research and provides: (1) a basis for the Nation's physical measurement system, (2) scientific and technological services for industry and government, (3) a technical basis for equity in trade, and (4) technical services to promote public safety. The Bureau consists of the Institute for Basic Standards, the Institute for Materials Research, the Institute for Applied Technology, the Institute for Computer Sciences and Technology, and the Office for Information Prograns.

THE INSTITUTE FOR BASIC STANDARDS provides the central basis within the United States of a complete and consistent system of physical measurement; coordinates that system with measurement systems of other nations; and furnishes essential services leading to accurate and uniform physical measurements throughout the Nation's scientific community, industry, and commerce. The Institute consists of the Office of Measurement Services, the Office of Radiation Measurement and the following Center and divisions:

Applied Mathematics - Electricity - Mechanics - Heat - Optical Physics - Center for Radiation Research: Nuclear Sciences; Applied Radiation - Laboratory Astrophysics ? - Cryogenics ${ }^{2}$ - Electromagnetics " - Time and Frequency ${ }^{2}$

THE INSTITUTE FOR MATERIALS RESEARCH conducts materials research leading to improved methods of measurement, standards, and data on the properties of well-characterized materials needed by industry, commerce, educational institutions, and Government; provides advisory and research services to other Government agencies; and develops, produces, and distributes standard reference materials. The Institute consists of the Office of Standard Reference Materials, the Office of Air and Water Measurement, and the following divisions:

Analytical Chemistry - Polymers - Metallurgy - Inorganic Materials - Reactor Radiation - Physical Chemistry.

THE INSTITUTE FOR APPLIED TECHNOLOGY provides technical services to promote the use of available technology and to facilitate technological innovation in industry and Government; cooperates with public and private organizations leading to the development of technological standards (including mandatory safety standards), codes and methods of test; and provides technical advice and services to Government agencies upon request. The Institute consists of the following divisions and Centers:

Standards Application and Analysis - Electronic Technology - Center for Consumer Product Technology: Product Systems Analysis; Product Engineering - Center for Building Technology: Structures, Materials, and Life Safety; Building Environment; Technical Evaluation and Application - Center for Fire Research: Fire Science; Fire Safety Engineering.

THE INSTITUTE FOR COMPUTER SCIENCES AND TECHNOLOGY conducts research and provides technical services designed to aid Government agencies in improving cost effectiveness in the conduct of their prograns through the selection, acquisition, and effective utilization of automatic data processing equipment; and serves as the principal focus within the executive branch for the development of Federal standards for automatic data processing equipment, techniques, and computer languages. The Institute consists of the following divisions:

Computer Services - Systenss and Software - Computer Systems Engineering - Information Technology.

THE OFFICE FOR INFORMATION PROGRAMS promotes optimum dissemination and accessibility of scientific information generated within NBS and other agencies of the Federal Government; promotes the development of the National Standard Reference Data System and a system of information analysis centers dealing with the broader aspects of the National Meilsurement System; provides appropriate services to ensure that the NBS staff has optimum accessibility to the scientific information of the world. The Office consists of the following organizational units:

Office of Standard Reference Ditti - Office of Information Activities - Office of Technical Publications - Library - Office of International Relations - Office of International Standards.

Headquarters and Laboratories at Gaithersburg, Maryland, unless otherwise noted; mailing address Washington, D.C. 20234.

- Located at Boulder, Colorado 80302 


\section{Energy Conservation Through Effective Energy Utilization}

1973 Engineering Foundation Conference

New England College

Henniker, New Hampshire

August 19-24, 1973

Edited by:

Jesse C. Denton

National Center for Energy Management \& Power

University of Penusylvania

Philadelphia, Pennsylvania 19174

Stephen Webber and John Moriarty*

Institute for Applied Technology

National Bureau of Standards

Washington, D.C. 20234

* Transferred to Federal Energy Administration

Co-Sponsored by:

National Bureau of Standards

Washington, D.C. 20234

National Science Foundation

1800 G Street, N.W.

Washington, D.C. 20550

Engineering Foundation

345 East 47 th Street

New York, N.Y. 10017

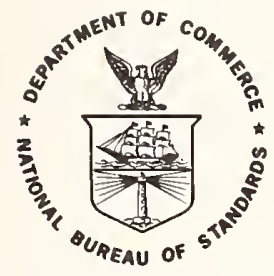

U.S. DEPARTMENT OF COMMERCE, Elliot L. Richardson, Secretary

Dr. Betsy Ancker-Johnson, Assistant Secretary for Science and Technology

NATIONAL BUREAU OF STANDARDS, Ernest Ambler, Acting Director 
Library of Congress Cataloging in Publication Data

Main entry under title:

Energy conservation through effeetive energy utilization.

(National Bureau of Standards spceial publication: 403)

"CODEN: XNBSAV."

Supt. of Docs. no.: C 13.10:403

1. Energy eonservation Congresses. I. Denton, Jesse C. II. Webber, Stephen. III. Moriarty, John E. IV. United States. National Burtau of Standards. V. United States. National Seience Foundation. VI. Engineering Foundation, New York. VII. Series: United States. National Bureau of Standards. Speeial publication; 103.

QC100.U57 no. 403 [TJ163.3] 602'.1s [333.7] 76.18680

\section{National Bureau of Standards Special Publication 403}

Nat. Bur. Stand. (U.S.), Spec. Publ. 403, 251 pages (June 1976)

CODEN: XNBSAV 


\section{PREFACE}

A conference on "Energy Conservation Through Effective Energy Utilization" was held at New England College, Henniker, N.H., August 19-24, 1973 by the Engineering Foundation.

Funding for the conference expenses was provided by the Engineering Foundation, the National Bureau of Standards, and the National Science Foundation. The conference was co-chaired by Dr. Jesse C. Denton, National Center for Energy Management and Power, and the late Dr. Robert R. Gatts, National Bureau of Standards.

The conference objective was to study the opportunities and implications of more effective utilization of thermal energy on an interdisciplinary basis. The conference focused on effective utilization of thermal energy as a means of energy conservation to identify areas in which research is needed and should have significant impact. The conference was successful in identifying some specific research tasks but in other cases, because of the broad ramifications and diversity inherent in the topic, it was only possible to identify vital research areas which need to be amplified and elaborated in greater detail to provide sharper focus for specific research topics. It is hoped that the proceedings will stimulate a national dialogue leading to substantive progress toward a balanced national program for energy conservation. There is, of course, much left to be done in thermal process technologies as applied in industrial processes, in industrial equipment, and in heating, ventilating, and air conditioning (HVAC) equipment for buildings. A clear message from the conference is that technology availability is not the pacing factor. Rather, the institutional factors relating to economics, management, finance, and national policy are the pacing factors for the introduction of much technology that is already available. The conference demonstrated that engineering design, when the other factors permit, can and does result in striking reductions in the energy intensiveness of thermal process technologies.

The proceedings of the conference reflect, in chronological sequence, the main presentations by the speakers. The single exception is the grouping of the Messrs. Berg and Shepherd presentations into an "Introduction" for the proceedings. The several discussion panels provided daily outputs which were incorporated in the rapporteurs' reports delivered in the Summary and Critique session of the last day of the conference.

Every effort has been made to minimize the editing and to reflect each author's original material as given. The editing criterion used was to shorten a paper only to avoid repetition of material or to reduce the technical details with respect to equipment. Great care was exercised to retain the major items of concern presented by each speaker. 

I. INTRODUCTION

Effective Utilization of Energy and Other Natural Resources,

C.A. Berg, National Bureau of Standards

(Now private consultant)

Energy Conservation Goals and Methods,

Robert E. Shepherd, Department of Commerce

II. NATIONAL CONTEXT FOR ENERGY CONSERVATION

National Benefits of Energy Conservation

Leon R. Glicksman and David C. White, Massachusetts

Institute of Technology

Options for Energy Conservation,

B. Hannon, University of Illinois

Measures of Thermal Energy Utilization,

B.B. Hamel and H.L. Brown, Drexel University

Economic and Environmental Implications of Effective Utilization of Energy,

Jesse C. Denton, University of Pennsylvania

III. ENERGY MANAGEMENT PRACTICE

Industrial Energy Analysis and Forecasting, D.R. Limaye, J.R. Sharko, and J.H. Kayser, Decision Sciences Corporation

Management's Role in Industrial Thermal Energy Utilization,

Allen S. Cook, American Can Company

Development of Industrial Energy Management Policies,

Michael C. Noland, Midwest Research Institute

Case Histories of Effective Energy Utilization in

Industry,

William Rudoy, University of Pittsburgh

IV. APPLICATIONS OF THERMAL PROCESS TECHNOLOGY

A Projection of Energy Demand by the Iron and Steel Industry,

D. Larson, Institute of Gas Technology 
Page No.

IV. APPLICATIONS OF THERMAL PROCESS TECHNOLOGY (cont.)

Potential Energy Savings in the Forming of Paper,

T. Speide1, Thermo Electron Corporation, and

D. Kallmes, M/K Systems

Potential for Energy Conservation in Heating, Ventilating and Air-Conditioning Equipment for Buildings

G. Kelly, T. Kusuda, and J. Hill,

National Bureau of Standards

ASHRAE and Energy Conservation,

Preston E. McNa11, Jr., Johnson Service Company, and Chairman, ASHRAE Research \& Technical

Committee

V. INSTITUTIONAL CONSIDERATIONS FOR ENERGY CONSERVATION

Factors Controlling the Manufacture and Marketing of Energy Conserving Products, J.B. Comly and C.M. Huggins, General Electric Corporate Research \& Development

Economic, Energy, Environment Tradeoffs,

Paul Swatek, Massachusetts Audubon Society

Regulatory, Legal and Tax Constraints on Energy Conservation - Polemic or Fact?

Hon. Charles Warren, Assemblyman, Califomia

State Assembly

Financial Feasibility of Energy Conservation Sheldon Sixfin, The Chase Manhattan Bank

\section{SUMMARY AND CRITIQUE}

National Context for Energy Conservation, Jesse C. Denton, University of Pennsylvania

Energy Management in Industry,

Robert G. Gatts, National Bureau of Standards (Deceased)

Application of Thermal Process Technology, Kenneth G. Kreider, National Bureau of Standards

Institutional Considerations Respecting Energy Conservation, Samuel Z. Klausner, University, of Pennsylvania 
Page No.

APPENDIX A

Energy Conservation Through Effective Energy

Utilization, Engineering Foundation Conference, August 1973

255

APPENDIX B

Participants in Engineering Foundation

Conference

258 

These proceedings of the 1973 Engineering Foundation Conference focus on effective utilization of thermal energy as a means of energy conservation. It is hoped publication will help stimulate the national dialogue toward a balanced national program for more energy conservation.

The varied professional backgrounds of the participants provided an interdisciplinary approach for action steps to be taken in areas where research is needed and will provide a significant impact. For example, the development of better stack controls was recommended as a specific research task, and the improvement of energy accounting systems and energy use norms was recommended as a useful research area. Broad agreement was reached that there is much left to be accomplished in thermal process technology as used in industrial processes; in industrial equipment, and in heating, ventilating, and air conditioning (HVAC) equipment for buildings.

A clear conclusion of the conference is that while new technology is important the introduction of much technology that is already available is equally, if not more, important. Institutional barriers relating to economics, management, finance, and national policy keep available technology standing in the wings. The conference papers and discussions show that engineering design, when it can be rigorously applied, does result in striking reductions in energy use in the thermal process technologies.

Key words: Automobile; break-even analysis; conservation; cooling; economics; energy; environment; fuel; heating; industry; imports; management; manufacturing; paper; petroleum; resources; standards; steel; thermal; thermodynamics. 

I. I N T R O D U C T I O N 
National Bureau of Standards Special Publication 403

Proceedings of 1973 Engineering Foundation Conference (Issued June 1976)

\title{
EFFECTIVE UTILIZATION OF ENERGY AND OTHER NATURAL RESOURCES
}

\section{by}

\author{
C. A. Berg \\ National Bureau of Standards \\ Washington, D. C. 20234
}

\begin{abstract}
An overview of the Nation's energy problems is presented to provide a basis of definition for the term "energy crisis." The term does not represent a crisis of depletion of energy resources but rather refers to energy cost. The dependency of the United States on fuel imports illustrates the problems that questionable reliability and increasing costs of fuel imports pose for American industry. Improving energy use efficiency would reduce energy consumption and, considering rising energy costs, may prove to be economically attractive to industry. A policy of national life-term costing of equipment, which includes energy cost of that equipment, should be promoted rather than the present criterion of justification which is based primarily on first costs. Further, a rational economic method for achieving effective and balanced use of all natural resources, based on total life-term costing, is advocated.
\end{abstract}

Key words: Costs; economics; energy; fuel; imports

Over the last few years public attention has been increasingly attracted to energy problems. More effective and better organized efforts must be brought to bear to resolve the Nation's energy problems. This paper outlines a view of the problems and attempts to provide a basis of definition for the term "energy crisis."

The supply of fuel is a serious concern, but the exhaustion of fuels does not constitute the energy crisis. Table 1 shows the world (per capita) consumption of fuels by the principal consumers. These data illustrate several things. First, the United States is the largest per capita consumer of fuels in the world. Second, the United States, compared with the other industrialized nations, consumes vast quantities of fuel. Table 2 shows oil imports by millions of barrels per day for the United States and Western Europe. One sees that the United States' imports are estimated to double in the period from 1973 to 1980 . We may go from importing approximately $20 \%$ of the oil we consume to importing $50 \%$, or more, of our oil. Present estimates indicate that the cost of imported fuel may then be between $\$ 20$ to $\$ 30$ billion a year. The importation of fuels to continue the operation of industry and to support life functions which are essentially dependent upon fuel, including electrical power generation, is a serious matter. We have been a large energy producer. We have been able to operate our industries on low-cost, high-quality fuels without having to rely on imports. That day has passed.

The world crisis means a turning point; the turning point reached in energy availability is that prices of fuel will no longer decline. Fuel availability can no longer be assumed. The costs and the stability of sources of fuel will become increasingly important considerations in the conduct of all operations that depend upon fuel.

Table 3 shows sources of petroleum imports into the U.S. Petroleum is one of the most sensitive types of fuel. The Middle East has an outstandingly strong position in supplying the United States with oil, as does the Caribbean. Neither area is noted especially for long term stability. These less-developed regions, characterized by political flux, are endowed. with rich petroleum resources. They also are the major sources of petroleum imports for the United States.

Table 4 shows the oil reserves presently known to exist. The United States has on the order of 45 billion barrels of proven reserves. The Middle East has 350 to 360 billion barrels. To appreciate what that means in terms of the period of consumption that the reserve could support, recall Table 1. If the United States were to provide its own oil out of its proven reserves, these reserves would last 15 to 20 years. Historically, however, the proven reserves of the United States have seldom been much more than 10 to 15 years of 
the contemporary rate of consumption. There is a reason for that. "Proven reserves" means oil which is known to exist by actual drilling; the oil is known to be there and can be extracted. The proven reserves are the result of heavy investment; one does not normally drill holes to find oil until a market is established.

Table 1

World Energy Consumption - per capita (1970)

\begin{tabular}{|c|c|}
\hline Country or Region & $\begin{array}{l}\text { Coal Equivalent } \\
\text { in kilograms }\end{array}$ \\
\hline World . . . . . . . . . . . . . & 1,897 \\
\hline Market economies: & \\
\hline Developed $1 / \ldots \ldots \ldots$ & 5,914 \\
\hline 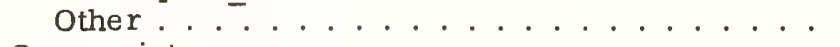 & 330 \\
\hline Communist areas: & \\
\hline Europe (including U.S.S.R) . . . . . . & 4,404 \\
\hline$\ldots$ & 543 \\
\hline United States . . . . . . . . . . . . . . & 11,128 \\
\hline 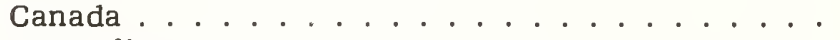 & 8,997 \\
\hline Australia . . . . . . . . . . . & 5,374 \\
\hline United King dom . . . . . . . . . . . . . . . . . . . & 5,358 \\
\hline West Germany . . . . . . . . . . . . . . . . & 5,151 \\
\hline U.S.S.R. . . . . . . . . . & 4,436 \\
\hline 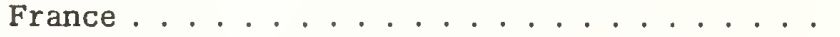 & 3,799 \\
\hline Japan . . . . . . . . . . . . & 3,215 \\
\hline 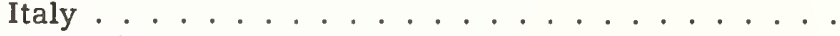 & 2,685 \\
\hline Argentina . . . . . . . . . & 1,686 \\
\hline 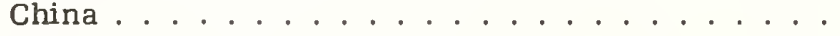 & 522 \\
\hline India . . . . . . . . . . . . . . & 189 \\
\hline Nigeria . . . . . . . . . . . & 45 \\
\hline Yemen . . . . . . . . . . . & 13 \\
\hline
\end{tabular}

1/ North America, Western Europe, Japan, Australia/New Zealand, South Africa, Israel. Source: Petroleum Press Service, April 1973

Table 2

Oil Imports (million barrels/day)

\begin{tabular}{|c|c|c|c|}
\hline & 1972 & Est. 1973 & Est. 1980 \\
\hline United States .... & 4.7 & 6.0 & $10-12$ \\
Western Europe... & 14.4 & 15.5 & $22-26$ \\
Japan ................. & 5.0 & 5.5 & $10-13$ \\
\hline TOTAL . 24.1 & 27.0 & $42-51$ \\
\hline
\end{tabular}

Source: Presidential Message Fact Sheet, April 18, 1973. 
Table 3

Sources of Crude Oil and Oil Product

Imports into the United States

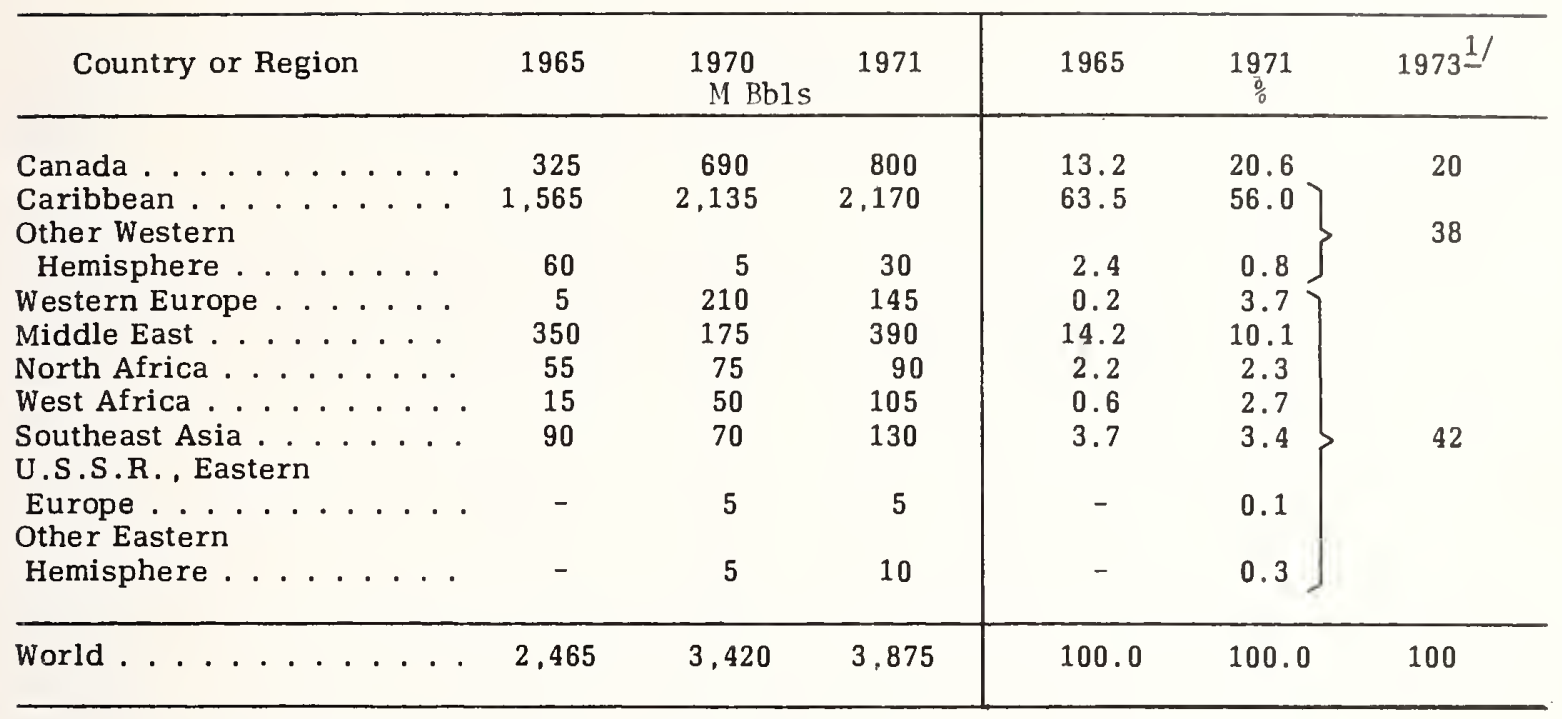

Source: British Petroleum Company, Statistical Review of the World Oil Industry (published annually) .

1/Presidential Energy Message Fact Sheet, April 1973. Current Rate

Table 4

Worldwide "Published Proved" Oil Reserves, end of 1971

\begin{tabular}{|c|c|c|}
\hline Country/area & $\begin{array}{l}\text { Barrels } \\
\text { (billion) }\end{array}$ & $\begin{array}{c}\text { Share of total } \\
\text { (percent) }\end{array}$ \\
\hline 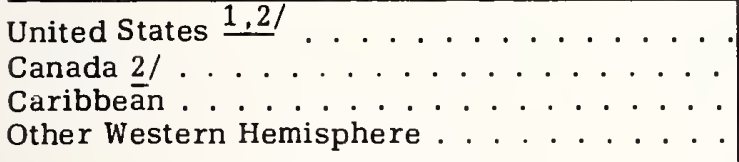 & $\begin{array}{l}45.4 \\
10.2 \\
17.1 \\
14.5\end{array}$ & $\begin{array}{l}6.8 \\
1.5 \\
2.8 \\
2.3\end{array}$ \\
\hline Total Western Hemisphere . . . . . . & 87.2 & 13.4 \\
\hline 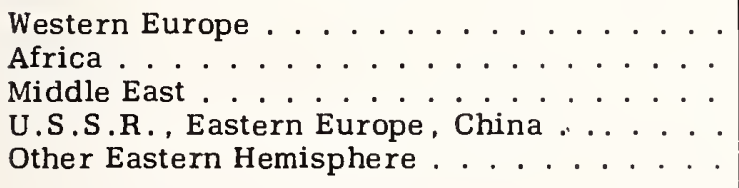 & $\begin{array}{r}14.8 \\
58.9 \\
366.8 \\
98.5 \\
15.6\end{array}$ & $\begin{array}{r}2.3 \\
8.9 \\
57.6 \\
15.4 \\
2.4\end{array}$ \\
\hline Total Eastern Hemisphere . . . . . . . & 554.6 & 86.6 \\
\hline $\begin{array}{l}\text { World (excluding U.S.S.R., Eastern } \\
\text { Europe, China . . . . . . . . . . . . } \\
\text { World . . . . . . . . . . . . . . . . . }\end{array}$ & $\begin{array}{l}543.3 \\
641.8\end{array}$ & $\begin{array}{r}84.6 \\
100.0\end{array}$ \\
\hline
\end{tabular}

1/Including estimated North Slope reserves of 9.6 billion barrels.

2/Includes oil that can be recovered for natural gas.

Proved reserves are generally taken to be the volume of oil remaining in the ground which geological and engineering information indicate with reasonable certainty to be recoverable in the future from known reservoirs under existing economic and operating conditions. The data exclude the oil content of shales and tar sands.

Source: British Petroleum Company. Statistical Review of the World Oil Industry 1971 (1972). 
There is an important difference between proven reserves and estimated resources. The term "resources" is used to describe fuel which may be found if an oil field or coal mine were developed. The estimated resources of petroleum make the absolute physical supply of fuels appear less serious a problem than do petroleum reserves. Venezuela, for example, is estimated to have resources of a trillion barrels of heavy oil. The United States has estimated resources of a trillion barrels of heavy oil. The United States has estimated resources of a trillion barrels of oil in oil shale. Canada has 600 billion barrels of oil in oil-bearing sands. Producing these estimated resources may be a problem, however. It is very costly to remove oil from shale and sand, and costly to refine heavy oil.

According to this analysis, the United States has an abundance of coal. Coal experts have estimated that we could support our present coal consumption for about 500 years on known reserves. If we were to mine 15 inch veins and restrict strip mining to those sites where the surface could be reclaimed, we could probably satisfy our needs for coal for 1500 years. However, in some cases the coal has high sulfur content. In most cases it has fairly high ash content. Coal can be expensive to clean up and expensive to use. The cost of using this fuel is going to rise.

Even though fuel resources are finite and can eventually be exhausted, the supply of petroleum and coal is not in imminent jeopardy. The crisis is that the low cost at which fuels can be made available is in jeopardy.

The reliability and stability of petroleum sources and the increasing costs of using all forms of fuel constitute an issue which American industry must take seriously. The United States has been operating with cheap fuels. Excess consumption of fuels has often been designed into industrial processes because the price of fuels has been declining. We have been in industrial competition with countries such as France, Japan, and West Germany. These countries are accustomed to importing costly fuels for the operation of industry. As a general rule, the efficiency of fuel utilization in countries which are essentially dependent upon petroleum imports or coal imports is somewhat greater than in those countries which are richly endowed with cheap, high quality fuels. The argument that the U.S. can pay an increasing import fuel bill by merely increasing exports is based upon the questionable premise that our industries are now equipped to operate with sufficient efficiency at substantially higher fuel prices to permit us to export effectively. This premise is not born out by examination of present day industrial plants.

Besides facing a problem of limited availability and high price of fuels, we might also find that we might have to import industrial technology to make effective use of the more costly imported fuels. We can avoid this vicious cycle with prompt and effective action.

Is it possible for the United States to reduce fuel imports by using fuels more efficiently? To answer this question one needs to know two things: How much fuel does the United States consume in various practices, and with what efficiency is the fuel used? Table 5 gives the summary data from the Stanford Research Institute report on "Patterns of Energy Consumption in the U.S.A.", and these data provide a preliminary answer to the first of the above questions.

These data show several major aspects of fuel use in the United States. The ultimate use of fuel occurs in three major areas. The first, the support of building services in residential and commercial buildings, accounts for about 33 to $34 \%$ of all fuels consumed in the U.S.A. For every kilowatt hour consumed in construction of a large building, about one kilowatt hour per year will be required to operate the building services. The second large sector, the operation of industrial processes, accounts for about 40 percent of all fuel consumption. The third major area, transportation, accounts for roughly $25 \%$ of our total fuel consumption.

We should not overlook the minor areas of fuel consumption. Using high quality fuel to provide low temperature heat is a waste. The data show that water heating in residential and commercial buildings accounts for $4 \%$ of the national fuel consumption. Also, cooking in residential buildings accounts for somewhat more than $1 \%$ of the total national fuel consumption. These mundane practices which seldom require heat above 100 degrees $\mathrm{C}$, consune a large quantity of high-quality fuel.

Industrial electrolytic processes (including refining of aluminum) account for about $1 \%$ of the total fuel consumption in the country. Hot water heating for the purpose of bathing and washing clothes consumes about four times as much fuel as the whole aluminum industry. Yet, in public discussions of fuel conservation, the aluminum industry has attracted more notice than the more mundane processes of everyday life. For example, according to industrial standards on hot water heaters, a new unit running in steady state shows a heat transfer efficiency of $70 \%$. The householder tends to assume that the device functions properly because the water is coming out hot, while the heat-transfer efficiency, after some corrosion, soot formation and dust accumulation, may actually drop as low as $35 \%$. Even if hot water heaters were kept clean and operating effectively so that the heat transfer efficiency were maintained at $65 \%$, the nation's hot water heaters would still be wasting more fuel than the whole aluminum industry consumes. This is not 
Table 5

ENERGY CONSUMPTION IN THE UNITED STATES BY END USE $1960-1968$

(Trillions of Btu and Percent per Year)

\begin{tabular}{|c|c|c|c|c|c|}
\hline \multirow[b]{2}{*}{ Sector and End Use } & \multicolumn{2}{|c|}{ Consumption } & \multirow{2}{*}{$\begin{array}{l}\text { Annual Rate } \\
\text { of Growth }\end{array}$} & \multicolumn{2}{|c|}{ National Total } \\
\hline & 1960 & 1968 & & 1960 & 1968 \\
\hline \multicolumn{6}{|l|}{ Residential } \\
\hline Space heating & 4,848 & 6,675 & $4.1 \%$ & $11.3 \%$ & $11.0 \%$ \\
\hline Water heating & 1,159 & 1,736 & 5.2 & 2.7 & 2.9 \\
\hline Cooking & 556 & 637 & 1.7 & 1.3 & 1.1 \\
\hline Clothes drying & 93 & 208 & 10.6 & 0.2 & 0.3 \\
\hline Refrigeration & 369 & 692 & 8.2 & 0.9 & 1.1 \\
\hline Air conditioning & 134 & 427 & 15.6 & 0.3 & 0.7 \\
\hline Other & 809 & 1,241 & 5.5. & 1.9 & 2.1 \\
\hline Total & 7,968 & 11,616 & 4.8 & 18.6 & 19.2 \\
\hline \multicolumn{6}{|l|}{ Commercial } \\
\hline Space heating & 3,111 & 4,182 & 3.8 & 7.2 & 6.9 \\
\hline Water heating & 544 & 653 & 2.3 & 1.3 & 1.1 \\
\hline Cooking & 98 & 139 & 4.5 & 0.2 & 0.2 \\
\hline Refrigeration & 534 & 670 & 2.9 & 1.2 & 1.1 \\
\hline Air conditioning & 576 & 1,113 & 8.6 & 1.3 & 1.8 \\
\hline Feedstock & 734 & 984 & 3.7 & 1.7 & 1.6 \\
\hline Other & 145 & 1,025 & 28.0 & 0.3 & 1.7 \\
\hline \multirow{2}{*}{\multicolumn{6}{|c|}{ Industrial }} \\
\hline & & & & & \\
\hline Process steam & 7,646 & 10,132 & 3.6 & 17.8 & 16.7 \\
\hline Electric drive & 3,170 & 4,794 & 5.3 & 7.4 & 7.9 \\
\hline Electrolytic processes & 486 & 705 & 4.8 & 1.1 & 1.2 \\
\hline Direct heat & 5,550 & 6,929 & 2.8 & 12.9 & 11.5 \\
\hline Feed stock & 1,370 & 2,202 & 6.1 & 3.2 & 3.6 \\
\hline Other & 118 & 198 & 6.7 & 0.3 & 0.3 \\
\hline Total & 18,340 & 24,960 & 3.9 & 42.7 & 41.2 \\
\hline \multicolumn{6}{|l|}{ Transportation } \\
\hline Fuel & 10,873 & 15,038 & 4.1 & 25.2 & 24.9 \\
\hline Raw Materials & 141 & 146 & 0.4 & 0.3 & 0.3 \\
\hline Total & 11,014 & 15,184 & 4.1 & 25.5 & 25.2 \\
\hline National total & 43,064 & 60.526 & 4.3 & $100.0 \frac{0}{8}$ & 100.08 \\
\hline
\end{tabular}

Note: Electric utility consumption has been allocated to each end use.

Source: Stanford Research Institute, using Bureau of Mines and other sources . 
said to detract from the attention given to the problems of effective energy utilization in production of aluminum, which is a matter of proper, and at times passionate, concern to numbers of people. There is also a great need, however, to improve the performance of simple equipment, such as water heaters, to increase the efficiency of fuel utilization.

Examination of industrial processes reveals three large scale processes - direct heat, process steam, and electric drive - which account for vast quantities of fuel consumption. In this country, process steam and direct heat consume more fuel than does transportation. These processes are known to have overall heat transfer efficiencies as low as $30 \%$. For example, the average cement kiln operated in steady state and in well-maintained condition will show a heat transfer efficiency of $30 \%$ for a wet process. The efficiency may be as high as $40 \%$ for a dry process. The efficiency of the average metal heat-treating furnace is about $30 \%$. It appears that heat transfer efficiencies can stand improvement. If the United States can use fuel more efficiently, then less fuel will be consumed.

The next questions are how much will it cost to improve the efficiency of industrial plant equipment, and whether it is economically justifiable to introduce the technology which would reduce industrial fuel consumption? In the studies conducted in the National Bureau of Standards we found three classes of economically justifiable and technically effective measures for improving the efficiency of industrial processes. The first is to apply maintenance practices and appropriate controls of plant operations. The second is to retrofit improved equipment to the existing plant; for example, to install better insulation or heat exchangers. The third is to replace present equipment with superior equipment.

We have found documented cases in which the application of exacting controls to steel reheat plants has yielded 25 percent reductions in fuel requirements with increases in productivity of $12 \%$ - an impressive reduction of fuel consumption which pays for itself. The data concerning retrofitting equipment show that by installing stack gas recuperators on industrial furnaces, furnace rail insulation, or combustion air preheaters, it is often possible to realize returns on investment in excess of $100 \%$. In one case an annual cost rather than an annual saving was reported. This involved combustion air preheaters which were to be installed in large heattreating furnaces. A considerable amount of fuel could be saved, but the device would bear a $\$ 1,000$ annual cost. Since the type of furnace to which that calculation applies can consume $\$ 50,000$ to $\$ 100,000$ worth of fuel each year, a very small rise in the price of fuel could turn that cost into a substantial saving. There is an additional economic justification for conservation devices. Many firms have now been placed on "quotas" by their gas or oil suppliers; the firm can buy just so many therms of gas, and no more. "any of these firms have plans to expand; at least they plan to continue production. To industrial management, the prospect of paying $\$ 1,000$ annually to run a device which will insure sufficiently low fuel consumption for reliable operation or planned expansion may be attractive.

If it is true that industrial equipment could be modified or replaced to use fuel more effectively, and that the changes could be economically justified, why hasn't it happened? The fundamental reason seems to be that in the justification of industrial equipment (or of building construction), first costs have been of higher priority than operating costs, especially those operating costs which are associated with fuel consumption.

The classical economist has a tendency to shudder when this statement is made, because it means that industry may not function by the classical rational rules of economics. If there is a whole array of problems to try to solve with a limited amount of resources, there is a tendency to work on those problems which are worsening and to let the ones that are improving take care of themselves. One of the ways to assess an industrial problem is by its costs. In the past several decades fuel prices have declined while the price of other factors of production have risen. Thus, industrial management has tended to focus on rising costs, like labor, rather than on the fuel costs. As a result, the life term costs of energy for operation have not been given the attention they deserve.

Ideally one might wish to see a policy implemented which would promote energy conservation through rational life-time costing of equipment. However, one would not wish to see a policy of energy conservation instituted for its own sake. Energy is the resource which presently concerns us. But, if we were to promote effective use of energy without any consideration for the consumption of other natural resources, it would be conceivable to deplete our copper reserves by producing heat transfer equipment.

Energy is only one of the valuable natural resources that we must use effectively. The following seven graphs illustrate the supply and demand projections of several natural resources. Figure 1 shows the consumption of metals in the United States. Iron consumption is the greatest, followed by aluminum and copper. Figure 2 shows projections of scrap, mine producticn, and imports. Figure 3 shows the U. S. positon in copper is insecure. The remaining figures show that U. S. import requirements for aluminum, zinc, and other metals are expected to climb 
HOW THE U.S. EATS UP METALS

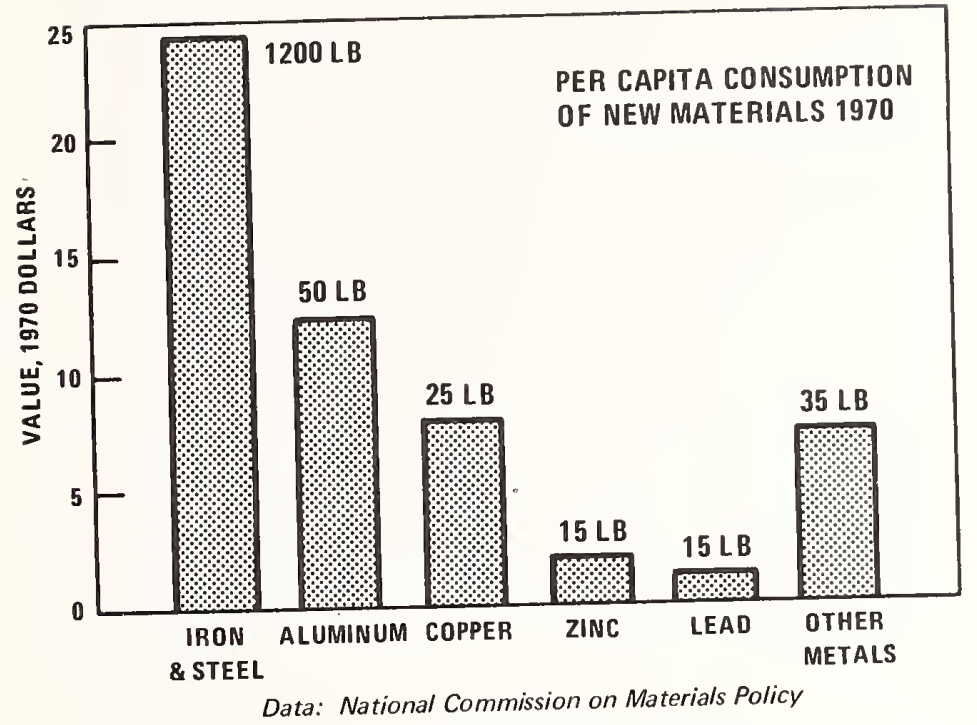

FIGURE 1

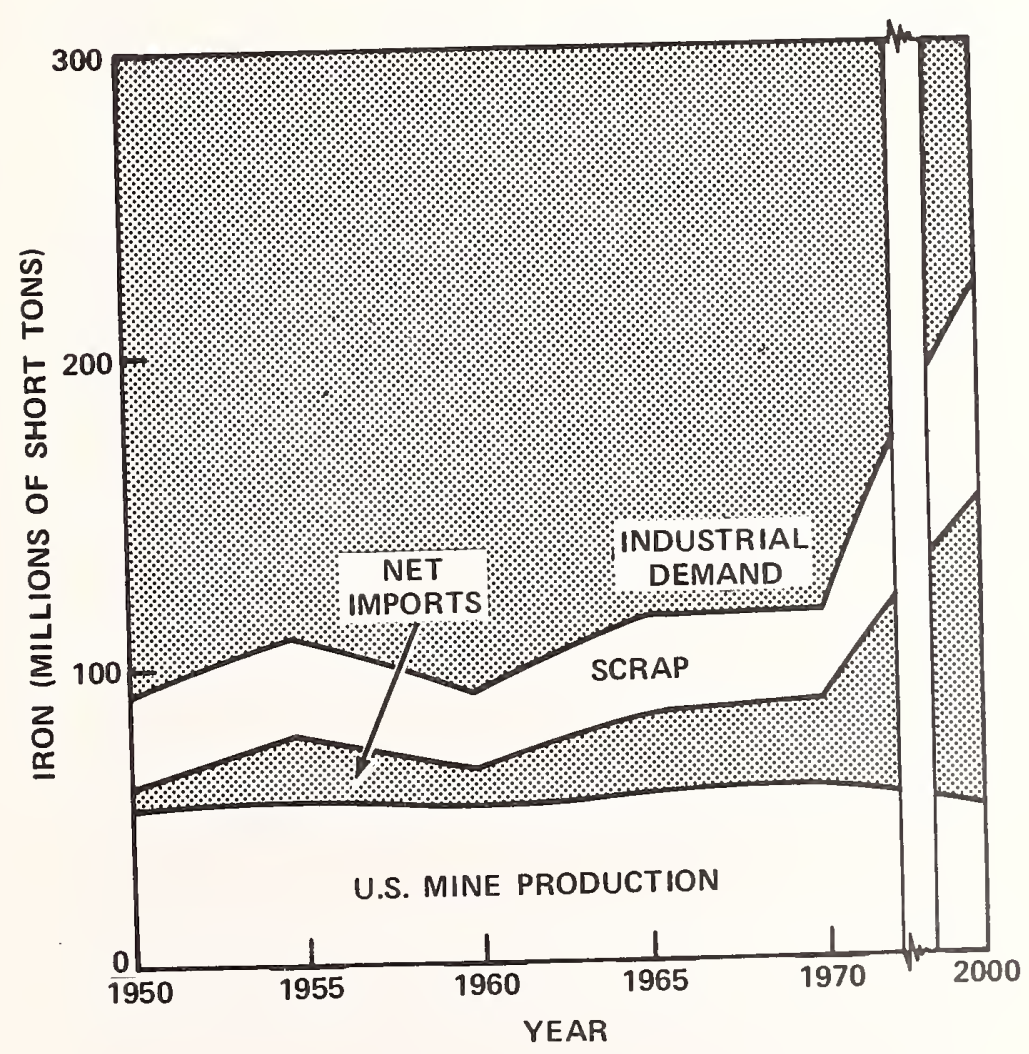

SOURCES OF METALS FOR THE U.S.A.

FIGURE 2 
FIGURE 3 CONSUMPTION OF COPPER IN THE U.S.A.

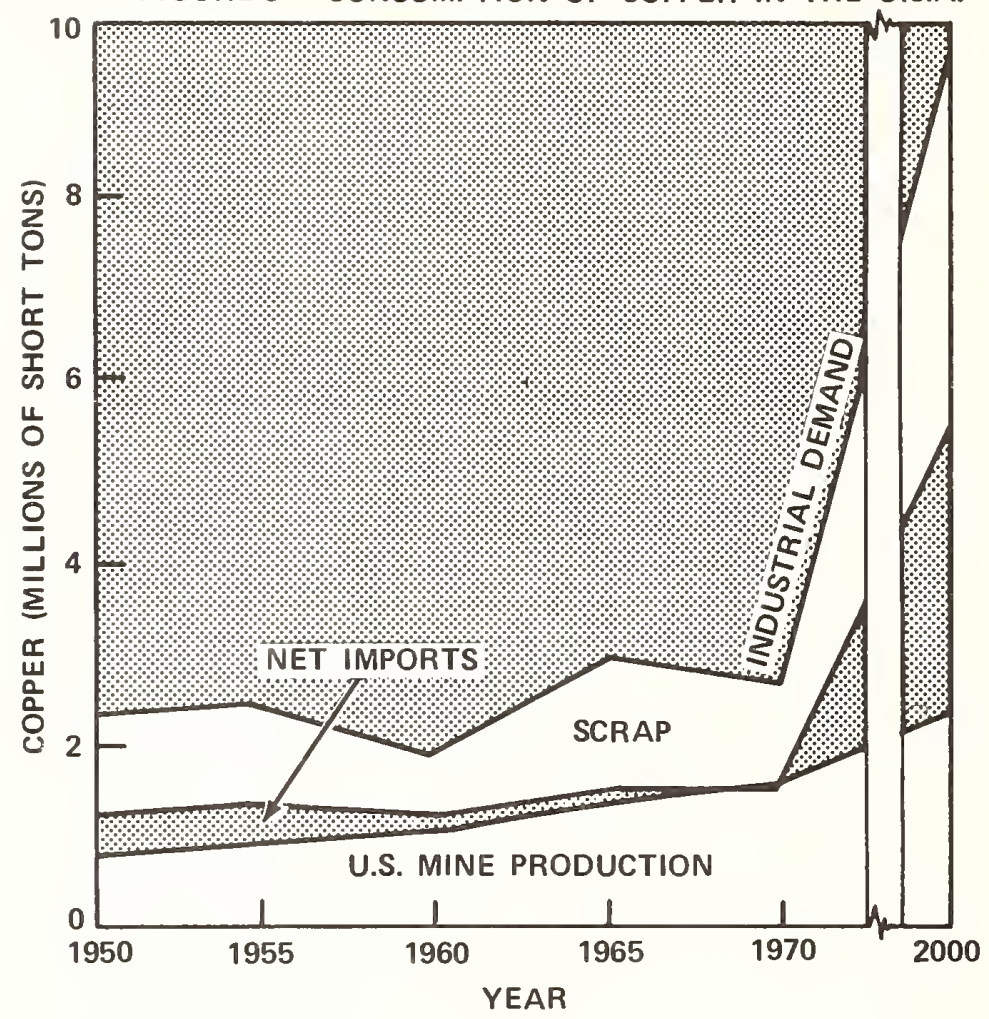

FIGURE 4 CONSUMPTION OF ALUMINUM IN THE U.S.A.

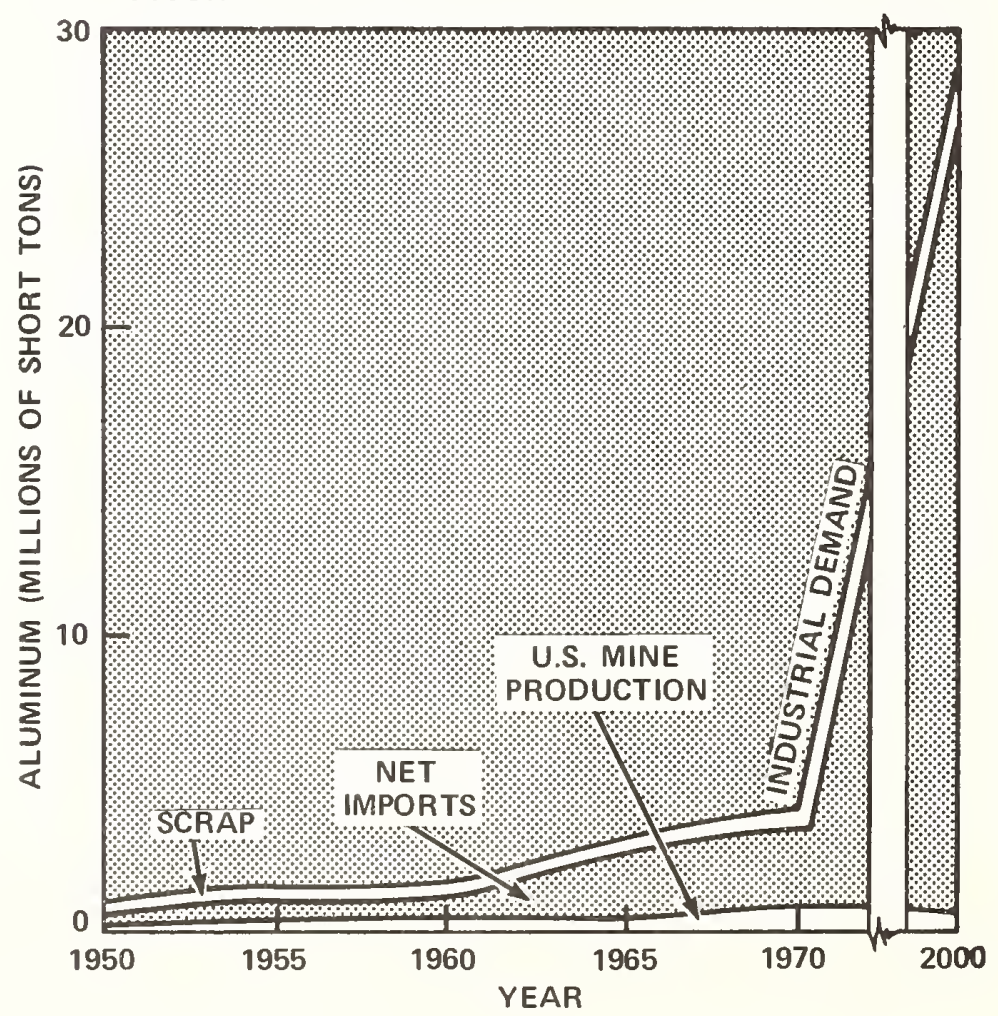


FIGURE 5 CONSUMPTION OF ZINC IN THE U.S.A.

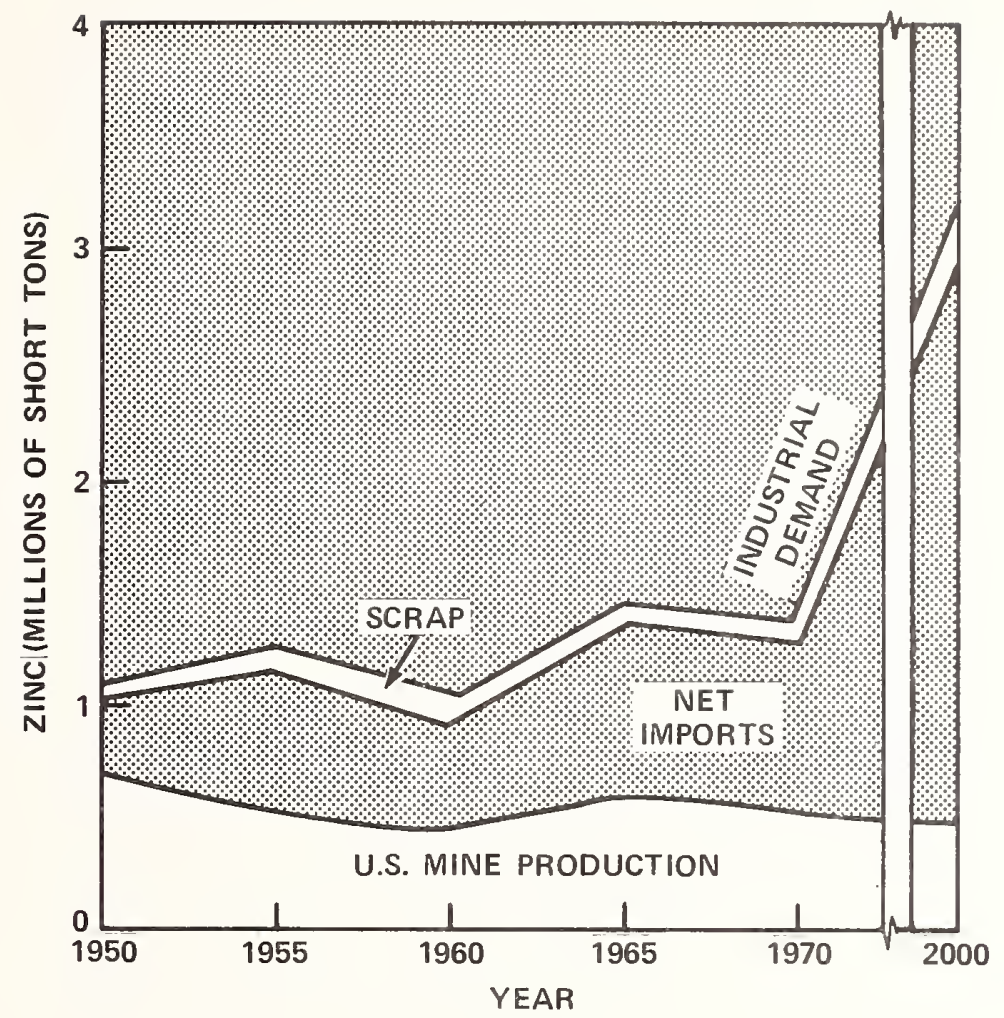

FIGURE 6 CONSUMPTION OF NICKEL IN THE U.S.A.

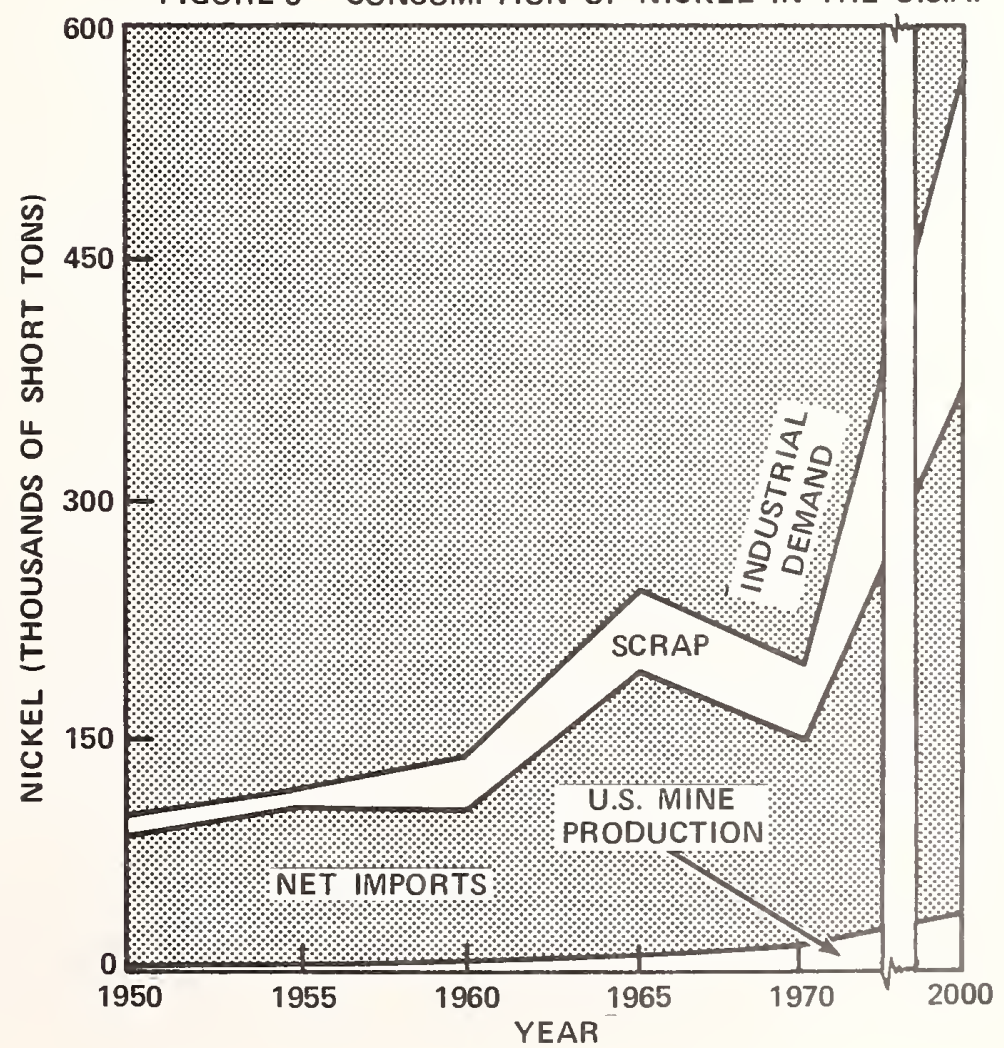




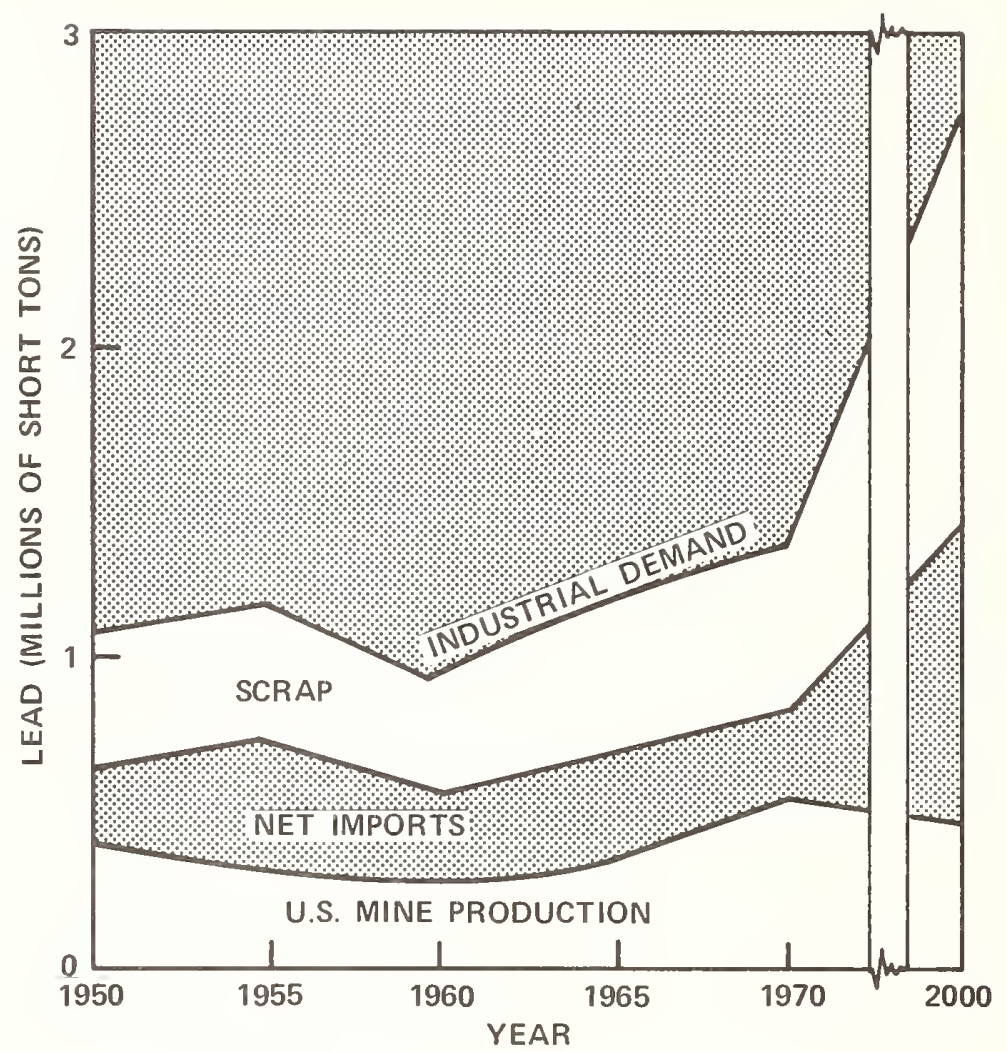

FIGURE 7 CONSUMPTION OF LEAD IN THE U.S.A.

rapidly; our own resources of these metals are nearly exhausted. Similarly, U.S. import requirements for lead are expected to rise rapidly. These figures, as a whole, illustrate one aspect of a very broad problem: the U.S. can no longer assume that vital natural resources fuel, metals, gravel, lumber and other vital resources - will be available in abundance and at low price. In a sense, our days of abundance may have passed.

I would like to propose that one of the essential problems in energy conservation is to recognize it is not just energy which must be conserved. What is now needed is not just a set of measures to conserve one resource at the expense of all others, but a rational economic method for achieving effective and balanced use of all natural resources. Using the classical theoretical notion of economics that the price of an item reflects its value is an imperfect way to compare oil with lead or other resources. But it is at least a method. When it is used with care, it offers a more effective way to balance the use of resources than simply ignoring the question. I suggest that we ought to seek to institute whatever measures are necessary to put total life term costing of equipment - and buildings - at the top of the list of priorities for economic justification. This would be one way to promote effective use of all the natural resources on which our way of life, depends. 


\title{
ENERGY CONSERVATION GOALS AND METHODS
}

\author{
by \\ Robert E. Shepherd \\ Department of Commerce \\ Washington, D. C. 20234
}

\begin{abstract}
The goals of the President's energy message of early 1973 and the feasibility of the 1974 goal of a $5 \%$ energy use reduction nationally are discussed. An overview of the Federal government's organizational structure is presented and discussed with reference to attaining these goals. Voluntary energy conservation measures and a major educational program

directed at energy users are urged to help solve the Nation's energy problems.
\end{abstract}

Key Words: Conservation; Energy; Organization

Tonight I would like to do three things. First, I would like to talk about the energy goals that the President laid out in his energy messages of April and June, 1973. Secondly, I want to talk about the particular shortterm energy conservation goal of conserving 5\% of the energy that we are projected to use over the next year. Lastly, I want to discuss briefly the present organizational structure of the federal government with respect to carrying out these goals.

The goals of the President's energy message can be summarized in three points. First, he has called on government and industry to develop a series of programs to stimulate domestic energy production. That includes a very large $\mathrm{R} \& \mathrm{D}$ package. A large part of the $\$ 100$ million in additional $R \& D$ funds, which were made available for this fiscal year, and of the 10 billion dollars for the following five fiscal years will be concentrated on increasing domestic energy production.

Another point in the message was to dampen the rising rate of demand; that is, to find new ways for energy conservation or energy efficiency. When I talk about energy conservation tonight it is in the context of efficiency. We want to start a whole series of programs to stimulate domestic energy production, including programs which enable us to use coal in an environmentally acceptable manner, to stimulate production of oil and gas, and possibly to use resources like tar sands and oil shale. Third, we have to develop an import policy to permit us to import those fuels that we need but can't produce ourselves. Import policy at the moment is still a pretty complicated business; I won't go into it in the talk.

Now, if you see the energy goals listed above as within the context of some other major government policies, I think you can see something of the nature of the problem that the federal government faces in moving forward on a coherent energy policy. Really what the president has charged the government to do is to increase the domestic supply of energy in an environmentally acceptable way without increasing costs, and I submit to you that this is an extremely difficult task. Therefore you have three major governmental policies which run head on into each other. You may think of those policies as vectors, and if you can figure out what direction policy is going to get pushed, more power to you. I think the direction it will get pushed is for 
a better meshing of environmental policy with energy policy, with an inevitable rise in the cost of energy, especially between now and 1980. Let me digress a minute on the balance of payments situation, which is one of the national policies which have a bearing on the energy situation. National security considerations, of course, call on us to limit our imports as much as possible. All aspects of social iustice make it difficult to deliberately do some things that we might want to do, such as put a whooping great tax on gasoline, a very regressive measure. I'm working on some balance of payments analysis to see what our balance of payments situation would be in terms of oil imports in 1980, if we import ten to twelve million barrels a day. It is, of course, important to know what will be the price of that oil. I was at a cocktail party with a group of oil buyers and some government officials so I took my own poll. I went around the room asking people what price they anticipated oil to be. At the end of the evening the range in current dollars was from $\$ 6.50$ a barrel to $\$ 15.00$ a barrel. Now that's a large increase over today's price. When I announced the results to one little group, a fellow from Texas said, "Where's that fellow that offered it at $\$ 6.50$ ? I'll buy all he's got right now." So I think we will have very much higher energy prices in 1980.

We're going to need them, if we want to stimulate the kind of domestic energy production that we need. The possibility of increased energy prices, however, introduces uncertainty into domestic production or supply forecasting. If those people in that room really believed that crude oil will sell for $\$ 10$ a barrel in 1980, then at that price you can do a lot of secondary and tertiary recovery of oil. You could bring in an awful lot of oil from Canadian tar sands. You could, subject to the limitations that were discussed here earlier, do a lot in the way of coal liquefaction and coal gasification, and possibly get into shale oil. I think people believe that the price probably won't reach $\$ 10$ a barrel, because alternate methods of domestic production could then be economically substituted for imports.

The second area I want to discuss involves short-term energy conservation goals. The President has directed the Federal Government to cut projected energy consumption by 7 percent. That consumption cutback will probably come primarily in buildings and building management. Those men in Washington buildings this summer can tell you that the air conditioning was reduced; it's turned off on weekends. Lights are being turned down, and so forth. A lot of things are being learned. GSA is now deliberately testing thoughts they've had, and the work done in the National Bureau of Standards on building technology is proving beneficial.

The President also called on the Nation to reduce overall energy consumption by 5 percent. A specific action was for the secretaries of Commerce and the Interior and Governor Love, the President's Assistant for Energy and Director of the Energy Policy Office to meet with representatives of American industries to discuss ways of cutting back unnecessary consumption of energy and to urge their active participation in the conservation effort. For example, finding ways to use energy more efficiently is a simpler step than seeking very basic changes in the sorts of things that are produced. The term "to urge the active participation of industry", that is, large industry and small businesses in the industrial and commercial sectors of the country, means that we in the government meet with business people and urge them to actively participate in the goal to conserve energy in their own particular industry or business. It can also mean that we would like them to work with the government to help get the idea of an energy conservation ethic, of wiser use of energy, carried to the American people. In my own judgment the federal government needs to make a sustained and nationwide effort to reach all segments of the United states, to ask people to take advantage of what we already know about how to use the energy in their businesses and in their homes more efficiently.

Now, when we talk about reducing energy nationwide by five percent, what does it mean? It could mean a lot of different things. For example, you could reduce energy consumption in the transportation sector by five percent by stopping all the automobiles in Texas. Seriously, there are other ways in which energy could be saved. There are goals capable of being 
accomplished in the course of the year, without much more than an executive decision to do so. Dupont's Consulting Service, (they're pretty good because they charge for it! ) leaves me fairly well convinced that a five percent energy economy is possible in the course of a year.

These goals can be accomplished on a voluntary basis. I think one thing we could all agree on is that this administration does not want to get further into government regulation of industry, or government regulation of any other aspect of American society. There's a great deal of pressure from a lot of different groups to put measures like mandatory energy conservation procedures into effect. We don't know enough yet to start legislating mandatory regulations or even mandatory incentives. I think, however, if we're not successful in meeting the voluntary goals, we may well find ourselves forced by public pressure, manifested through Congress, by people who mean well but don't fully understand the implications of what they're doing, to have some sort of mandatory energy conservation system.

More probable than that, we will be forced by the same kind of forces to put into effect a mandatory allocation program. There has been in existence in the country since last May, a voluntary petroleum allocation program which was whipped up in a hurry. Given the speed with which it was drawn up, it isn't too bad. It was drawn to handle some very real problems this spring, like getting crude oil to crude deficit refiners, getting the product distributed to independent marketers and getting products which these independents didn't have to their main consumers, which tend to be in agricultural sectors of the country. The administration has been under great pressure to institute a mandatory petroleum allocation program, which I can assure you we don't yet know how to do. I can assure that the repercussions and implications for industry as well as for other sectors of the country haven't been analyzed yet.

The energy distribution network, and in particular, the petroleum distribution network, that has developed in the United States is one that up until the last year or two had a lot of surplus in it. I won't go into all of the ways in which the system was kept in equilibrium, but the two main ingredients were the oil import program and the Texas and Louisiana Railroad Commissions. The fact was that there was always some surplus in the system. If you could do a projection that showed demand in the United States in balance with supply, there really would be shortages on a regional basis, because the system needs an excess to make it work. We are facing this winter a situation in which, if we could reduce anticipated consumption by five percent, the federal government won't need a mandatory program, which when established will not be easily dislodged. The success of voluntary programs may determine the extent of government intervention in and regulation of energy industries in the years ahead. A mandatory petroleum allocation program has been designed. It's published for public comment; all comments are welcomed and will be read. The program is the best that four very bright guys could develop over a period of two or three months. I will be amazed if anybody here really thinks it will work. We have it out for public comment, though, so if the energy situation does force us to go to a mandatory program later this year, we'll be as well prepared as possible.

It seems to me that if the government and the business community either separately or in cooperation, want to reduce energy usage by five percent next year and lay the foundation for a long-range conservation program, there are four ingredients necessary.

One is to tell the story; that is, tell why we need energy conservation and what we can do to encourage the implementation of knowledge we have today. Secondly, we can assemble and disseminate information about untried or potential conservation approaches. Thirdly, we can continue the work in research and development that we are presently doing. Lastly, we can emphasize new basic research.

We should start doing all of these things right now, but if we want to have an impact on energy consumption in the United States over the next year we have to get the message out today about what we know today. 
That calls for the federal government to undertake a fairly massive campaign, something like a "Save Energy Month", with a presidential announcement on national television, meetings with industry, and local meetings in towns and cities to make the question of energy conservation an important one in the mind of everyone. Increasing domestic energy production does conflict with the goals of environmental protection and lowcost energy. Conserving energy, on the other hand, is compatible with environmental protection and with keeping costs down. Energy conservation is something that I think American business, other sectors of the nation, and the government could cooperate with meaningful results.

I'm not going to discuss all the concepts we have for this campaign, but one of the things we're doing, is putting together a presentation which will tell why we need to think in terms of energy efficiency, and will illustrate in detail the kinds of measures that could be taken in the various sectors of the economy. We will have a slide presentation, with text, that anybody inside or outside the government can use. I would prepare the presentation on film and video tape, so it can be available for use over educational brodcasting, in universities, in schools, Commerce field offices, or for smokey the Bear or whoever else might want to give such a show. If government would do what I think it ought to do, we'd also have an hour of prime time on commercial television this fall, but I don't know if that will come to pass. I would appreciate any specific ideas or any specific recommendations of how energy can be used more efficiently, that are graphic and attention-grabbing without distorting the long-run aims by faulty and misleading ideas.

We've reached the third part of my speech. I thought I'd take just a few minutes to look at how the energy policy is set in the federal government today, and how it will be set, formulated and implemented after the formation of the Department of Energy and National Resources. The reason that you can't talk meaningfully about energy policy without involving so many agencies is because energy cuts across into every kind of program in almost every department's responsibilities. As it becomes a higher priority, it becomes a matter of greater priority in every department and bureau of the federal government. For example, the Labor Department is concerned about the implications of the mandatory petroleum allocation program. If the situation gets grim enough so it has to be put into effect, and plants in Northeast ohio shut down because they can't get fuel, people who work in those plants are going to be very much affected. So the Labor Department is involved.

The Energy Policy Office, which was formed in June and announced on June $29 \mathrm{th}$, is headed by John Love, who resigned as the Governor of Colorado to take the post. He follows Charles DiBona, who had been announced as the senior White House energy expert in the April message. At that time, Dibona was to report through a triumvirate of Henry Kissinger, George Schultz, and John Erlichman. Now Mr. DiBona is charged with the overall policy formulation and policy direction for energy in the federal government. As the problems associated with our having to import ever-increasing quantities of oil from the Middle East come into play, there are a lot of national security and Council staff are getting much more heavily involved in energy policy, particularly from the national side. We talked to them about the President's new cost of living program. Anything to do with energy policy is very much affected by the positions that are taken in the cost of Living Council with respect to cost and prices, so Mr. Schultz and his department are also directly involved.

You don't do anything in this administration without the hidden or unhidden hand of the office of Management and Budget in there someplace, if only because they have the last crack at your budget. The office of Management and Budget is charged with organizing committees to evaluate the comments on the mandatory petroleum allocation program and to bring about some new and enlightened melody of environmental energy policies. 
A great deal of effort is going on right now to create, on a defacto basis, a Department of Energy and Natural Resources. The focal point is the Department of Interior. The secretary of the Interior is Rogers Morton; his deputy is Mr. Whitaker. There's a deputy undersecretary named Ken Lay who is involved in energy conservation matters, but the assistant secretary for energy and minerals is steve Wakefield.

The office of oil and Gas has three groups within it: one is an analytical reporting group; the other two are responsible for administering oil import programs.

Data analysis is a new office in Interior; you should follow its fortunes closely. Their job is to get the data on energy available to the government, put it in better form, and analyze it, in order to increase the accuracy in supply and demand forecasting and price forecasting. They look for all of the kinds of data on energy sources that we would all like to work with when we are wrestling with problems. The office is just beginning and it isn't fully staffed yet.

Also, we have the Energy Conservation office headed by John Gibbons from Oak Ridge, who is an excellent man. His special assistant is $3 i l l$ Porter, with whom I have been working until Gibbons gets on board. Bonneville Power is a pretty big undertaking, with 10 new offices, which when developed should be able to play a major role in improving the kind of data that's available to the government, and to help outline coherent longer range energy conservation policy.

The interests of other agencies can be divided between a Regulatory and a Research and Development area of interest. The person in the federal government who's charged with sorting out on interagency basis how to spend the $\$ 10$ billion in $R \& D$ Eor the next five years, and this year's $\$ 100$ million is Dixy Lee Ray of the Atomic Energy Commission. There will be input from all agencies, but Jixy is certainly the key person in it.

On the Treasury side, there is Bill Simon. The chairmanship of the oil policy Committee was transferred from the office of Finergency Preparedness to Treasury in February; I think it's either about to be disestablished, transferred to Governor Love, or some other arrangement made. I think there will be further reorganization of these agencies.

The Federal Power Commission is an independent Regulatory Commission established by congress. It is probably not going to be disestablished, and will continue to have regulatory functions in the fields of natural gas and electricity.

The Federal Trade Commission is carrying on a campaign to bring major oil companies into court on anti-trust cases. Even if they never do anything else in the energy field, that organization will be with us for at least another 5 to 10 years, directly involved in energy. mhe Treasury Department, which has a certain yen to have something to say about tax and tariff policy, is going to continue to stay involved and interested in energy matters, even though their oil policy responsibilities may be moved. They'll also continue to be very interested, of course, in overall economic policy, which gets them into the whole question of prices and costing, questions of balance of payments, and so forth.

The State Department

is that Department which implements foreign policy; they are going to be very much involved so long as energy in the international field is important.

The Council of Economic Advisors will participate; they'll be interested, as is Consumer Affairs.

The Department of Defense obviously has a direct interest in the national defense and national security aspects of energy. Mhey have a real interest in import policy and other policies which affect the cost of the energy they use.

Also involved in the international aspects of energy, the Central Intelligence Agency will be asked to do all kinds of analyses and studies about international energy flows. 
The Department of Justice is going to be involved to see that justice is done, primarily from a point of view of anti-trust consideration.

The Department of Agriculture is interested in fuel availabilities for farmers. The Secretary of Agriculture wants to expand agriculture production, which will help lower prices and also have agriculture products to export. For this a lot more energy is needed in the form of gasoline, diesel fuel, and propane, and those are the things we're having trouble with. An expanded agricultural program for next year may plunge us into an energy shortage which will then require somebody to decide who really needs those fuels the most, the steel factories or the farms.

Lastly, the Department of Transportation is involved on all questions of transportation policy, and is an agency which, in terms of its regulatory and legislative influence, may have more influence on energy use patterns than any other single department in the government.

\section{Questions:}

Q. What role will the Department of Comerce play in the government's energy program?

A. I think the primary role of the Department of Commerce should be to see that we have national policies which insure an adequate supply of energy to the industrial and commercial users in the United states. Also, Commerce should try to get industry to actively participate in energy conservation matters. We have to take an active interest in questions of energy supply, particularly domestic energy supply. A part of Commerce known as Domestic and International Business Affairs is interested in the conditions under which fuel is imported.

Another part of Commerce is the Maritime Administration, which manages the maritime subsidy programs. They are interested in energy from the point of view of what kind of tanker fleet the United States should have.

There are a number of energy conservation programs in the $\mathrm{N}$ tional Bureau of standards. Work is being done on building technology improving the efficiency of old and new buildings. There are also programs in industrial efficiency and consumer appliance labeling. 
I I. $\quad \mathrm{N} A \mathrm{~T}$ I O N A L C O N T E X T F O R E N E R G Y C O N S E R V A T I O N 


\title{
NATIONAL BENEFITS OF ENERGY CONSERVATION
}

by

Leon R. Glicksman and David C. White :1assachusetts Institute of Technology Boston, Massachusetts 02139

\begin{abstract}
Starting from the correlation between a nation's gross national product and its energy consumption per capita, the consequences of economic growth on the world's estimated energy resources is discussed. In the absence of new energy technologies or a reduction of energy consumption in relationship to GNP, sustained high economic growth will be difficult and costly to achieve as our own resource base diminishes. The developing nations of the world will be competing for resources as their own GNP's increase, further exacerbating the resource depletion problem. As the nations of the world compete for scarce resources, there are potential international complications beyond those presently apparent in the effect of petroleum imports on America's transportation sector.
\end{abstract}

Key Words: Correlation; Economic; Energy; Imports; International; Petroleum

\section{Introduction}

In the United States, an abundance of energy supplies and a low price of energy have led to a steady rapid growth in energy consumption for over 150 years. Sheap energy to fuel our economic growth has been our nation's policy. There have been few incentives to use energy efficiently or to conserve energy. Our use of energy in the past has followed the same "throw away" philosophy we have practiced for our consumer goods.

In the last two decades the Urited States has become a growing importer of energy fuel. Today it is evident that careful long-range planning is needed to assure adequate energy supplies for the future. serious effort to conserve energy must be made to limit our future consumption of energy to levels which can be met by supplies that can be produced and consumed with acceptable environmental impacts. We will need to rely on foreign sources for these energy supplies or to develop new technologies that can effectively utilize our domestic solid fossil and and nuclear fuels. A dependence on foreign suppliers could have serious effects on our balance of payments and on our international relations. A reliance on domestic solid fossil fuels poses environmental problems, particularly in the large quantities of those fuels required to meet present and projected demands.

In this paper we explore the potential role of energy conservation in overcoming the near-term problems related to energy supplies and, more importantly, in meeting future energy requirements without major economic or environmental disruptions. 
Patterns of Future Growth

For every country in the world, there is a close correlation between a nation's gross national product per capita and its per capita energy

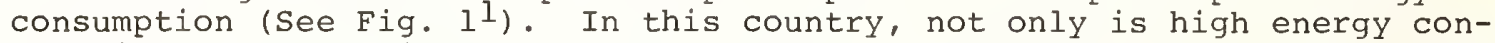
sumption due to a high GNP, but the energy consumption per unit GNP, which decreased until 1965, is now rising (Fig. 22). The total amount of energy consumed to date is a small fraction of our total estimated resources, but the implication of a high growth rate on future consumption is serious. The resource base of the United States shown in Table $1^{3}$ is huge, $250 \mathrm{Q}$ for fossil fuels ( $1 \mathrm{Q}=1018 \mathrm{BTU}$ ) and double that for nuclear fuels used in a fast breeder. The total energy consumed to date has been approximately two Q. Figure 3 shows the future cumulative energy consumption for various growth rates. By 2050, at a five percent growth rate, we will have consumed $700 \mathrm{Q}$, equal to our total estimated resource based! If the growth rate is three percent, instead of five percent, then by the year 2100 the total energy consumed will be about 700 , a full order of magnitude saving in fuel resources by a reduction of two percentage points in the growth rate. Figure $4^{4}$ shows the estimated yearly cost for energy consumption as a percent of the GNP. It is assumed that the GNP grows at $4.5 \%$ and the average cost of energy doubles in thirty years (2.5\% growth rate) due to increased unit costs of imported energy or due to the use of domestic energy sourcss which are more expensive to produce. In 2020, at a $4.5 \%$ growth rate, energy costs will be more than $20 \%$ of the GNP, and at a $6 \%$ growth rate energy costs will be almost $50 \%$ of the GNP! It seems certain that economic pressures alone will diminish the growth rate before such extremes are reached. However, the plateau we finally reach and the energy resource requirements to maintain that plateau will strongly depend on the growth rate we follow for the next few decades.

The difficulties inherent in high sustained growth rates can be shown using the example of nuclear power for electrical generation. Let us assume, ideally that all future increases in electrical generating capacity are met by nuclear plants; new fossil plants are added only to make up for the capacity of retired fossil plants. Further, assume that fast breeders are not commercially operational until 2010; after 2010 all new plants are fast breeders with a doubling time for fuel production of eight years. Using the estimated uranium fuel costs given in Table 1, the cost of fuel for the nuclear reactors installed between 1970 and 2010 can be estimated. The results are shown in Figure 55, with costs shown as a function of GNP (assuming GNP grows at 4.5\% yearly). The 7.2\% growth in electrical demand represents a doubling in consumption every ten years. In 2010, with a $7.2 \%$ growth rate, the cost of uranium will be more than 2.5\% of the GNP. The cost jumps even higher as all of the projected supplies at $\$ 50 / 1 b$. are expended. For the $7.8 \%$ growth rate a plateau above 2\% of the GNP is reached in 2000 and persists until 2030, whereas with a 5\% growth in electrical consumption, in 2005 a plateau below $1 \%$ of GNP for uranium costs is reached. With a cost of $\$ 450 / \mathrm{KW}$ for nuclear plants, the capital cost of new plants in 2010 is $2.15 \%$ and $0.8 \%$ of the GNP for a $7.2 \%$ and $5 \%$ growth rate respectively. In the period 2012 to 2020 the difference between the fuel costs for the two growth rates is greater than $2 \%$ of the GNP.

One can reasonably expect that new technologies such as fusion reactors will increase the available supply of energy and possibly reduce its cost. This technique still requires a long lead time before it will be operational; the "pinch" in available resources until that time depends on our ability to reduce the future growth of energy consumption. 


\section{ENERGY CONSUMPTION, POPULATION, AND GNP}

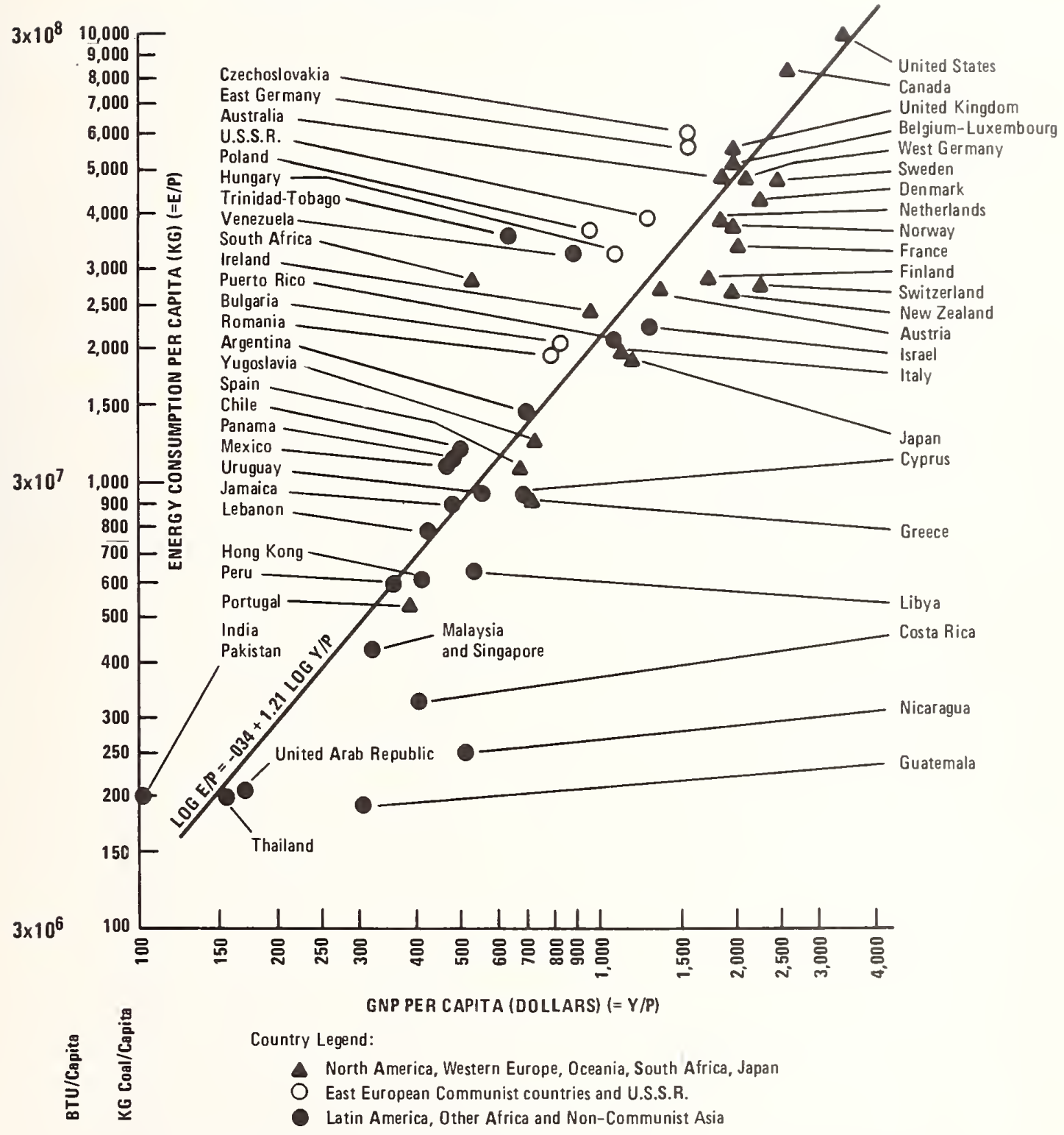

GNP PER CAPITA AND ENERGY CONSUMPTION PER CAPITA: 49 SELECTED COUNTRIES, 1965.

\section{FIGURE 1}




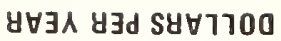

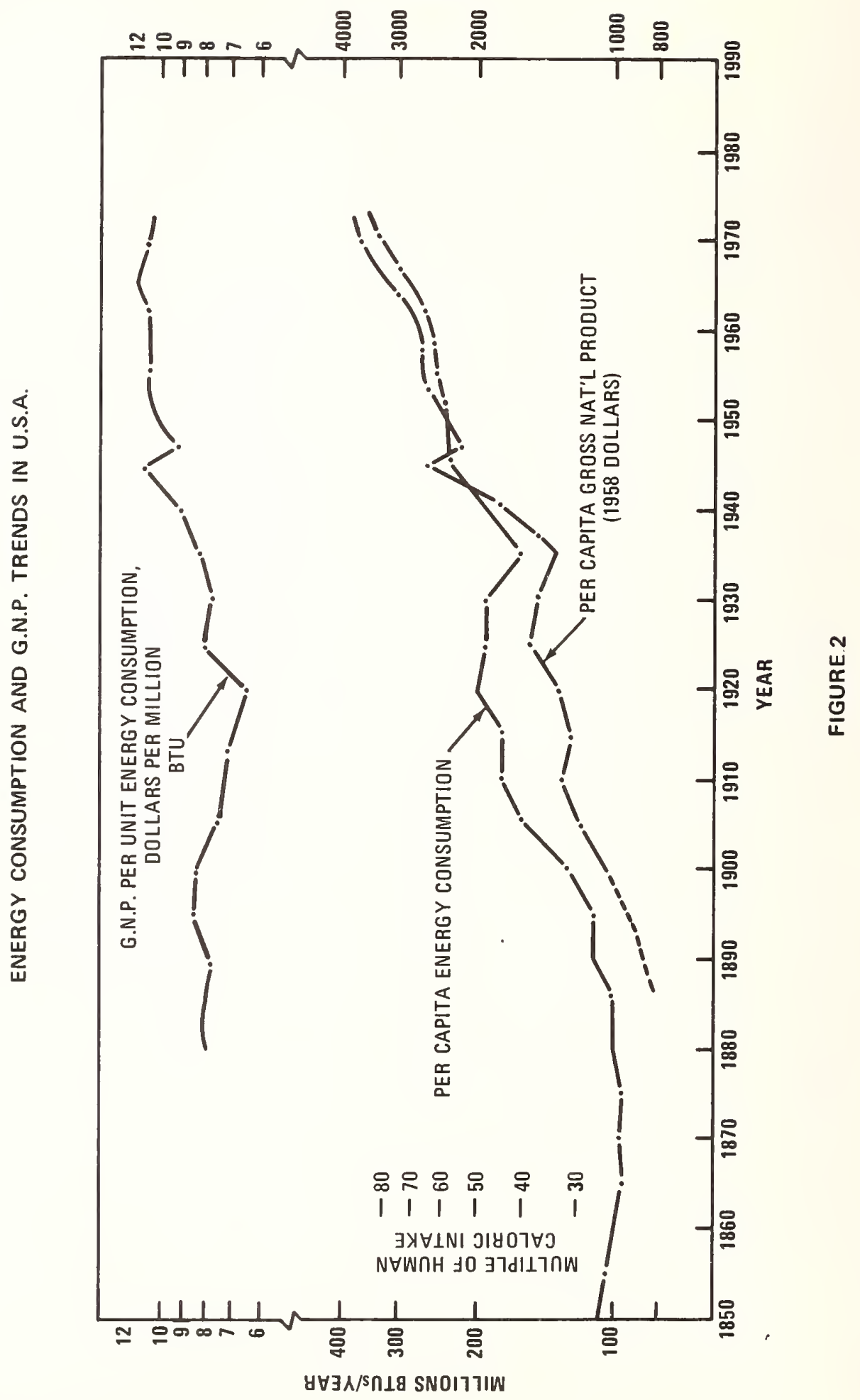


U. S. RESOURCE BASE FOR FOSSIL FUELS AND URANIUM

\begin{tabular}{|c|c|c|c|c|}
\hline & $\begin{array}{l}\text { Total Resource } \\
\text { Base - U.S.G.S. } \\
\text { (natural units) }\end{array}$ & $\begin{array}{c}\mathrm{Q} \\
\left(10^{18} \mathrm{Btu}\right)\end{array}$ & \begin{tabular}{|l|} 
Identifiable \\
\& Recoverable \\
(natural units)
\end{tabular} & $\begin{array}{c}Q \\
\left(10^{18} \mathrm{Btu}\right)\end{array}$ \\
\hline COAL & $3,200 \times 10^{9}$ tons & 77 & $\begin{array}{l}200-390 \times 10^{9} \\
\text { tons }\end{array}$ & $4.8-9.4$ \\
\hline $\begin{array}{l}\text { Low Sulfur } \\
([\text { Less than } 1 \%])\end{array}$ & (100 × $10^{9}$ tons) & $(2.4)$ & (12 $\times 10^{9}$ tons $)$ & $(0.29)$ \\
\hline $\begin{array}{l}\text { PETROLEUM } \\
\text { LIQUIDS } \\
\end{array}$ & $\begin{array}{l}2,900 \times 10^{9} \\
\text { barrels }\end{array}$ & 16.8 & $\begin{array}{l}52 \times 10^{9} \\
\text { barrels }\end{array}$ & 0.3 \\
\hline $\begin{array}{l}\text { Oil \& Natural } \\
\text { Gas Liquids }\end{array}$ & & & & \\
\hline NATURAL GAS & $6,600 \times 10^{12} \mathrm{cu} \mathrm{ft}$ & 6.8 & $290 \times 10^{12} \mathrm{cu} \mathrm{ft}$ & 0.3 \\
\hline SHALE OIL & $\begin{array}{l}26 \times 10^{12} \\
\text { barrels }\end{array}$ & 149.0 & $\begin{array}{l}160-600 \times 10^{9} \\
\text { barrels }\end{array}$ & $0.9-3.5$ \\
\hline TOTAL & & $249.6 Q$ & & $6.3-13.5 Q$ \\
\hline
\end{tabular}

\begin{tabular}{|c|c|c|c|}
\hline \multirow{2}{*}{$\begin{array}{l}\text { URANIUM } \\
\left(\mathrm{U}_{3}{ }^{0}\right) \\
(\$ / 1 \mathrm{~b} .)\end{array}$} & \multirow{2}{*}{$\begin{array}{c}\text { U. S. } \\
\text { Resources } \\
\mathrm{U}_{3}{ }^{0} 8 \\
\left(10^{6} \text { tons }\right)\end{array}$} & \multicolumn{2}{|c|}{$\mathrm{Q}$ of Electricity Generated } \\
\hline & & $\begin{array}{l}\text { Water Reactor } \\
\left(10^{18} \text { Btu }\right.\end{array}$ & $\begin{array}{l}\text { Fast Breeder } \\
\left(10^{18} \text { Btu }\right.\end{array}$ \\
\hline 8 & 0.594 & 0.11 & 13.8 \\
\hline 10 & 0.94 & 0.17 & 21.6 \\
\hline 15 & 1.45 & 0.25 & 33.6 \\
\hline 30 & 2.24 & 0.39 & 53 \\
\hline 50 & 10 & 1.76 & 232 \\
\hline 100 & 25 & 4.4 & 578 \\
\hline
\end{tabular}

$1 Q=1018_{\text {Btu }}$

$1 Q$ coal $=41.5$ billion tons

$1 \quad \mathrm{Q}$ oil $=173$ billion bbl.

$1 Q$ natural gas $=970$ trillion cu $\mathrm{ft}$ 
TOTAL ENERGY CONSUMED

FOR

DIFFERENT GROWTH RATES

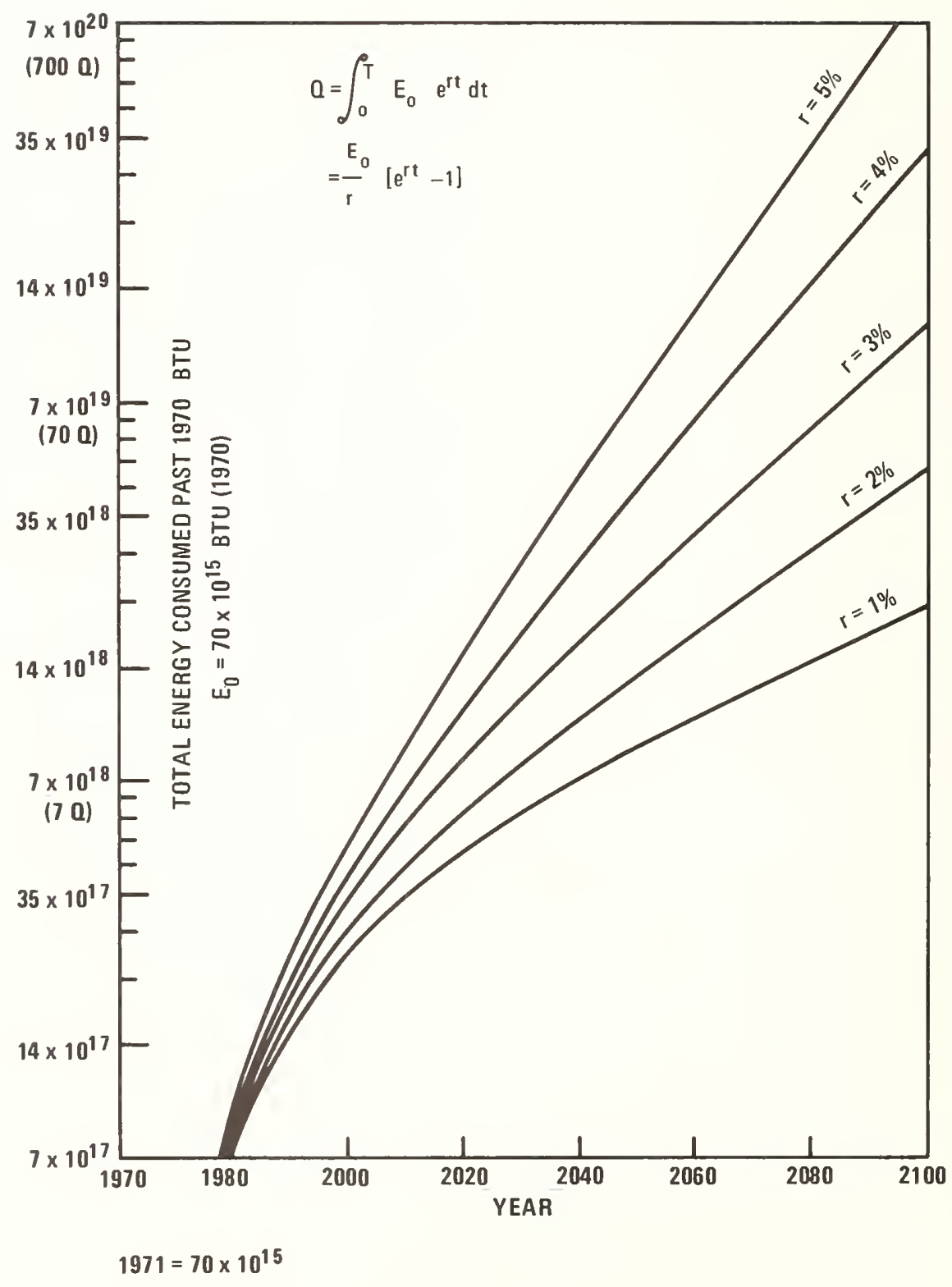

FIGURE 3 


\section{YEARLY COST* FOR ENERGY AS PERCENT OF GNP}

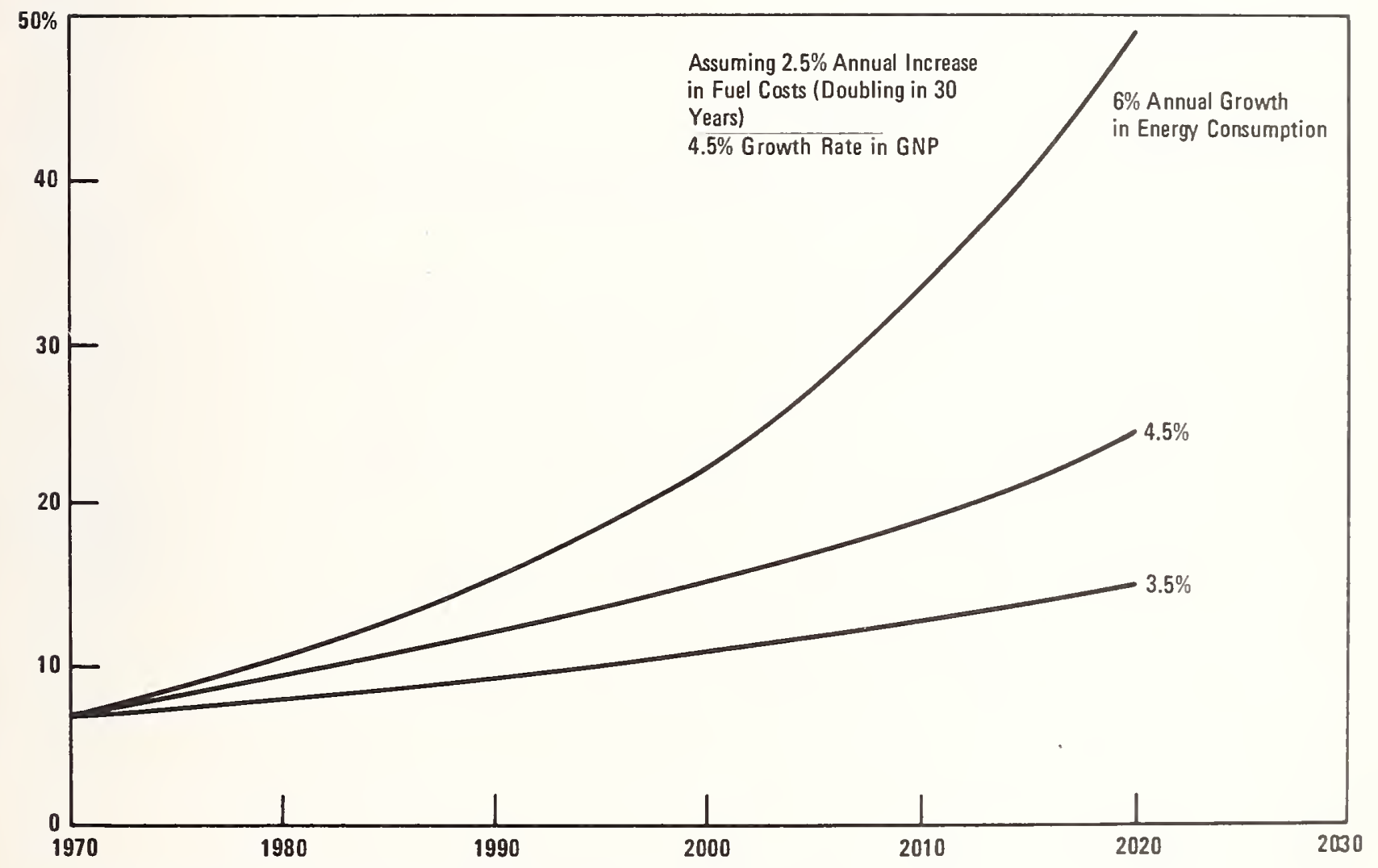

*ANNUAL COST FOR TOTAL ENERGY OUTPUT TO FINAL CONSUMER AT POINT

OF CONSUMPTION EXCEPT ELECTRICAL DISTRIBUTION COSTS

FIGURE 4 
URANIUM COSTS AS PERCENT OF GNP (NON-BREEDERS)

ASSUMING 4.5\% GROWTH IN GNP

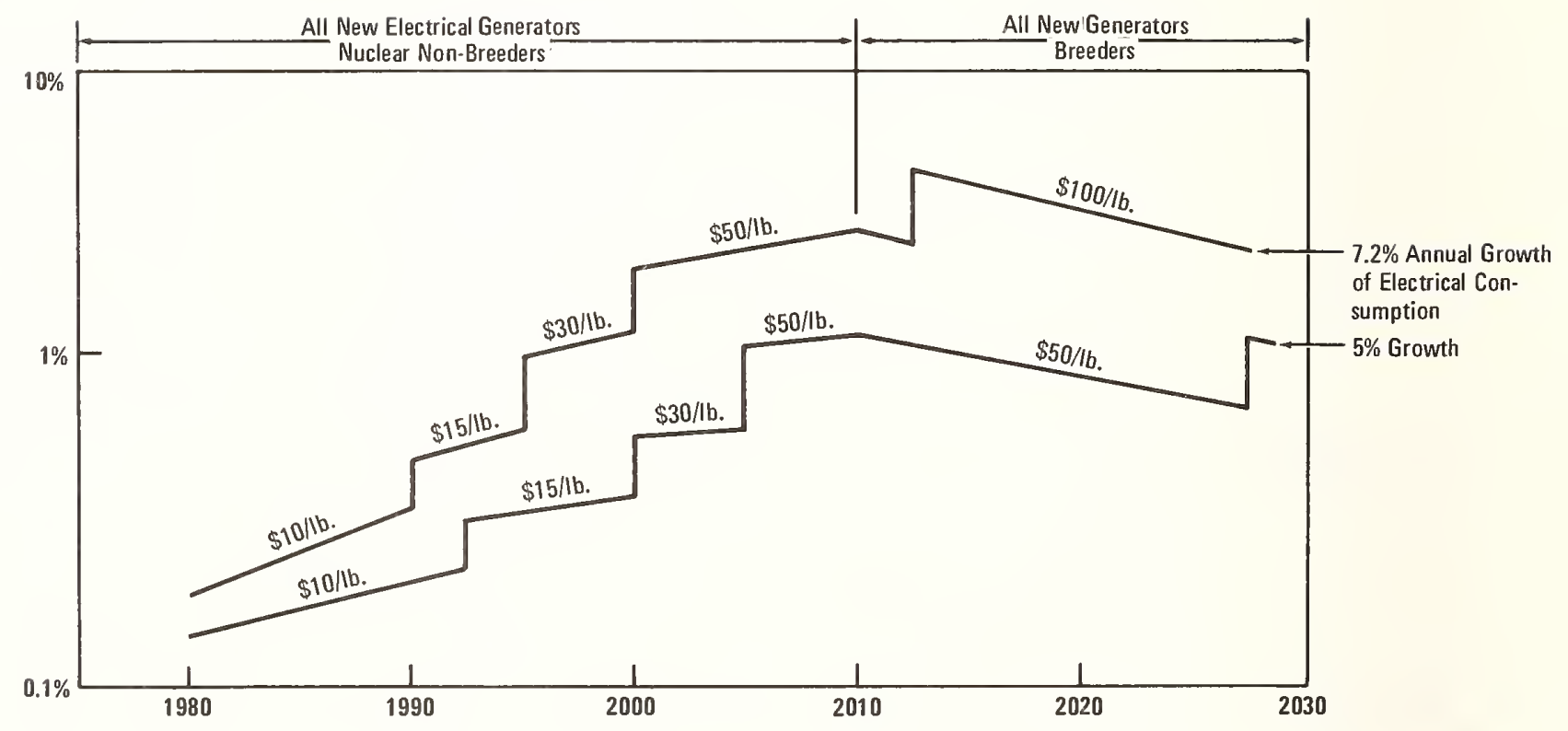

FIGURE 5 
In the near term, the nation faces a shortage in petroleum supplies brought about in part by environmental standards that cause increased gasoline consumption in automobiles and by limitations on environmentally acceptable fuels that can be burned in electrical power plants. The projections of future demand for petroleum are shown in Figure $6^{6}$. Note that most of the additional petroleum demand is projected to be met by imports. This projection is a function of national fuel policies; any reduction in the rate of growth of demand will have a significant impact on our import requirements. Since imports constitute about $25 \%$ of our present petroleum supply, an immediate 5\% reduction in petroleum demand will result in a $20 \%$ reduction in import requirements. Table $2^{7}$ gives the uses of energy sources in the United States. Over $50 \%$ of petroleum is consumed in transportation; for the near future no alternate energy source is available for transportation uses. Production of petroleum from coal or oil shale is possible, but development of economical large-scale processes and the construction of enormous processing facilities will require time and have undetermined environmental consequences.

The only feasible way to reduce the projected import requirements in the immediate future is by programs of energy conservation that reduce energy waste and stress more efficient utilization of energy for each task performance.

The projected increase in petroleum consumption by various segments of transportation is shown in Figure $7^{8}$. Note that the scale from 10 to 100 billion gallons is reduced; the increase in consumption by automobiles is considerable. Unfortunately, the most efficient transportation modes are the least used, especially for passenger transportation (Figure $8^{9}$ ).

The growth of petroleum consumption due to automobiles is expected to reach a plateau. Between 1951 and 1968 the average miles driven per year by passenger vehicles rose by less than $6 \%$. As the population reaches a constant level and the number of cars per family reaches a saturation level, the total vehicle mileage should also reach a constant. The amount of petroleum consumed at that time will be determined by the decisions we make in the next few years concerning emission controls and other constraints.

Malliaris and Strombotne have presented an interesting study of automotive conservation methods.** Table $3^{10}$, reproduced from their work, estimates the potential energy conservation of several proposals. Some of these proposals, which involve major disruptions of people's normal habits, such as a switch from automobiles to rapid transit for commuting, result in only marginal conservation of energy. Further, the establishment of adequate rapid transit facilities is a lengthy, costly program.

The proposal to reduce the weight and size of automobiles does result in a noticeable reduction in petroleum consumption. It has been shown that the gas consumption of an automobile is approximately linearly proportional to the weight of the vehicle. Since the average life of an automobile is short (in 1969, less than 10\% of the cars were over 10 years old), a reduction in the average weight of new cars will in a few years substantially reduce the average weight of the entire automobile population.

Reduction in the average weight of automobiles will also reduce our consumption of raw materials; $21 \%$ of the total steel production is used by the automotive industry as well as $10 \%$ of the aluminum, $55 \%$ of lead, 36\% of $\mathrm{zinc}$, and $65 \%$ of rubber.*

It has been estimated***that the energy expended in producing a new car is equivalent to the energy consumed by the car in its first year of operation. The greatest part of this energy is used for metal production and forming, which are highly energy-intensive segments of the industrial sector. The impact on petroleum imports of conservation measures in automobile design and operation can be seen from the following: if the rate of growth of demand over the next few years can be reduced from 4 \% to $3 \%$, the estimated petroleum imports at the time will be reduced by $20 \%$. 
PROJECTED U.S. DEMAND FOR PETROLEUM

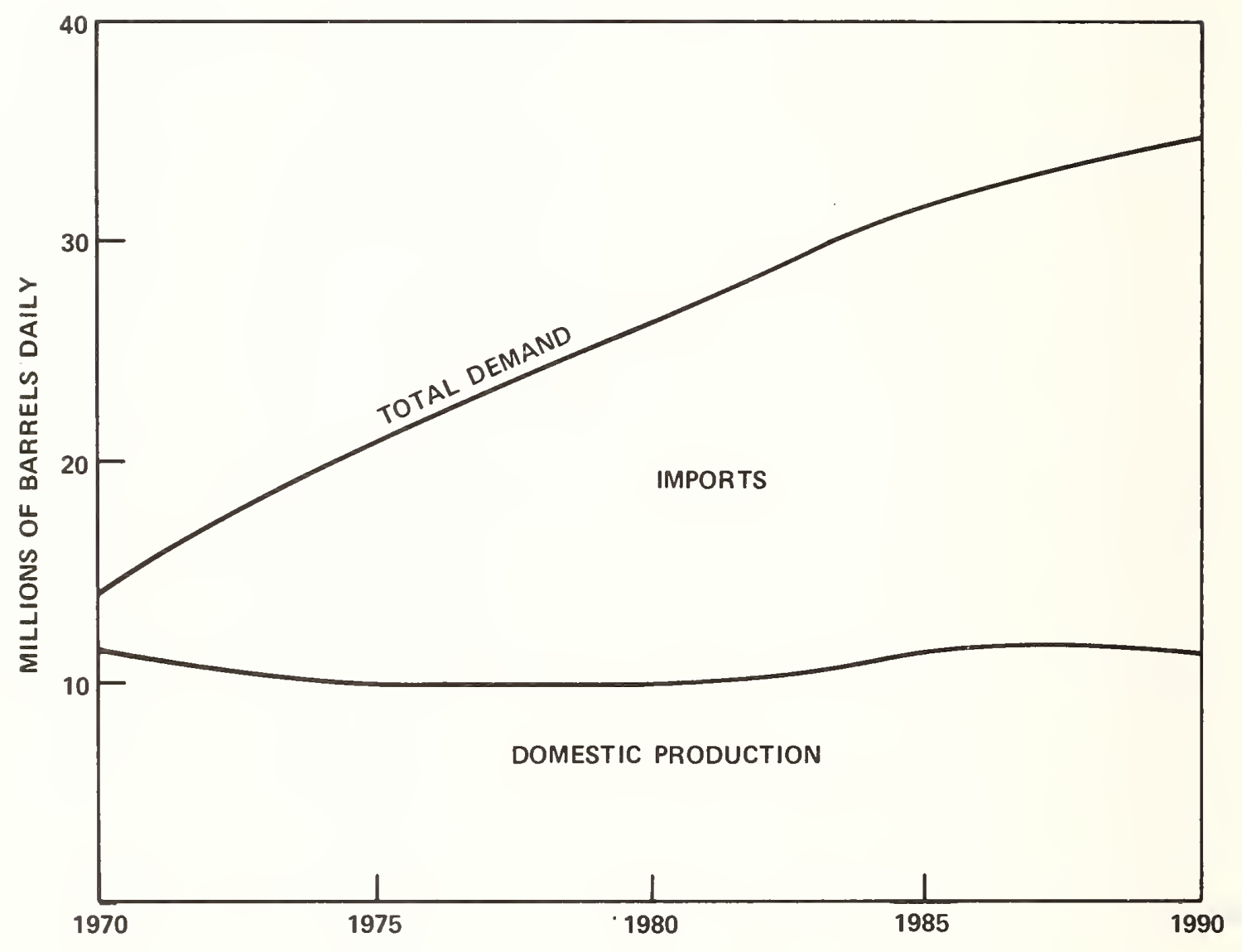

FIGURE 6 


\section{TABLE 2}

\section{ENERGY SOURCES AND USES IN UNITED STATES (1971)}

$\%$ OF TOTAL ENERGY

RESIDENTIAL

\& COMMERCIAL

$$
0.57
$$

10.65

NATURAL GAS

PETROLEUM

9.49

7.81

23.39

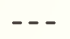

NUCLEAR

HYDRO

6.47

15.13

1.20

0.01

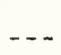

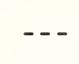

$+-$
5.98

32.95

ELECTRIC

GENERATION TOTAL

\subsection{6}

18.21

5.98

3.50

44.20

0.59

0.59

4.06

4.06

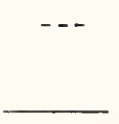

20.70

29.42 
FIGURE 7

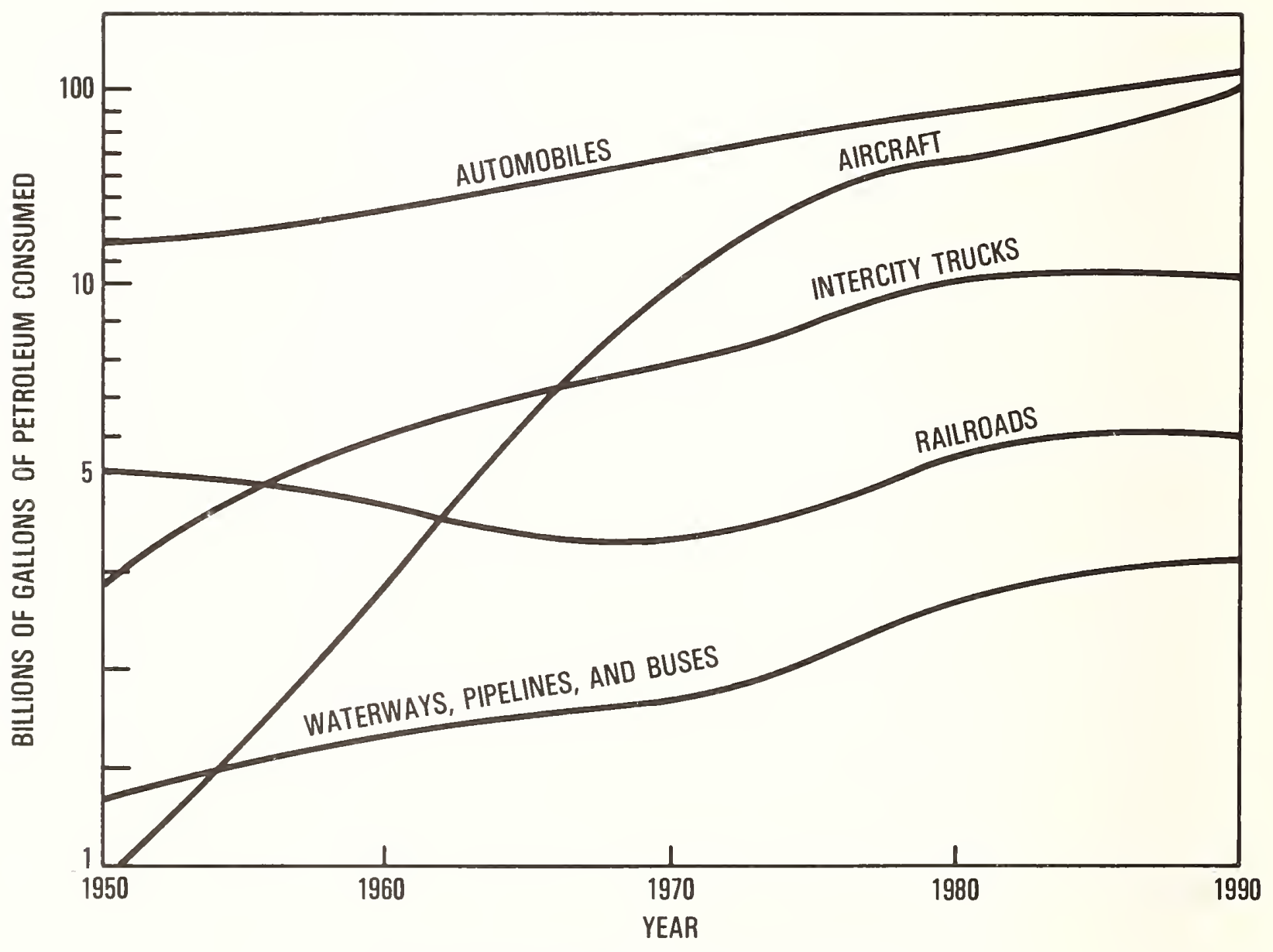

PETROLEUM CONSUMED IN TRANSPORTATION 
FIGURE 8

BILLIONS OF NET TON-MILES

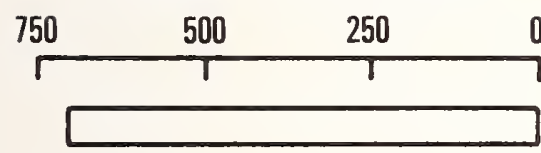

RAILROADS-FREIGHT

NET PROPULSION EFFICIENCY

\begin{tabular}{llll}
0 & 100 & 200 & 300 \\
\hline & $T$ &
\end{tabular}

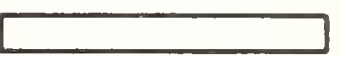

RAILROADS-PASSENGERS

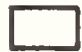

$\square \quad$ BUSES

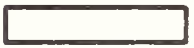

TRUCKS

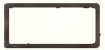

PERSONAL AUTOMOBILES

$\square$

OIL PIPELINES

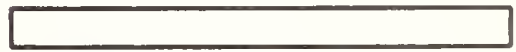

WATERWAYS
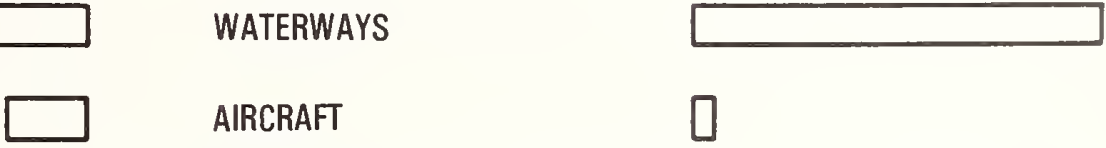

AIRCRAFT

$\square$

TOTAL, PASSENGERS

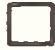

TOTAL, FREIGHT

TOTAL

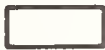

TRANSPORTATION MODE USE AND EFFICIENCY 


\section{SUMMARY OF DISCUSSED ACTIONS AND THE \\ CORRESPONDING PETROLEUM CONSERVATION \\ POTENTIAL IN PERCENT OF TOTAL TRANSPORTATION \\ ENERGY FOR 1970}

1 .

2 .

3.

4 .

5 .

6 .

7.

8.

9.

10.

\section{ACTION}

Convert $50 \%$ of Passenger Car Population to Small Cars (22 $\mathrm{mpg}$ )

Introduce in $50 \%$ of Highway Vehicles a $30 \%$ Reduction of Fuel Consumption

Eliminate $50 \%$ of Urban Congestion

Achieve $50 \%$ Success in Limiting Highway Speeds to $50 \mathrm{mph}$

Persuade $50 \%$ of Urban Commuters to CarPool

Shift $50 \%$ of Commuters, (to \& from City Centers), to Dedicated Bus Service

Shift $50 \%$ of Intercity Auto Passengers to Intercity Bus and Rail, Evenly

Shift $50 \%$ of Intercity Trucking to Rail Freight

Shift $50 \%$ of Short Haul Air Passengers to Intercity Bus

Persuade $50 \%$ of the People to Walk or Bike up to 5 miles, instead of Driving
FUEL CONSERVATION

9.08

11.58

1.18

2.98

3.18

1.98

3.08

3.48

0.298

1.68

\section{Foreign Relations}

An immediate problem posed by the present growth in energy consumption is the gap between United States petroleum consumption and domestic production. An estimate of cost of oil imports for the next twelve years is given in Figure 9l1. By 1983, the cost of oil imports is estimated to range between 25 and 50 billion dollars. To avoid a trade deficit, the present dollar volume of United States exports must approximately double (1971, 43 billion dollars) while the dollar volume of imports of quantities other than petroleum must remain constant. We may be forced to commit a large portion of agricultural production to foreign trade which may affect domestic food prices in a manner similar to what we are experiencing this year. A viable alternative to trade deficits is a strict conservation policy. The projected costs of imported petroleum will cause severe pressure on the international monetary system and possibly cause domestic shortages of goods sold on the world market.

Even though our energy consumption is growing rapidly, the consumption of the rest of the world is growing faster. Figure 1012 shows the projected demand for Western Europe and Japan compared with the United States. The greatest part of the world's crude oil reserves is concentrated in the Middle East. The United States, along with Western Europe and Japan, will become major consumers of Middle Eastern oil. Figures 1113 and $12^{14}$ " 
FIGURE 9

RANGE OF COSTS OF U.S. OIL IMPORTS

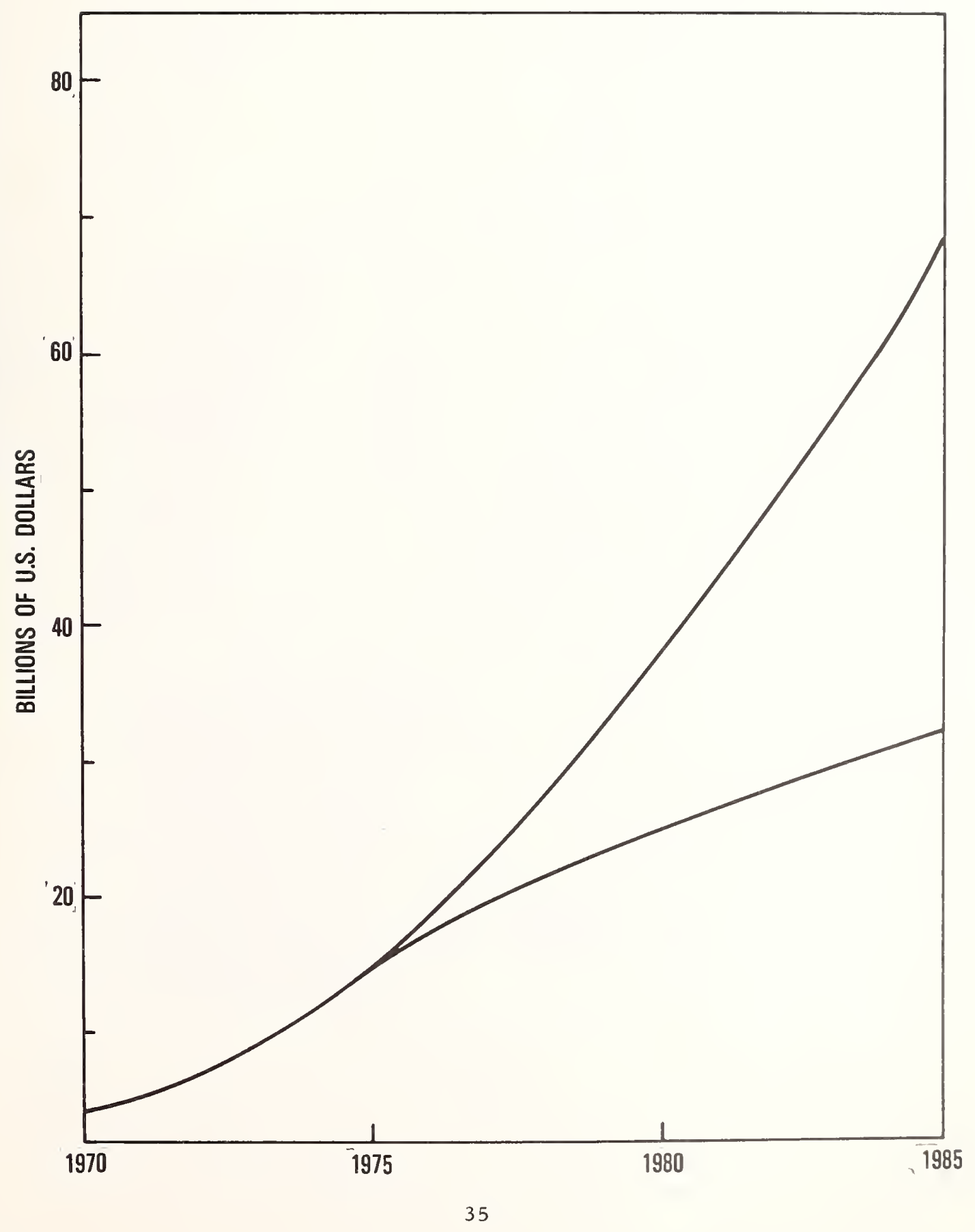




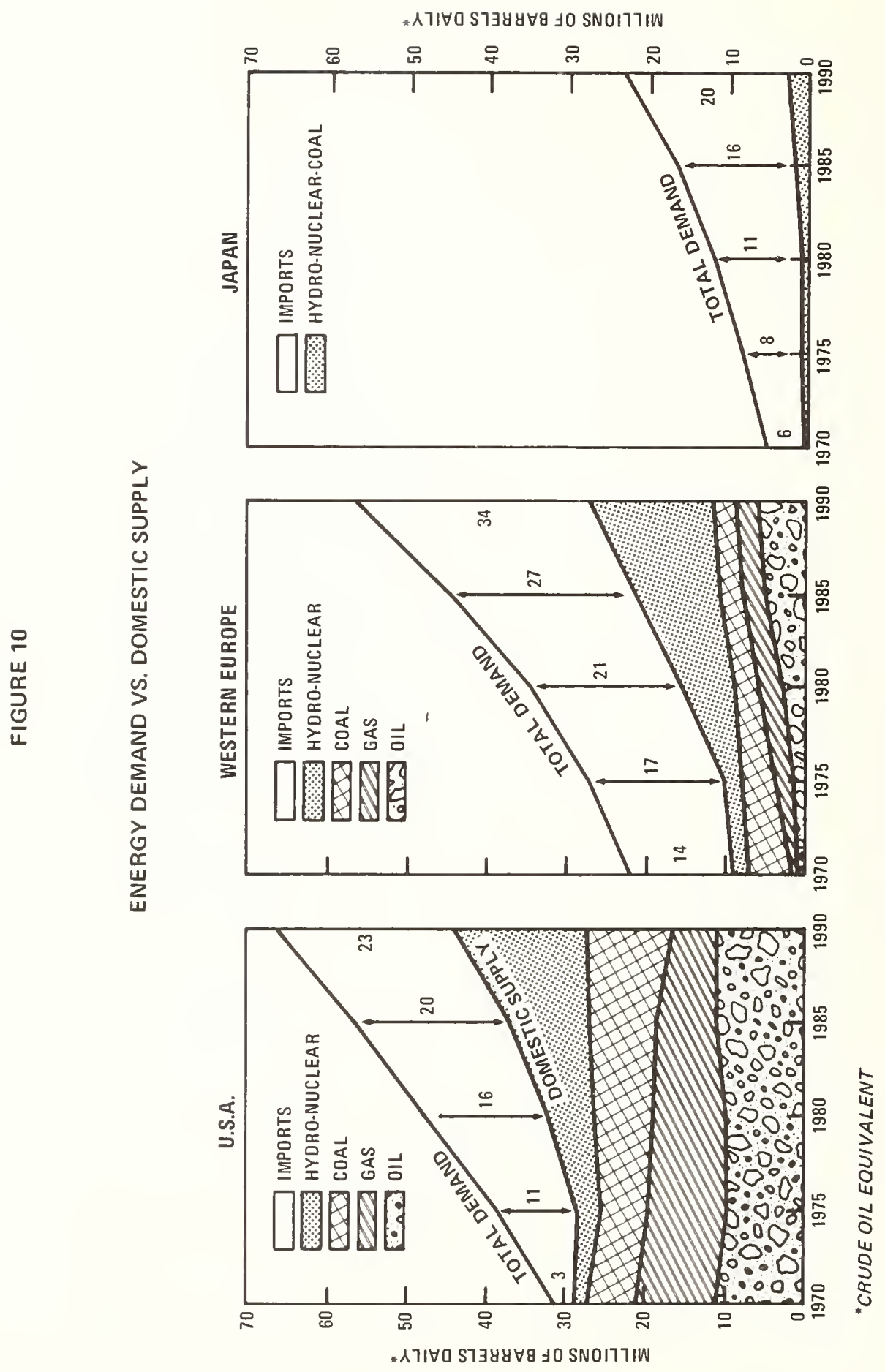


FIGURE 11

1970 WORLD PETROLEUM

CONSUMPTION AND MAJOR MOVEMENTS

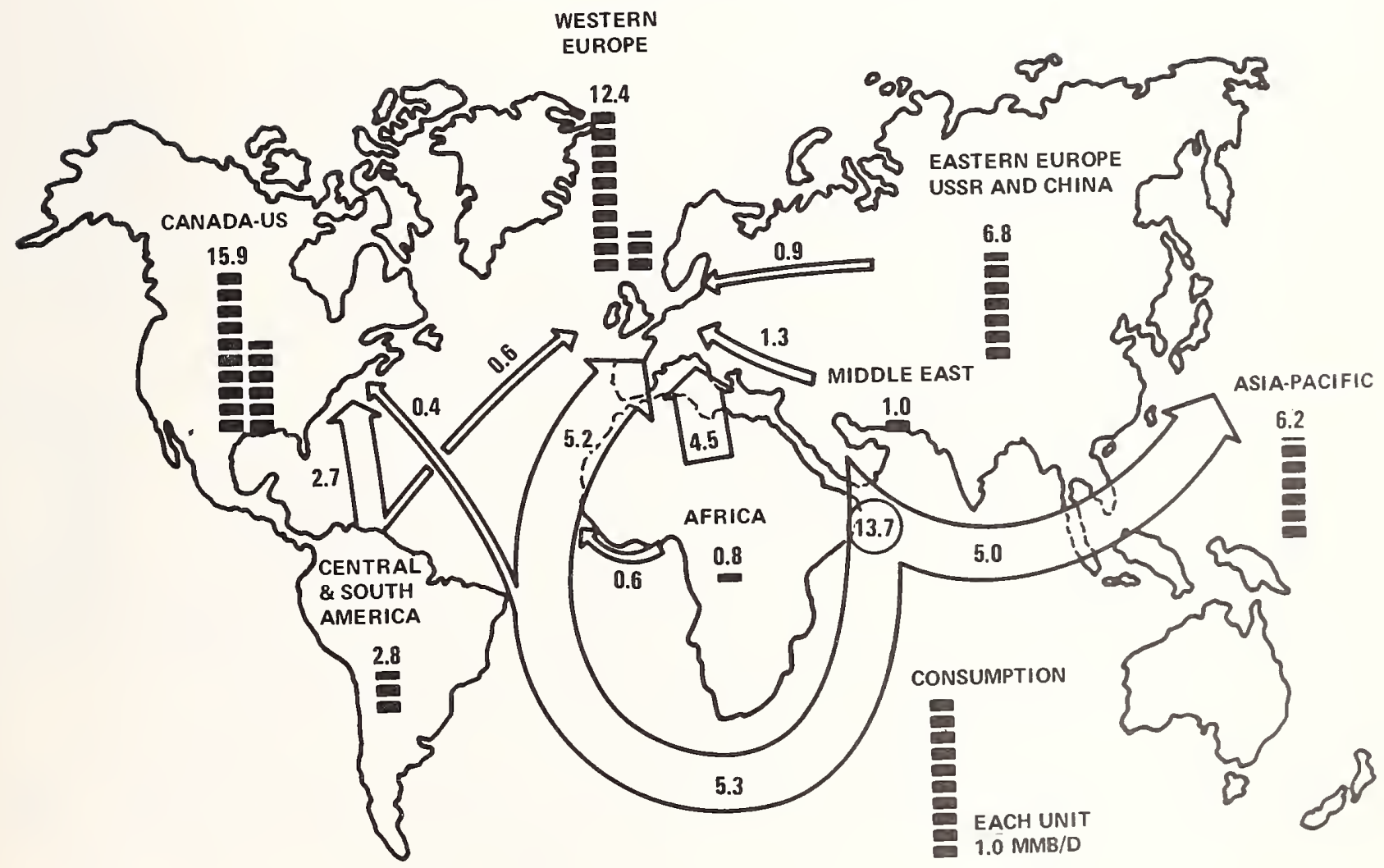




\section{FIGURE 12}

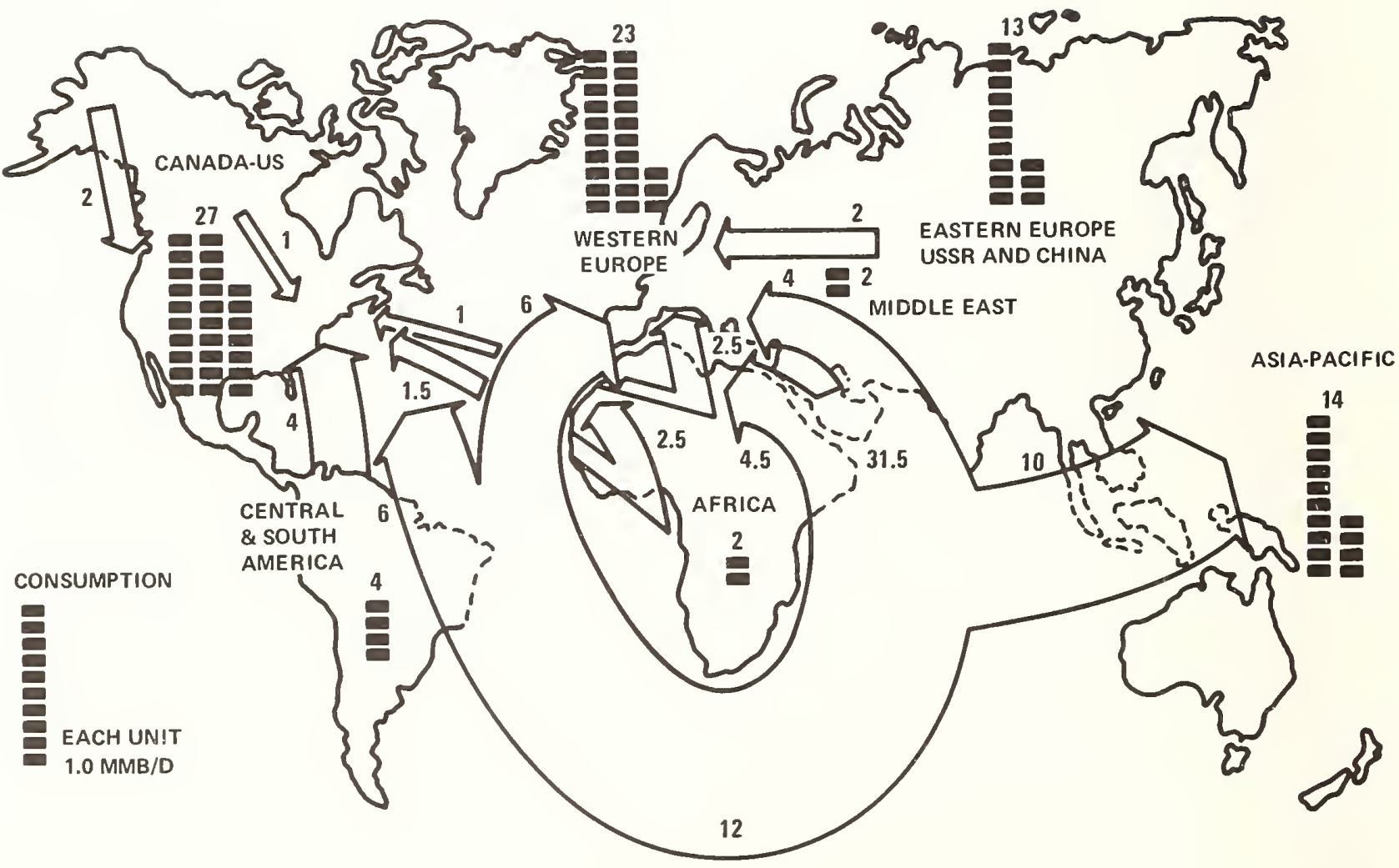


show how the pattern of petroleum movement will shift over the next decade. The critical problems of allocating the Middle Eastern supplies and providing the necessary shipping capacity must be solved. On one hand, one can envision a free-for-all between the consuming nations, each offering lucrative agreements to the producing nations for oil rights. The strain of this competition could cause a major re-alignment of traditional alliances. For example, if the United States and Japan were able to monopolize most of the Middle Eastern oil supplies, Western Europe would have to turn to Russia for petroleum. One could imagine scenarios as frightening as supplies curtailed by producing nations to raise revenues or to influence major international decisions by their customers, or even armed intervention by consumers to assure adequate supplies.

on the other hand, the major producing and consuming nations may realize that only long-range co-operative planning will assure supplies and compensation adequate for all. The establishment of world-wide conservation policies could be an important step in assuring adequate supplies. The energy problem may provide an impetus for an integrated world economy with perhaps more friendship and cooperation in political dealings.

\section{Conclusions}

If the present growth rate of energy consumption is maintained in the future, various consequences will be felt in this country. A continuation of the high growth rate will resul': in a rapid depletion of our economically available supplies of fuels, possibly before alternative fuel technologies have been developed. The high growth rate will force a much larger portion of our future GNP to be used for energy production. The projected gap between our projected petroleum consumption and our domestic production will force us to rely heavily on imported fuel. If the oil-producing countries can maintain a high tax on petroleum, it will be almost impossible for this country to avoid a huge trade deficit. This deficit will, in turn, cause many domestic and international repercussions.

The decrease in the rate of population growth will help to reduce the growth of energy consumption. Energy consumption will also decrease if the unit price of energy increases sufficiently, but his decrease is at the expense of a reduced standard of living, at least for some segments of the population. Government regulation of fuel consumption will not be effective unless a very complex, highly innovative and coordinated program to regulate all fuels is instituted. If only one fuel is controlled, for example, if natural gas is rationed, then oil can be used as a substitute fuel and the pressure on oil supplies will increase.

Conservation of energy appears the most desirable method to reduce energy consumption beyond that achieved by a zero population growth. Conservation will also produce side benefits in the form of natural resource conservation, reduced air and thermal pollution, and reduced noise.

The importance of energy conservation can be fully grasped when the present rate of growth is projected into the future. A change in the rate of growth from $5 \%$ to $3 \%$ can reduce the cumulative use of energy for the next 130 years by a factor of ten. Even the 3\% growth rate results in enormous levels of energy consumption. 


\section{$\underline{\text { References }}$}

1. (Figure 1)

Darmstadter, Joel with P. D. Teitelbaum and J. G. Polach, Energy in the World Economy, a Statistical Review of Trends in Output, Trade, and Consumption since 1925. Published for Resources for the Future, Inc. Baltimore, Md.: John Hopkins Press, 1971, p. 66.

2. (Figure 2)

Hottel, Hoyt C. and Jack B. Howard, "An Agenda for Energy", In Technology Review, January 1972, p. 39. Updated using: U.S. Dept. of Commerce, Bureau of the Census, Statistical Abstract of the United States, 1972, Washington, D. C.: Government Printing Office; National Petroleum Council, U.S.Energy outlook: A Summary Report of the National Petroleum Council, Washington, $\bar{D} . \overline{C .:} \mathrm{N} P \overline{\mathrm{C}}, 1972, \mathrm{p} \cdot \mathrm{l} 6$; Executive Office of the President, Office of Emergency Preparedness, The Potential for Energy Conservation, A Staff Study, Washington, D.C.: Government Printing Office, 1972, P. A $-\overline{2}$.

3. (Table 1)

Data from: Theobald, P. K., S. P. Schweinfurth, and D. C. Duncan "Energy Resources of the United States",U. S. Department of the Interior, Geological Survey Circular 650. Washington, D. C.: U.S.G.S., 1972,Also Benedict, Manson, "Electric Power from Nuclear Fission", in Technology Review, October/November 1971, p. 37.

4. (Figure 4)

InterTechnology Corporation, The U.S. Energy Problem, $\forall$ ol. II, Appendices Volume, Part A. Prepared for the RANN Program of the National Science Foundation. Warrenton, Va.: InterTechnology Corporation, 1971, pp. A-36 - A-39.

5. (Figure 5)

Uranium prices taken from Benedict, Manson, op. cit., p. 37.

6. (Figure 6)

Shell Oil Corporation, "The National Energy Outlook". Houston, Texas: Shell Oil, 1973, p. 4 .

7. (Table 2)

Executive office of the President, Office of Emergency Preparedness, op. cit., p. A-2.

8. (Figure 7)

Rice, Richard A., "System Energy and Future Transportation", in Technology Review, January 1972, p. 36 .

9. (Figure 8)

Ibid.

10. (Table 3)

Malliaris, A. C. and R. L. Strombotne of the United States Department of Transportation, "Demand for Energy by the Transportation Sector and Opportunities for Energy Conservation". Presented at the conference "Energy: Demand, Conservation and Institutional Problems", held at M.I.T., February 12-14, 1973, p. 24. 
11. (Figure 9)

Shell Oil Corporation, op. cit., p. 24.

12. (Figure 10)

Ibid., p. 30 .

13. (Figure 11)

Ibid., F. 32 .

14. (Figure 12)

Ibid., p. 33.

15. * 1970 Automobile Facts and Figures, Automobile Manufacturers Association

16. ** Malliaris and Strombotne, "Demand for Energy in the Transportation Sector and Opportunities for Energy Conservation", presented at the conference Energy: Demand, Conservation and Institutional Problems, M.I.T., Feb., $\overline{1973}$

17.*** Berry and Fels, "The Production and Consumption of Automobiles", a report to the Illinois Institute for Environmental Quality, July 1972 . 

National Bureau of Standards Special Publication 403

Proceedings of 1973 Engineering Foundation Conference (Issued June 1976)

OPTIONS FOR ENERGY CONSERVATION

by

B. Hannon

University of Illinois

Urbana-Champaign

Urbana, Illinois 61801

\begin{abstract}
An input-output model useful in measuring energy use, efficiency of production processes, and product uses is presented. The model provides estimates of total energy and employment shifts in a variety of processes and products. Several of these demand shifts and their potential impacts are discussed. United States industry, in general, becomes more energy-intensive as it grows. The impacts of demand shifts and changing character of industry as it evolves on consumer cost, employment, and pollution should be thoroughly understood before policy recommendations should be initiated.
\end{abstract}

Key Words: Economic; Energy; Input-Output Model

A country that runs on energy cannot afford to run short. If it does, its processes, from the most fundamental metal processing to incidental pleasure transportation, decline dramatically. Yet in the United states, where fast rising per capita energy demands (50\% increase since $1952(1,2)$ ) nearly intersect the home supplies of some energy forms, we turn more and more to imported petroleum as the chief source of energy. This raises the dependence of this country on the rest of the world, raises the risk of an interrupted energy supply, and raises the risk of United States involvement in an armed intervention to protect a foreign energy source. It is true that we "can't afford to run short", yet the price demanded for extending the energy supply lines may become more than the country is willing to pay. Home supplies can be extended through the substitution of coal for oil and gas and through the use of nuclear electric power. The substitutions require time. The long range planning horizon for most utilities is about 10-15 years. Massive capital reallocation for fuel substitution would be required to postpone the anticipated intersection of supply and demand (3). Further, fear of the environmental impacts of strip mining for coal, power plant emissions of heat, radiation, oxides of nitrogen and of sulfur, etc., auto emissions, and other air, soil and water pollutants, does not seem to retard our unbridled consumption of energy.

The concept of energy conservation appears to be a loophole in the fabric of the energy dilemma. Using less energy in homes, industry and transportation, by both increased efficiency and restricted use of energy, would decrease external dependency and avoid additional environmental impact.

A country that runs on energy cannot afford to waste it.

Modeling Energy Use

This paper discusses the options for energy conservation by describing a model and early results obtained by the Energy Research Group at the Center for Advanced Computation (CAC) in the University of Illinois at Champaign-Urbana. The work is supported mainly by the National science Foundation and the Energy Policy Project of the Ford Foundation. 
CAC has developed a mathematical model as a result of an in-depth look at the methods for conserving energy. Before speaking of conserving energy (or of increasing energy supply), one should have a detailed understanding of where energy is going and the total energy cost of every good and service. One could then determine the energy conserved by switching from one good or service to an alternative or by eliminating its use. Likewise the energy cost of the substitution of new technology could be estimated.

A simple static model which accounts for all the activities in the United States and for which much data has been collected is all that is initially required. Such a model was developed by Leontief and the United States Department of Commerce $(4,5)$ for dollar flows in the United States economy. This model has been converted to an energy flow model by

Herendeen (6) for 1963, utilizing the most recent data available. The model is linear and is described by the matrix equation

$$
E=R(I-A)^{-1} P q
$$

$\mathrm{E}$ is the direct and indirect energy use of a prescribed type; $\mathrm{R}$ is a vector which describes the amount of that type of energy in British Thermal Units (BTU) per dollar of total output of each of the industries in the United States; I is the unity matrix; A is the Department of Commerce's direct dollar matrix of transactions between each industry and all the others; $P$ is an activities matrix of the dollar flow from each industry to a particular activity per dollar of that activity; and $q$ is a vector which describes the total amount of dollars spent under a certain proqram on each of the activities described by $\mathrm{P}$. In our model the maximum size of $\mathrm{R}$ is 362 elements; of A, 362 squared elements; of $\mathrm{P}, 362$ rows and 220 columns, and of q, 220 elements.

There are currently five $R$ vectors representing coal, refined petroleum, gas, electricity and the total primary energy. If the meaning of $\mathrm{R}$ is changed slightly to occupational employment per dollar of total output for each industry (7), then $\mathrm{E}$ is the total (direct and indirect) employment of a particular occupation required for the specified $q$. Currently the model can represent 165 occupations. Pollution vectors are now being fitted to the model. If we are to be realistic in setting goals for energy conservation, the employment and pollution effects must be understood and taken into account.

For a specified list of activities (q), the direct and indirect energy and employment requirements and pollution generated in the industrial and commercial sectors can be determined for the technology in use in 1963 . We are currently developing $R$ vectors for 1967 with the hope that the $A$ matrix will soon be available from the Department of Commerce. At this point, we can begin to understand how energy uses change with alterations in demands for goods and services.

Direct energy is energy used by a particular industry to produce a unit of its goods and services. Indirect energy is that energy used by all the suppliers of materials and services to this industry and by all the suppliers of the suppliers, etc., to supply only those materials which were needed for the unit of good or service. Indirect energy is the limit of an infinite sum of terms, which increase in plurality, but decrease in value. This process, in some case, includes the amount of production in a "feedback" process. For example, it includes the consumption of cars used by steel company executives to make the steel which is consumed in making a car.

Projecting the matrix to future years is difficult. Changes must be made to the elements in $\mathrm{R}$ to reflect the change in efficiency and substitution effects of the industrial and commercial use of energy, e.g., a switch to oil from coal to generate electricity. Changes in A must reflect the new technologies adopted by an industry, e.g., electric steel furnaces replacing the open hearth processes. Changes in $\mathrm{P}$ must be made to reflect the technological change in final processing techniques and the changes in consumer choice, e.g., the increasing amounts of paper and plastic packaging used in retail food establishments. 
The $\mathrm{R}$ vectors will change rapidly, yet as more data become available from specific energy use studies, projection difficulties increase. The A matrix is relatively stable (8) but the Bureau of Labor statistics has made several projections. The $P$ matrix is being developed by special investigation at CAC and the Department of Commerce. Error propagation and sensitivity analysis techniques are under study at the center. The entire model with its techniques for manipulation is being installed on the national ARPA (9) computer network. Installation should be finished for the 1963 models by August of 1973 .

The matrices and vectors can be reduced to any desired size by aggregation techniques. On the other hand, more detail than is now available is often needed and pertinent rows and colums of the $A$ matrix must be judiciously subdivided.

\section{Energy Conservation Options}

Many specific techniques can be imagined to conserve energy. From this plethora of opportunities, one can discern three general categories: efficiency of production, efficiency of product use, and control of the rate of energy use. Each of these can be thought of in the context of three broad classes of users - personal consumption, government and industry - in order to realize the options for energy conservation.

$\underline{\text { Production Efficiency }}$

Because of the low cost of energy (only 3.6\% of producers' price in 1963), it is presumed by many that industries simply do not strive to use energy efficiently in their production processes. Compelling arguments for this point of view are made by Berg (10), who claims that about $25 \%$ of the total United States energy use could be saved through more

efficient use. For example, savings of up to $39 \%$ could be realized in the operation of certain equipment in the steel industry.

Railroads have improved their energy use efficiency by a factor of 10 since the early part of the century through a change to diesel fuel and through improved hauling techniques (11). Recycling of aluminum, steel, paper, cardboard and plastic offer rich energy saving opportunities (12). The most pervasive energy increase in industrial processes, however, is believed to have occurred via automation, i.e., the displacement of labor from the production process. The ratio of production workers' wages to the cost of electricity increased steadily by 25\% from 1951 to 1969 (13, 14). During that time the wholesale price index for electrical machinery increased by 50\% (15). These factors indicate the pressure on the industrial decision makers to eliminate the increasingly expensive worker from the process and to substitute machines which increase its energy intensity.

We have examined the process of automation in some detail, with the model described in equation (1) (16). If $q$ is specified so as to require a one dollar increase in delivery to final consumption from a given industry, then Fig. I shows the direct and indirect energy use and employment arising throughout the economic system. While a large proportion of the industries are centrally clustered, there are some very energy intensive industries (asphalt coatings and asphalt paving, cement, primary aluminum building paper, and chemicals) and some very labor intensive industries (hospitals, hotels, credit agencies).

The pattern shown in Figure 1 represents the energy and labor requirements of an additional dollar delivered to final demand. It represents, for a consumer, the direct and indirect effect on energy and employment of the expenditure of one dollar in each industry. It does not include any multiplier effects of the expenditure. It is, therefore, inappropriate for use in an impact analysis.

Another way to consider the problem is to examine the effects of a 10 percent proportionate growth in each industry, with an offsetting decrease prorated among the other industries in proportion to their share 


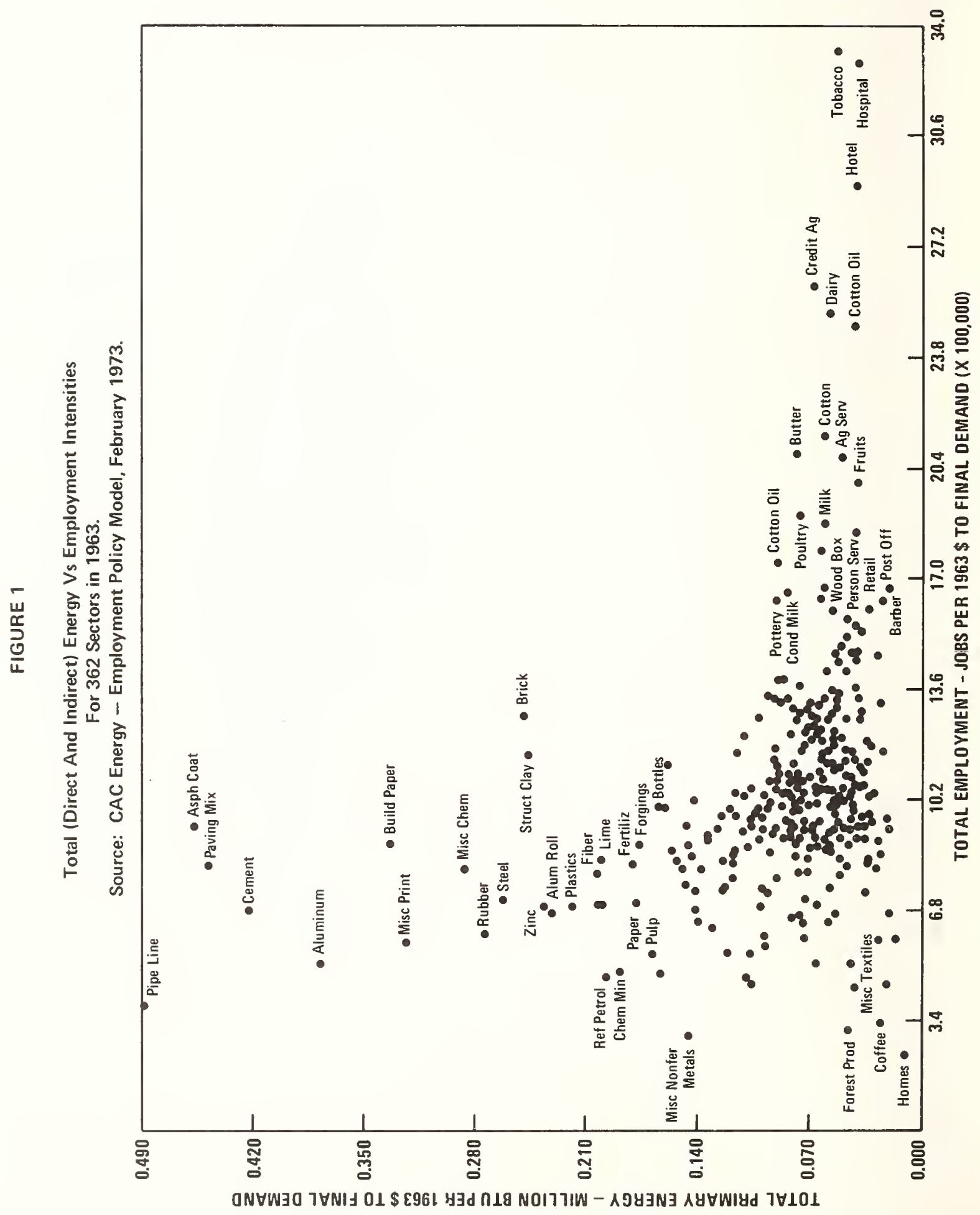




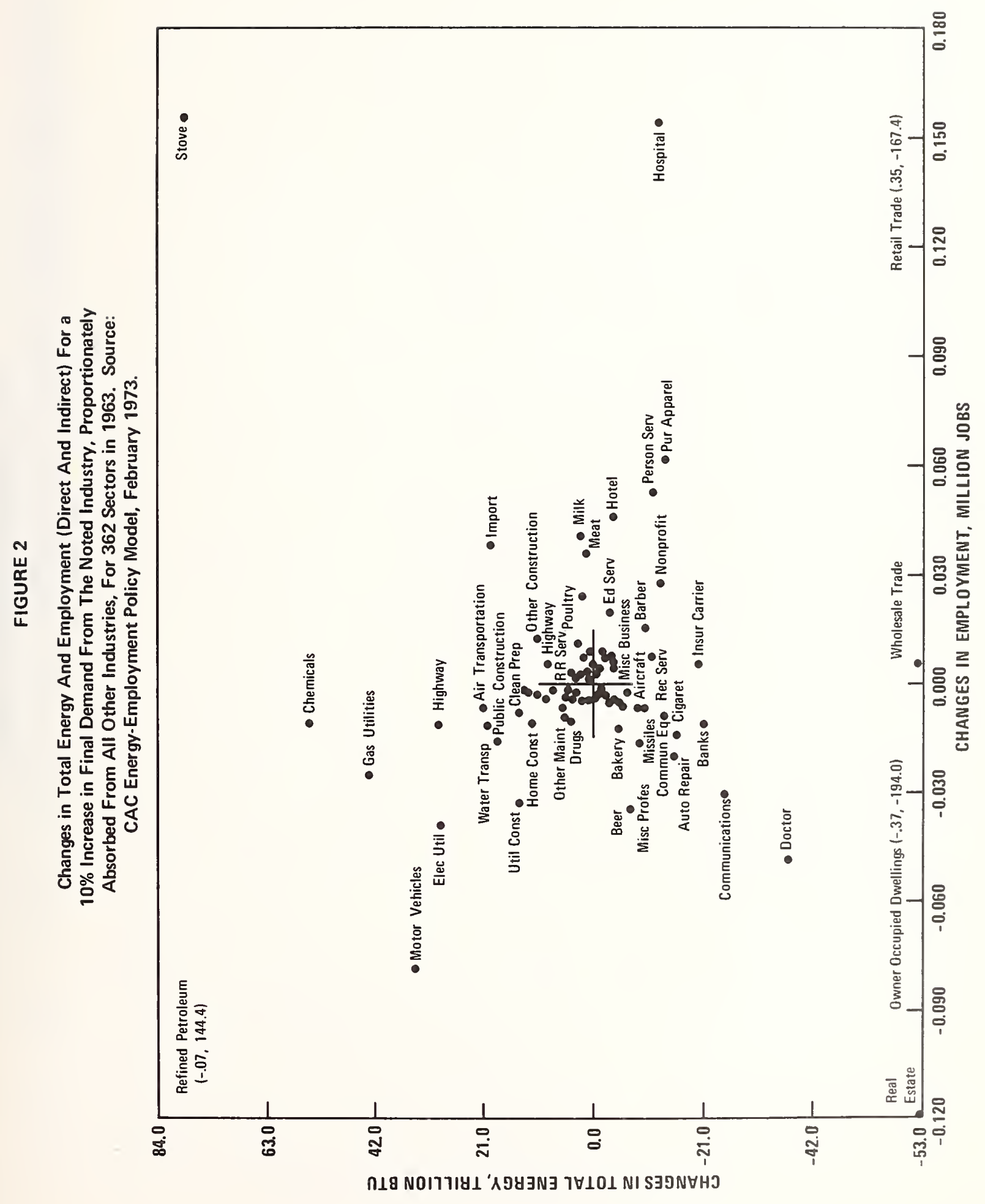




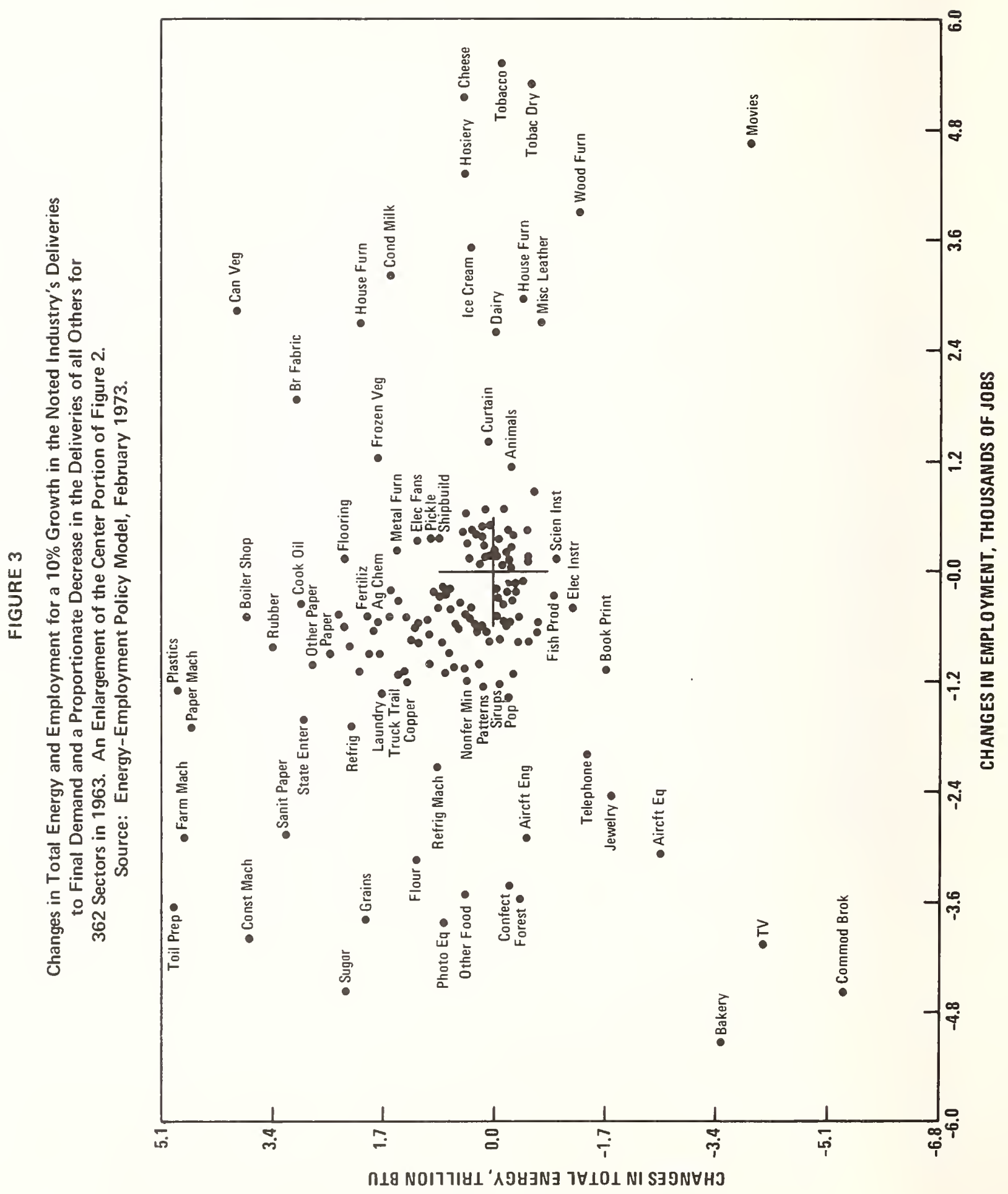


of deliveries to final consumption. In Figures 2 and 3 , first quadrant industries are primarily agricultural; second quadrant industries are basic material production, construction and fabrication oriented; third quadrant industries are service oriented with a high degree of technology and high wages, and fourth quadrant industries are service oriented without a great degree of special labor saving technology and with low wages. Most industries fall into quadrant 2, indicating that the nature of the structure of the 1963 economy is to respond to an increase in production by becoming more energy intensive and less labor intensive.

Figures 2 and 3 are addressed more to the policymaker concerned about the question of growth. The magnitudes reflect the relative dependence of the United States society in 1963 on each of its industries. For example, a $10 \%$ increase in delivery to final demand by "motor vehicles" would have required a direct and indirect energy increase of 34 trillion BTU and a decrease in employment of 104,000 jobs (direct and indirect). Further, a $10 \%$ increase in deliveries of postal services to final demand would have reduced energy consumption by about 4 trillion BTU and increased employment about 36,000 in 1963. Note that some intermediate products deliver little to final demand.

A problem with this approach is that the gain in delivery to final demand is absorbed proportionately from all other industries. On the other hand, the product of an industry competes with only a few other products, e.g., aluminum with steel and wood as structural members, steel with glass and plastic as food containers. (This type of product competition is described in the next section.)

If one industry's gain were at the expense of a few competitors, the complexion of Figure 2 and 3 would change. Suppose, for instance, that a one billion dollar gain in primary aluminum deliveries was obtained at the expense of an identical loss in steel deliveries. Then from Fig. 1 energy use would increase about 116 trillion BTU (about 0.2\% of the total) and employment would decrease by 15,000 jobs (about 0.03\% of the total). An identical increase in primary aluminum deliveries at the proportional expense of all other industries would produce an increased use of energy of 332 trillion BTU and a loss of 65,000 jobs.

The results so far indicate that, in general, most United states industries are trading labor for energy (becoming more energy intensive, less labor intensive) as they grow. Such industries as well as their competitors can be identified through the use of the CAC models (Equation 1). Thus, if economic growth is desired it can be guided so as to minimize the impact on energy use and maximize employment demands. In any event, the model clearly provides an estimate of the total energy and employment impact of desired shifts in demands.

Several other process efficiency studies, either underway or completed, include Moyers' (18) study on the value of residential insulation. Also, Stein (19) and Socolow (20) have shown the value of better heating and lighting techniques for public buildings and residences.

$\underline{\text { Product Use Efficiency }}$

The variety of goods and services available in the United States today provides what Toffler calls "overchoice" (21). When the historical perspective of the development of the products is added, the variety of the system is even larger. For example, beer is available in 23 different package combinations. At the same time about five other configurations, including the consumer-owned container, have become obsolete. Another example of variety is the choice of passenger transportation between cities; plane, train, bus and car. But the intercity passenger train is now almost defunct.

One can speculate that certain members of the existing variety of products are more energy efficient, per unit of service, than others. For instance, it has been shown (12) that refillable bottles are about onethird less energy consumptive per unit of beverage than are paper, glass, aluminum or steel disposable containers. Fold (22) demonstrated that if 
the nation were to shift completely to returnable beverage containers, employment would rise by 130,000 jobs, and annual consumer costs would decrease by $\$ 1.4$ billion. The national energy savings would be about $0.5 \%$, half of which would not be saved if the consumer savings were absorbed by an increase in average personal consumption.

Several other product comparisons are now being investigated at the Center. In particular, the intracity auto and bus are being compared. Results of energy and labor cost of the auto in 1963 are presented in Table 1. The auto consumed $12.4 \%$ of the GNP, required $12.0 \%$ of the total employment and consumed about $20.7 \%$ of the total United States energy. This amounts to about 7900 BTU per passenger-mile and 5.5 jobs per hundred thousand passenger-miles. Preliminary estimates indicate that the bus is about one-third as energy intensive as the auto, and that total United states energy use could be reduced by about five percent by a full shift to buses. All United states transportation required (direct and indirect) $42 \%$ of the total national energy consumption in 1963 (6).

An extremely interesting product alternative is the use of picture phones as a substitute for physical transportation (23).

Another interesting application of the concepts of product-use efficiency is shown in Table 2 where the total energy and employment demands to supply a pound of protein by various means is determined. Cheese is considerably more energy efficient than meat, milk, or fish in the forms consumed in the United States in 1963.

other produce alternatives, such as food preparation and packing, clothing fibers, home appliances, etc., are also being investigated for their unit energy and employment demands at the Center.

Table 1. Energy and Employment (Direct and Indirect) for the Private Auto in 1963

\begin{tabular}{|c|c|c|c|}
\hline Category & $\begin{array}{l}\text { Final Demand, } \\
10^{9} \$(6) \\
\end{array}$ & $\begin{array}{c}\text { Energy, } 10^{12} \mathrm{BTU} \\
(6) \text { of total }) \\
\end{array}$ & $\begin{array}{c}\text { Employment } \times 10^{3} \text { Jobs }(17 \\
(\% \text { of total }) \\
\end{array}$ \\
\hline $\begin{array}{l}\text { Fuel, produce } \\
\text { refining } \\
\text { retail }\end{array}$ & $\begin{array}{l}5.86 \\
- \\
4.05\end{array}$ & 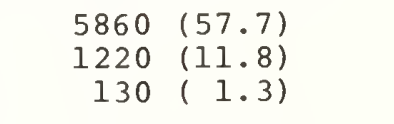 & $\begin{array}{l}278.8 \\
652.4^{-}(3.9)\end{array}$ \\
\hline $\begin{array}{l}\text { Oil, produce } \\
\text { retail }\end{array}$ & $\begin{array}{l}0.83 \\
0.55\end{array}$ & $\begin{array}{ll}50 & (0.5) \\
20 & (0.2)\end{array}$ & $\begin{array}{ll}39.5 & (0.5) \\
88.6 & (1.2)\end{array}$ \\
\hline $\begin{array}{l}\text { Auto, produce } \\
\text { retail }\end{array}$ & $\begin{array}{l}14.43 \\
10.67\end{array}$ & $\begin{array}{r}1010(9.8) \\
350(3.4)\end{array}$ & $\begin{array}{ll}1155.5 & (16.1) \\
1718.7 & (24.0)\end{array}$ \\
\hline $\begin{array}{l}\text { Tires, produce } \\
\text { retail }\end{array}$ & $\begin{array}{l}0.83 \\
0.55\end{array}$ & $\begin{array}{ll}80 & (0.8) \\
20 & (0.2)\end{array}$ & $\begin{array}{ll}54.6 & (0.8) \\
88.6 & (1.2)\end{array}$ \\
\hline $\begin{array}{l}\text { Maintenance } \\
\text { and parts }\end{array}$ & 21.7 & $340(3.3)$ & $1797.7 \quad(25.1)$ \\
\hline Parking & & $390(3.8)$ & \\
\hline $\begin{array}{l}\text { Highway Const. } \\
\text { (Fuel taxes) }\end{array}$ & 4.96 & $580(5.6)$ & $471.6 \quad(6.6)$ \\
\hline Insurance & 8.96 & $280(2.7)$ & $803.1(11.2)$ \\
\hline Total & $\begin{array}{l}73.4 \\
(12.4 \% \text { of } \\
\text { total GNP) }\end{array}$ & $\begin{array}{l}10330(100.0) \\
(20.7 \% \text { of total } \\
\text { U.S. energy used })\end{array}$ & $\begin{array}{l}7149.4(100.0) \\
(12.0 \% \text { of total } \\
\text { employment) }\end{array}$ \\
\hline
\end{tabular}

(a) Excludes household and government industries employment (10.7 million jobs). 
Table 2. The Total Energy and Employment Required to

Deliver a Pound of Protein to the Consumer thru Various Food Products in 1963

Producer's
Price a 1963
\$/lb.

Food Product

Meat Products

Cheese, Natural and Processed

Fluid Milk

Fresh or Frozen Packaged Fish

Total Produc-
tion Energy (b)
to Protein Ratio
$\mathrm{Kcal} / \mathrm{lb}$

32,600

18,800

51,200

0.12

0.35
Production

Energy to

Energy Con-

tent Ratio

(b)

6.3

2.6

6.1

6.5
Total Employment (b) Demands, $\mathrm{Jobs} / \mathrm{millia} \mathrm{lb}$. of protein

(a) Statistical abstract of the United States 1971, Department of Commerce; approximate

(b) Marketing energy not included, add about 10 to 15\%; total caloric energy used.

The impact of such shifts on consumer cost, employment and pollution should be thoroughly understood before policy recommendations can be made.

Rate of Energy Use

Ultimately all the product and process energy efficiency gains may be inadequate. Then the rate of energy use would have to be restricted. What are the priorities of restriction? How does the individual and his/her family draw upon the energy resource base? In which areas of use (direct and indirect) will an energy use restriction be least harmful? How does the direct and indirect energy use per family vary with such socio-economic variables as age and income of the family head? A study to determine the energy cost of various lifestyles is underway at the center. The first goal is to establish, through the use of equation (1), the influence of age, income, family size, etc. on the total energy budget of a family. Such studies will reveal the family dependence of total energy for housing, food, clothing, transportation, etc. so that if a priority of need is established, energy savings due to rationing can be estimated. Further, the impact on low income families of an increase in energy cost can be estimated. Finally, studies such as these can be used to plumb the energy demands of varying degrees of affluence, or leisure, by convenience and variety of consumer products.

A very preliminary total energy and employment comparison of the average urban family (about three persons) in the United States in 1950 and 1960 is made in Table 3 .

Several interesting tentative conclusions emerge. First, energy use and employment change are not proportional to change in constant dollar expenditures. Second, direct energy consumption is about one half of the total energy demand. Third, each family generates about the expected direct and indirect employment ( 1.1 per family), that the family itself provides, i.e., working head of household and one out of 10 working spouses.'

The effect of family (four person) income level on energy demand is shown in Table 4. Due to the preliminary nature of the estimate, the same energy coefficients were used for the same category, in each income class. 
Table 3. Preliminary Total (Direct and Indirect) Energy and Employment Generated by the Average U. S. Urban Family in 1950 ( 3.0 people) and in 1960 (3.1 people) (a)

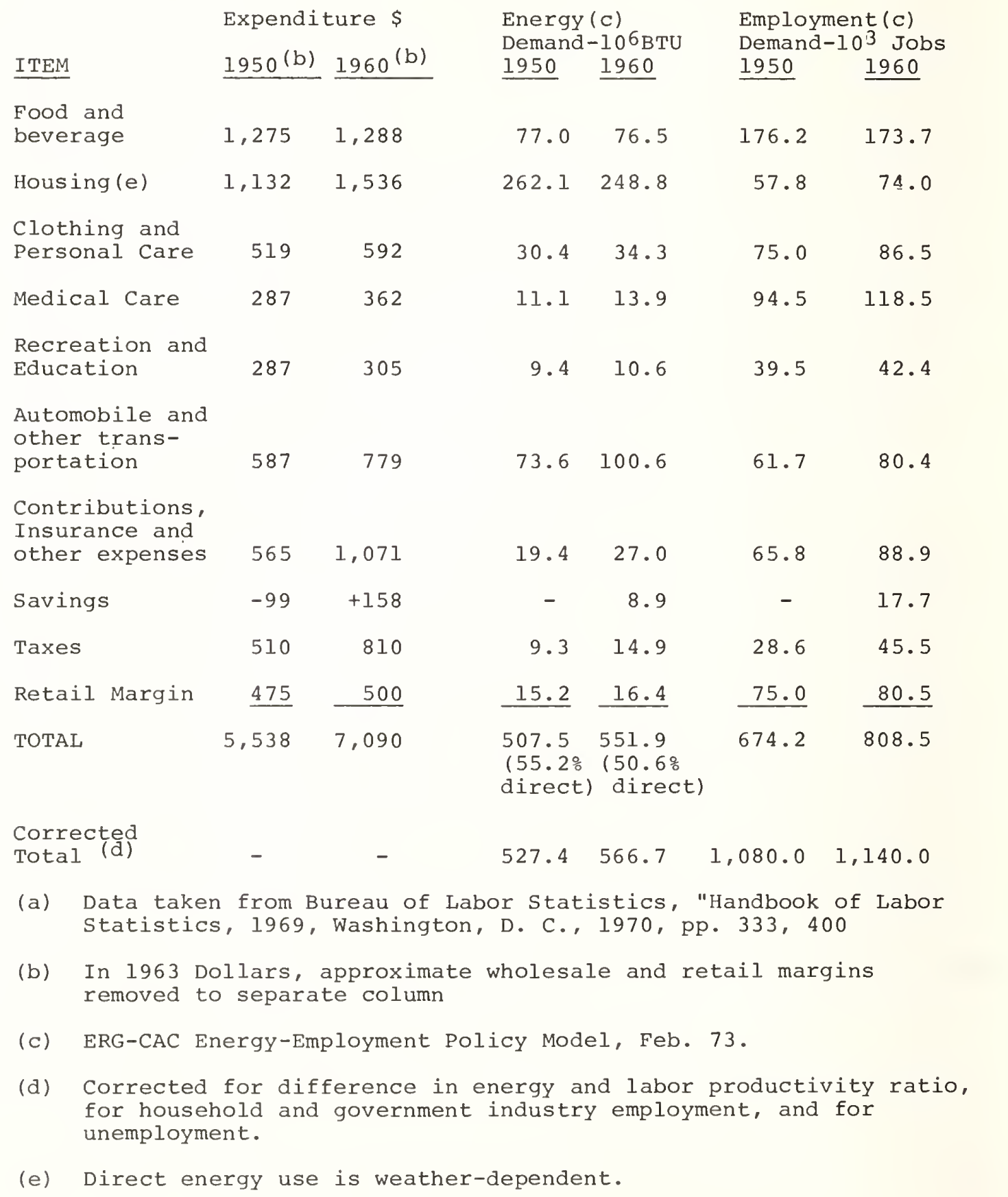


Table 4. Preliminary Direct \& Indirect Energy Budgets of Three Different Income Class Four Person Families, 1970

Low Budget

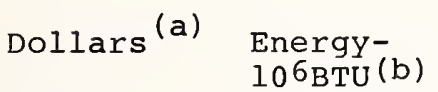
(percent) (percent)

Total

Food 6,960

$(22.5)$

(18.5)

$(43.0)$

$(10.8)$

Intermediate Budget

High Budget

Housing

(c)

(19.1)

Transport (16.3)

Clothing

\& Personal

Care

$(8.6)$

$(6.8)$

$(8.1)$

$(6.2)$

$(8.1)$

$(6.3)$

Medical

Care

$$
\text { ( } 7.8)
$$

(4.1)

$(5.2)$

$(3.0)$

$(4.9)$

$(1.6)$

$(4.8)$

$(1.6)$

( 3.5$)$

$(2.7)$

(2.4)

( 1.9$)$

\section{Social.}

Security

Personal

Income

Tax

$(10.0)$

(2.5)

(14.3)

$(3.4)$

(18.4)

(4.4)

Retail

(Approximate)
(10.7)
(10.5)
$(4.4)$

$(10.3)$
Other

(4.7)

$(4.4)$

(4.4)
Energy-
$10^{6} \mathrm{BTU}$

(percent)

(13.1)

(50.7)

(11.3)

(a)

(a) U. S. Dept. of Labor, HANDBOOK OF LABOR STATISTICS, 1971, Washington, D. C., Bulletin 170 $\overline{5}$, tables $126,27,28$.

(b) Energy-Employment Model, Center for Advanced Computation, University of Illinois, Urbana, Feb. 1973, Corrected for 1963 to 1970 Energy Productivity Change.

(c) Proportioned from Intermediate Income to High and Low Budget using data from Table 3. Energy will vary with climate. 
This procedure yields a total family energy demand which is roughly proportional to income. A more detailed estimate now underway at the Center for Advanced Computation will demonstrate how those in each different income class vary their specific buying habits accordingly. The data of Table 4 do reveal an energy dependency on food which declines with income, an energy dependency on housing which rises with income and an energy dependency on transportation which peaks with the intermediate income level. These three categories demand about 75\% of the total family direct and indirect energy. The same three categories require $58 \%$ of the low budget income and about $47 \%$ of the other two budgets. From this information we can infer that a rise in the price of energy would be preferentially difficult for the low budget family.

\section{Additional Research}

Possibilities for future research on energy conservation are plentiful. In particular, the impact on energy consumption of information flow through the consumer (advertising, status gradients, etc.) needs to be quantified. Under an energy conservation program it may need regulating.

Government activities and policies appear to have a major impact on energy use. For example, an inequitable subsidy of airlines and trucks over railroads produce unfavorable economic attractiveness for the less energy intensive railroads. In addition, taxation programs may significantly favor such things as family growth and urban sprawl. Also, the demonstration effects alone of such internal federal programs as recycling paper, building heating and lighting patterns, and highly efficient fleet automobiles, could lead to significant future energy savings for the rest of the nation.

The energy storage and distribution systems should be optimized against sudden shortages, particularly for critical areas of production such as agriculture. Agriculture and food processing required, on the average, in 1963, about 4.5 times as much energy in the form of fossil fuels (directly and indirectly) as the delivered energy content of the developed food. In all, food processing for human consumption required about $9 \%$ of the energy consumed in the United States in 1963 (6). Priorities for emergency rationing should be estimated so as to maintain the fundamental energy services to the nation. However, the conservation potential of agriculture and food processing can be realized through use of less packaging and more labor intensive farming.

Plans for implementing the adoption of well known means of conserving energy should be enacted. For example, residential insulation and high efficiency autos are very productive and well recognized areas for nearterm energy savings.

Land use planning is probably the most fundamental long term key to energy conservation. Communities could be planned around total energy systems in which waste heat from small power plants is used to heat or cool the community's buildings. Work and home could be located geographically so as to minimize transportation energy requirements.

\section{References}

1. National Economic Research Associates, Inc., "Energy Consumption and Gross National Product in the United States", 80 Broad Street, New York, New York, March, 1971, Table 1.

2. United States Department of Commerce, Statistical Abstract of the United States, 1971, Washington, p. $21 \overline{0}$.

3. Inter-Technology Corporation, The U.S. Energy Problem, Box 340 , Warrenton, Va. 22186, November, 1971, volume 1, Summary, Figure 4, p.9.

4. Leontief, W. W., Input-Output Economics, Oxford University Press, New York, 1966 . 
5. U. S. Department of Commerce, Input-Output Structure of the U.S. Economy: 1963, Washington, 1969, Volumes $I$, II, III.

6. Herendeen, R. A., "Use of Input-Output Analysis to Determine the Energy Cost of Goods and Services", Center for Advanced Computation, University of Illinois, Urbana, 61801, Document No. 69, 20 Feb., 1973.

7. Bezdek, Roger, "Alternate Manpower Forecasts to 1975 and 1980 , Second Guessing the U. S. Department of Labor", 1972 Proceedings of the Business and Economic Section of the American Statistical Association, pp. $431-436$.

8. Carter, A. P., "Changes in the Structure of the American Economy", 1947 to 1958 and 1962, Review of Economics and Statistics, 49, 1967, pp. 209-224.

9. Roberts, L. G. and Wessler, B. D., "The ARPA Network", Advanced Research Projects Agency, Washington, D. C., May 1971.

10. Berg, Chas., "Energy Conservation thru Effective Utilization," National Bureau of Standards, Washington, D. C., June 1972.

11. Interstate Commerce Commission, "Transportation Statistics in the U. S.", Washington, D. C., annual report.

12. Hannon, Bruce, "System Energy and Recycling: A Study of the Container Industry", American Society of Mechanical Engineers, New York, 72-WAENER-3, 1972 .

13. Bureau of Labor Statistics, Employment and Earnings, U.S., 1907-70, Washington, D. C., Bulletin 1312-7, Table 5.

14. Edison Electric Institute, Statistical Yearbook of the Electric Utility Industry for 1969 , New York, Sept., 1970, p. 53 .

15. U.S. Department of Commerce, Statistical Abstract of the U. S., 1971, Washington, D. C., 92 edition, p. 336.

16. Folk, H. and Hannon, B., "An Energy, Pollution and Employment Policy Model", Center for Advanced Computation, University of Illinois, Urbana, 61801, Document No. 68, February, 1973.

17. Hannon, Bruce and Nakagama, S., "The 1963 Direct Employment Intensity' Vector", Center for Advanced Computation, University of Illinois, Urbana, 61801, Document No. 63, January 1973.

18. Moyers, John C., "The Value of Thermal Insulation in Residential Construction: Economics and Conservation of Energy", Oak Ridge National Lab, Oak Ridge, Tennessee, 37830, Report ORNL NSF EP 9, December, 1971 .

19. Stein, Richard, "Architecture and Energy", Stein and Associates, 5885 th Ave., New York, 10036, December 1971.

20. Grot, Richard, and Socolow, R. H., "Energy Utilization in a Residential Community", Center for Environmental Studies, Princeton University, February, 1973.

21. Toffler, Alan, Future Shock, Random House, New York, Chapter 12, July 1970. 
22. Folk, Hugh, "Employment Effects of a Mandatory Deposit Regulation", Institute for Environmental Quality, State of Illinois, 309 West Washington, Chicago, 60606, January 1972.

23. Goldsmith, A., "The Relationship of Telecommunications to Urban Transportation", 8th Autumn Meeting, National Academy of Engineering, 12 October 1972. 
National Bureau of Standards Special Publication 403

Proceedings of 1973 Engineering Foundation Conference (Issued June 197.6)

\title{
MEASURES OF THERMAL ENERGY UTILIZATION
}

\author{
by \\ B. B. Hamel and H. L. Brown \\ Department of Mechanical Engineering \\ Drexel Institute of Technology \\ Philadelphia, Pennsylvania 19104
}

\begin{abstract}
It is necessary to quantify, or structure, the ideas of thermal energy utilization in order to develop an efficiency of energy utilization. Such a quantitative analysis is useful in assessing any modification or change in design of an energy system. A method of analysis useful in assessing modifications in an energy system is presented. The concept of thermodynamic availability is used to determine maximum energy utilization efficiency. The method is illustrated by evaluating the efficiencies of several water heating systems.
\end{abstract}

Key words: Energy; heating systems; model; thermodynamics.

The purpose of this paper is to quantify, or structure, our ideas of thermal energy utilization in order to develop an efficiency of energy utilization. Such an analysis will be useful in assessing any modification or change in design of an energy system. Utilization is defined to have two aspects. The first, and the one of primary concern here, is illustrated by the question: given a service function, how can the sources of energy and system elements be optimally connected? Secondly, can the service function be redefined so that less energy is used?

To answer these questions we define the system (Figure 1) to be composed of three basic elements: 1) a discrete energy user which provides a service or operates on a product or material, 2) a converter, which changes the energy form for distribution and 3) an energy storage element. The other lines in Figure 2 represent sources of energy which are supplied across the boundary of the system and the transport transmission lines between the three elements. The elements and energy flows are then defined in terms of energy and thermodynamic availability.

We have examined the energy system of the house and have classified each of its components (Figure 2). Since hot water heaters, furnaces and heat pumps are converting energy for distribution to various end uses, these were classified as converters. All other elements such as lighting, oven, etc., were classified as discrete energy users.

We have defined thermodynamic availability (Figure 3) in such a way as to be able to compare mechanical energy with thermal energy on the same basis at different temperatures and to be able to assign a quality or value to thermal energy. We do this by determining how much work a quantity of thermal energy can do. We recognize that heat and work are both forms of energy. We can convert all work into heat, but we cannot convert all heat into work. The amount of work gained from a given quantity of energy is a measure of the value of that energy. From a Carnot cycle operating between temperatures $T_{0}$ and $T$ ( $T$ greater than $T_{0}, T_{O}$ defined as dead state) an amount of work $W$ is produced. This is termed the availability for this system.

We compare the actual system consumption of this availability to what would be the ideal, minimum consumption if the system elements and connections were optimal (Figure 4). From this we develop the effectiveness parameter, which is a measure of performance of the energy system. This takes into account all uses of energy, both cascading and conversion, in the system. Thus, we attempt to maximize utilization.

We demonstrate this by the example of a hot water heating system (Figure 5). The demand is for $150^{\circ} \mathrm{F}$ hot water and, in this illustration, we are constrained to the use of electric power and the waste heat from the house. We could work this example for gas or oil as well, but, to limit the scope of the example, we have examined only electric power. We can calculate the availability demanded by the $150^{\circ} \mathrm{F}$ hot water. It represents the minimum work required to produce $150^{\circ} \mathrm{F}$ hot water from $600 \mathrm{~F}$ ambient temperature using the ideal, Carnot heat pump.

We examine 5 different systems used to produce the hot water (Figure 6). The first is straight resistive heating. The second is resistive heating with preheat from a house waste heat reclamation loop. The third is direct use of a heat pump with the $60^{\circ} \mathrm{F}$ ambient temperature as a low temperature source. The fourth is the use of a combination heat pump with $60^{\circ} \mathrm{F}$ low 
temperature reservoir and a preheat loop; and the fifth is a heat pump with a heat reclamation loop supplying the low temperature reservoir at some temperature $T$. The question is, which of the 5 is the most effective system in supplying the energy? Which system requires the minimum availability to do the job? How are they ranked? Using the effectiveness efficiency parameter, we can make a useful comparison.

We compared all systems to resistive heating for purposes of illustration (not to set up resistive heating as a straw man); the larger the ratio the more effective the system. We have evaluated the systems for various loop temperatures (Figure 7). A heat pump alone (System 3) ranks next to last (second only to resistive heating) as far as effectiveness is concerned. Those systems with heat reclamation loops are much more effective. Also, we can see the impact of the loop temperature; as we increase it along with our waste heat collection, we improve performance. The significant gain is shown using the loop as the low temperature side of the heat pump. In such a system we are not dependent upon outside air, water or ground as our reservoir. Such systems and others, such as low temperature solar systems, open the horizon for more effective energy utilization through energy management. I am examining only the technical - energy aspects. A complete analysis must include capital and operating costs, but it is apparent that energy costs will be reduced.

We have established an entry point into system design or functional analysis which we did not have before. We have a technical basis from which to proceed and establish our economics .

We are applying this functional analysis to very complex systems: the Pennsylvania Power and Light Company energy-efficient home, a food processing plant (Campbell Soup), oil refineries, and total energy systems in New York. We are doing this in the initial design phases in some cases, and during plant operations in other cases looking to plant modifications to improve performance.

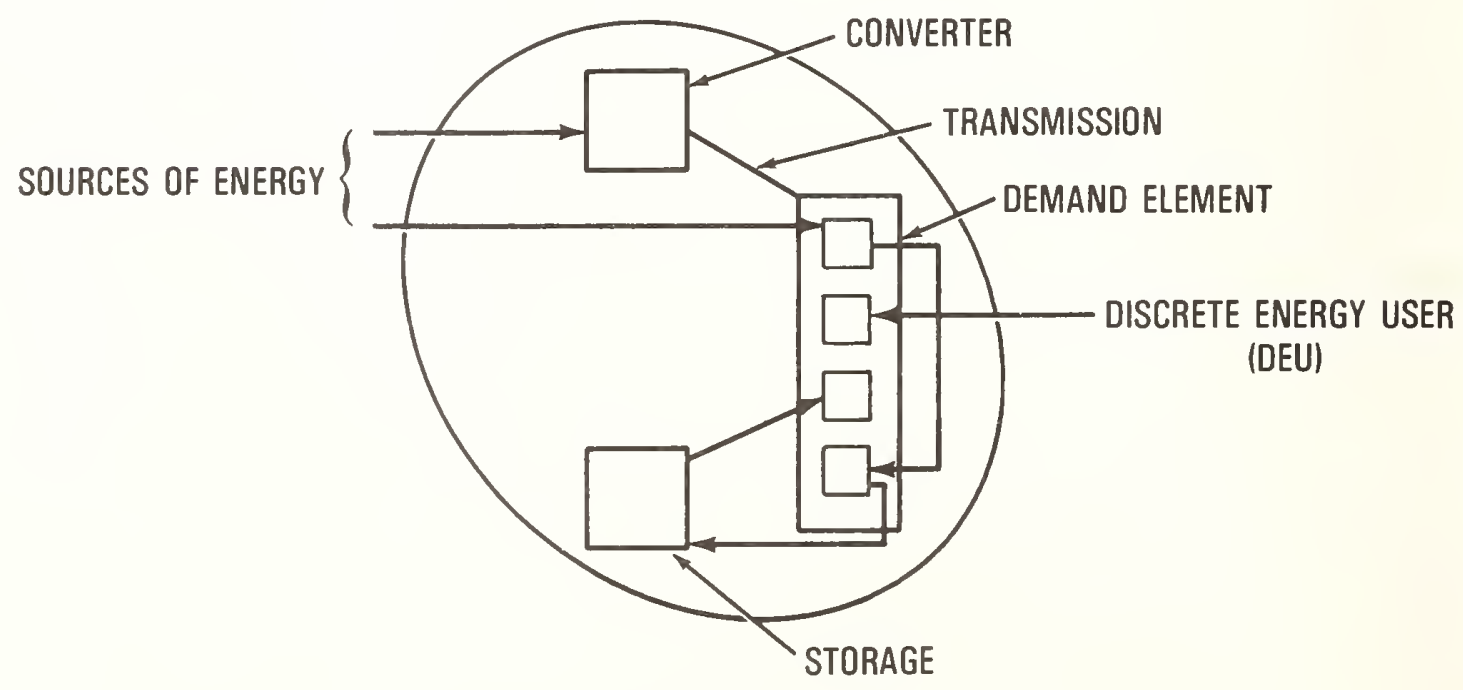




\section{HOUSE ENERGY SYSTEM}

Discrete ENERGy USERS

1) LIGHTING: INCANDESCENT

2) LIGHTING: $F L U O R$.

3) Small Mechanical

4) Smalt thermal

5) RANGE

ש) $0 \vee E N$

7) Clothes Dryer

8) DISHWASHER

9) Clothes Washer

10) Hot Water System

11) HEATING SYSTEM

CONVERTERS:

A) Hot Water heater

B) HEATER

c) Heat Pumps 


\section{A V A I LAB I LITY}

1. GIVEN A QUANTITY (BTU'S) OF ENERGY, IN A THERMODYNAMIC SYSTEM - CAN WE DEFINE I T'S $\checkmark A L U E$ ?

2. VAlue: HOW MUCH USEGL WORK CAN WE PERFORM WITH THIS ENERGY?

3.

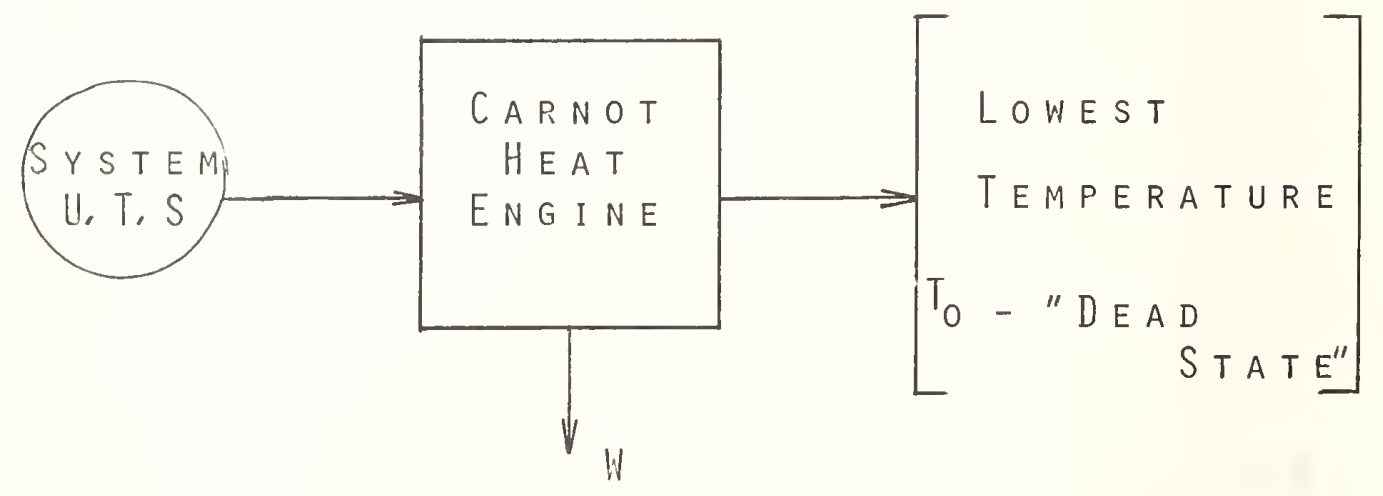

$$
W=U-T_{0} S
$$

4. WORK (W), DONE BY SYSTEM I S THE AVAILABILITY, 
FIGURE 4

\section{SYSTEM UTILIZATION EFFICIENCY}

1. TO DEFINE A. UTILIZATION EFFICIENCY WE NEED TO COMPARE THE ACTUAL SYSTEM CONSUMPTION OF AVAILABILITY $\left(A_{\text {IN }}\right)$ TO SOME IDEAL, MINIMUM CONSUMPTION IF THE SYSTEM ELEMENTS AND CONNECTIONS WERE OPTIMAL.

2. The "I DEAL SyStem": I) Discrete EneRgy USERS: FOR EACH DEU THERE IS A M INIMUM AVAILABILITY NEEDED, A $N^{\prime}$ IF THE THERMAL ENERGY WERE ADDED REVERSIBLY,

II) CONVERTERS: I DEAL IF CARNOT ELEMENTS WERE USED.

3. THE UTILIZATION EFFICIENCY:

$$
E=\frac{\sum A_{N}}{A_{1 N}}
$$




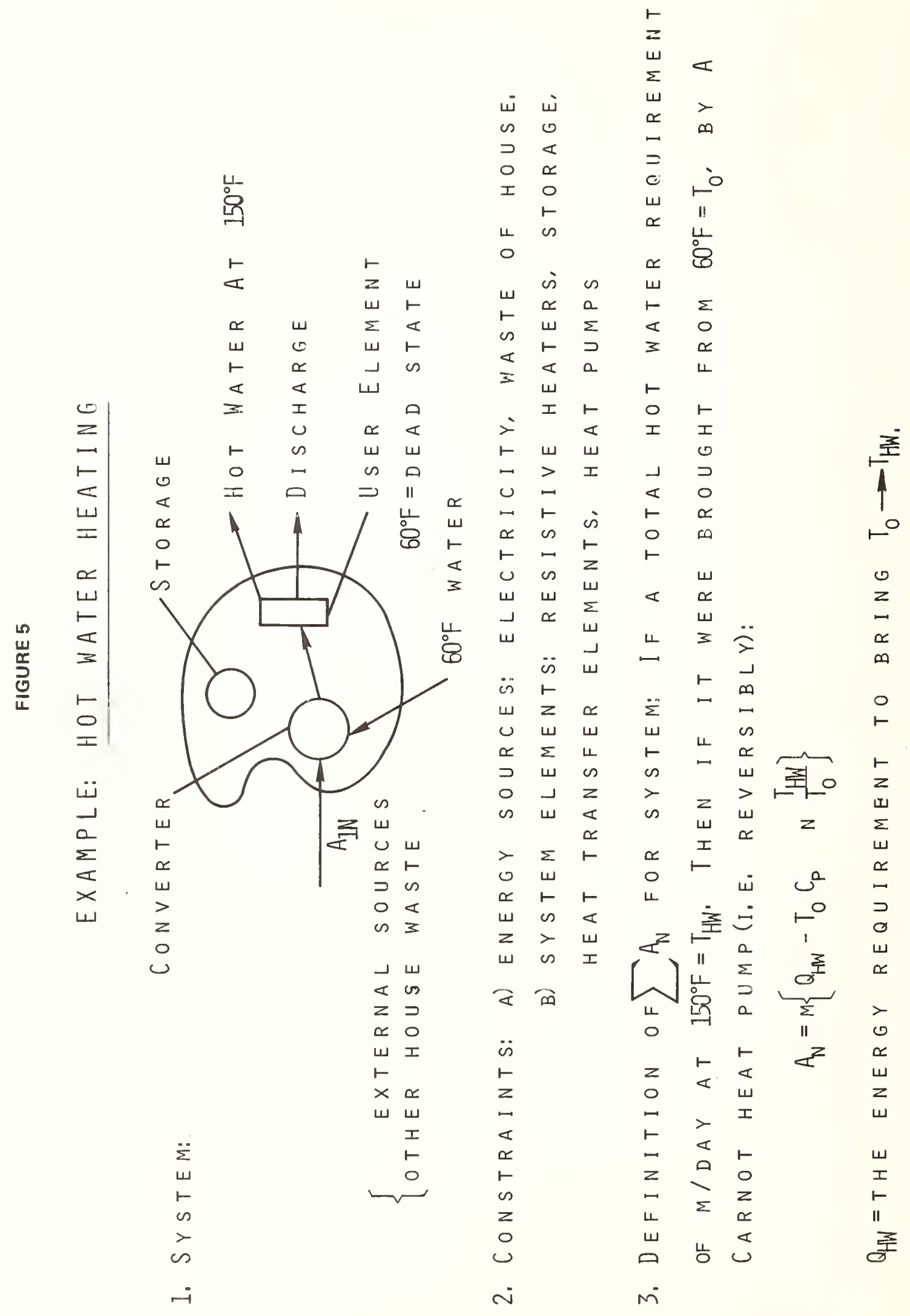




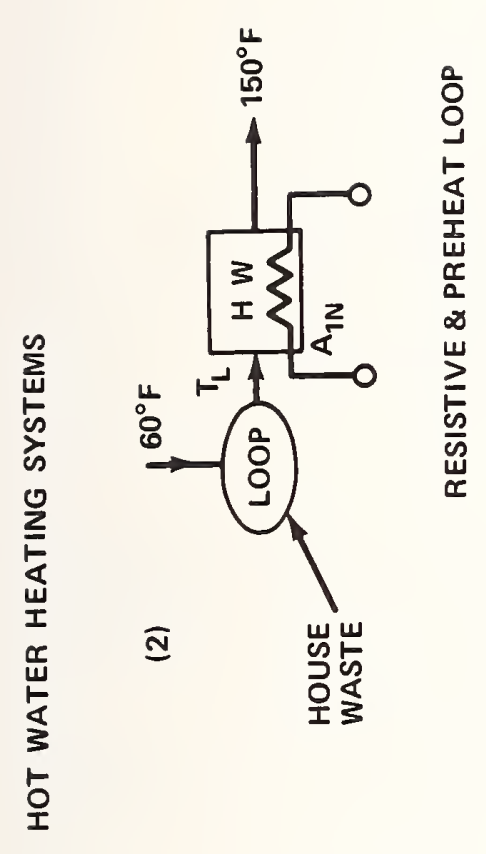

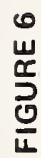

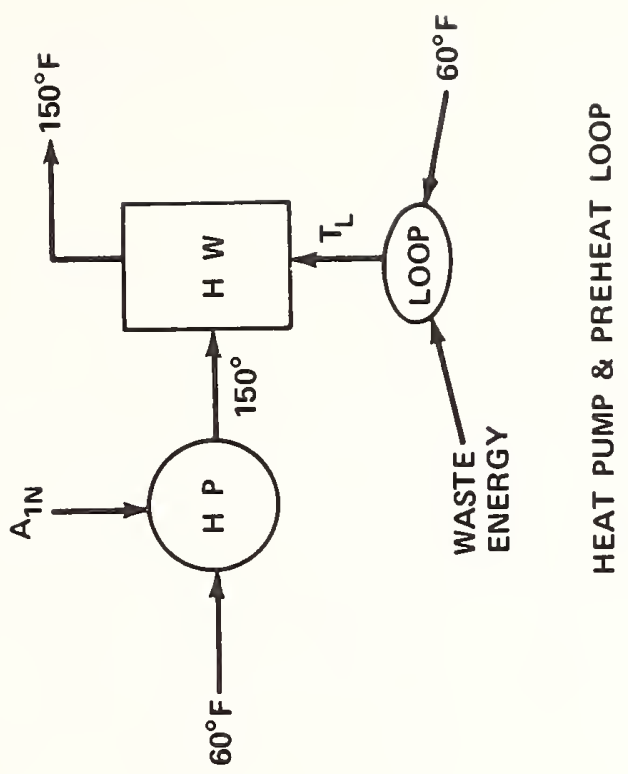

I
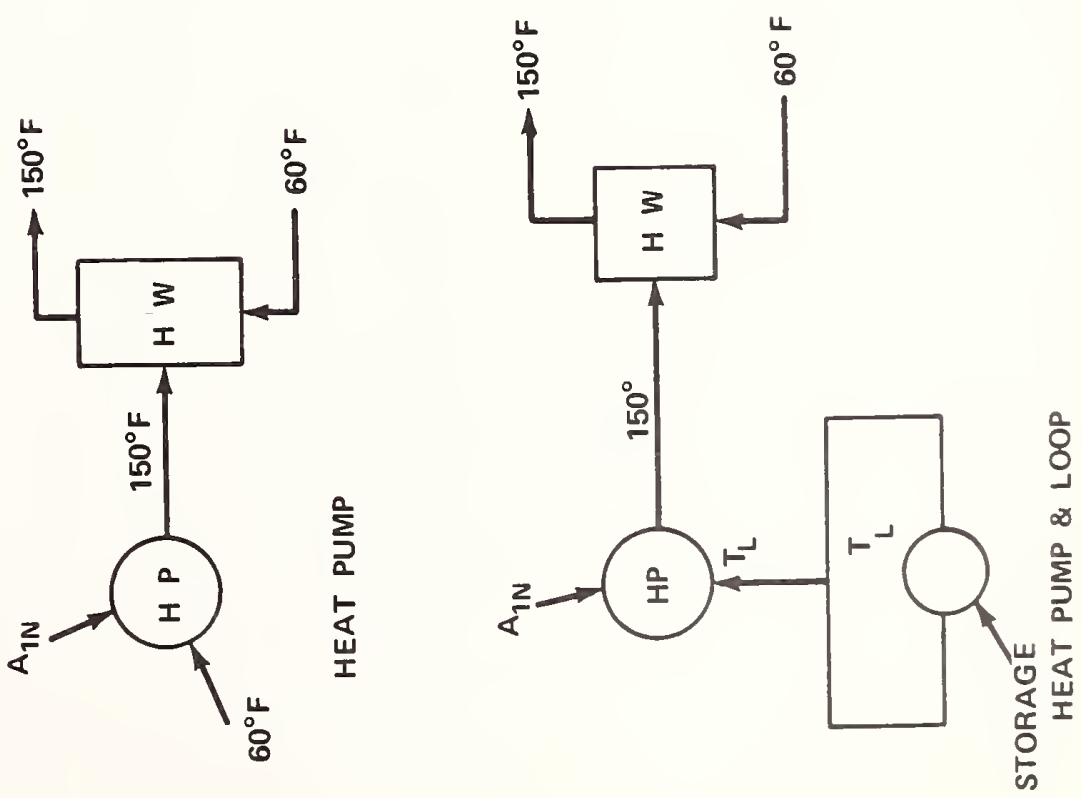

폼 


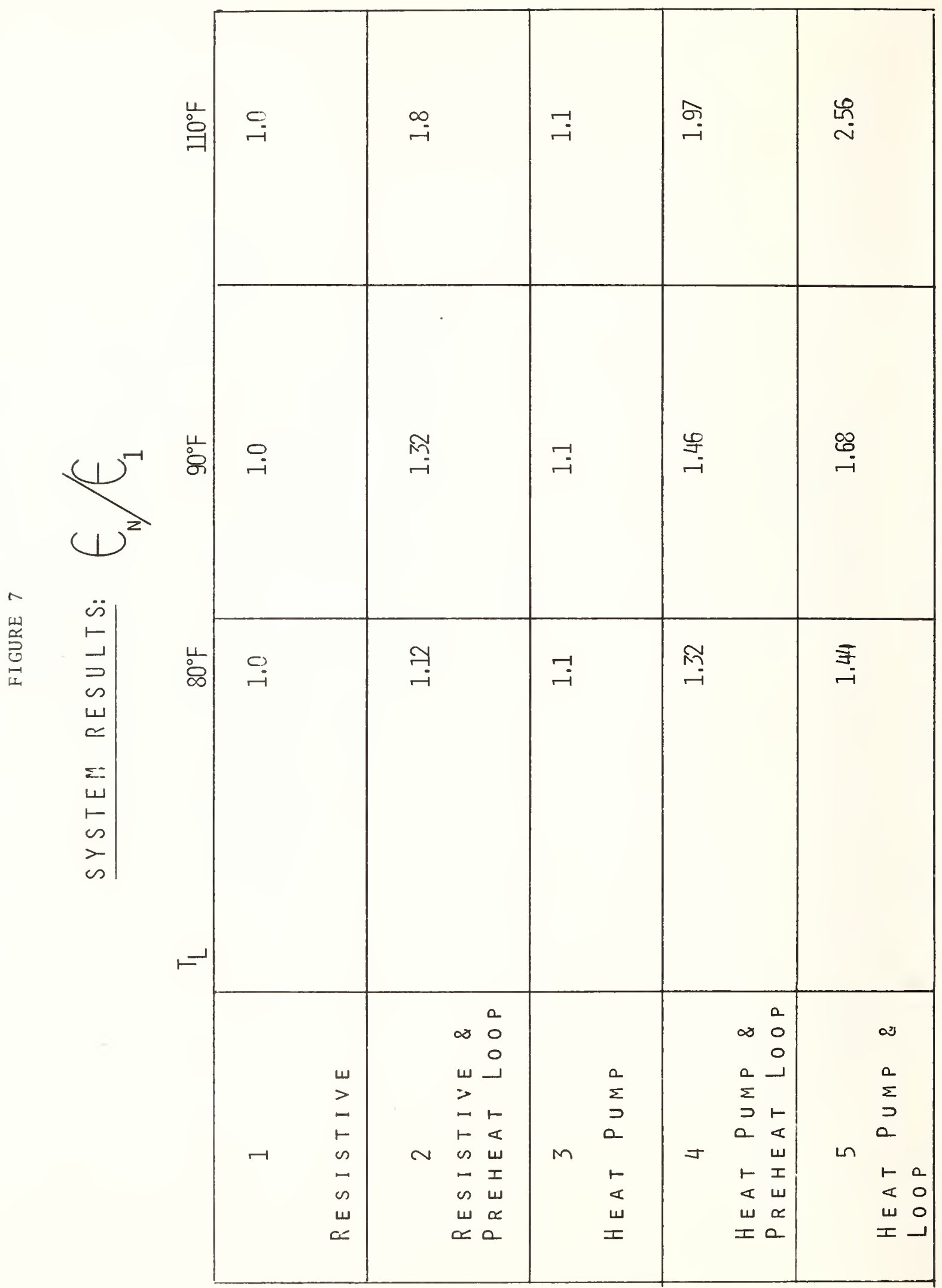


National Bureau of Standards Special Publication 403

Proceedings of 1973 Engineering Foundation Conference

(Issued June 1976)

\title{
ECONOMIC AND ENVIRONMENTAL IMPLICATIONS \\ OF EFFECTIVE UTILIZATION OF ENERGY
}

\author{
by \\ J. C. Denton \\ Director, National Center for Energy Management and Power \\ University of Pennsylvania \\ Philadelphia, Pennsylvania 19174
}

\begin{abstract}
Technology uses energy, materials, money, people, etc. to produce products and services for society. The resultant products and their impacts on resources, society and the environment exist in a dynamic interrelationship. Technology transform analysis is an analytical model which is proposed to identify and elucidate the interrelationships between these elements and to assess the consequences of their modification. The technology transform analysis is prerequisite to the application of input-output analysis if the interrelationships between energy, environmental, economic, and human factors is to be displayed in a compatible fashion. An abbreviated example analysis of the automobile industry is presented to demonstrate the complexities which must be included and the subtleties which appear. Possible pitfalls of an incomplete analysis are discussed.
\end{abstract}

Key words: Automobile; economic; energy; model; transform analysis.

Technology uses energy, materials, money, people, etc. The resultant products and their impacts exist in a complex, dynamic interrelationship. An analytical model is needed 1) to identify and elucidate the interrelationships between the elements and 2) to assess the consequences of their modification. One of the applications of this model would be to determine the economic and environmental implications of effective utilization of energy .

The basis of the model is technology transform analysis (Figure 1). A specific technology transforms resources into desirable products and services, with an inevitable impact on the environment. A specific technology turns an input, termed " $R$ ", into two outputs, termed "products and services" and "environmental load". One of the outputs we like and the other we don't like. The lower half of Figure 1 lists four categories of resources and their outputs. We start with energy and do the sort of balance that engineers of all types learned to do a long time ago. We put energy in. Some of it gets stored in the "products and services" while, in accord with the laws of physics and thermodynamics, some energy is rejected. Materials are put in; some materials are stored in the "products and services", but some materials are wasted and wind up as environmental load. The third input is people. We put people in and expect to get the same people out the other side, otherwise somebody will be upset. The environmental load results from the impact technology has on these people. They are subject to industrial health problems and occupational accidents, for example. By the time they reach home at the end of the day, they are a day older and have lost one day of their life-time productive capacity. If technology were like a sauna bath, they might come out better than when they went in; but it isn't. The fourth input is money. It takes money to buy equipment, money to pay the people who run the equipment, money to buy the materials and the energy. Identifying the environmental load resulting from money was initially a problem, since technology produces money (otherwise a venture is not profitable and shuts down in a hurry), and we like money. If the value added is construed to be a negative environmental load, however, then the value added serves to balance the cost of the other environmental loads, from the society's point of view. That is, considering the value added as a negative environmental load, if the value added were equal to the cost of the other environmental loads, then one has a balancing system to determine the societally acceptable environmental loads.

The term "environmental load" does not imply either environmental "impact" or environmental "quality". Those are issues to be discussed later in the conference. Environmental impact must include the ability of the environment to absorb a load without significant damage. Environmental quality must include decisions as to relative detriments of environmental impacts. Right now I prefer to speak only of the environmental load. These issues are difficult to address and will not be considered further here. 
FIGURE 1

TECHNOLOGY TRANSFORM ANALYSIS
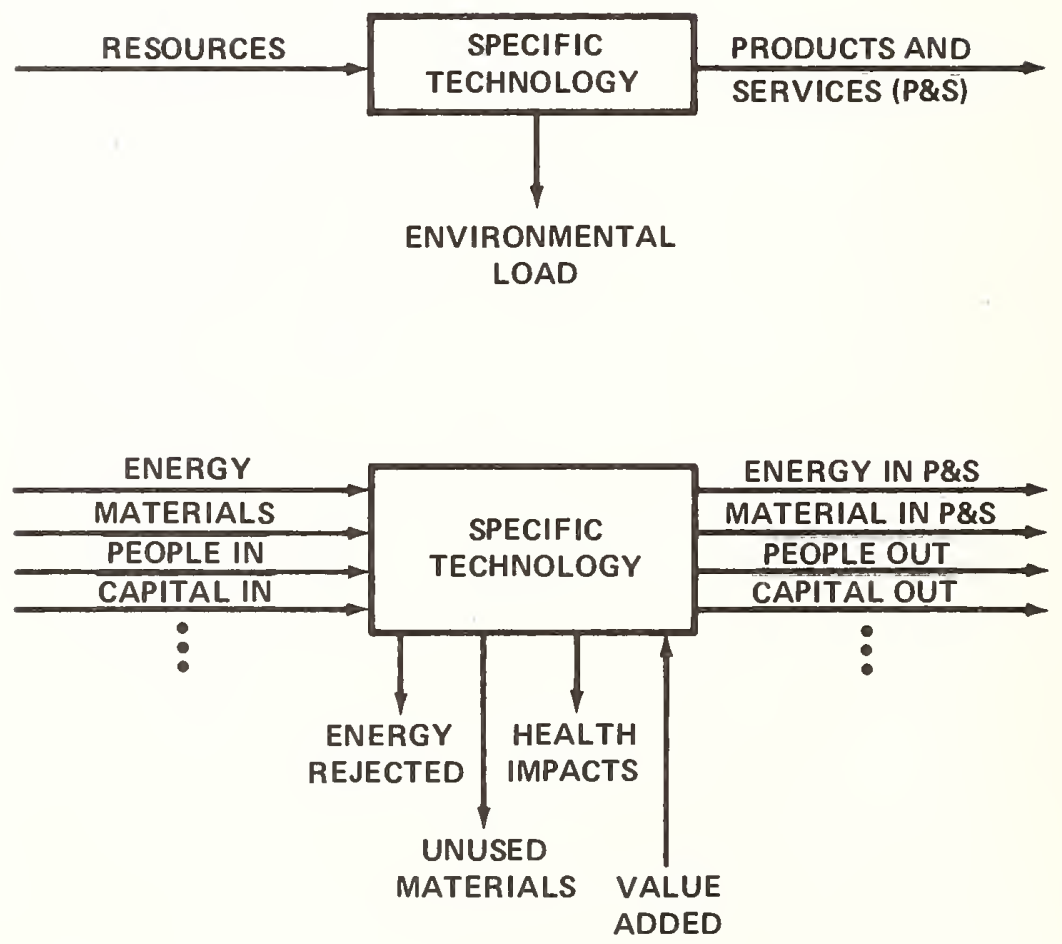
FIGURE 2

INPUT-OUTPUT FLOW TABLE

\begin{tabular}{|c|c|c|c|c|c|c|c|c|c|c|c|c|c|}
\hline & & \multicolumn{8}{|c|}{ PRODUCERS } & \multicolumn{4}{|c|}{ FINAL MARKETS } \\
\hline & & $\begin{array}{l}\text { Agri } \\
\text { culture }\end{array}$ & Mining & $\begin{array}{c}\text { Construc } \\
\text { tion }\end{array}$ & $\begin{array}{l}\text { Manufac } \\
\text { turing }\end{array}$ & Trade & $\begin{array}{c}\text { Transpor } \\
\text { tation }\end{array}$ & Services & Other & Persons & Investors & $\begin{array}{l}\text { Foreign } \\
\text { ers }\end{array}$ & $\begin{array}{c}\text { Govern } \\
\text { ment }\end{array}$ \\
\hline \multirow{8}{*}{ 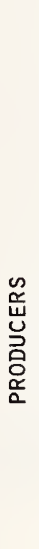 } & Agriculture & & & & & & & & & & & & \\
\hline & Mining & & & & & & & & & & & & 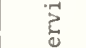 \\
\hline & Construction & & & & & & & & & $\stackrel{4}{5}$ & 苞 & 足 & ने \\
\hline & Manufacturing & & & & & & & & & 穿 & i & 密 & 8 \\
\hline & Trade & & & & & & & & & $\delta_{-1}^{-1}$ & in & $\begin{array}{l}\text { 듀 } \\
\text { y }\end{array}$ & is \\
\hline & Transportation & & & & & & & & & 点 & ע & $\begin{array}{l}D_{0} \\
\text { 崔 }\end{array}$ & 总 \\
\hline & Services & & & & & & & & & 害 & $\bar{a}$ & 8 & एँ \\
\hline & Other & & & & & & & & & 2 & Оू & $\frac{\ddot{\nu}}{z}$ & 8 \\
\hline \multirow{3}{*}{$\begin{array}{l}\text { 㞻 } \\
\text { 号 } \\
\text { 岁 } \\
\text { 岁 } \\
\frac{1}{>}\end{array}$} & Enployees & Employee & e compens & ation & & & & & & \multirow{3}{*}{\multicolumn{4}{|c|}{$\begin{array}{c}\text { GROSS NATIONAL } \\
\text { PRODUCT }\end{array}$}} \\
\hline & $\begin{array}{l}\text { Owners of busi- } \\
\text { ness \& capital }\end{array}$ & Profit & type inco & me and cap & ital cons & umptior & allowance & & & & & & \\
\hline & Government & Indirect & $t$ busines & $s$ taxes an & d current & surpli & is of govt. & enterprise & s, etc. & & & & \\
\hline
\end{tabular}


FIGURE 3

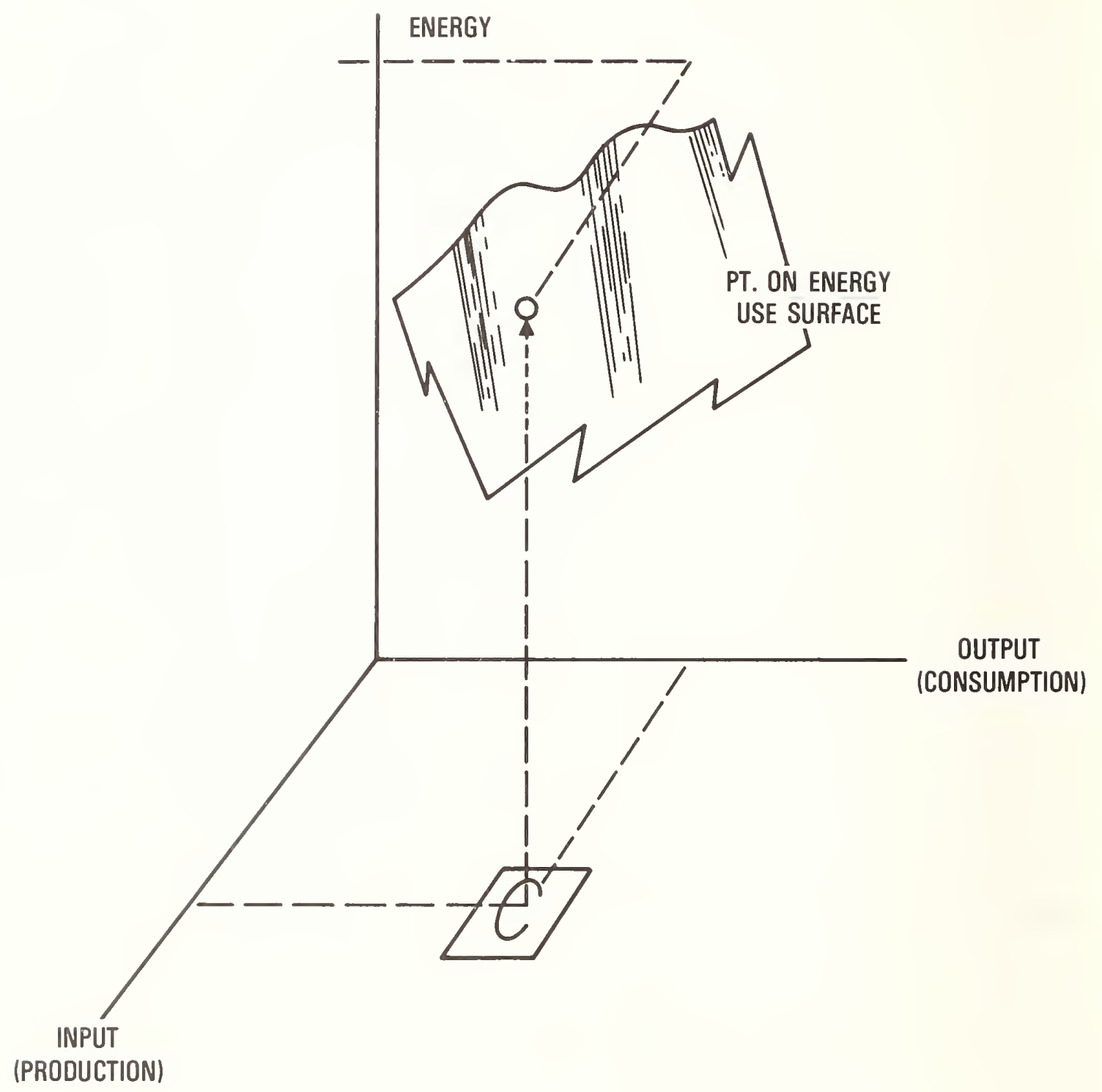

ENERGY USE AND INPUT-OUTPUT 
FIGURE 4

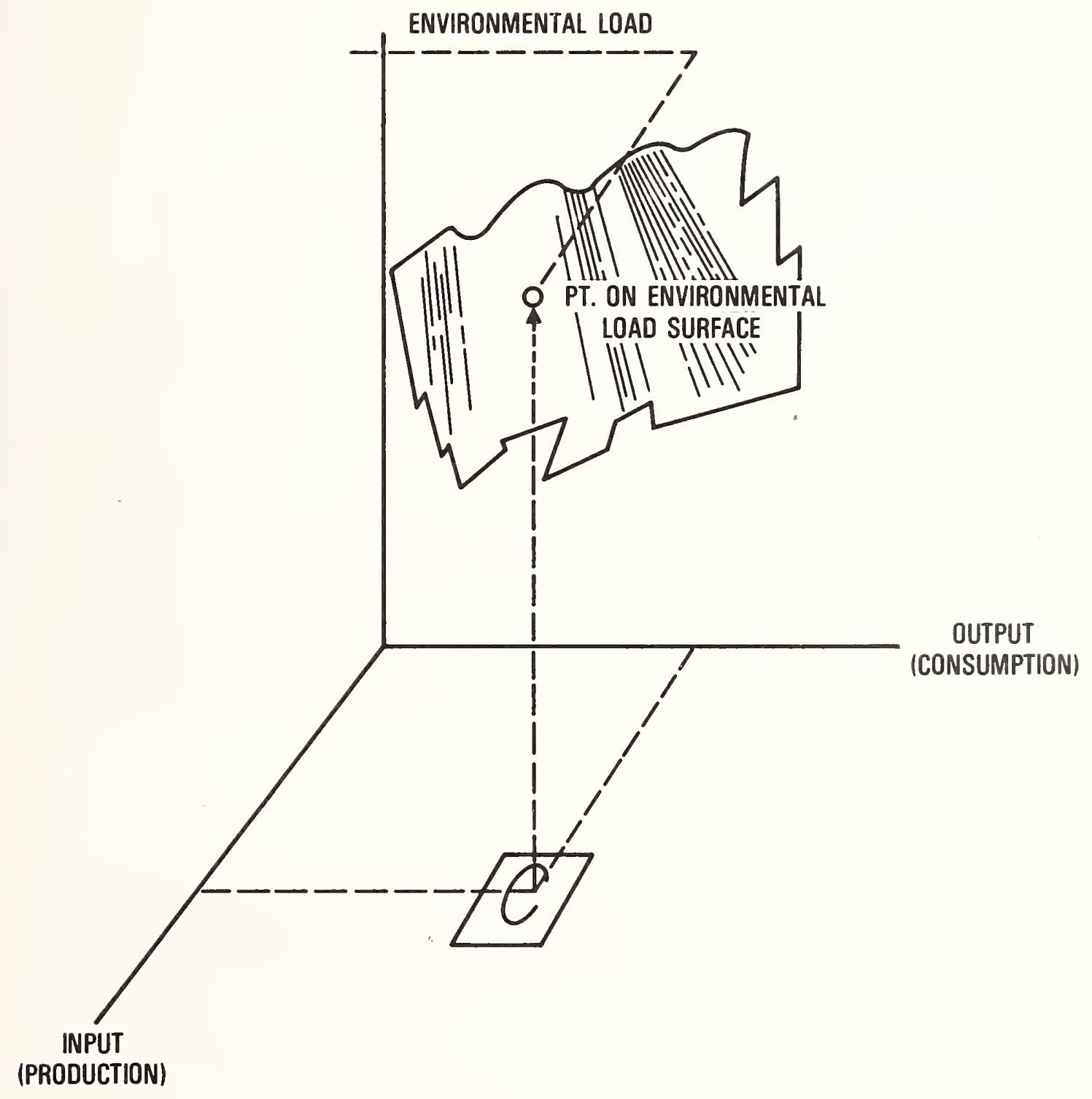

ENVIRONMENTAL LOAD AND INPUT-OUTPUT 


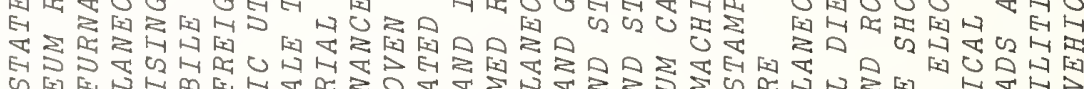

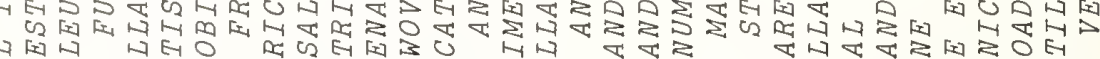

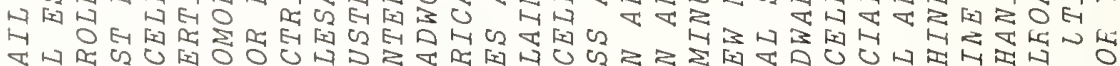

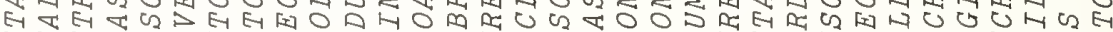

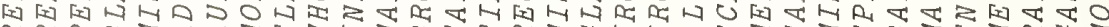

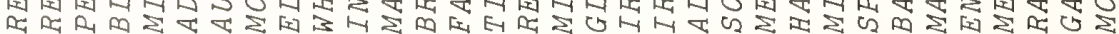

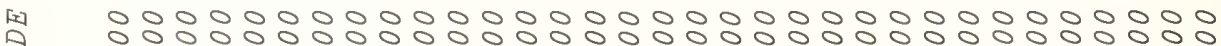

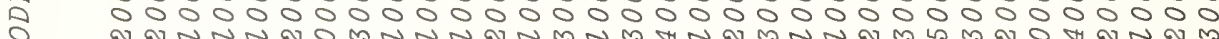

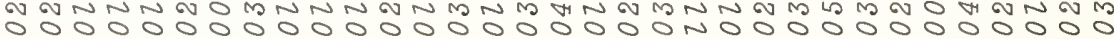
$\dot{0} \dot{0} \dot{0} \dot{0} \dot{0} \dot{0} \dot{0} \dot{0} \dot{0} \dot{0} \dot{0} \dot{0} \dot{0} \dot{0} \dot{0} \dot{0}$

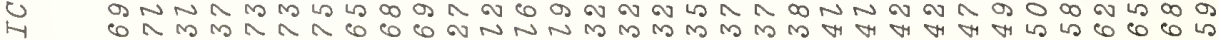




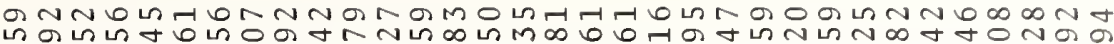

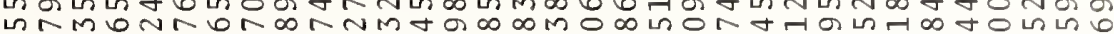
0 NMn Un

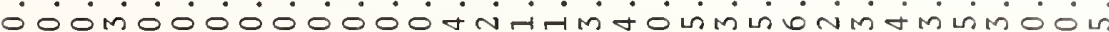

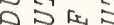

$\Leftrightarrow \rightarrow \mathrm{A}_{1} \bigcirc \mathrm{A}$

D. EI E

N 50

a

$\mathrm{A} \geq 0$

$\rightarrow$ He

가 $\mathrm{Cr}$

0 R

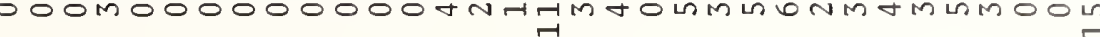

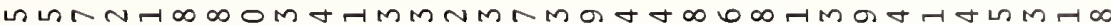

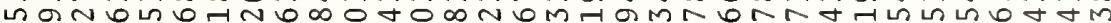

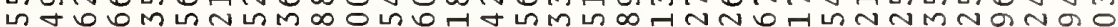
mal - $\dot{0} \dot{0} \dot{0} \dot{0} \dot{0} \dot{0} \dot{0} \dot{0} \dot{0} \dot{0} \dot{0} \dot{0} \dot{0} \dot{0} \dot{0} \dot{0} \dot{0} \dot{0} \dot{0} \dot{0} \dot{0} \dot{0} \dot{0} \dot{0}$

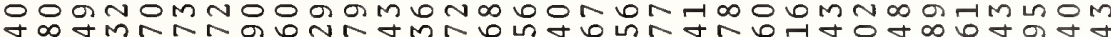

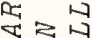
H

$\odot$ ना न

$B$
0
$H$

$0 D \mathrm{~F}_{4} D$ [a] $A_{1} O A$ OC, E- E a $D E D$

UM⿻ IM

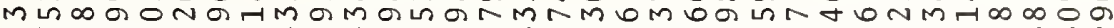
NMGNN $000 M N N N N$ N

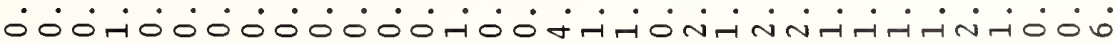

$\geq$

H

ENE O

$D D$ M

A 0

ar: $D$

돈 느

सH

HANNOUN オ $\infty$ N जO

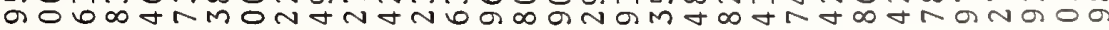
$\dot{0} \dot{0} \dot{0} \dot{0} \dot{0} \dot{0} \dot{0} \dot{0} \dot{0} \dot{0} \dot{0} \dot{0} \dot{0} \dot{0} \dot{0} \dot{0} \dot{0} \dot{0} \dot{0} \dot{0}$ im N

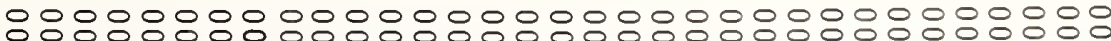

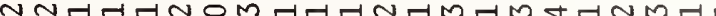
000000000000000000007000000000000

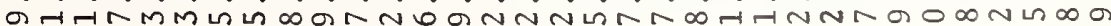

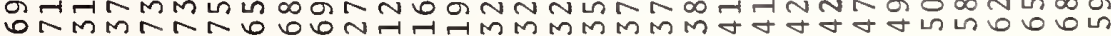




$$
\begin{aligned}
& \text { i } \\
& \text { 겅으 } \\
& O \text { EY } \\
& \text { 此过 } \\
& \text { ए } \\
& \text { D. } \Sigma
\end{aligned}
$$

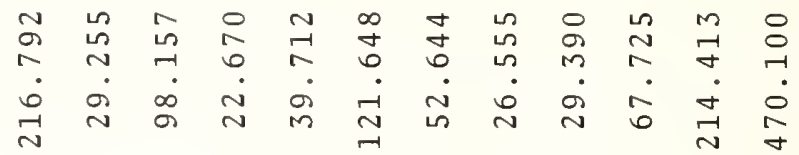

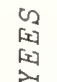

$$
\begin{aligned}
& \geq 0
\end{aligned}
$$

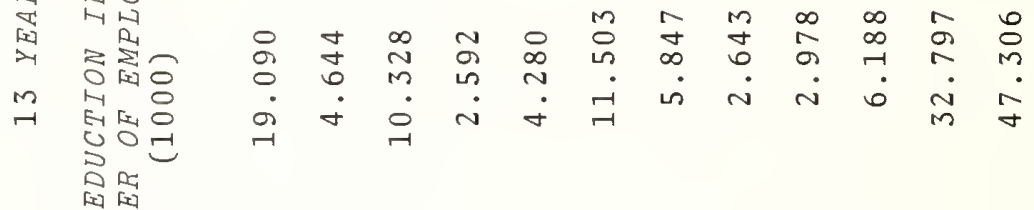

$$
\begin{aligned}
& \text { Fin } \\
& \text { D舟 } \\
& \text { 怘 }
\end{aligned}
$$

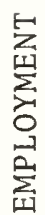

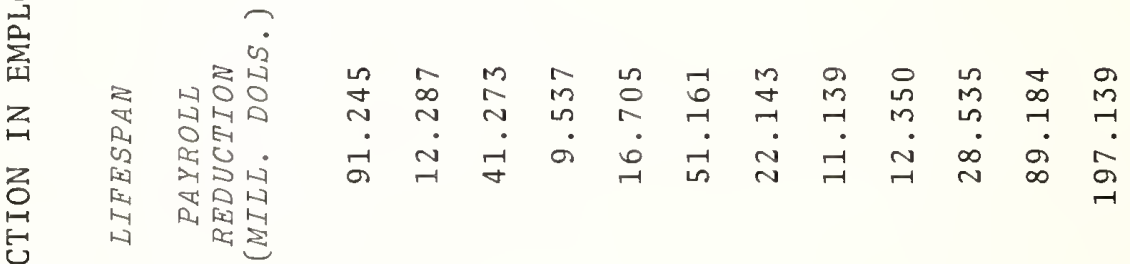

$$
\begin{aligned}
& \text { 岂 } \\
& \text { 这 }
\end{aligned}
$$

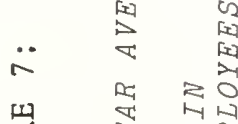

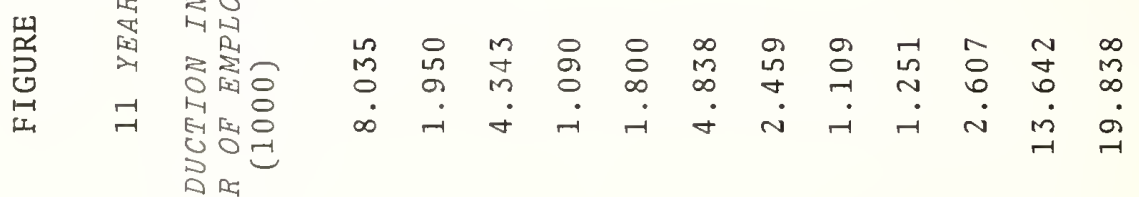

$$
\begin{aligned}
& \text { D 머 } \\
& \text { 더담 } \\
& \text { 다 므 } \\
& \lesssim
\end{aligned}
$$

DS 02

머멈

In

i 200

$\rightarrow-1$

近

EY

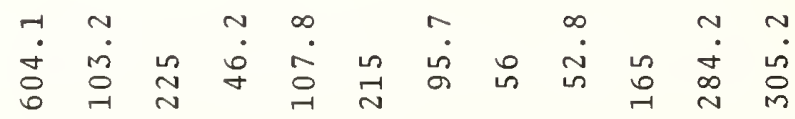

EY O

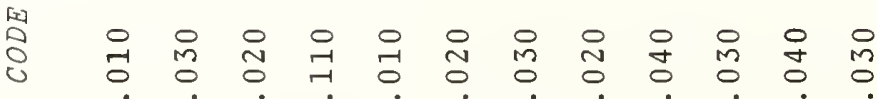

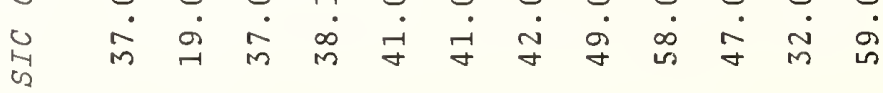


I visualize any company or industry as a collection of very specific technologies. In the steel mill, for example, there is a rolling mill which rolls out a plate. There are different rolling mills driven in different ways in different plants; any industry is a mix of various spccific technologies. Sufficient data are available to quantify the analysis of each specific technology. This approach refers the energy, materials, employmcnt, money, etc., flows directly to the specific technology .

Figure 2 is an input-output flow table. The producing sectors are on the left and the markets on the top. Certain producers also constitute a portion (even a large portion) of the market. The data represented by the input-output table is the basis for other elements of the model I am describing .

Using the input-output table as a horizontal plane in Figure 3 and the data obtained from technology transform analysis we erect a normal to the horizontal plane and construct an energy use surface for each of the coefficients in the input-output plane. To account for use of different types of energy we construct several energy use surfaces. Figure 4 indicates that exactly the same approach may be used to construct environmental load surfaces. In this case we must have a different surface for each environmental load because the different types cannot be combined to a single load.

We now have three types of elements: the energy use surfaces, the environmental load surfaces, and the input-output methods which relate them to gross national product, employment, and other national indicators. How do we apply the elements?

In order to demonstrate the approach, we did an exercise this summer. It was strictly an academic exercise, so I will not defend the numbers. I will present the result of the first iteration; and then I am going to conjecture that there are some ways out of the dilemma that shows up in the initial iteration, and try to forecast some of the things that we can expect to observe. The purpose of this model is to provide a general framework in which we can relate economics, environment and energy .

Figure 5 is part of the Standard Industrial Classification code, a numbering system which facilitates computer operations and structures the collection of data. These are only the most important sectors for the example presented below .

We wanted to identify modifications of the energy use process that would result in effective utilization of thermal energy. We started with the assumption that the effective utilization of energy could be improved by more effective utilization of the energy by the user. In the transportation sector, one possibly effective strategy of the energy user may be to increase the lifespan of the automobile.

To see the effect of a single modification on the economy-energy-environment complex, we postulated an extension of the average lifetime of the automobile subject to the constraint that total transportation service remained constant. We searched the literature to determine the average lifetime of an automobile, which was found to be ten years. I would conjecture that it may be shorter today, but the data we used showed a ten year average lifetime. We assumed that the average lifetime was extended one more year to eleven years, and, for a more drastic change, three more years to thirteen years. We then assumed that the total use of automobiles in transportation would remain the same, so that we could reflect the additional lifetime back into the production system to see changes in production. With a constant demand and increased lifetime per unit, less new units would be needed. Figure 6 shows that a reduction in output does result In the last line, the output would be reduced by 2.5 billion dollars of value, or $6.5 \%$ of total production if the lifespan were increased to 11 years .

The decrease in output seems efficient; less energy would be used to produce automobiles energy would be conserved. But, what are the consequences of this reduction on other sectors of the economy?

If automobile production is reduced, employment of production workers would be reduced as well. Figure 7 shows that 19,000 workers would be put out of work, with a corresponding payroll reduction of almost $\$ 200$ million. Not only automobile workers would lose their jobs, however. A reduction of production in associated industries (which supply material for the automobile industry, for example) would also result, with a corresponding reduction in those sectors. Figure 8 shows the impact this unemployment would have had in 1970, when the unemployment rate was $4.9 \%$. A one year ex tension of the automobile's lifespan would have increased unemployment to $5.2 \%$.

It costs energy to manufacture automobiles. We have searched the literature and found an estimate of the amount of energy this represents. Energy consumption would have been lowered, resulting in an energy savings for the year equivalent to 3.2 million barrels of oil. That same year $(1970)$ the daily oil imports were 3.4 million barrels. Thus, the first iteration of this model indicates that a $10 \%$ increase in the lifespan of automobiles would save approximately one day of oil imports at a cost of putting 19,000 people out of work. 
Would the energy saving be worth the cost in unemployment? The question is academic at this point because the analysis is not yet complete. It is evident that we have identified only a few of the possible variables and their interrelationships out of a vast and complex system.

In order to refine the first iteration, one must determine the specific manner in which the production process and its allied sectors will change to accomplish the increase in the lifetime of the vehicle. If you were to assume, for example, that no change will be made in the manufacturing process but instead the change would be in more and better repair and maintenance of the vehicles (assuming the same number of passenger miles) then employment in maintenance and repair would increase and jobs (of a different type) would become available for the displaced production workers. Likewise, for the energy saving one might change the number very significantly by the approach taken to extend the lifespan because of the interconnectedness of all of these sectors in the input-output tables.

I am using this demonstration to indicate to you the complexity of such an analysis and the pitfalls of drawing premature conclusions from an incomplete analysis.

There are two points I want to make. The first is that to make an accurate prediction, an analysis must be specific and quantitative, yet complex enough to include the consequences of the consequences on each and every interrelationship in the system. Secondly, what may initially seem to be a clearcut, beneficial modification of a system may, after a complete analysis of the total effect on the total system, be found to be an adverse effect.

We do not yet have the ability to make a total analysis, but I believe we have the capacity to design one and to put it into operation. Only with such an analysis can National measures be taken to modify a system in a way which will accomplish our objectives and simultaneously minimize the accompanying detrimental impacts on the Nation's health.

FIGURE 8

PERCENT UNEMPLOYED 1970

4.9

PERCENT UNEMPLOYED 1970

INCLUDING REDUCTIONS IN EMPLOYMENT

IN SELECTED INDUSTRIES

11 YR. L.S. 13 YR. L.S.

$5.02 \quad 5.12$

OIL EQUIVALENT OF ENERGY SAVED

IN ONE YEAR (from ten year average)

11 YR. L.S.

13 YR. L.S.

3.2 million barrels $\quad 7.6$ million barrels

OIL IMPORTS 1970

3.4 million barrels per day 
I I I. EN ER G Y M A N A G M E N T P R A C T I C E 


\title{
INDUSTRIAL ENERGY ANALYSIS AND FORECASTING
}

\author{
by \\ D. R. Limaye, J. R. Sharko and J. H. Kayser \\ Decision Sciences Corporation \\ Benjamin Fox Pavilion \\ Jenkintown, Pennsylvania 19046
}

\begin{abstract}
Although the industrial sector is one of the largest consumers of energy (over $33 \%$ of total energy consumption), relatively little is known in detail about the end use characteristics in this sector because of the diversity of processes and practices. Two approaches are discussed: a detailed engineering process analysis, involving an in-depth look at each major product in each industry; and a survey approach employing interviews and questionnaires. Studies are presented on the Chemical and Allied Products industry (SIC 28) . A breakeven analysis is employed to determine the prices at which two fuels are economically equivalent. An overall methodology is presented for integrating all of the different aspects of industrial energy analysis. The initial steps are the identification of end use characteristics, energy requirements per unit of output, process economics, and qualitative factors affecting energy use. Based on these and on estimates of total industrial output, the total energy requirements can be determined.
\end{abstract}

Key words: Break-even analysis; economics; energy; industrial.

Introduction

While the industrial market is one of the largest consumers of energy and accounts for over $33 \%$ of the total energy consumption* in the U. S . , relatively little is known in detail about the end use characteristics in this market. The applications of energy in the industrial sector are numerous and varied, and specific industrial processes have special requirements for energy. For example, blast furnaces require a special type of coal (metallurgical coal), glass manufacture requires gas for controlled heat, and aluminum requires electricity.

Although the industrial market is complex in terms of types of applications, its study is facilitated by the segregation of the market into major industry categories. As can be seen from Figure 1, only a few industries consume a large proportion of the energy. The first six SIC groups consume over $80 \%$ of the total energy .

In view of the current energy crisis in the U.S., it is increasingly important to make optimum use of our energy resources. Due to the relative abundance and low cost of energy in the past, the industrial sector (as well as other sectors) has tended to utilize energy without due regard to opportunities for energy conservation or efficiency. There are, however, a great number of opportunities to make improvements in the manner in which energy is consumed for a variety of industrial applications.

In order to maximize the efficient utilization and conservation of energy, it is first necessary to understand the nature and type of energy use, factors which influence choice of energy, and potentials in and constraints to optimum energy utilization. This paper discusses some approaches to analyze and forecast the utilization of energy in the industrial sector.

\footnotetext{
*From Bureau of Mines figures. Total U. S. energy consumption in 1970 was 67.4 quadrillion $\mathrm{BTU}$. Industrial energy consumption accounted for 22.5 quadrillion BTU of the total.
} 
FIGURE 1

MAJOR INDUSTRIAL ENERGY IISERS (1967)

\begin{tabular}{|c|c|c|}
\hline INDUSTRY & $\begin{array}{c}\text { ENERGY CONSUMPTION } \\
\text { (MILLION OF KWH EQUIV.) }\end{array}$ & $\begin{array}{c}\% \text { OF TOTAL } \\
\text { ENERGY CONSUMPTION }\end{array}$ \\
\hline $\begin{array}{l}\text { CHEMICALS AND ALLIED } \\
\quad \text { PRODUCTS }\end{array}$ & 72.038 & 20.9 \\
\hline $\begin{array}{l}\text { PRIMARY METALS } \\
\text { IIIDUSTRY }\end{array}$ & 709.924 & 20.6 \\
\hline $\begin{array}{l}\text { PETROLEUM AND COAL } \\
\text { PRODUCTS }\end{array}$ & 408,482 & 11.8 \\
\hline $\begin{array}{l}\text { STONE, CLAY AND } \\
\text { GLASS }\end{array}$ & 360,133 & 10.4 \\
\hline $\begin{array}{l}\text { PAPER AND ALLIED } \\
\text { PRODUCTS }\end{array}$ & 338.896 & 9.8 \\
\hline $\begin{array}{l}\text { FOOD AIND KINDRED } \\
\text { PRODUCTS }\end{array}$ & 263.655 & 7.6 \\
\hline $\begin{array}{l}\text { FABRICATED METAL } \\
\text { PRODUCTS AND } \\
\text { MACHINERY }\end{array}$ & 178,524 & 5.1 \\
\hline $\begin{array}{l}\text { TRAIISPORTATION AND } \\
\text { ELECTRICAL } \\
\text { EQUIPMENT }\end{array}$ & 176.030 & 5.1 \\
\hline OTHER & 304.725 & 8.7 \\
\hline & $3,461,407$ & 100.0 \\
\hline
\end{tabular}

SOURCE: CENSUS OF MANUFACTURERS, 1967 
FIGURE 2

FUEL USE - INDUSTRIAL SECTOR

\begin{tabular}{|c|c|c|c|c|c|c|}
\hline \multirow{2}{*}{ FUEL } & \multirow{2}{*}{$\begin{array}{l}\text { SPACE } \\
\text { COND. }\end{array}$} & \multicolumn{2}{|c|}{ BO ILER } & \multirow{2}{*}{$\begin{array}{l}\text { PROCESS } \\
\text { ENERGY }\end{array}$} & \multirow{2}{*}{$\begin{array}{l}\text { FEED- } \\
\text { STOCK }\end{array}$} & \multirow{2}{*}{$\begin{array}{l}\text { LIGHTING/ } \\
\text { MECHANICAL } \\
\text { DRIVE }\end{array}$} \\
\hline & & SPACE & PROCESS & & & \\
\hline COAL & & $x$ & $x$ & $x$ & & \\
\hline OIL & $x$ & $x$ & $x$ & $x$ & $x$ & \\
\hline GAS & $x$ & $x$ & $x$ & $x$ & $x$ & \\
\hline ELECTR ICITY & & & & $x$ & & $x$ \\
\hline
\end{tabular}


FIGURE 3

PRICE ELASTICITIES FOR INDUSTRIAL DEMAND*

FUEL PRICE

\begin{tabular}{|c|c|c|c|c|}
\hline FUEL & $\begin{array}{c}C O A L \\
A 1\end{array}$ & $\begin{array}{r}0 I L \\
A^{2}\end{array}$ & $\begin{array}{r}\text { GAS } \\
A^{3} \\
\end{array}$ & $\begin{array}{c}\text { ELECTRIC } \\
A^{4}\end{array}$ \\
\hline COAL & -2.32 & 3.04 & 0.628 & 0.745 \\
\hline OIL & 1.38 & -3.02 & 1,14 & 0.895 \\
\hline GAS & 0.318 & 2.73 & $-1 . E 8$ & 0.013 \\
\hline ELECTRIC & 0.145 & 0.0139 & 0.763 & -1.26 \\
\hline
\end{tabular}

* based on cross-sectional analysis of 1962 census of manufactures data. 
There is, in general a paucity of information regarding energy utilization at the end use level. References 1 and 2 give a general discussion of the information sources for energy. The only source that gives any information at a level below the industrial market as a whole is the Census of Manufacturers. Unfortunately, even this information is sketchy. The 1962 Census attempted to present detailed information on fuels and electric energy consumed at the 4 digit SIC level. However, fuel use characteristics are significantly different in different parts of the U.S. and while the Census published information on a state-by-state basis in 1962, it did so only at the 2 digit SIC level. Furthermore, the 1967 Census completely omitted the regional detail.*

In any case, the Census or any other regularly published government source does not give any information regarding specific end uses of energy. For information regarding energy utilization, one has to turn to industrial firms, equipment manufacturers, trade associations, engineering or consulting firms or other sources. It would be inappropriate to describe in detail here the difficulties and problems of obtaining valid, accurate, quantitative information on energy utilization. The authors would like to point out, however, that there are significant problems. Some of the approaches that are being used to obtain information on industrial energy use are described in another section of this paper.

Energy Use by Type of Fuel

Four major energy sources are used in the industrial sector - coal, oil, gas and electricity . These four could be further subdivided; however, in this paper, fuels will be aggregated into the four major energy sources.

Industrial applications can be broadly classified into the following major types:

Space Conditioning - direct fired, where the fuel is directly burned for space conditioning (i.e., not burned under a boiler).

Boiler Use - further subdivided into space conditioning and process energy depending on how the steam from the boiler is utilized.

Process Energy - excluding that from boiler steam.

Feedstock - where the fuel is used as an ingredient in the process.

Lighting .

Mechanical Drive - as in motors.

Each of the four major energy sources can be used for a number of these types of end uses. Figure 2 shows the broad classification of the end use for each fuel.

\section{Effect of Price on Energy Use}

A number of recent studies have been undertaken to analyze the elasticity of demands to changes in price in the industrial sector. A review of the various studies and their coverage is found in Reference 3. Some of the more notable efforts have been those by Baughman (4), Verleger (5), Mooz (6) and Limaye and Sharko (7). Although the different studies have resulted in varying estimates of elasticity, there is a general consensus that the industrial demand for energy is sensitive to price.

A set of estimates for elasticity of energy consumption relative to prices was derived using a cross-sectional analysis of the state-by-state data from the 1962 Census of Manufacturers. These estimates are shown in Figure 3. Similar results have also been derived for five major SIC groups.

* Conversations with the Bureau of the Census indicated that although the information was collected, it was not published due to insufficient funds. The 1971 Census information has recently been published in detail. 
In looking at the results of such analyses derived by statistical/econometric techniques, it must be noted that the different types of uses have been aggregated. Also, the data come from a time period where there were no significant constraints on availability of energy, no environmental regulations, and relatively stable prices. Such results are of limited use in evaluating the potential for energy savings. A more detailed analysis at end use level is required.

\section{Analysis of End Uses}

Two approaches are available for a detailed analysis of end uses in the industrial sector:

A detailed engineering/process analysis, involving an in-depth look at each major product in each industry.

A survey approach through interviews and questionnaires.

The authors have used both these approaches in some recent studies of specific industry groups. One study involved the Chemicals and Allied Products Industry (SIC Group 28) at the 3 digit level. Figure 4 lists some of the major products and processes/equipment for each of the 3 digit industries in this group.

In a survey approach, industrial users have been asked to provide information regarding the following for each major process or equipment:

Qualitative and/or quantitative measures of current efficiency of utilization .

Potential for conservation.

Impact of increased fuel costs.

Impact of fuel availability .

Impact of environmental regulations.

Impact of technological changes.

The survey results are being combined with detailed engineering and economic analyses to determine the specific end use characteristics, the potential for more efficient utilization, and the impact of various major factors affecting energy use. The results of this study will be available shortly (8) .

\section{Factors Affecting Energy Use for Specific Processes or Equipment}

A large number of different factors affect the uses of energy for particular end use applications. Some of the most important factors are, of course, the capital costs and the fuel costs. In some cases, operating and maintenance costs are significant factors. Efficiency of utilization is becoming more important as the energy crisis becomes more critical. Some of the other factors which influence energy use are:

Process technology

Space Requirements

Equipment manufacturer support

Labor requirements and skill levels
Equipment reliability

Reliability of fuel supply.

Energy supplier assistance.

Regulatory factors (environmental, OSHA, etc.).

An excellent discussion of some of these factors and their influence on specific end uses can be found in Reference 9 . 


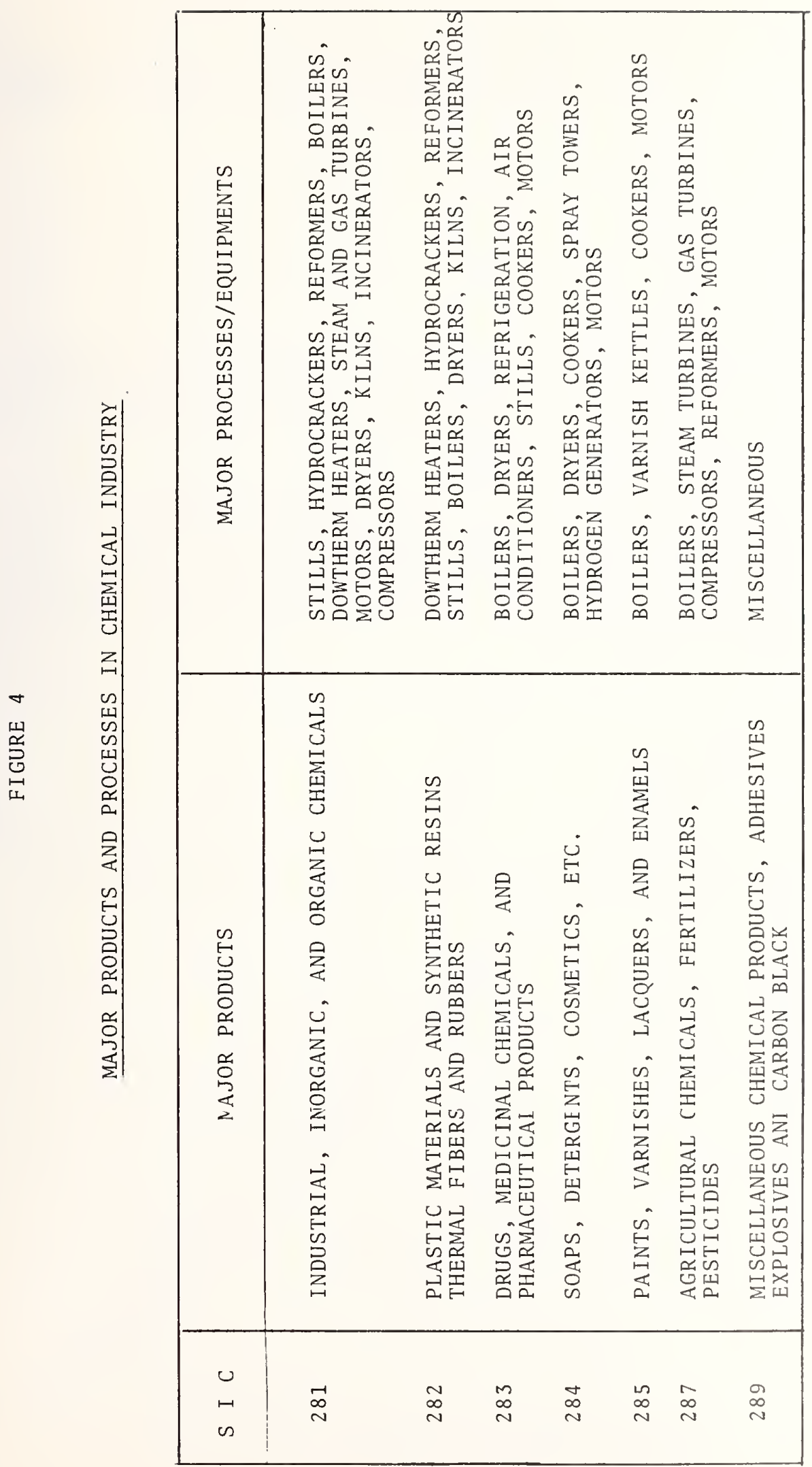


Taking into account the various factors affecting process energy use, an analytical approach can be formulated for major processes. This is best illustrated through a hypothetical example. Let's take Process $\mathrm{X}$ for which four alternatives are available:
A - Gas burner with oil standby.
B - Propane burner with gas standby.
C - Oil burner with gas standby.
D - Electric heating.

Figure 5 shows the annual owning and operating costs, efficiency of utilization, energy requirements, energy costs and total costs. As can be seen from Figure 5 , the choice would be A (natural gas). The use of C (oil) would actually conserve energy ( 8000 MMBTU), but would not be economically attractive. At first sight, D seems attractive, but since D uses electricity, which is a secondary form of energy, and involves an efficiency of about $35 \%$, D is not attractive either from an economic or an energy conservation viewpoint.

We, therefore, have a trade-off between $A$ and $C$ involving a saving in energy but a higher cost to the user. If natural gas were not available or the price of gas increased to over $\$ 1.25$, it would no longer be economically attractive; either oil would be selected or efforts would be made to improve the efficiency of utilization. The goal of more effective utilization of energy could be achieved for this process through economic means as the price increases. Alternatively, it could be achieved by end use regulation by curtailing gas for this process and making it available to other processes where gas has a "high-form" value or, in other words, has inherent properties which are required for product quality.

\begin{tabular}{|c|c|c|c|c|}
\hline & A & B & $\mathrm{C}$ & D \\
\hline ANNUAL COST OF OWNING & 10,000 & 15,000 & 12,000 & 30,000 \\
\hline ANNUAL OPERATING COST & 15,000 & 25,000 & 28,000 & 18,000 \\
\hline TOTAL OWNING AND OPERATING & 25,000 & 40,000 & 40,000 & 48,000 \\
\hline EFFICIENCY & $40 \%$ & $40 \%$ & $50 \%$ & $60 \%$ \\
\hline ENERGY REQUIREMENTS (MMBTU) & 40,000 & 40,000 & 32,000 & 27,000 \\
\hline PRICE OF ENERGY ( $\$ /$ MMBTU) & 0.75 & 1.00 & 1.10 & 3.00 \\
\hline TOTAL COST OF ENERGY & 32,000 & 40,000 & 35,200 & 81,000 \\
\hline TOTAL COST & 57,000 & 80,000 & 75,200 & 129,000 \\
\hline
\end{tabular}

Figure 5

ECONOMIC ANALYSIS OF PROCESS 


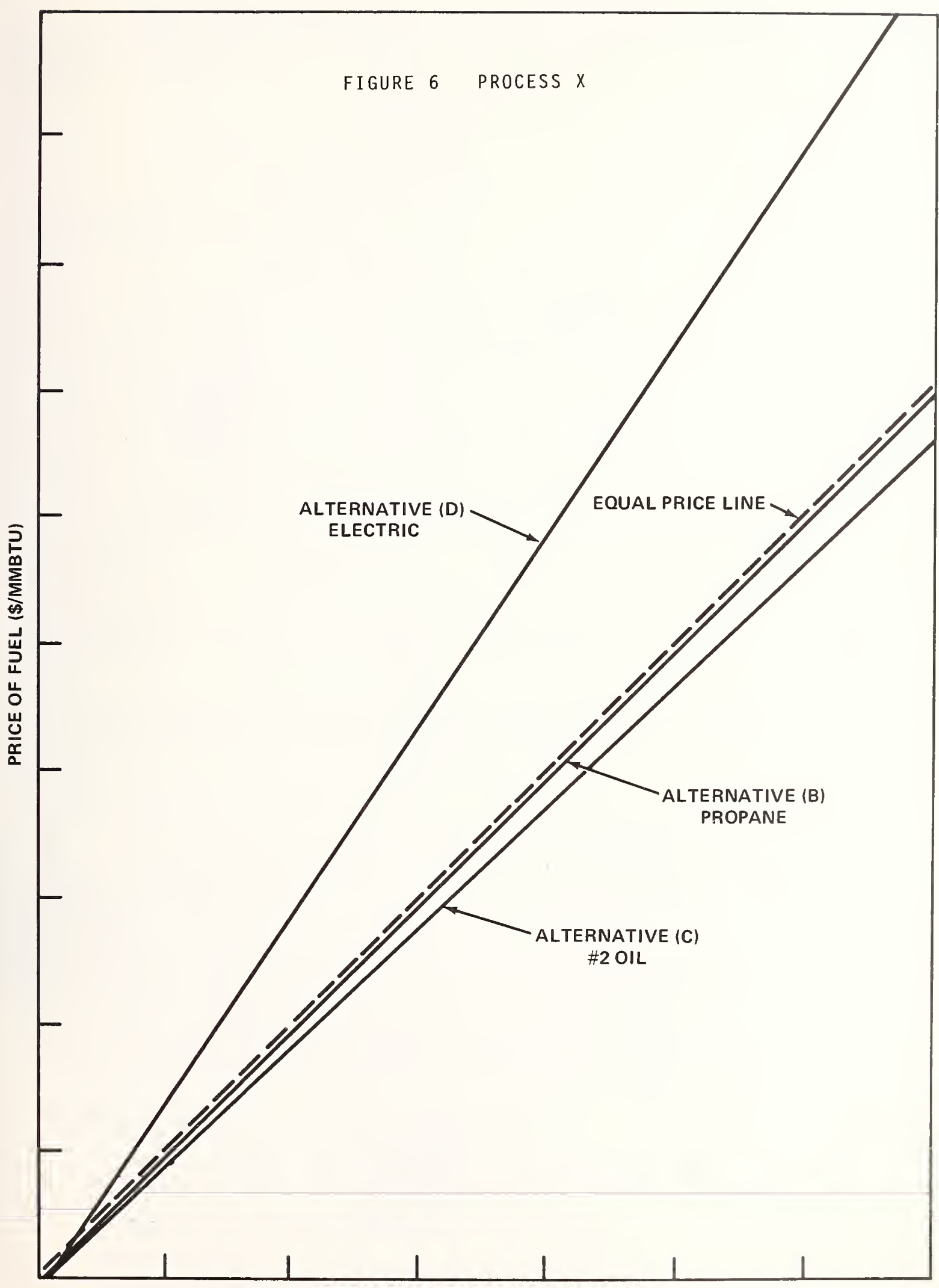

BREAKEVEN GAS PRICE (\$/MMBTU) 


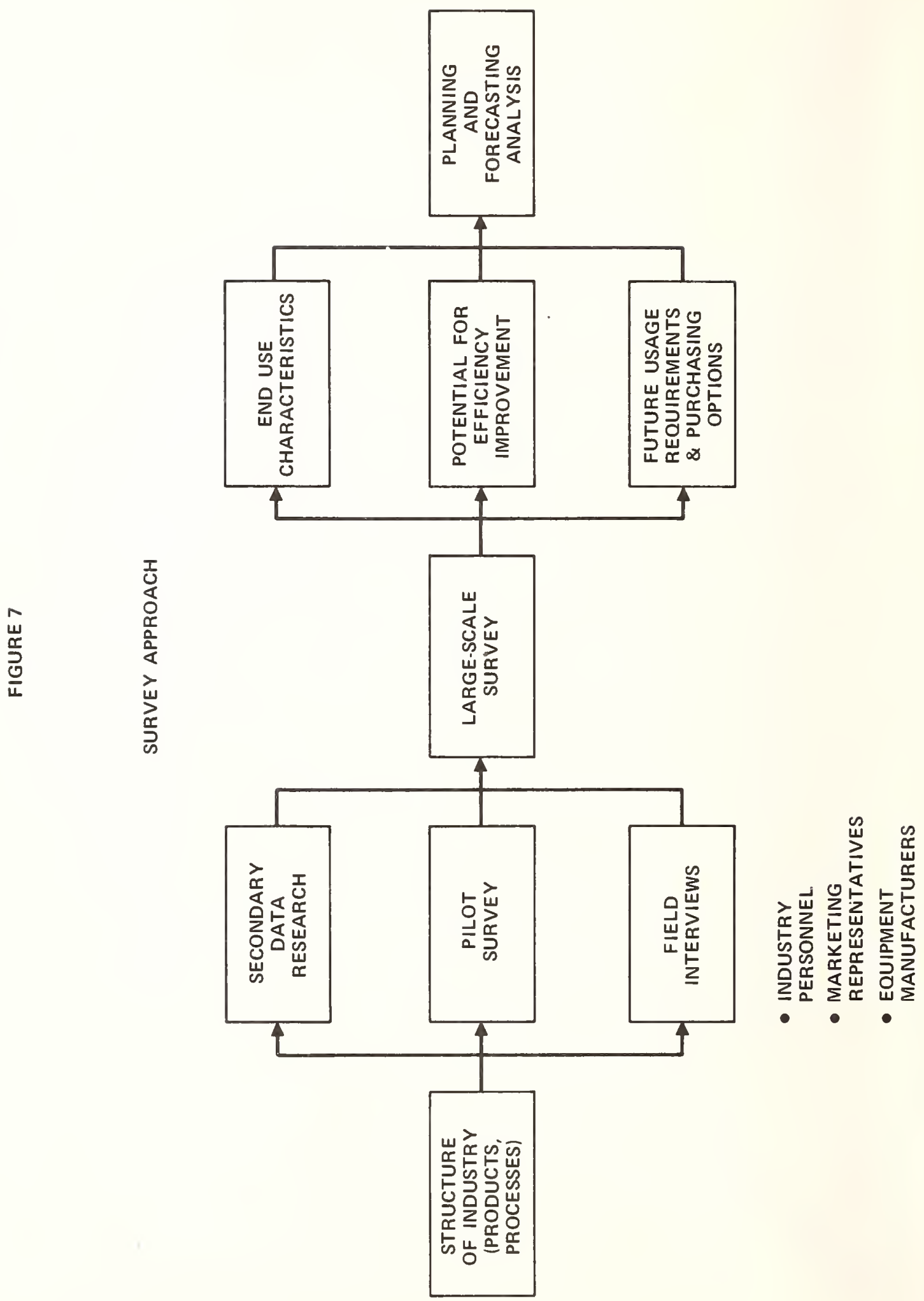


A useful analytical tool in process analysis is Breakeven Analysis, or the determination of prices at which two fuels would be economically equivalent. The breakeven price is given by the following formula.

$$
\begin{aligned}
& P_{A}-\underline{A_{B}-A_{A}} \\
& \text { MMBTU }_{\text {A }} \\
& \mathrm{P}_{\mathrm{AB}}=\frac{}{\text { MMBTU }_{\mathrm{B}}} \\
& \text { MMBTU }_{\text {A }} \\
& \mathbf{P}_{\mathrm{AB}}=\text { BREAKEVEN PRICE OF FUEL B RELATIVE TO A } \\
& \mathrm{P}_{\mathrm{A}}=\text { PRICE OF FUEL } \mathrm{A} \\
& \mathrm{A}_{\mathrm{B}}=\text { ANNUAL OWNING AND OPERATING COST OF B } \\
& A_{A}=\text { ANNUAL OWNING AND OPERATING COST OF A } \\
& \text { MMBTU }_{\mathrm{A}}=\text { ENERGY REQUIREMENT IN MMBTU FOR A } \\
& \text { MMBTU }_{\mathrm{B}}=\text { ENERGY REQUIREMENT IN MMBTU FOR B }
\end{aligned}
$$

Such breakeven price equations can be very useful in determining fuel substitution potentials at the process level. An example of a breakeven chart showing the breakeven price of gas for each of alternatives B, C and D is shown in Figure 6.

\section{Survey Approach}

Using a survey approach, detailed information can be collected regarding end use, qualitative factors affecting fuel use patterns, anticipated technological changes, future requirements, etc. While the survey approach has a number of major drawbacks, such as quality of response, potential bias in the samples, etc., in some cases it offers the only method for obtaining the required information.

An example of the survey approach is shown in Figure 7. In the authors' work the pilot surveys have usually provided an excellent indication of the quality and quantity of response and have led to improvements in the survey instrument and a larger survey.

An initial survey of industrial users in the East North Central region for the petroleum and chemical industries showed the large use for process energy. Figure 8 shows the energy consumption broken down by type of fuel and type of use. Figure 9 shows the distribution of fuel types in space heating and process energy plus feedstock. The current studies are concentrating on getting a better understanding of the nature of the process and feedstock components.

Methods for More Effective Energy Utilization

A large number of factors have affected industrial energy usage and have resulted in efforts to increase the efficiency of energy utilization in industrial uses. These factors include:

Increased costs of fuels and energy .

Quality of fuels.

Limited availability of certain types of fuel. 
FIGURE 8

\section{INDUSTRIAL SURVEY}

PETROLEUM AND CHEMICAL INDUSTRIES

\section{PERCENT ENERGY CONSUMPTION BY FUEL TYPE}

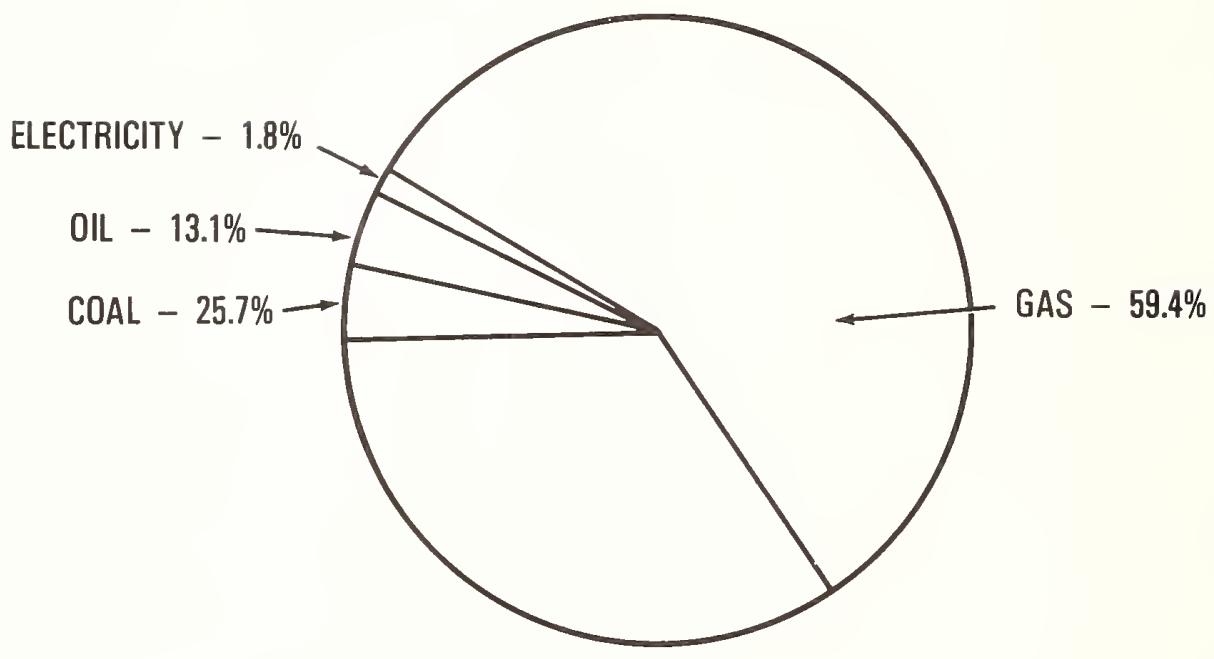

PERCENT ENERGY CONSUMPTION BY APPLICATION

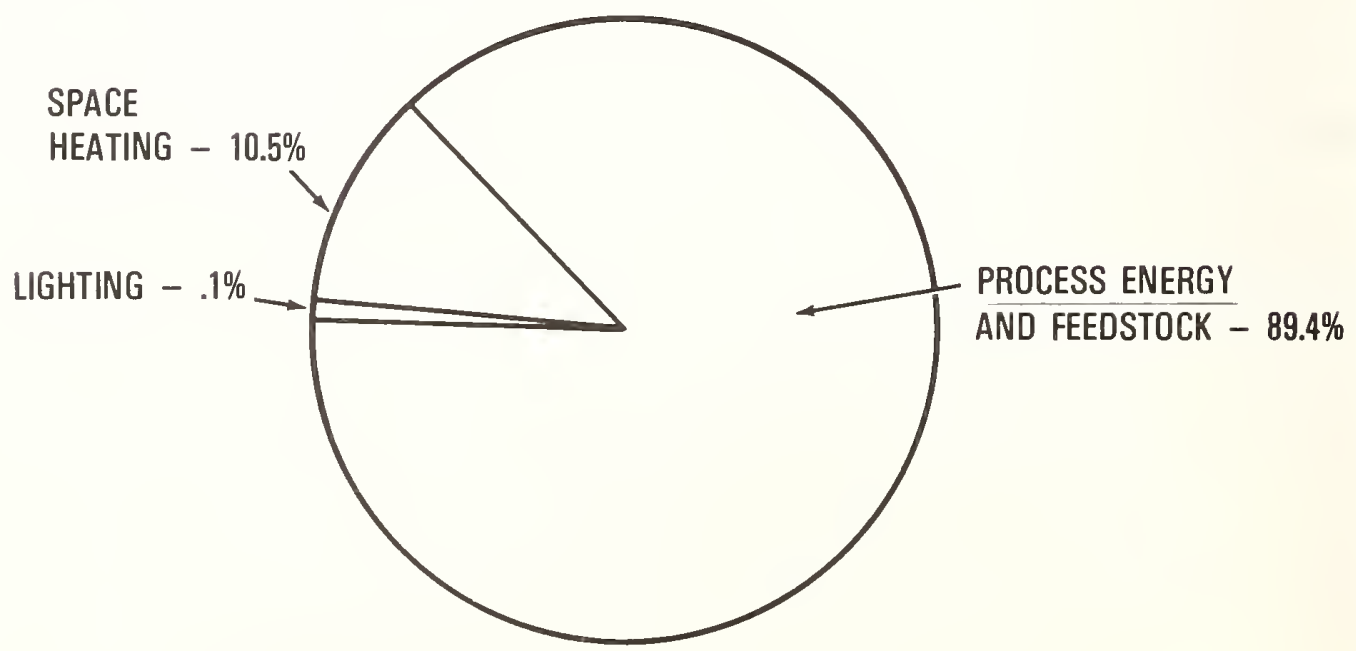


Interruptability of supply, especially gas.

Increased national emphasis on energy conservation.

Environmental regulation.

Improvements in technology .

Other regulations, such as Occupational Safety and Health, etc.

The efficiency of energy utilization in the industry can be increased by improvements in current methods and operating procedures and also by development of new equipment. A number of different methods can be used for improving efficiency. Some of the more important ones are briefly discussed below. A detailed discussion of these can be found in References 10 and 11 .

\section{Better Utilization of Equipment}

Better utilization of equipment can be achieved by carefully examining the production processes, schedules, and operating practices. For example, improvements can be made by:

Rearranging schedules to utilize process equipment for continuous periods of operation, thus avoiding numerous short runs and minimizing heat-up losses.

Shutting down or idling equipment at holding temperatures whenever production is interrupted, especially on weekends.

Reducing the temperature settings on thermostats.

Reference 10 cites examples where 5 to $15 \%$ savings in gas usage have been obtained by these methods.

\section{Better Heat Confinement}

This method involves use of the basic concept that heat is only useful where it is confined to locations where it will advantageously affect work spaces or work in process. Methods to prevent unnecessary heat loss include:

Close surveillance of combustion and heat transfer efficiency .

Improvement of structural heat confinement.

Maintenance of optimum flame geometry.

Reduction of building heat losses by sealing cracks, replacing broken windows, etc.

Insulation of lines conveying steam or hot liquids.

\section{Better Equipment Maintenance}

Regular and careful equipment maintenance assures satisfactory performance and reduces fuel consumption. Preventive maintenance can also be of great assistance.

For example:

Removal of heat transfer barriers.

Elimination of gas or steam leaks.

Maintenance of appropriate lining and thickness on furnaces. 
FIGURE 9

USE OF FUELS IN PETROLEUM AND CHEMICAL INDUSTRY EAST NORTH CENTRAL REGION

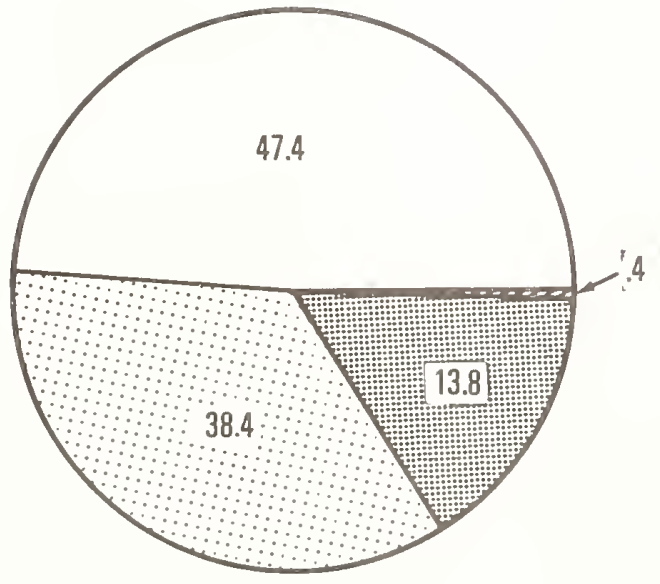

SPACE HEATING

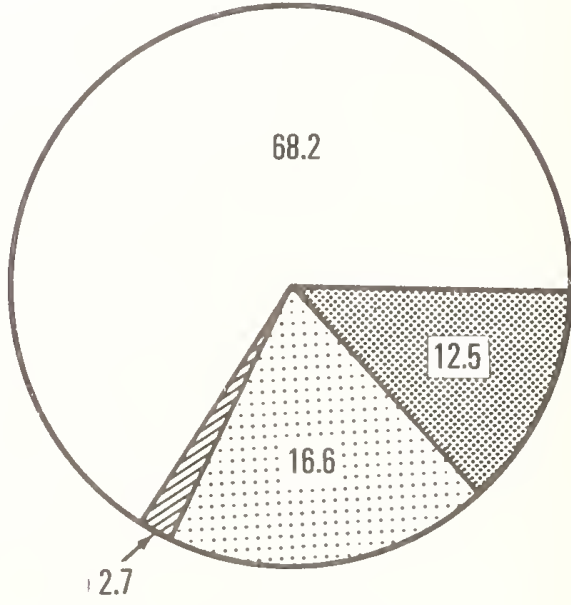

PROCESS ENERGY

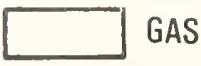

ELEC.

COAL

\% OIL 
FIGURE 10

ANALYSIS AND FORECASTING OF DATA

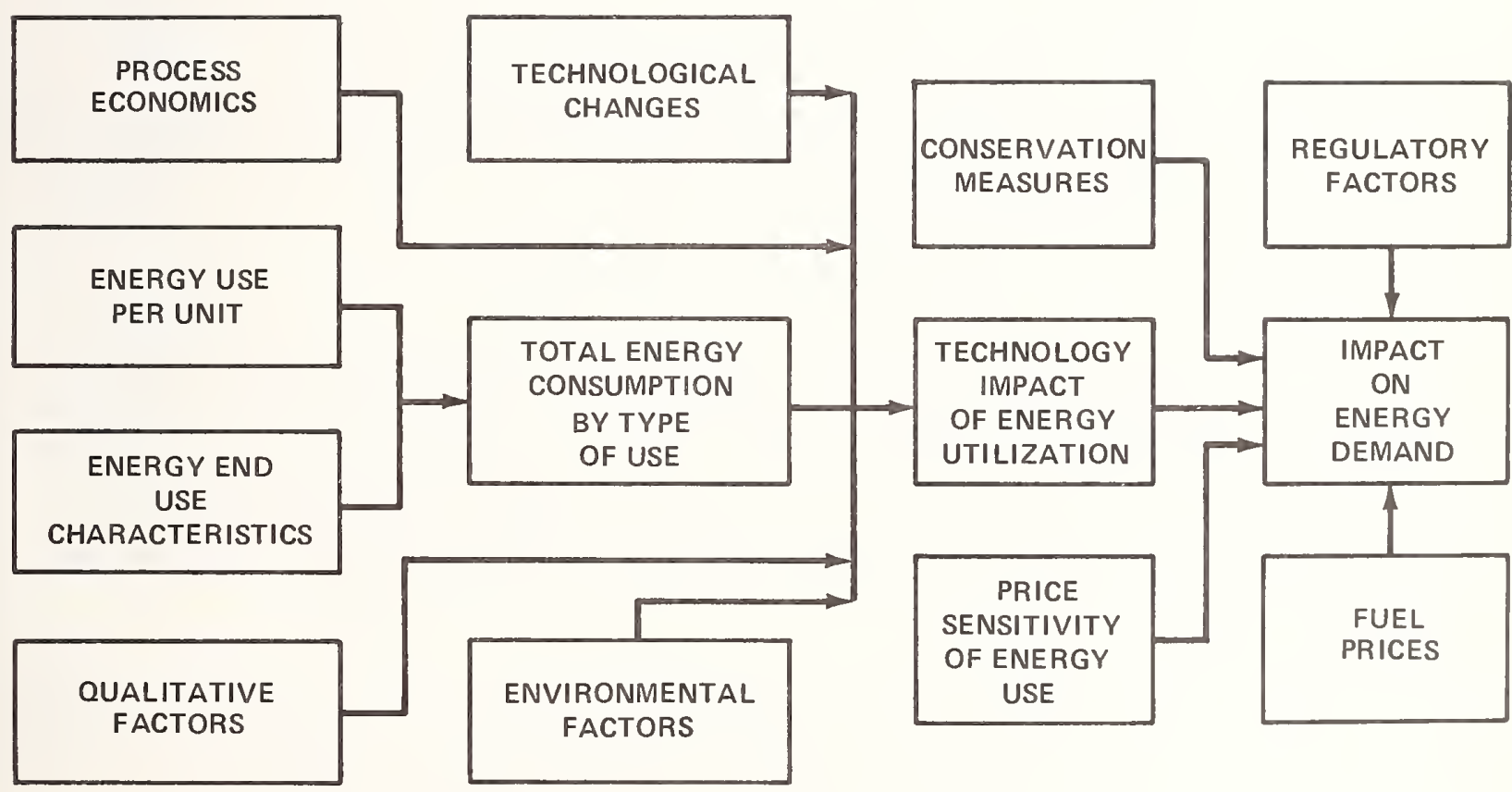


In many industrial processes waste heat is being vented directly into the atmosphere. If this can be recovered and utilized, the process efficiency can be improved. The waste heat can be used to heat combustion air, to preheat incoming products, or to heat plant air for space conditioning.

\section{Upgrading Existing Equipment}

Replacement or improvement of existing equipment can lead to significant savings

in certain cases. Some of the methods to upgrade equipment include:

Installation of automatic temperature and flow control devices.

Substitution of sealed-in burners for open hole furnace firing .

Additional insulation.

Better heat exchange devices.

6. New Equipment and Processes

Installation of the latest designed equipment and processes which utilize advanced heat processing technology can accomplish a substantial amount of savings in fuels and energy utilization. While this involves an initial capital cost, it generally allows for a reduction of energy costs and generally an improvement in product quality .

The foregoing discussion indicates that there are a wide variety of methods for improving energy utilization efficiency in industrial operations. Specific application of methods and techniques depends on the particular end uses in each industry .

\section{Analysis and Forecasting}

An overall methodology for integrating all of the different aspects of industrial energy analysis in order to forecast future demands is shown in Figure 10. The basic initial steps are the identification of end use characteristics, energy requirements per unit of output, process economics and qualitative factors affecting energy use. Based on these and on estimates of total industrial output, the total energy requirements can be determined.

At this point an analysis of technological, environmental and regulatory factors as well as the potential conservation measures can be performed to evaluate the impact on energy demands. The final result could show the total demand for energy by end use, the potential for conservation, and the alternative methods for achieving the energy savings.

Summary

This paper has attempted to highlight the problems and issues in industrial energy analysis and forecasting and to postulate alternative investigative approaches. It is hoped that the authors' current and future work will lead to useful results. However, a lot more work needs to be performed. This paper would, therefore, be of value if it could serve as a basis for further discussion and formulation of improved approaches for the collection and analysis of valid, accurate information on energy utilization and potential efficiency improvement. 


\section{$\underline{\text { References }}$}

1. A Survey of Fuel and Energy Information Sources, Vols. I and II, MITRE Corporation, McLean, Va., November 1970 (NTIS Access No. PB 197386).

2. Limaye, D. R. and Sharko, J. R., TERA - The Total Energy Resource Analysis Model, Phase I Final Report, American Gas Association, September 1971.

3. Limaye, D. R., Ciliano, R., and Sharko, J. R. " "Quantitative Energy Studies and Models A State of the Art Review", prepared for the Council on Environmental Quality, Executive Office of the President, Decision Sciences Corporation Research Paper Series \#114.

4. Baughman, M. L. . "Dynamic Energy System Modeling - Inter-Fuel Competition". Ph.D. dissertation, Energy Analysis and Planning Group, Massachusetts Institute of Technology, September 1972 .

5. Verleger, P. K., "An Econometric Analysis of the Relationships Between Macro Economic Activity and U. S. Energy Consumption:, in M. F. Searl (Ed.) Energy Modeling, Resources for the Future, Inc., Washington, D. C., March 1973.

6. Mooz, W. E., and Mow, C. C., A Methodology for Projecting the Electrical Energy Demand of the Manufacturing Sector in California, prepared for the Resources Agency of California with support from the National Science Foundation, RAND Corporation, Santa Monica, Calif. , R-991-NSF/CSRA, January 1973.

7. Limaye, D. R., and Sharko, J. R. "Analytical Techniques for Energy Policy Evaluation", in M. F. Searl (Ed.) Energy Modeling, Resources for the Future, Inc., Washington, D. C. , March 1973.

8. Study of the Industrial Market, Chemical and Allied Products Segment, Summary Report, to be available Fall 1973.

9. Consolidated Natural Gas Service Company, Inc., A Price-Demand Sensitivity Study of the Industrial Energy Market. Volume II - Cost Analyses. Pittsburgh, Pa., July 1972.

10. Rich, J., "One Utility's Approach to Conserving Gas", Industrial Gas, Vol. 51, No. 12, December 1971.

11. Rich, J. and Reid, D., "A Guide to Process Combustion Methods", Industrial Gas, Vol. 51. No. 7, July 1971 . 
National Bureau of Standards Special Publication 403

Proceedings of 1973 Engineering Foundation Conference

(Issued June 1976)

\author{
MANAGEMENT'S ROLE IN INDUSTRIAL \\ THERMAL ENERGY UTILIZATION
}

\author{
by \\ Allen S. Cook \\ American Can Company \\ American Lane \\ Greenwich, Connecticut 06830
}

\begin{abstract}
The industrial sector has a vital role and stake in decisions with respect to utilization of the country's thermal energy resources. Energy management responsibility requires a significant reorientation of the management job toward energy conservation. Industrial management's present dedication is to competitive free enterprise and energy substitution for human toil. The reorientation is toward acceptance of higher energy costs and toward security of energy supply. Discussions are presented on what industrial manufacturing can do and some factors external to industrial process thermal energy utilization. In the former category a new process technology, ultraviolet curing, is presented to exemplify conservation results from application of a new technology. In the latter category, it is emphasized that a given company cannot operate in isolation in its energy conservation efforts without running the risk that the total energy required by the society may increase .
\end{abstract}

Key words: Conservation; costs; economics; energy; thermal.

My employer, the American Can Company, is particularly grateful for the opportunity to be part of this conference and to express our thoughts. By way of background, I think American Can represents a reasonably typical composite of the nation's industrial sector, which has a vital role and stake in the decisions to be made with respect to utilization of the country's thermal energy resources. We are larger than average, with $\$ 2$ billion in sales volume, and we cover a wide range of industrial processes: petro-chemicals, specialty chemicals, forest products such as lumber, pulp and paper making; metal can fabrication, of course; all forms of plastics processing such as injection molding, blow molding, thermoforming and extrusion in a multiplicity of packaging products; printing; and a variety of package manufacturing processes involving paper, film, foil, and composite materials.

I am not an engineer nor a scientist, but I do portray myself as a professional businessman, with liberal arts undergraduate and business school graduate training from Harvard. My initiation to the energy management field was only very recent; prior to that I have been engaged in management of aspects of American Can's many businesses, either overseeing manufacturing activity, running a marketing and sales department, finance and planning functions and, most recently, as General Manager and Vice President of our fine paper and forest products business. One might sum up my recent experiences as that of a business administrator.

The role of a business administrator is primarily to motivate others to accomplish the objectives of the enterprise. I find that the energy management responsibility requires a significant reorientation of the management job toward energy conservation. Let me explain. The history of our Nation's industrial success is replete with examples showing that corporate individualism operating under the profit motive in a free trade atmosphere has been the major factor contributing to that success; and, second, no small part of these achievements has been due to industrial management's dedication to the substitution of inexpensive electric and thermal energy for human labor in the production of goods and services. Our progress as a nation and our current material prosperity can be directly attributed to industrial management's dedication to these two precepts, competitive free enterprise and energy substitution for human toil.

The required reorientation we now find is the necessity for management to accept the reality that in the future: first, energy input is no longer going to be inexpensive; and, second, that in order to secure energy supplies and to minimize energy costs, industrial society will have to act collectively in conjunction not only with its own members but also with government, the public, agriculture, the transportation industry, and all segments of the energy supply industry. 
Gentlemen, this necessity to share energy supplies on a regulated allocation basis will represent a new and challenging way of life for industrial management. How well, how effectively, and how quickly we react is what this newest business job title, "Energy Management", is all about.

It will take time before manufacturing management first accepts and finally acts in accord with this reorientation. Perhaps my own company's situation is typical. In 1972 our total costs of doing business, exclusive of income taxes paid, were $\$ 1.9$ billion. Almost $\$ 700$ million, or $37 \%$ was expended for labor and salaries, and $\$ 50$ million or $2.6 \%$ was spent to supply energy to the multitude of manufacturing processes involved. With people input being fourteen fold our energy input, it is understandable that management will question the theorem that substitution of capital and mechanical energy for labor is not still a valid industrial objective. In terms of resource allocation, with this type of labor-energy mix, even when our energy costs double to $\$ 100$ million, as they soon will, management is still likely to, and, of course, should continue to focus its improvement efforts to labor savings, where a $10 \%$ reduction would mean a seven fold payoff for a labor cost saving project vis-a-vis an energy conservation capital expenditure.

Fortunately, there already exists a high level of understanding in U. S. management of the implications of the world's energy problems and such a simplistic cost-benefit analysis as just used does not dominate corporate capital resource allocation policies. Effective managers are well aware that what is at stake is the continuation of output and sales on which profits are generated. What will take time for industrial leadership to come to grips with is, first, that energy will no longer be inexpensive; and, second, the necessity to act collectively and publicly with all parts of society, if we are to attain allocations of available energy supplies to the most appropriate uses. Business management must recognize its obligation to make clear to the public what the trade-offs are: gasoline for your car or mine versus possible industrial employment curtailment; resources dispensed to mass transit versus highway spending; and, of course, pollution abatement time tables versus employment, brown-outs, etc., to name only a few such issues. Recognition by business management that it must actively expend effort in stating its case in the inevitable energy supply allocation process that we as a nation are about to undergo is absolutely essential in order to avoid the threats of capricious misallocation of energy supplies. It is in this process of unwinding its resources to meet with the public, relate its story, give and take with all parts of society, that business management has tended historically to be both slow to react and reluctant to engage. Industrial energy managers and top industrial leadership can ill afford to perpetuate such reticence, this time, on this topic.

In order to be effective in such a confrontation, industrial management must rapidly demonstrate both progress and skill in "energy conservation through effective energy utilization". My remarks will review two areas of the topic: first, some thought on what we in industrial manufacturing can contribute; and then, with the co-chairman's indulgence, I would request approval to broaden the scope of the conference theme to suggest serious consideration of further research and study of factors external to industrial process thermal energy utilization, as significant possibilities for further conservation of energy in industrial processes. I tend to think of this subdivision of thinking as "internalities" and "externalities".

Excluding from my data base the energy used to generate electricity by utilities, industrial usage of fuels for thermal energy in 1970 was estimated to amount to 21.8 quadrillion BTU's or "quads", or about $43 \%$ of all fuel consumption of 50.9 quad. I'm sure this statistic understates actual thermal energy demands by manufacturing, because it excludes by-product residues used as fuel sources, such as bark, sawdust, etc., solid wastes, and recycled process sources of energy, for example black liquor solids used in the Kraft pulp process. It's probably more appropriate to conclude that American manufacturing uses at least $50 \%$ of the thermal energy produced in the country, exclusive of that required for the generation of electricity. One study I am familiar with projects the 1970 consumption of 50.9 quad will grow to 80.6 by 1985 , with industrial manufacturing still accounting for almost $42 \%$ of it, or 33.5 quads. Obviously then, what industry can contribute to thermal energy conservation has a very significant impact on the total energy problem. The President's conservation goal of 5\% applied to 1970 industrial usage is 1 quad, or the equivalent of 167 billion barrels of fuel oil distillates. Thinking ahead to 1985, without compounding, if American industry achieved the 5\% goal we could reduce equivalent distillate consumption 280 billion barrels per year. Now, going one step further, if American industry is able to apply itself as effectively to a $5 \%$ conservation objective on an annual basis, as we have been able to demonstrate when faced with other challenges, for the next 6 years the results would be indeed spectacular. Five per cent conservation per year exceeds the forecast of consumption demand increase of $3.8 \%$ per year. We would arrive at 1985 with industrial thermal fuel requirements of 19.6 quads, or more than 2 quads less than we burned in 1970 ! Are there any of us here today who can challenge the reasonableness of a 5\% conservation goal, at least for the next 6 years? 
Internal industrial thermal energy conservation opportunities can be divided into three general categories:

A. Improved utilization through engineering improvement of existing processes.

B. Process changes to utilize potential fuel sources that are currently being discarded, such as solid waste, or used for other purposes of higher added value. These opportunities tend to be a function of cost or value per BTU related to the new investment required to change one's process.

C. Discovery of new technology reducing the energy requirement per unit of output.

Achievement of meaningful energy savings in existing processes, savings that we all know are there and which can be realized, is a function of management girding up its loins to do the job by effective personnel motivation, planning and administration. For companies who make high thermal energy input products, the establishment of a formalized energy management responsibility is highly desirable to give the effort both the focus and direction required. A new box on the organization chart doesn't get the job done. Line business managers do that. An energy management function gives the line manager the tools to get the job done. To get more for your energy buck, business managers have to be first educated to what their energy use and costs are, to what the future energy supply available is likely to be and what it is going to cost, to what problems or opportunities the energy crunch is going to present, and what alternative solutions should be pursued. Getting participation from key local plant operators is the prime ingredient to energy conservation success.

I do not mean to slight the inputs that technical staff with energy engineering skills can contribute, but in most companies these resources are limited and there probably is a higher priority use for their skills, which I'll get to in a minute. More important, though, the local plant operator knows his own shop. He knows where the energy "leaks" or wastage are, and generally he's in a position to act and act fast if top management gives him the resources he needs to do the job, be it money, technical skill, or new sources of energy supply. In our company, for example, we have instituted local plant energy conservation committees, generally spearheaded by our in dustrial engineers, unless the type of facility is large enough to support its own power engineer. Line business management has given each plant an energy conservation goal and progress against that goal is monitored, just as other management objectives are followed.

This activity has not been organized on a formalized basis for too long, but it is starting to produce both ideas and results, and I recommend it as the single most important step in an energy management program.

A significant portion of American Can's thermal energy requirements is for the purpose of drying. Removing moisture in the paper making process is a very significant example of this, but in addition virtually all of our packaging operations use tremendous amounts of heat to set and cure a massive volume and range of inks and coatings applied to containers. I will be mentioning in a moment new process technology which promises to reduce thermal energy requirements for curing coatings and inks by a fantastic margin; but, in the present situation, it will take several years to equip our operations with this new technology. In the interim, any of you who have had experience with air drying-ovens know what a cumbersome impediment an oven tends to be in a smooth product flow and that hot air curing is not a particularly efficient process from an energy standpoint. In addition to this basic thermal inefficiency, our packaging business uses ovens in conjunction with printing and coating operations for a wide range of specific customers requirements, so that 35 to $40 \%$ of available operating hours have to be devoted to change-over, or "make ready", in which period no product is moving through the drying apparatus. Well, quite obviously, what I am describing here is an ideal opportunity for a local plant energy committee to go to work on the application of low investment energy conservation ideas. The actual thermal engineering input required is modest and, because gas has been cheap, our company previously couldn't justify the instruments and controls required to minimize gas usage. We certainly can now, and our plants haveflooded us with good ideas which we are implementing. We should be able to achieve the President's $5 \%$ goal in our metal can plants on this type of present process improvement alone. It is illustrative of what I mean by the first category of improved utilization which I call "getting more for your buck".

The second opportunity I mentioned involves the use of BTU sources that are currently going to waste. You may question the precision with which this concept matches our conference theme of effective utilization as a means of conservation. We have all read of the sizeable energy source available in solid wastes, a term we tend to associate with a garbage truck stopping at our doorstep, or something the consuming public creates, but how thoroughly have we studied our own industrial process wastes to determine what additional BTU's might be generated therefrom. 
This obviously is an area which does require specialized engineering know-how before it demonstrates improved and effective results. My association with the forest products industry gives me an advantage here, because use and reuse of all raw material inputs in the lumber-pulp-paper industry is a way of life. It is instinctive for a pulp mill guy to look at any process by-product and ask himself how he can wring out some energy from it. Lumber and paper people are like farmers in thought processes; they live with an organic and regenerative basic raw material, cellulose, which gives them more opportunity than those of you who deal with stone, glass, iron, steel or other inorganics. The pulp and paper industry is fortunate. It already has $36 \%$ of its energy supply available internally and some plants go as high as $65 \%$, from pulping liquor solids and bark. Despite this already high level of energy self-sufficiency, pulp and paper mills are planning to increase their internal fuel self-sufficiency to a $50 \%$ level by 1975 , by further reprocessing of material.

It is my contention that a whole new vista of internal process fuel sources can be opened up in many other industries if we put our minds to the task and use the chemical engineer's philosophy of process optimization to do the job the way the pulp and petrochemical industries do it today.

A few examples have been uncovered already by our can makers, and bending metal certainly doesn't have the advantages or recycling possibilities I just cited for the forest products industry. We use a large gallonage of coatings, all of which are diluted with solvents before being applied to the container. We likewise employ a variety of solvents in wash-up operations during changeovers of printing presses and coating equipment. We already have one facility burning washup solvents as a heating fuel supplement. The horrendous amount of additional energy required to incinerate the printing ink and coating solvents to meet air quality standards has motivated us to install two pilot carbon absorption units to recycle these materials. In one instance we expect to recover heating fuel energy; the other should reclaim reusable solvent.

of course, the big danger in advocating increased investigation of recycling material for its energy values is that each of us acting individually may proceed on a very logical, good payout basis from our own viewpoints and unwittingly from the total economy standpoint create a negative energy conservation result. It is in avoiding this error that I believe non-profit institutions and, hopefully, our government can make contributions.

The cellulose in my blood keeps showing itself, but no paper maker can go for a drive in farm country without thinking about all the fibre that agriculture creates which is not consumed. In most cases it is not feasible as a raw material for paper, but the energy crunch has promulgated serious evaluation of agricultural residues as a fuel source. If the incremental energy required to collect, store, and deliver it to the boiler is greater than the BTU's we generate, we may have solved our own problem, but in the process we undoubtedly have made the country's problem worse! All recycling involves this danger and one way we can avoid the dilemma of negative conservation is to stick to our own in-house process waste. I suggest the plastics industry, specialty chemicals, soap and detergent, textiles, printing and publishing, and rubber may have hidden BTU's they can now afford to recycle. But before these industries go all out on the idea, it is important that the total production cycle and its energy balance be studied and evaluated. If the waste material is not now going down a sewer or into a hole in the ground, let us be careful before we decide to burn it or recycle it. For example, the plastics industry is an obvious case which today recycles some high BTU waste material to lower product technical specification uses. We all sell waste plastic to the toymakers. Before we burn that waste let's make sure the net added BTU to produce toys from new virgin material isn't going to outweigh its heat value.

One of the reasons for this conference is to identify areas where research is needed to assist the objective. May I suggest that too few of us have an understanding of the energy inputs and balances of our total product production process. Gaining such knowledge is virtually impossible for most of us. It can only be done at the university level or by special non-vested interest groups with the skills and working knowledge needed. Our company makes cans from steel and tinplate, but I confess to zero knowledge of the energy balances of the steel industry upon whom we depend for our basic raw material. I am shocked to read, as I have on several occasions, that our U.S. agricultural industry, whose productivity is the envy of the world, on balance is the most inefficient energy user of them all, its caloric output being extremely wasteful in relation to its total energy input. It seems to me that identification of and clear straightforward tables of energy factors to produce the basics of our life and life style are desperately needed, if we are to make the correct decisions on energy in the future. For example, in our business I can tell you it takes 40 million BTU to make a ton of paperboard, starting at the pulp mill, and very shortly I'll know how many BTUs are required to fabricate that papenoard to a food carton. But I haven't had time yet to measure the energy input of our own timberlands that supply the basic wood to the pulp mill. Even when I complete this energy balance, which represents American Can's part of the process, I don't know where to turn to get information on what amounts of 
energy are required for the chemicals, resins, inks, coatings, and all the other raw materials we use, to say nothing of all the transportation steps involved in producing the food carton or supplying the raw materials. This suggestion implies a massive data base is needed, and to trace every product to its roots is clearly very difficult if not impossible. Assembling the basic building blocks or modules of energy input requirements that can be used intelligently by all who play a role in the energy management process is certainly a possibility, and should be pursued.

The final category for effective energy utilization is technological breakthroughs that reduce the thermal energy input per unit. Not being of technical background, I don't believe I can offer this conference much by way of specific suggestions that should be researched. However, I can share with you our company's experience both in developing such a breakthrough concept in our specialty chemicals division and one which we are rapidly bringing on stream in our container manufacturing plants as a commercial reality, because I'm sure it has other applications and because it is illustrative of what has to transpire if we are to get our nation's energy demand and supply back into reasonable balance.

I've referred to the importance of thermal energy for drying container inks and coatings to American Can's business. The discovery and development of ultra-violet curing, UV, has emerged in the nick of time. Our own $M$ \& $T$ chemical development in this field under the trade name "Americure" is already in the market place for selected applications. The energy reduction in substituting a chemical reaction triggered by ultra-violet light in the setting and curing of inks and coatings in place of oven drying is substantial. Additionally, there are advantages in reduction of air pollution and other significant process cost savings. A gas-fired oven equipped with fume incineration uses 12.4 million BTU's per operating hour, 12 million of which are gas source thermal inputs. A UV installation does the same job, and maybe a little better in terms of product quality, for a mere 102,000 BTU's per hour. We should all be so lucky with our energy problems!

I don't even know the history of UV curing, whether it was a lab accident or a conscientious well-planned discovery, but I'm sure it has applications beyond what has been publicized to date to substitute for thermal energy processes. More important, it may also stimulate investigation of other chemical reactions that can replace direct heat applications to processes. My layman's approach to the energy problem may be wishful thinking, but I throw out the generality for what it's worth. Most of us are confronted with significant energy input increases to meet air and water quality standards in accordance with regulatory time tables that unfortunately prohibit the risk of investment in promising, but untried, new technology that may achieve the pollution abatement standards with far greater thermal efficiency than existing proven procedures. If any of this audience can bring out at this conference the need for speed-up of research and development on promising new low energy processes, such as ion exchange, reverse osmosis, high pressure wet oxidation, or perhaps even condensation techniques that can substitute for the current pyrolysis and chemical additive approach to meeting air and water quality standards, you certainly will have made an important contribution to the purpose of the conference. It seems to me the time is ripe for gaining a more sympathetic and less emotionally motivated ear in the Environmental Protection Agency and the Congress for revision of the pollution abatement statutory time tables, if we can demonstrate we are on the threshold of some discoveries, such as UV curing, that can do the pollution clean-up job with substantially less thermal energy than seems to be the case with most current technology.

This concludes my thoughts on how industry should approach its internal thermal energy consumption problems, and leads to some brief remarks on externalities that can have an important bearing on industrial thermal energy consumption. I would like to repeat quite emphatically that industrial management is well aware that it must demonstrate positive progress in greater energy utilization and conservation within its own house, before it can expect an understanding hearing of its viewpoint on external factors that create increased industrial thermal energy demand. My suggestions relate to three broad areas.

I have already touched on the first of these. Imagine for a moment that our moon is habitable and that you are an intelligent being of an advanced moon civilization possessed with the optics and electronics to monitor every aspect of life on the planet earth. Wouldn't you be asking yourself how those stupid earthlings could have ever decided to promulgate regulations that decreased the already inefficient energy utilization quotient of its chief transportation device, the internal combustion automobile engine, by a factor of perhaps as much as $50 \%$, at the very time when a sane observer could see the raw material energy source, a non-renewable fossil, was reaching a predictable poirst of exhaustion? I'm referring to the American Petroleum Institute estimates that car emission control devices have increased U. S. gasoline consumption by 300,000 barrels per day . and that 9 to 10 miles per gallon is now the average car efficiency. How could such an intelligent, creative society as ours have failed to see that this was going to be the consequence of the entirely 
desirable and necessary Federal Air Quality Act, given all the facts of life which the Congress had before them when the legislation was enacted?

An understanding of the interrelationships of demands for improved environmental quality , the supply of energy, and the potential collapse of the transportation system is beginning to emerge.

The necessity to treat and administer these as a unified whole, rather than separate functions, is dawning upon us. The point of this story is that it is not too late to make the appropriate adjustments to our environmental quality standards and time tables for industrial processes and avoid the errors of inefficient energy utilization we have capriciously imposed on the transportation industry. This does not mean that we should not go forward as energetically as possible with the objectives of the clean air and water acts, but in the process let's do so in a manner that conserves our limited energy resources to the utmost until we have supplanted our current fossil fuel supplies with the renewable energy sources we are developing.

My reference to the transportation industry and its problems is the second externality which cannot be ignored in a discussion of industrial process conservation. The 1970 consumption statistics indicate 16.4 quadrillion BTU's were required in the United States to move our goods and transport our population, all of it in the form of petroleum. A most likely forecast for $1985 \mathrm{re}-$ quirements in transportation is 28.2 quads. That 15 year $72 \%$ forecasted increase in energy demand is exceeded only, in percentage terms, by the utility industry. Both the Rand Corporation and Battelle Institute have done investigations of transportation energy requirements and, although there are differences in their findings, there seems to be relative agreement on the folloing energy requirements for each transportation mode:

$$
\text { Water Transport }
$$

Railroad

Truck

\section{BTU per ton mile}

750 BTU per ton mile

\section{2,400 BTU per ton mile}

If our observer on the moon was amazed at the $50 \%$ decrease in automobile engine efficiency stemming from emission control equipment, what must he think of our wisdom in utilizing our transportation system resources in the face of a fossil fuel shortage? What can we do to utilize more fully our existing rail or water network, which possess three to five times the energy efficiency of the highway vehicle, instead of letting this network decay into bankruptcy? Correction of our misallocation of transportation resources has only indirect benefits to industrial process energy conservation, in that, if we could optimize the use of rail and water modes, it would make everybody else's fuel supplies last that much longer. But the key point, it seems to me, is that we have now reached the time when industry, transportation, the public and their government must work together to redress the imbalance of transportation fuel inefficiency. If business and commerce are willing to face the responsibility of improved utilization within their own houses, do we not have an equal responsibility to see that the transportation industry, which essentially is an extension of our manufacturing processes, does not squander its allocations of fuel supplies? Solutions to this very complex problem boggle the mind, especially since transportation, by law, is in the public domain and a regulated industry subject to a frightenirig array of political pressure groups. I am not suggesting that this conference divert itself from its already massive assignment, but the need for equal concern and investigation of improvement in transportation energy utilization is so readily apparent that perhaps some of you can play a role in initiating the action required.

One final externality may be of more direct interest to the aim of the conference. Earlier I stressed the need for business management to adjust to the necessity to work with all segments of the economy in improving energy utilization. One area that may offer opportunity for significant energy conservation, but which requires extensive engineering effort to realize, is the combination of industrial processes to share fuel values. This leads to consideration of another regulated business, the electric public utilities, who in 1970 used almost 14 quads equivalent of fossil fuels to boil water. It seems amazing for a society as developed as ours that engineering and management of both the utilities and industry have generally avoided combining the electric utility plant with an industrial process that could make use of the steam energy being wasted from the typical generating plant. Many industries of which pulp and paper is but one example have found it of benefit to both boil water for steam and generate their own power in the process, but for reasons I have never fully understood there are very few installations of public utility generating capacity also producing steam for process utilization. Total 1985 electric generating requirements for the country have been estimated at 44.3 quads, $62 \%$ of which, or 27.3 quads, will be non-fossil fuel supplies - chiefly nuclear of course. That 44 quads compares with 16.8 Q 
in 1970 , giving some indication of the tremendous number of new generating plants that must be installed. This seems to be an excellent opportunity for industrial processes to join together with the utilities to conserve fuels. By the same token, it may be that the utility industry should be taking a look at the value of utilizing industrial process energy to boil water and make electricity. Perhaps the engineering obstacles are too great, but both the steel industry and glass making come to mind with their tremendous furnaces to melt and refine ores, operating on a continuous basis. Cannot some brilliant designers find a way to employ this heat source to also make generating steam without impairing the reliability of the basic process furnace?

Your patience in listening to a layman's queries of items somewhat external to your conference intent is appreciated. May I again thank you, on behalf of American Can Company, for the opportunity to participate in the work of your conference.

Q. I'm wondering how far has your company gone in meeting the $5 \%$ goal and do you expect that you will achieve that goal?

A. In the can-making end of the business, I think we can make this quite easily by reducing the losses we have. Some of our other large parts of the business are dependent on electrical energy and I find that finding ways to save electrical energy is a lot harder than thermal. When we get into our chemical and pulp and paper I think it would be a breeze. In fact, I argued for a first year goal like $20 \%$ in most parts of the business. General Motors brags about $20 \%$ in its first year.

Q. At one point of your talk I got the impression that you were implying that it might be possible to make a 5\% energy reduction compounded. Would you explain that?

A. I used it in a sense comparable to productivity. I was really starting with tcday's base, and, if you accept that real industrial output is going to grow at about $3.8 \%$, theoretically the 5\% conservation effort could exceed our growth and demand requirement and we wind up using actually less energy .

Q. I don't think you can keep up forever.

A. But again I go back to the example. General Motors, who bragged about $20 \%$ the first year, is not going to keep that up. That $20 \%$ the first year gives a pretty good bite toward the effect of a 5\% compounded conservation rate for 10 years. 
National Bureau of Standards Special Publication 403

Proceedings of 1973 Engineering Foundation Conference

(Issued June 1976)

\title{
DEVELOPMENT OF INDUSTRIAL ENERGY MANAGEMENT POLICIES
}

\author{
by \\ Michae1 C. Noland \\ Midwest Research Institute \\ Engineering Division \\ 425 Volker Boulevard \\ Kansas City, Missouri 64112
}

\begin{abstract}
A systematic approach to energy management at the operational level must be custom-fitted to specific industrial facilities. Preliminary results of attempts to (1) determine the steps being taken by industry in response to changing energy supply conditions and the potential for conservation inherent in that response and (2) develop guidelines for the establishment of plant energy management policies in the manufacturing and process industries are presented. The major incentive for future conservation of energy by industry is cost. The only alternative is regulation and enforcement. The economic incentive involves both direct energy cost and the indirect costs of energy security. The approach to energy problems taken by different firms follows no discernibly systematic pattern, varying from little concern to progressive programs. An outline of steps in the development of industrial energy management policies is presented.
\end{abstract}

Key words: Conservation; economic; energy; management; manufacturing

We have the unenviable task at this conference of identifying and delineating the "opportunities and implications of more effective utilization of thermal energy". In this morning's session we have the even less enviable charge of addressing energy management practices in industry, an even more challenging assignment than it first appears. This is because a systematic approach to energy management at the operational level cannot be developed which applies equally well to all industrial facilities. Obviously, we cannot formulate a list of ten best energy conservation actions for the manufacturing and process industries and expect that 1 ist to be equally applicable to all manufacturing and process plants. Similarly, the advisability of converting to various alternative fuels can differ markedly from plant-to-plant, region-to-region.

We can regard this conference as addressed to one aspect of a larger question: "How can we reduce the future demand for energy?" I sometimes think that when we discuss the potential for energy conservation in industry we are all perched on the edges of our chairs waiting for someone to announce that a breakthrough has been achieved....that a simple guideline has been developed which, if applied, could significantly reduce energy demand without painful economic or social side-effects. But, alas, that hasn't happened, and it's not likely to happen. Energy conservation - particularly energy conservation in industry - will be achieved in elemental pieces - by a myriad of different energy management practices applied to a myriad of individual situations.

I believe that energy conservation in the manufacturing and process industries can best be achieved by the development of energy policies customfitted to the needs of individual energy consumption centers. It is true that general guidelines, such as "reduce heat in unoccupied areas" and "utilize waste heat", are helpful. It is also important that good systems 
engineering practices be applied to energy policy development. But the ultimate effectiveness of energy management practices depends on how applicable they are to the energy problems faced by the plant manager.

The potential for energy conservation in industry has been much more difficult to characterize than the potential in the transportation, residential, and commercial sectors.

Even the attempts to define the industrial potential have rarely involved the active participation of industry. As a result it has been difficult to discern and record the response of industry to rapidly changing energy economics.

I would like to discuss with you this morning some preliminary results of attempts to:

1. Determine the steps being taken by industry in response to changing energy supply conditions - and the potential for conservation inherent in that response; and

2. Develop guidelines for the establishment of plant energy management policies in the manufacturing and process industries.

These studies have been underway for only a few months. As additional data are obtained from surveys of industry, and as further refinement is made of the suggested guidelines for policy development, it is very likely that some of the results will change.

The Potential for Energy Conservation in Industry

Estimates of the potential for energy conservation in the industrial sector can be described as tenuous, at best. Although we know how much energy is consumed by different types of industry, the detailed consumption data within industries are inadequate. It is difficult to estimate how much energy could be saved by energy-conscious design of industrial process equipment. Even more important, we have no means of predicting the response of industry to energy conservation programs - whether voluntary or mandatory. It is this shortage of fundamental planning information, more than any other factor, which complicates the development of energy conservation programs targeted at industry.

In order to identify conservation potential we need to know how much of what type of fuel is used for what purposes in which processes, by each classification and subclassification of industry. To develop specific plant energy management policies, it would be desirable to have this type of information for specific industrial manufacturing or process plants. Unfortunately, much of the information concerning industrial energy consumption is somewhat dated, and non-specific.*

Most of the potential energy savings are expected to result from incentives to upgrade the energy efficiency of industrial processes. It is argued that increases in energy costs, perhaps by means of an energy use tax, will compel industry to design and develop more energy efficient processes and equipment and to accelerate the replacement of obsolete equipment to effect energy savings. There are two central unknowns in such a scenario.

First, something must be known about the price elasticity of demand for energy. How much will the cost of energy have to increase before the consumer (here, industry) considers it to his benefit to reduce demand. In many segments of industry, energy costs have been such a small fraction of operating costs or product costs that it might take a very large percentage increase in energy cost before efficiency improvements become cost effective. Second, energy utilization improvements in processes and equipment must be the result of feasible design changes and development efforts. Energy

* Editor's note: At this point in his paper presented to the Conference, Mr. Noland summarized studies which indicated the potential for energy conservation in industry. Rather than reiterate these findings, we refer the reader to the reports presented on the first day of this Conference under the topic entitled "National Context for Energy Conservation", in this volume, and "Potential for Energy Conservation", Office of Emergency Preparedness, October, 1972. 
savings will be the result of an accumulation of process improvements. improvement must be both feasible and cost effective.

Incentives for Energy Management in Industry

I believe there are four principal incentives for the future conservation of energy by industry. The first is cost...the second is cost...the third is cost... and the fourth is legislation. My point is obvious. Energy savings will be realized in the industrial sector if there is an economic reason to achieve such savings. That is the central motivation. The only alternative is regulation and enforcement.

If we consider energy management policy in more global terms than conservation, we can identify two obvious economic incentives for the development of such policy on a plant-by-plant basis: 1) the savings realized by reducing energy use, and 2) the economic losses prevented by avoiding loss of production when fuel supply is curtailed.

Demand reduction constitutes conservation. It is economically attractive only if the energy cost savings over an acceptable period of time are greater than the cost of implementing the conservation measures. It remains difficult to convince an operations manager that he should make an invest-. ment in energy conservation if it holds no promise of economic return. Conservation measures can be economical, however. For example, one large manufacturing firm in the Midwest operates on a two-shift, 5-day basis with maintenance performed on the third shift. They now shut down energyconsuming process units, space heating, and lighting from the end of the second shift on Friday until about 5:00 a.m. Monday. This incurs a $\$ 400=$ $\$ 500$ labor cost for shutdown each weekend, but a fuel savings of $\$ 5,000-$ $\$ 6,000$ is realized. Most firms which implement such plans find that system controls are not usually adequate to effectively isolate those processes or areas to be shut down.

The second incentive - energy security - is influential if the loss associated with process downtime or facility closure due to energy curtailments is important. Many factors must be examined to evaluate the impact of such an event. It depends on production schedule, materials and product shelf lives, unit costs, plant shutdown and start-up costs, union agreements concerning temporary plant closures, back-up fuel availability, anticipated length of shutdown, and numerous other considerations.

The economic incentives for industrial energy conservation are energy savings and energy security. Of course, it is remotely conceivable that industry could be directed to reduce energy demand regardless of cost. We could, by inaction, find ourselves in an emergency situation in which industry is forced to reduce consumption in order to overcome a fuel crisis.

However, no incentive is adequate unless management attention and talent is directed to energy utilization and efficiency. It has been our observation that most industrial management teams exhibit two philosophies regarding energy policy. Within most companies, there is an element of management (usually at the top levels) which has been informed of potential energy supply problems and believes that something should be done. Within the same company, there is frequently a management element (generally at the operating level) which does not assign a very high priority to the task of heading off such problems. This latter group is usually faced with more immediate operating or production problems and cannot find the time to address a longer range potential energy problem. Unfortunately, the former management group usually assigns the task of plant energy policy development to the latter group. And, too often, very little substantive progress is made.

Survey of Energy Policies in the Industrial Sector

As a preliminary step toward developing guidelines for plant energy policies, we have inaugurated surveys of a wide cross-section of industry. Interim results are summarized, in part, in Tables 1 and 2 . We have also contacted several dozen leading companies in the Midwest and have discussed energy problems with their executives and operating managers. I will attempt to distill some of their opinions. 
INDUSTRIAL FUEL SUPPLY

REGIONAL ENERGY SURVEY

Plants experiencing fuel shortages

during past year (includes winter 1972-73) .......66\%

Natural gas............ $75 \%$

Fuel oil.............. 25\%

Number of natural gas curtailments.................. 0-i5

Cumulative length of natural gas curtailments........... 0-90 days (back.-up fuels used, maintenance performed)

Plants with back-up fuel provisions................ $70 \%$

Fuel oil for natural gas. $80 \%$

Fuel oil/diesel fuel to

generate electricity... 25\%

LP gas for natural gas.... 20\%

Coal for natural gas...... 13\%

Plants expecting shortages during next year........... 82\%

Natural gas........... 65\%

Fue 1 oil............... 50\%

Gasoline/diese1 fue1..... 22\%

LP gas/propane.......... 25\%

Plants considering alternative energy supplies.......... 23\%

Fuel oil for natural gas

Convert to electricity

LP gas for natural gas

Back-up electric generation

Coal for natural gas

TABLE 2

\section{INDUSTRIAL ENERGY UTILIZATION \\ REGIONAL ENERGY SURVEY}

Plant manager rating of

plant energy efficiency:

Above average....... 26\%

Average........... 60\%

Plant manager rating of

building insulation effectiveness:

Below average......... 14\%

Above average....... $0 \%$

Average........... 76\%

Below average....... 24\%

P1ants implementing energy conservation actions.............. 73\%

Process heat recovery

Monitoring and control of lighting leve1s

Capacitors to correct power factors

Improved insulation

Improved process scheduling

Increased equipment maintenance

Increased rate of equipment replacement

Improved process design

Computerization to reduce peak loads

Plants planning energy conservation actions..................48\%

Plants in which energy use is increased

by environmental regulations..................... 48\%

Plant manager estimates of expected average annual increase

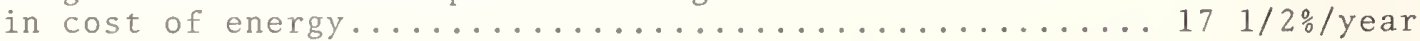

Source: Midwest Research Institute 
Our surveys show that the central energy problem faced by facility managers is a lack of information on which to base management decisions. Many plant managers and facility engineers have serious concerns about energy costs and energy security. But most concede that they are guessing at what energy shortages they will encounter - or what measures to take in the future.

They are receptive to energy conservation concepts because they foresee large increases in the cost of energy. But the conservation techniques which have real potential in the manufacturing and process industries require capital investment, - e.g., more energy-efficient process equipment, better fuel controls, material recovery and recycling systems. And better information concerning fuel regulation, distribution, and availability is necessary to facilitate the decision-making process:

The approach to energy problems taken by the firms with which we have worked follows no discernibly systematic pattern. Some do not believe they will be affected by future fuel shortages. Others have experienced shortages and are seriously concerned about energy economics and security. About 60 percent of the firms surveyed experienced fuel shortages during the past year. Three-fourths of the shortages were natural gas and the remainder were fuel oil. Some firms experienced curtailments of both fuels. Electrical outages due to severe weather were not tabulated.

Several firms experienced more than a dozen natural gas curtailments, with accumulated durations of up to 3 months.

Number 2 fuel oil and LP gas were the principal back-up fuels. Many firms which experienced natural gas shortages also expect shortages of their back-up fuels. A few firms had to use periods of natural gas curtailment to perform plant maintenance operations.

Most industries believe that shortages of natural gas, propane, and fue 1 oil will be widespread during the next 5 years. Nonetheless, many firms are adding to their LP gas and fuel oil storage capacity as a safeguard against natural gas curtailments. Some are converting entire

facilities from natural gas to fuel oil. A few firms have expressed interest in conversion to coal, perhaps by means of on-site gasification plants.

About one-fourth of the firms surveyed rate their facilities above average in efficiency of energy utilization.

Approximately half of the manufacturing and process firms surveyed attribute part of their increased energy demand to the need to conform to environmental standards at the plant level. Most believe that environmental regulations will have a future impact on their energy demand.

Industry appears to anticipate large increases in energy costs during the next 3 years -10 to 20 percent annual1y.

Anticipated industrial growth is expected to be reflected in increased energy demands. Some firms regard fuel shortages and costs to be serious constraints on near term growth.

We have categorized responses as energy conservation "actions" rather than "programs". None of the firms surveyed have initiated systematic fuel and energy management programs.

It is interesting to note that, although about three-fourths of the companies cited some current energy conservation action, less than half indicated that additional efforts were being planned. Coupled with the fact that only a small percentage rated their plants as below average in terms of energy efficiency, this might indicate that many firms believe they have their energy supply and utilization problems under control.

Only a very sma11 number of firms have indicated that they are attempting to improve process and equipment energy efficiency as a conservation measure. No firms stated that they are systematically attempting to identify areas of energy inefficiency.

One firm stated that it was replacing process equipment more frequently than in the past in order to increase energy efficiency. In some cases, such action could be counter to national conservation goals if energy use in production of the new equipment is considered.

Most energy conservation initiatives in industry involve space heating 
and lighting needs. They include improved insulation and access in plant buildings, use of waste heat for space heating and coordination of heating, air conditioning, and lighting with work schedules.

A wide variety of energy conservation methods were reported by the firms surveyed. They included:

Use outdoor air for cooling whenever possible.

Set thermostats near minimum and maximum operating temperatures of equipment.

Turn off unused equipment and lighting.

Organize work schedules for minimum travel and reduced travel frequency.

Encourage carpools among employees.

Use capacitors for power factor control.

Increase insulation thickness in existing facilities.

Plan improved insulation systems for new facilities.

Recover waste heat from power generation or process heat for use in space heating.

Equip steam generators with economizers.

Improve control of fuel nozzles and injection systems.

Reduce fuel leaks and spillage through improved maintenance.

Refine maintenance efforts to avoid decreases in energy efficiency of equipment.

Re-evaluate illumination levels necessary for operation and reduce where allowable.

Reduce size and horsepower of company-operated passenger vehicles.

Provide air locks for building entrances.

Periodically check heating units for combustion efficiency.

We also asked the firms surveyed to suggest governmental action which would help alleviate the problems of energy supply and demand faced by industry. The responses included very little reference to energy conservation programs. No mention was made of federal, state, or local incentives to encourage conservation or otherwise reduce demand. A few firms

recommended that energy conservation be encouraged in non-industrial sectors. Most responses indicated that energy problems in industry can be solved by action in other sectors of the economy - action not under the control of the private sector.

It is also useful to note that no responses suggested governmental incentives to encourage the development of more energy efficient processes and the replacement of old, less efficient processes. Tax incentives to encourage capital investment for equipment or process upgrading would be an example.

To summarize the interim survey results:

Many firms have experienced fuel shortages in the recent past. The economic impact of such shortages has depended on the availability of backup fuels.

Most firms expect shortages of either primary or back-up fuels, or both, during the next few years and anticipate large increases in energy costs. Most firms believe that, on an individual basis, they are adequately addressing plant energy problems, but they have not initiated systematic energy management and planning programs. Energy conservation actions are few but, where taken, have proven to be of significant economic value.

Interim Guidelines for Energy Management

It is, of course, not feasible to set down criteria for developing energy management policy which are equally applicable to all industry situations. Two major factors prevent this. The first is the obvious fact that energy consumption patterns differ markedly from industry-to-industry and from plant-to-plant within an industry. Secondly, supply and distributjon of energy is regionally dependent. The latter consideration is frequently overlooked, but availability of fuels in the U. S. depends strongly on geography, particularly under conditions in which supply and demand imbalances exist. 
Nonetheless, it is useful to delineate guidelines for the development of energy policy. In some cases, such guidelines can be an important element in energy management and, even in the least applicable cases, can be a check list of some utility.

The obvious shortcoming of these guidelines is a lack of specificity. They can be justly criticized on the grounds that they don't address the detailed problems faced by individual plant managers. They do not outline methods to improve the energy efficiency of specific saving actions. And, as yet, they are far from constituting a cookbook for the development of plant energy policy.

Not much has been done to identify the energy conservation potential of efforts to upgrade the efficiency of specific equipment. We need systematic evaluation of what can be done to improve efficiency - detailed information such as: Energy consumption of process A can be reduced by $X$ percent if modifications 1,2 , and 3 are made. This is a big, but not unrealistic, task.

The following is a first attempt to outline steps in the development of industrial energy management policies. It combines items suggested by many analysts of energy technology and energy economics. By its very nature it solicits modifications, extensions, and refinements.

1. Designate a corporate team to investigate energy problems and formulate an energy management policy for each facility. The individuals responsible for energy management at each major facility should serve on this team. It should also have representation from the corporate management and planning staff and the engineering department. It should be vested with authority adequate to investigate prevailing energy supply and demand situations and to implement policy recommendations. The tasks of the energy policy team should be assigned a priority consistent with the current or potential importance of energy problems in the company operation. The team should inventory talents within the firm which could contribute to the analysis and utilize those talents.

2. The energy policy team should specify the need for such a policy and the objectives of the team's efforts. It should examine available corporate energy-related data and prepare a report which outlines the overall energy status of the company. This should serve as baseline information.

3. The need for expert counsel or assistance from outside the company should be determined early in the planning effort. If such assistance is advisable, it should be obtained sufficiently early to contribute to the project planning tasks.

4. A thorough inventory of energy supply and use throughout the firm should be developed. In most cases, this task will require considerable effort. It should result in a detailed description of how energy is obtained and used in each facility, with information down to the level of specific processes and equipment. It should catalog energy suppliers and tabulate historical data concerning energy supply and price trends. Fuel and energy cost data should be compiled as a basis for future monitoring of the cost impact of energy actions. An inventory of fuel storage capabilities and back-up fuel supplies should be included. This effort should generate a data base for energy policy development.

5. One member of the team or a consultant should be assigned the task of analyzing regional energy supply, distribution, and consumption

characteristics. The objective should be to identify trends which will affect the availability of fuels and energy to the company, such as:

consumption trends of other firms, industries, or economic sectors which could compete for the same fuel supplies,

national issues which impact on the availability of fuels or the distribution of fuels to different regions (e.g., importing crude oil),

economic trends of the region which could effect energy availability, and

environmental regulations affecting fuel use. 
6. An analysis of energy and fuel curtailments should be conducted. This should consist of case history evaluation of past fuel shortages and power outages with the view toward identifying predictors for such events. For example, have natural gas curtailments been preceded by consistent weather patterns as characterized in terms of degree-days? Assistance should be solicited from energy suppliers in this task.

7. Systematic "energy inspections" of all facilities should be conducted. These are intended to identify specific areas of energy inefficiency and potential for energy conservation. The inspections should be preceded by the development of checklists to help the inspector identify energy-sensitive areas. Each firm, or at least each industry, will probably find it necessary to develop custom-fitted checklists which recognize particular energy use characteristics of the industry. Inspectors should try to spot wasteful practices. Often a list of methods to save energy can help identify areas where wasteful practices prevail. For example, the knowledge that automatic controls can be used to increase combustion efficiency keeps the inspector alert for poor combustion control. The energy inspection should also serve to find operations where loss of energy would be critical, identify processes where back-up fuels could be used, and, in general, develop a comprehensive picture of the energy efficiency of the operating facilities. The inspection should include office, warehouse, and other facilities in addition to the process or manufacturing plants. An inspection report should be filed for each site.

8. An examination should be made of such items as work and production schedules, vehicle fleet operation, staff travel, and other activities which constitute areas for potential energy savings. Recommendations should be developed.

9. A review of new technology related to the principal equipment or processes used by the company should be carried out. The objective should be to identify technical improvements which can upgrade energy efficiency. The results should be correlated with the output of Steps 4 and 7 .

10. Maintenance and equipment replacement schedules should be examined to determine their impact on energy efficiency. Recommendations should be made.

11. A study of the tangible and intangible costs associated with fuel or power shortages should be made. This should include the loss of production and service, the costs of plant shutdown, the risk of customer dissatisfaction, factors related to labor agreements, long-term impact on growth, and numerous other considerations. The objective of this analysis is to develop guidelines which, with the cost data from Step 4 , can be used to evaluate the cost-effectiveness of energy actions.

12. The energy project team should utilize the output of the steps listed above to develop recommendations for energy-related actions. The recommendations should be classified as directed at energy economy or energy security. This is obviously a crucial task, and the effectiveness with which it is carried out depends on the thoroughness of the preceding efforts. The project team should now have a comprehensive understanding of the role energy plays in the company, the areas where energy savings can be achieved, the actions necessary to achieve those savings, the cost benefits of the savings, the areas in which the energy security of a plant can be reinforced, the problems encountered in obtaining fuels and energy, and many other items. Formulation of the recommendations should draw upon as many elements of company operation as possible. An important part of this task is to develop methods by which the recommendations can be implemented. A formal report should be prepared which summarizes the project activities, compiles company energy data, and presents the recommendations and the implementation strategies. The latter two items - the recommendations and implementation strategies - should be presented as a series of recommended corporate energy management policies. The recommendations should include methodology for the continued evaluation of the effectiveness of the policies and the modification of the policies to improve effectiveness. 
What I have outlined here is a major undertaking in operations analysis. The effort devoted to each step and the detail in which the recommendations are presented depend on someone's judgement concerning the importance of energy to company operation. As I pointed out earlier, there is no need to undertake such a study unless you are confident that it will lead to recommendations which will save more money than they will require to develop and implement.

I want to repeat that these suggestions are interim ones. They result from partial studies, and it should be clear that they will evolve into something more specific as more definitive information is compiled. By early next year we hope to have gone through the steps outlined above for a number of actual cases. We also hope to investigate the potential for improving the energy efficiency of several specific industrial processes. In the meantime I solicit your suggestions and encourage you to point out errors of commission or omission in the development of these strategies.

Q. In regard to your last comments to make sure that the pay-off is there: from your list of recommendations, do you have any criteria to indicate how you would actually proceed with such an analysis?

A. I think, really, you have to go through some of these steps before you have available the type of planning information on which to base those very crucial judgements.

Q. Let's say you get down to the point where you know the thermal load and the amount of electricity required. Do you have any criteria at that point?

A. I don't have any to suggest; I'm sure that on a more individual basis, people who have worked with this in the plant probably do have some which have worked for them. 



\title{
CASE HISTORIES OF EFFECTIVE ENERGY UTILIZATION IN INDUSTRY
}

\author{
by \\ William Rudoy \\ University of Pittsburgh \\ Department of Mechanical Engineering \\ Pittsburgh, Pennsylvania 15261
}

\begin{abstract}
Energy conservation through effective energy utilization falls into three classes: better "housekeeping" or energy management of present systems; application of present off-the-shelf technology to existing systems; and revision of existing systems to provide the same objective with less energy. Three general components enter into any implementation of energy conservation - technology, economics, and people. There is a great deal of off-the-shelf technology that could be employed and case studies are presented showing significant gains in energy conservation in the area of comfort conditioning of the industrial environment. In most cases, the rule-of-thumb economic payback period of two years for revising a system is not met. The decision to move toward more efficient utilization, even when the other two components are favorable, is often influenced by the attitudes of key personnel.
\end{abstract}

Key words: Attitudes; conservation; energy; industrial; systems

How much we can reduce our present energy consumption through effective energy utilization falls into three general classes:

1. Better "housekeeping" or energy management of present systems .

2. Application of present off-the-shelf technology to existing systems .

3. Revision of the existing systems to provide the same objective with less energy .

Even though we may be working towards breakthroughs with new systems in the third category, we can be implementing the first two now. An order of savings of fifteen to twentyfive percent seems to be a reasonable expectation as indicated in the following case histories of western Pennsylvania installations.

We should be looking for three general components of implementing energy conservation: 1) technology, 2) economics, and 3) a people factor.

In most of these cases, the rule-of-thumb economic payback period of two years used by financial people for revising a system was not met. Other considerations usually forced the decision that brought about the more efficient utilization.

Industry uses energy either in the manufacturing process or to provide a proper working environment. It is necessary to understand what makes a working environment acceptable to people. A more complete analysis of all the factors may be found in the literature, for example in Fanger's book on Thermal Comfort, in the 1972 ASHRAE Handbook of Fundamentals, Chapter 7 on Physiological Principles, or in an article by Dr. P. E. MeNall in the June/July 1973 issue of Building Systems Design. For our discussion today, let us consider only those factors relating directly to thermal comfort by the environment. A simplified analysis would show the human body as a heat engine which converts energy to work; the second law of thermodynamics requiles that heat be rejected. Therefore, for thermal comfort, we require a controlled net cooling process. never heating of the body. Whenever the cooling rate exceeds that which is comfortable, we seek to reduce the cooling rate, usually by space heating (which is only one of many possible solutions to reduce the cooling).

How does the body reject heat? Analyzing this will permit us to find alternate solutions. perhaps with lower energy requirements. The transfer of heat and mass (evaporation of water) from the body is determined by surrounding air conditions such as 1) temperature, 2) humidity. and 3) motion, and enclosing surface temperatures and radiation conditions such as 1) walls, 


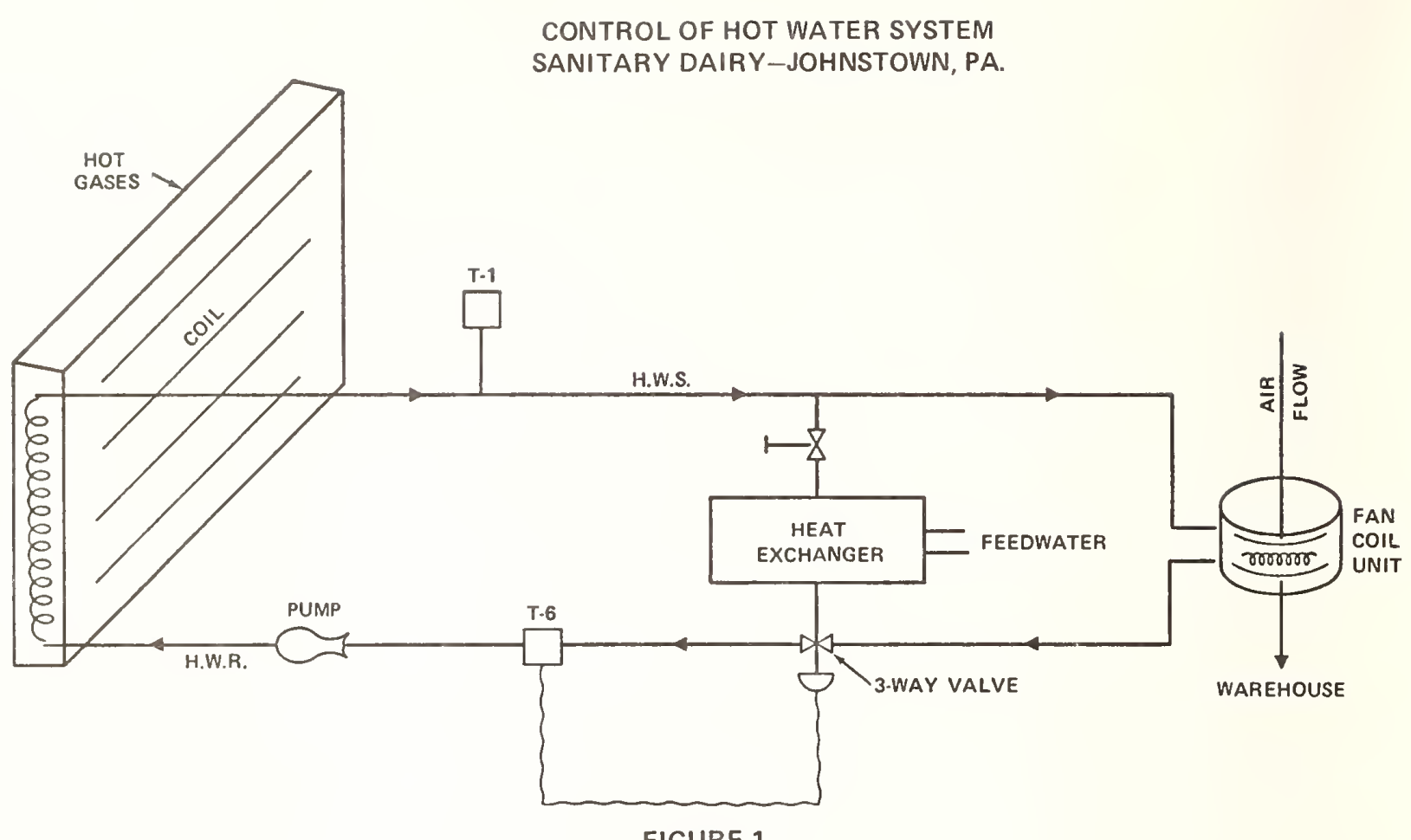

FIGURE 1

COIL AND BY-PASS INSTALLATIGN

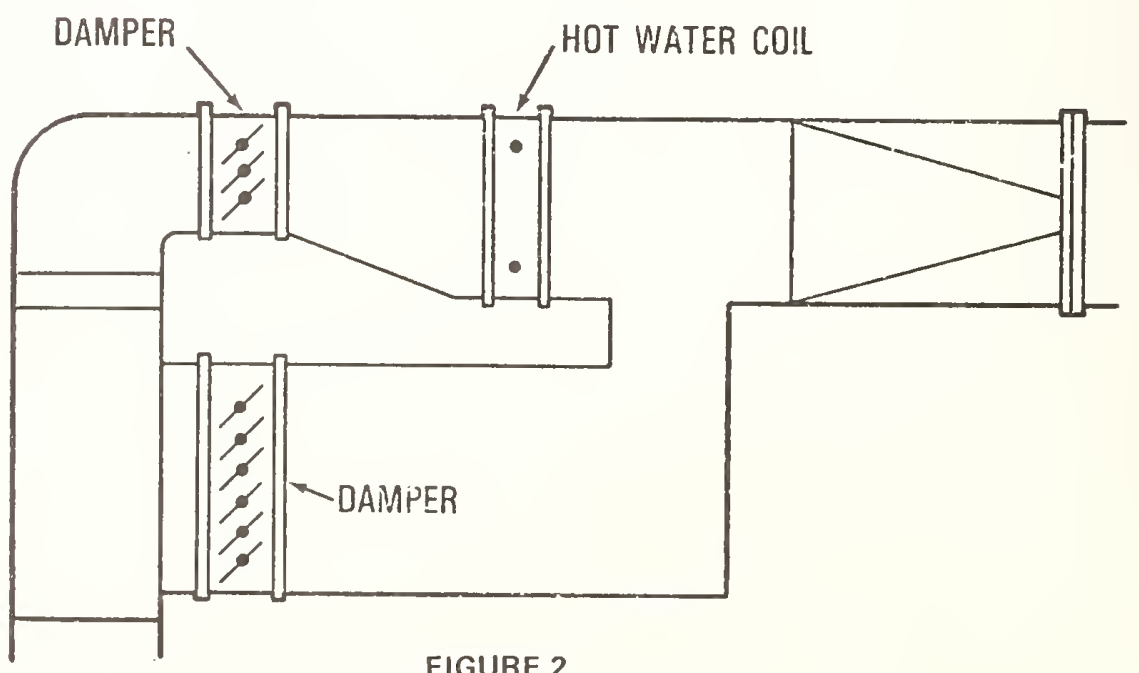

FIGURE 2 
2) ceiling, 3) floor, and 4) glass.

A combination of all these conditions determine the net rate of heat loss from the body.

For example, in a situation with a relatively low mean radiant surface temperature enclosing the body, it might be necessary to maintain an offsetting air temperature of $80^{\circ} \mathrm{F}$ or more for any degree of comfort. By offsetting the radiant heat loss by some sort of radiant heat directly to the body, the air temperature which would be required might be reduced to $70^{\circ} \mathrm{F}$ or lower. A simplified calculation of the yearly energy requirements for space heating for a building, based on the degree day method, would indicate an approximate savings of $25^{\circ}$ following a reduction of $8^{\circ} \mathrm{F}$ in the space temperature.

Is this the case in actual installations? Infrared space heating applications probably are the best examples of this kind of application. In the case of one locomotive repair shop, a number of changes were made, the major one being the replacement of a space heating system using steam coils with gas as the fuel with a system using gas-fired infrared heaters. Previous to the change the lowest gas consumption was $4220 \mathrm{MCF}$ (thousand cubic feet) per year. For the year 1972-1973, the gas consumption for the infrared heaters was $2930 \mathrm{MCF}$, a reduction of approximately 30 percent. Also, better comfort conditions were achieved.

Three other infrared case histories are shown below:

\section{Application}

Production Area-Toy Manufacturer Electrical Supply Shop

Auto Parts Warehouse

\section{Fuel Reduction}

The switch from unit heaters to a closed combustion infrared system by the toy manufacturer was not to conserve energy but to eliminate material problems with the interchanger on the unit heaters. The auto parts warehouse converted because of lack of comfort with unit heaters, not because of the savings which accrued. The impression one gains is that, more often than not, the system that best fits the real objective also brings along with it a better energy utilization.

Next, let us move on to some other applications. A dairy in the process of expanding its production and warehouse facilities was faced with the problem of maintaining a minimum temperature of approximately $65 \mathrm{~F}$ in the planned $13,000 \mathrm{sq}$. ft. warehouse. Gas had been the fuel energy of the plant and additional gas was unavailable. In the process of studying other energy sources and systems, the management of the dairy, in conjunction with the gas company representative, looked at the possibility of using the waste heat from the process steam boilers. The flue gas temperature in the stack was approximately $500^{\circ} \mathrm{F}$ and the boiler load was high enough that the waste heat represented more than three times the heat required for space heating in the new warehouse. A check on the gas consumption of the boiler showed a profile that made heat recovery possible when the thermal mass of the warehouse was included so as to average out the low use periods. Also, the relatively loose requirement as to the swing in space temperature in a warehouse made heat recovery feasible without additional thermal storage.

Since the initial study indicated the feasibility of such a system, it was decided to have a consulting engineer design a system for bids. The schematic layout is shown in Figure 1. Standard hot water forced-convection heaters were used for the warehouse space heating. The hot water is supplied by a standard finned tube coil placed in the boiler stack. The physical layout of the coil and stack is shown in Figure 2. In this particular design a bypass was inserted. since the heating system was not designed to accept all the heat that was available at the high firing rates of the boiler.

An additional advantage was obtained in this application with the process steam boilers Since practically all the process steam was used throughout the plant with no provision for condensate returns to the boiler, makeup water was supplied at a temperature of from $40^{\circ} \mathrm{F}$ to $60^{\circ} \mathrm{F}$. Therefore, a parallel heat exchanger was added to preheat the makeup feedwater when space heating was not required by the warehouse. This indicated that the dairy would be able to heat the new 13,000 square foot warehouse and to use less gas than previously. The complete system has been operating for over a year and the results confirm the estimates.

While this application seems to be an ideal case for efficient energy utilization, there are other aspects that should be analyzed. The people factor was quite interesting. Although the president of the dairy was an enthusiastic backer of the heat recovery system, the stationary engineer who was in charge of the boiler room and refrigeration facilities was somewhat less so. Since he was within two years of retirement, he wanted the least amount of change or disruption to his routine. Whenever the plans were discussed or contractors were on the job, he managed to be busy somewhere else. The installation, of course, eventually went in, but the normal "bugs" that arise when getting a system to operate properly had to be eliminated without the aid of the man who properly could be expected to be most helpful. The purpose in discussing this aspect is to 
point out that rarely can energy conservation or any other system be implemented by technology or economics alone. In this relatively simple case, management, plant operatirg personnel, a consulting engineer, contractors, and utility representatives, all had to combine to produce the desired results.

Coincidentally, a few months after the heat recovery system of the dairy was in operation, a die-casting shop was faced with almost the same problem of heating a similarly-sized new warehouse. Among the sources of waste heat available was a cooling water circuit for the die-casting machines of $800 \mathrm{GPM}$ with water leaving the plant for cooling towers at $93^{\circ} \mathrm{F}$ and returning at $82^{\circ} \mathrm{F}$. This represents a source of over 4 million BTU/HR. The estimated peak requirement for a $65^{\circ} \mathrm{F}$ warehouse was $1 / 2$ million BTU/HR. The operation of the plant is almost continuous through the week and throughout the year. A tentative design was developed and the equipment selection from standard-type hot water coils was made directly from manufacturer's data. In this case, however, a different manufacturer's representative created doubt in the plant engineer's mind, since the standard catalog for heating units did not show any ratings below a water temperature of $160^{\circ} \mathrm{F}$. Since the plant engineer would have to shoulder all responsibility for any system that went in, this additional doubt helped force a decision to go with the more usual fuel burning unit heater, oil in this application. Although no technological breakthroughs were required for this heat recovery system and all principles (heat transfer and thermodynamics) were simple, the application was rejected because of the novel approach with off-the-shelf technology.

Another area where energy use efficiency can be improved is that related to industrial furnaces and industrial combustion systems. Cheap energy of the recent past has permitted inefficient combustion systems to go unnoticed. The management of one refractory plant was so shocked by the estimated fuel inefficiency based on the results of a combustion analysis of their ovens that they invested $\$ 45,000$ into burner replacement, gas meters, and combustion analysis equipment. Now they are making regular in-plant checks on the combustion process. In addition they are using some of the waste heat from the ovens for space heating in another plant. They are also contemplating the use of the rejected heat from the after cooler of a large air compressor for space heating also.

The other source of significant reductions in energy consumption is the exhaust gases from industrial furnaces. Many such furnaces operate at temperatures over $2000^{\circ} \mathrm{F}$. Using the exhaust gases to preheat the combustion air through heat exchangers called recuperators can reduce fuel consumption by 20 to 25 percent. These devices have been standard equipment in most countries with high energy costs. For example, one German engineer who came to work in the United States about 10 years ago for a manufacturer of recuperators couldn't believe the energy that was being wasted. The rush to investigate the possibilities of energy savings has only recently begun and is now swamping the manufacturers of recuperators, but present-day economics generally show payback periods longer than two years. Therefore, many possible installations are not going ahead if the only motivation is the old economic guideline.

One recuperator installation that did go in was applied to a rotary forge furnace in December, 1968. This was an experimental installation to test the validity of the savings and the operation. Data were collected over a two week period before the recuperator was installed. Gas consumption and work were recorded. The same data were recorded after the system was revised and was operating properly with the recuperator. The savings ranged between 18 and 20 percent. It was estimated that better scheduling of the work would increase this savings. In addition to this saving for the same work, there was an additional energy reduction during idle time. Since the furnace could respond much faster, the idle temperature was reduced from $2400^{\circ} \mathrm{F}$ to $1400^{\circ} \mathrm{F}$ during lulls in the working day and from $2200 \mathrm{~F}$ to $1300 \mathrm{~F}$ during weekend idling. When the furnace is started up after any shutdown, the working temperature of $2400^{\circ} \mathrm{F}$ can be obtained in less than an hour, compared to several hours for operation without the recuperator preheating the combustion aix. It was estimated that an additional reduction of 10 to 15 percent is possible due to the reduction in temperature during idle time. This of course, depends on the amount of idle time as a percent of total work time.

Other indirect benefits accrued to this application through better product quality as a result of better control of temperature and excess air.

The installation of the recuperator required a period of adjustment on the part of the operators as well. The educational, or re-educational, process during this time period must have contributed to the increase in product quality as well as to the reduced energy consumption. These same results have been observed following the installation of other recuperators. One plant manager puts it this way, "Just watching a furnace improves its efficiency", referring to the attention paid to any component by management.

Another plant manager of a medium sized steel product plant commented on obtaining a 20 percent reduction in fuel use. He first directed the energy problem facing his plant, and its possible effect on plant operations and employment, to the attention of his plant employees. He 
then required that all fuel meters be recorded daily and the results be on his desk each morning . He isn't quite sure what happened, but the fuel consumption rate decreased. This points up one of the important factors present in almost every effective energy utilization case history, that of measurement.

Before summarizing our conclusions regarding the case histories, I want to show how these energy saving programs were initiated. Almost all of the cases cited here came about as a result of a formal energy conservation program instituted in 1971 by the Peoples Natural Gas Company of Western Pennsylvania. Seven industrial development men backed by a central staff of three specialists have been making surveys of their regular industrial customers. These surveys are of two kinds: one is a combustion analysis of gas burning equipment and the other is a plant survey for possibilities of energy conservation, particularly seeking out heat recovery possibilities. Energy conservation awards in the form of appropriately inscribed wall plaques are used to recognize outstanding achievement in energy conservation systems or ideas for energy conservation. The spin-off from these awards has been extremely successful in motivating additional efforts. For example, an award to onesmall plant of Westinghouse Electric Corporation may have aided in initiating a company-wide program, including prizes for the best suggestions. An award to one consulting engineer has caused others to recognize the possibilities in designing energy conservation systems. The skepticism that some of us have for awards is soon dispelled by the reactions of those who receive them, and even more so by the reactions of some who believe they should receive an award and feel left out! utilization:

In summary, we can make these observations from the case histories of effective energy

1. Awareness of the energy dilemma is present and there is receptiveness to energy conservation methods.

2. The application of well-established basic principles and off-the-shelf present technology can show appreciable energy reductions in the range of 20 percent in many cases.

3. Recognition of the specific possibilities of energy conservation needs to be developed on a much wider basis among: 1) plant engineers, 2) management, 3) consultants, and 4) manufacturers representatives.

4. The present guidelines for capital expenditures on energy conservation systems may restrict implementation. The validity of these guidelines should be examined.

5. A positive well-planned energy conservation program with specific manpower responsibilities can show definite results.

While energy conservation is not the cure-all to our energy headache, it does provide us with the opportunity to put good engineering in practice. This, after all, is what we should be doing with or without an energy dilemma. 

IV. A P P L I C A T ON S OF THERMAL $P$ R O C ES S T ECH NOLOGY 


\title{
A PROJECTION OF ENERGY DEMAND BY
} THE IRON AND STEEL INDUSTRY

\author{
by \\ D. Larson \\ Manager, Applied Combustion Research \\ Institute of Gas Technology \\ 3824 South State Street \\ Chicago, Illinois 60616
}

\begin{abstract}
The iron and steel industry is not only one of the larger consumers of energy $(7.5 \%$ of the total U.S. energy use in 1968), but is also a very complex industry. The interrelationships between projected demand for products and the amounts of fuels needed for manufacturing the products are difcussed as we11 as the trends that could change the amounts of fuels needed per unit of product. Conclusions drawn are that there should be a $65 \%$ increase in production and a $28 \%$ increase in energy consumption in the industry between 1971 and 1985. The growth rate of energy consumption decreases with time and should almost level off by 1985. The change in energy requirements per ton of finished product is primarily the result of technological changes. Therefore, trends that phase out obsolete inefficient equipment can accelerate this energy utilization efficiency. Most of the improved efficiency is expected in the ironmaking and steel-making processes and very little change is forecast in the reheating and finishing portion of the industry.
\end{abstract}

Key words: Energy; forecast; industry; iron; steel

Introduction

Numerous projections of future energy consumption recently have been prepared to assess our country's energy situation. A11 these projections have been based on growth statistics of the residential, commercial, and industrial energy demand coupled with many other factors, such as population growth. The number of variables that have been included differs from study to study, but none of the studies has individually analyzed all the "fine structure" of the energy-consuming sectors and the technological reasons for the demand. This is understandable because this approach would require a great deal of research and information analysis over a long period.

However, work is now under way that will add detail to earlier studies and that may act as the basis for future modifications. As one example of the work that is now going on, the iron and steel industry is discussed in this section. The iron and steel industry is a major energy consumer in the industrial sector. It also is one of the most complex industries; that is, it uses all forms of energy and it manufactures substantial amounts of in-house fuels in the form of coke-oven and blast-furnace gases. The following discussion considers 1) the interrelationships between the projected demand for the products and the amounts of fuels needed for manufacturing the products and 2) the trends that could change the amount of fuels needed per unit of product. However, the study has made no assumptions about the availability of fuels and fuel switching that might occur because of fuel scarcity. 
FIGURE 1 PROJECTION OF DEMAND FOR ALL PURCHASED

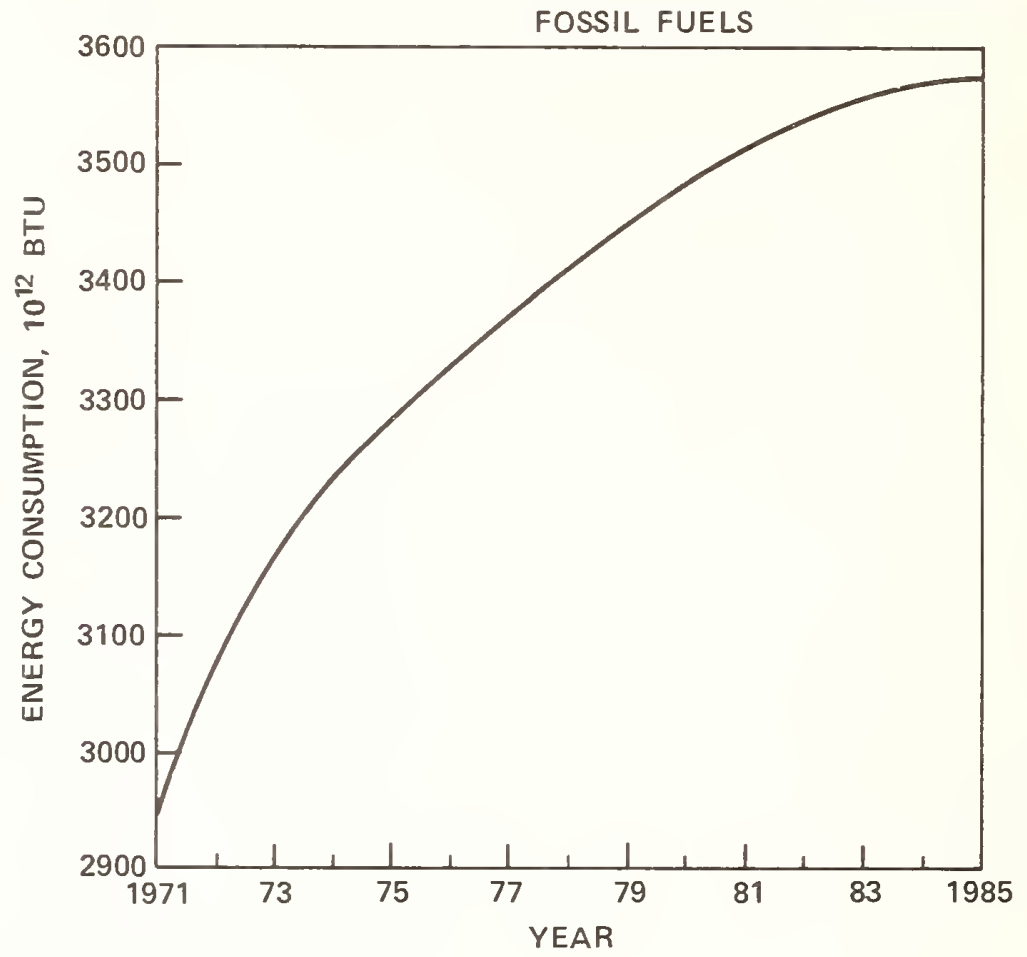

FIGURE 2 PROJECTED INCREASE OF ORE DEMAND AND

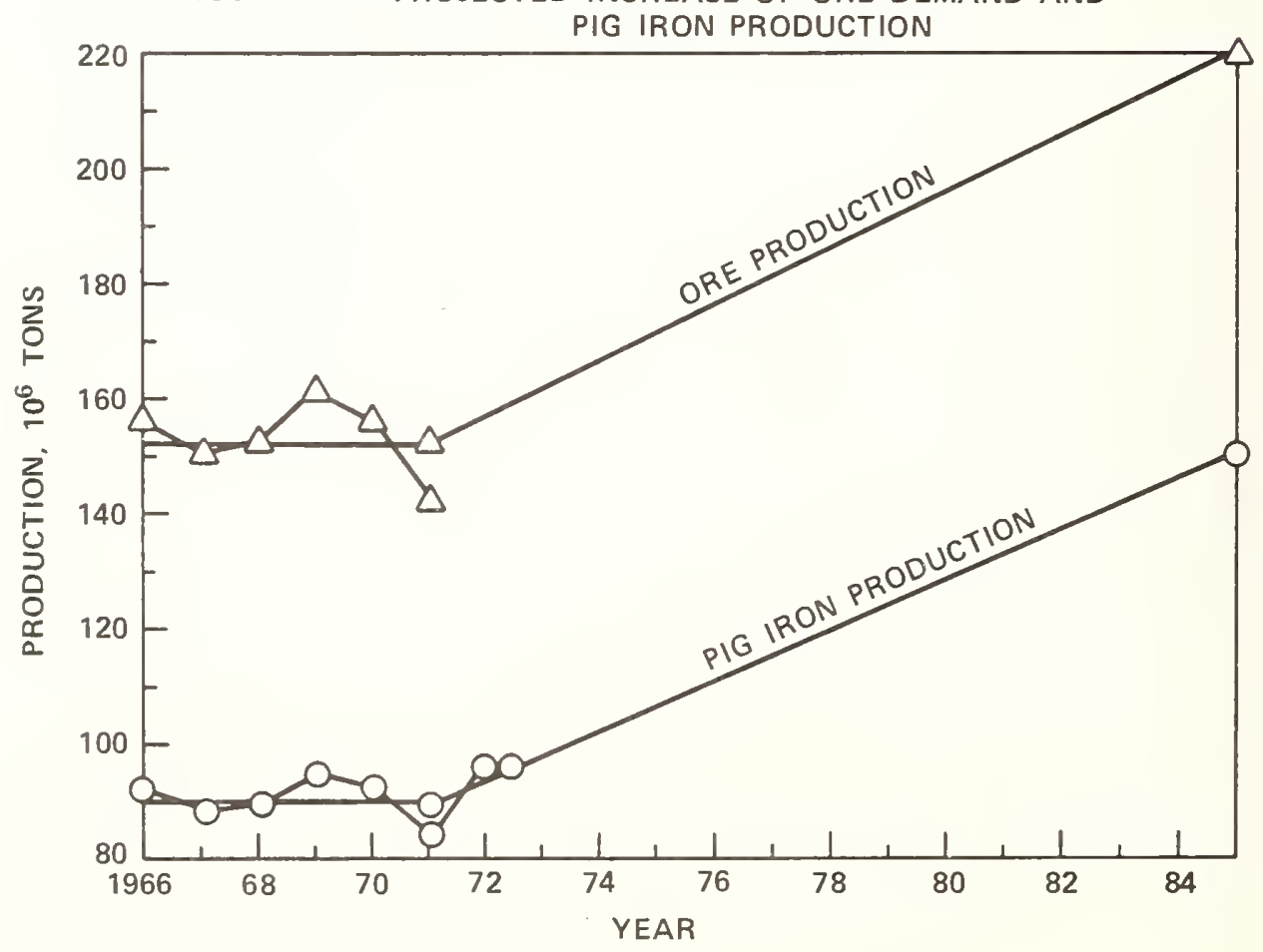


The only assumptions that are made are that 1) natural gas and fuel oil are generally interchangeable, except where the process being considered can operate on only one type of fuel, 2) coking coal is not interchangeable with boiler-grade coal, and 3 ) the use of j.n-house manufactured gases between processes will continue at the same ratio as at present. This last assumption is based on the technical and economic considerations that originally dictated the use of in-plant gases and the large expense that must be incurred if the type of fuel is changed.

Summary of Results

The energy used in blast furnaces, basic steelmaking processes, and various reheating operations, which include rolling and finishing, amount to more than $18 \%$ of the total energy consumed by all industry in the U. S. In 1971, this amounted to approximately 2950 trillion BTU. (Actually, this figure is about 250 trillion BTU low at all time periods because it excludes fuels used for processing imported iron and steel). This energy was consumed as fuel oil, tar and pitch, natural gas, coke-oven gas, blastfurnace gas, and coal. By 1985, steel production is expected to increase to 200 million tons/year and energy consumption is expected to reach 3574 trillion BTU/year, as shown in Figure 1. This figure does not include fossil fuels used by other industries to make electric power or oxygen which is used by the steel industry. This is a $65 \%$ increase in production and a 28\% increase in energy consumption between 1971 and 1985 .

Interestingly, the growth rate of energy consumption decreases with time and appears to almost level off about 1985. However, the projected growth rate in production increases almost linearly to 1985 , as shown in Figure 2 .

The ratio of data from both figures indicates that the total energy required to make 1 ton of finished steel will decrease from about 24 million BTU in 1971 to 19 million BTU by 1985.

This change in energy requirements per ton of finished product is the result of technological changes more than any other factor: trends that phase out obsolete inefficient equipment, process changes that allow greater steel production by using oxygen rather than fossil fuel, and changes in blast-furnace operation that reduce coking rates. A summary of fuel usage by process in 1973 and 1985 is presented in Table 1.

Effects of Technological Change

The projection of future energy consumption by the iron and steel industry is based only on existing technology and established trends for increased use of this technology. Many new developments are being researched in the laboratories of industry; however, these developments are not far enough advanced to have a significant impact on the steel industry's energy consumption by 1985.

The most significant changes in energy consumption by this industrial sector will occur in the ironmaking and steelmaking processes. Very little change is forecast in the reheating and finishing portion of the industry.

In ironmaking, the most significant factor will be the decrease in coke rates to the blast furnace. By 1985, coke rates are projected to be approximately 0.5 ton/ton of pig iron, a reduction of about $20 \%$ from current practice. However, this change will produce a significant reduction in coke-oven and blast-furnace gases, and this will increase the demand for other fuels, such as oil and natural gas.

In steelmaking, the most significant factor in the reduction of total energy consumption will be the phasing out of the open-hearth process and its replacement with the basic oxygen furnace (BOF) process. Other changes worthy of consideration are hydrocarbon injection to increase blast-furnace production, oxygen injection into blast furnaces, and increased use of pelletized ore rather than sintered ore.

Effect of Changing Ore Treatment Method The production of sintered ore has been decreasing steadily for the 


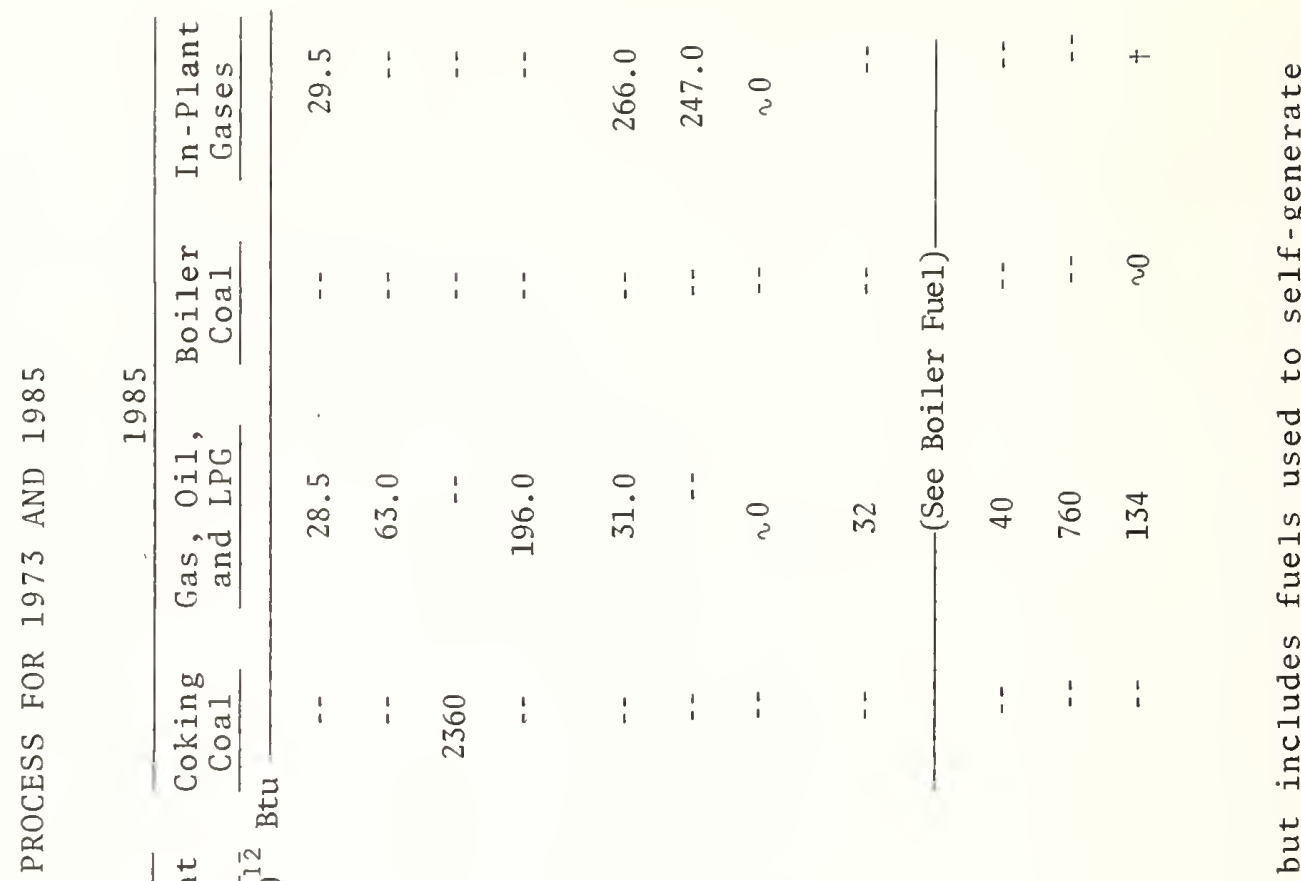

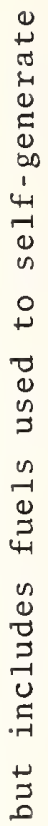

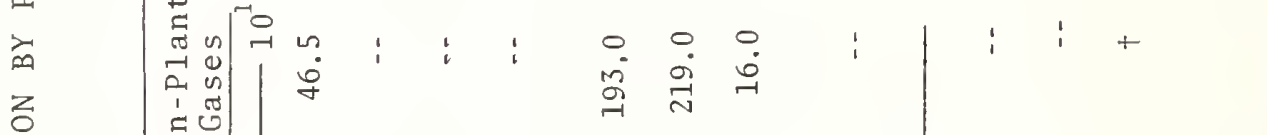

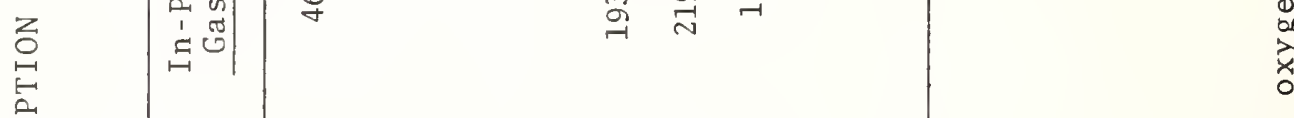

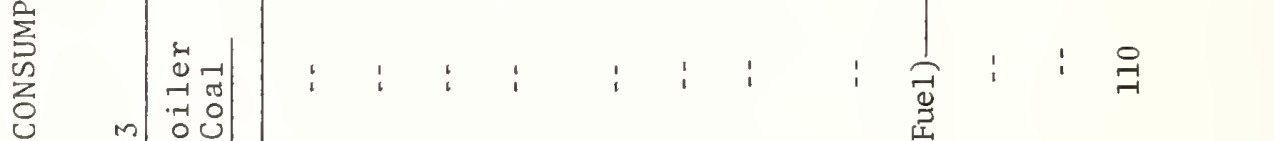

它

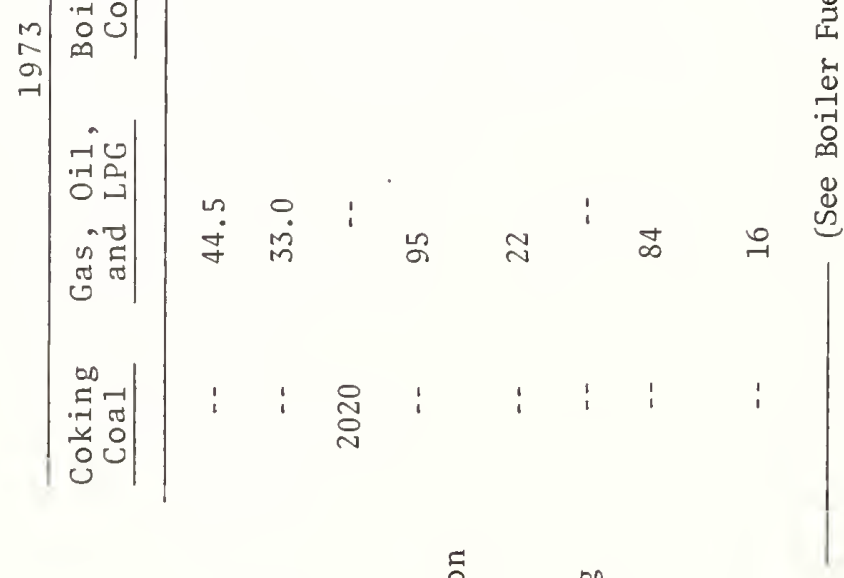

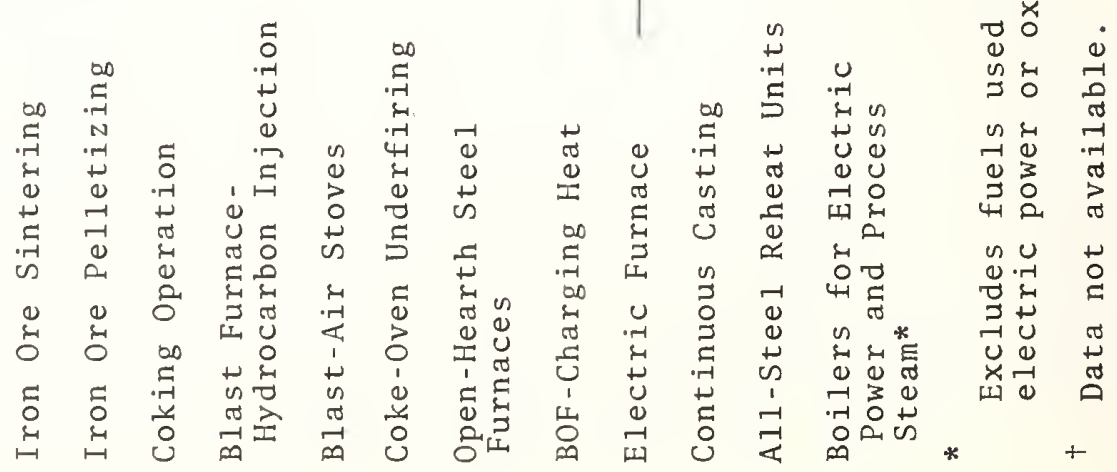




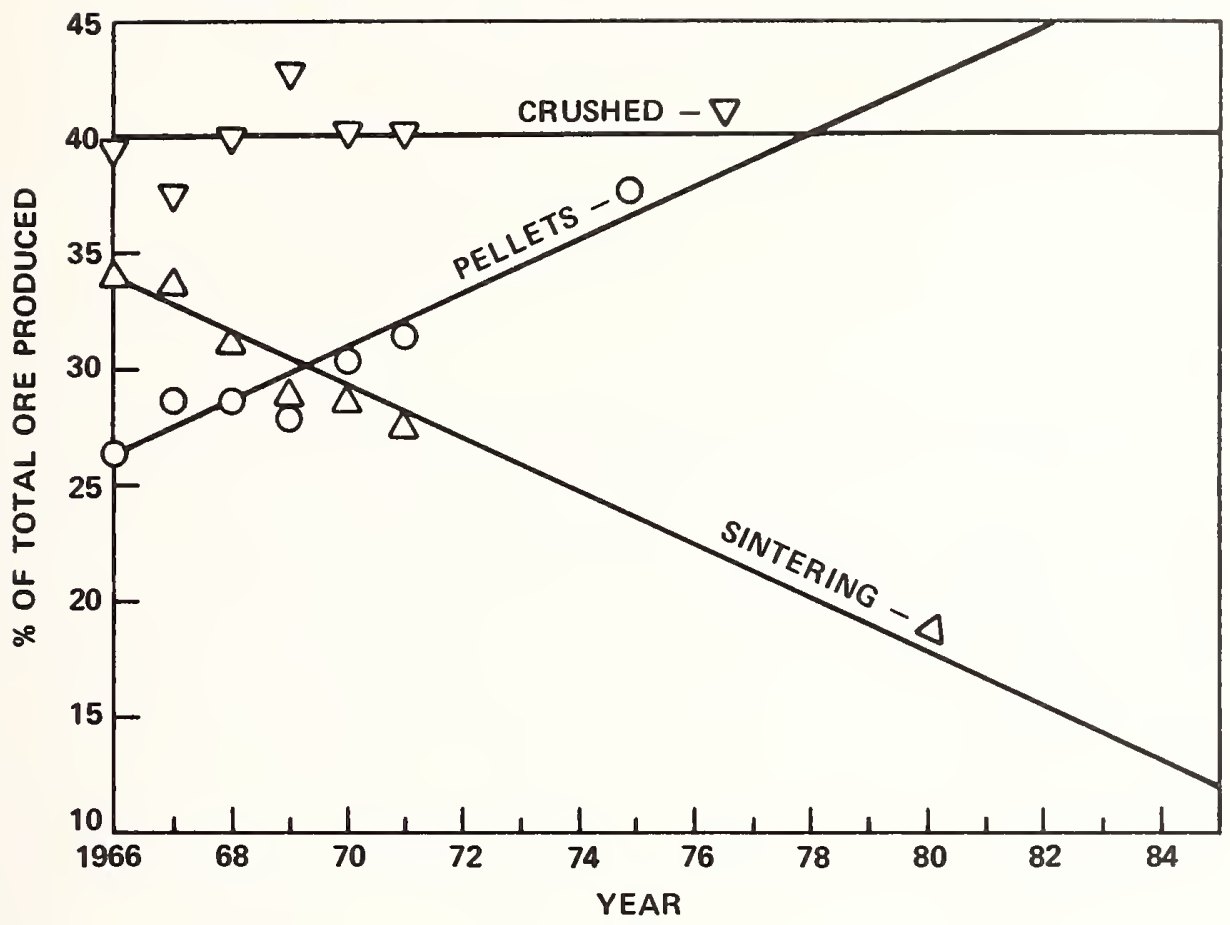

FIGURE 4 PROJECTED ANNUAL IRON ORE PRODUCTION BY VARIOUS TREATMENT METHODS

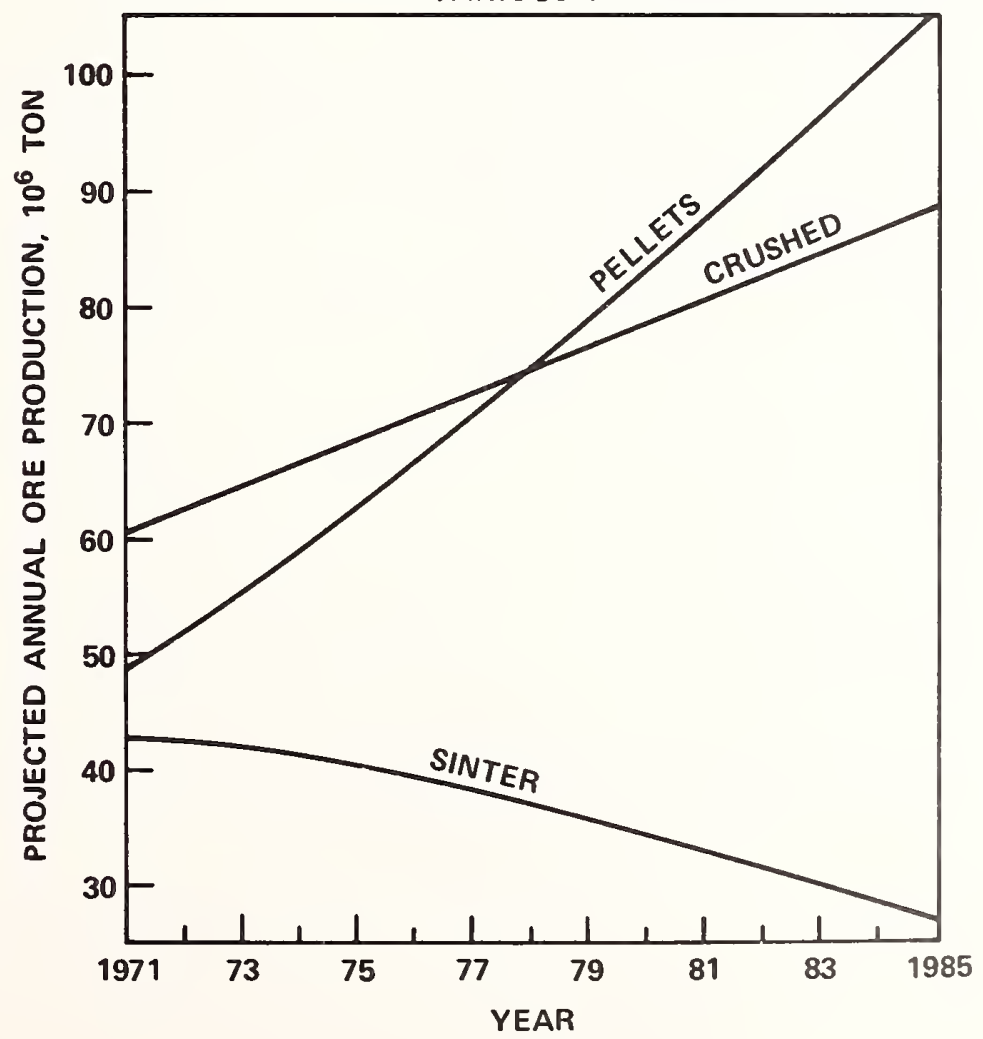


FIGURE 5 PROJECTED CONSUMPTION OF FUELS FOR IRON ORE SINTERING AND PELLETIZING

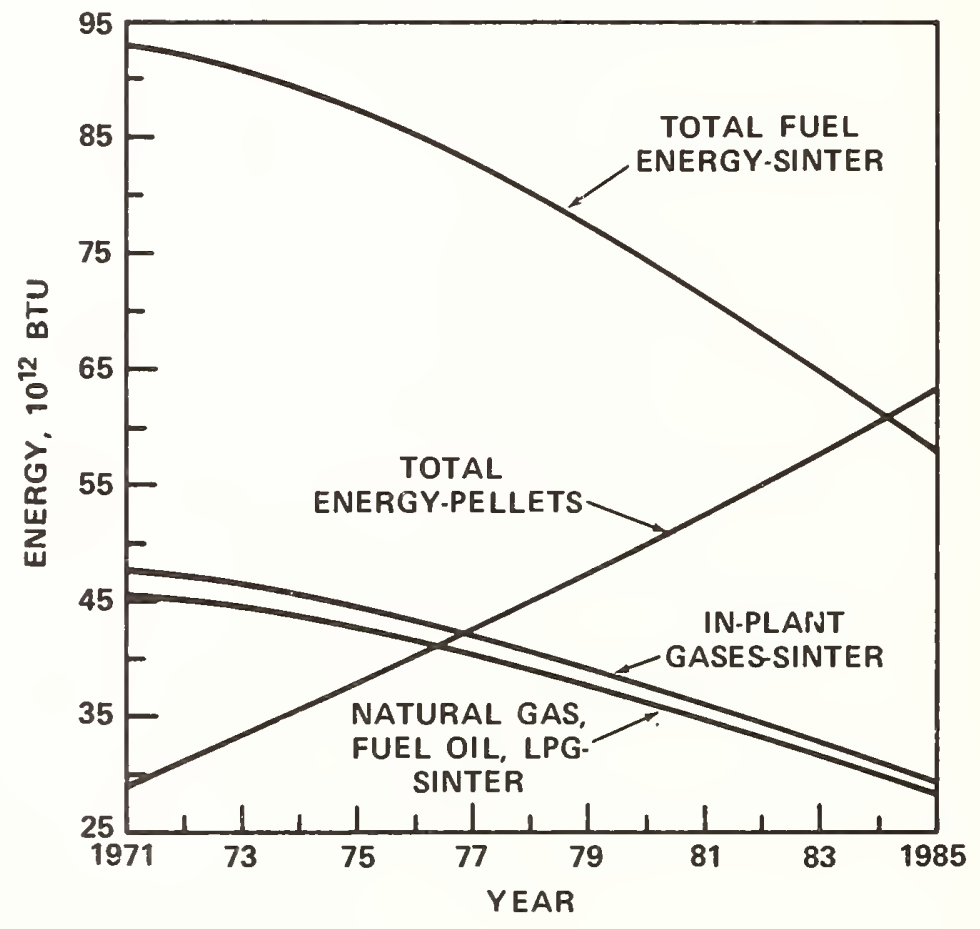


FIGURE 6 AVERAGE BLAST-FURNACE COKE RATE

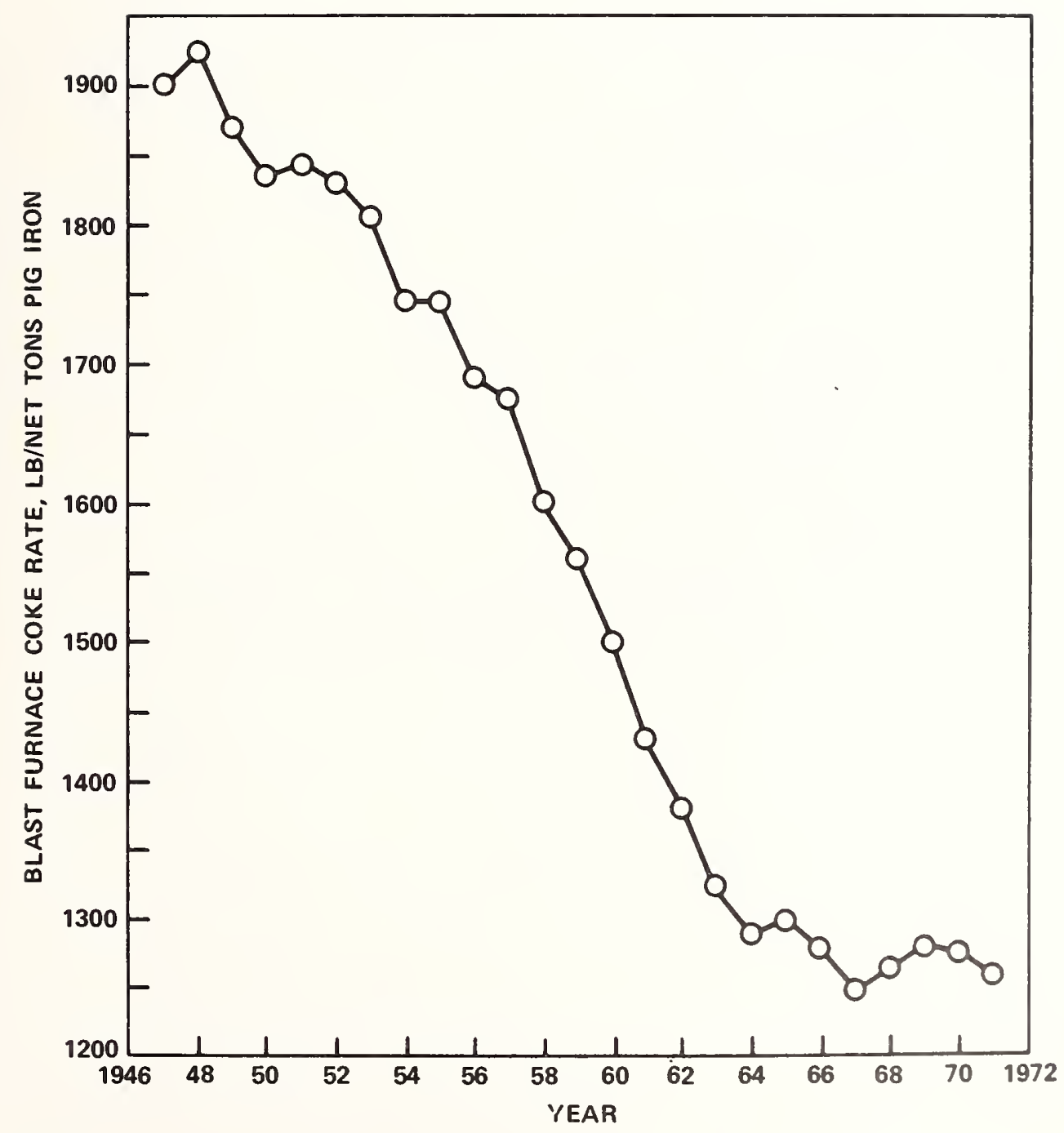


FIGURE 7 PREREDUCTION, \%

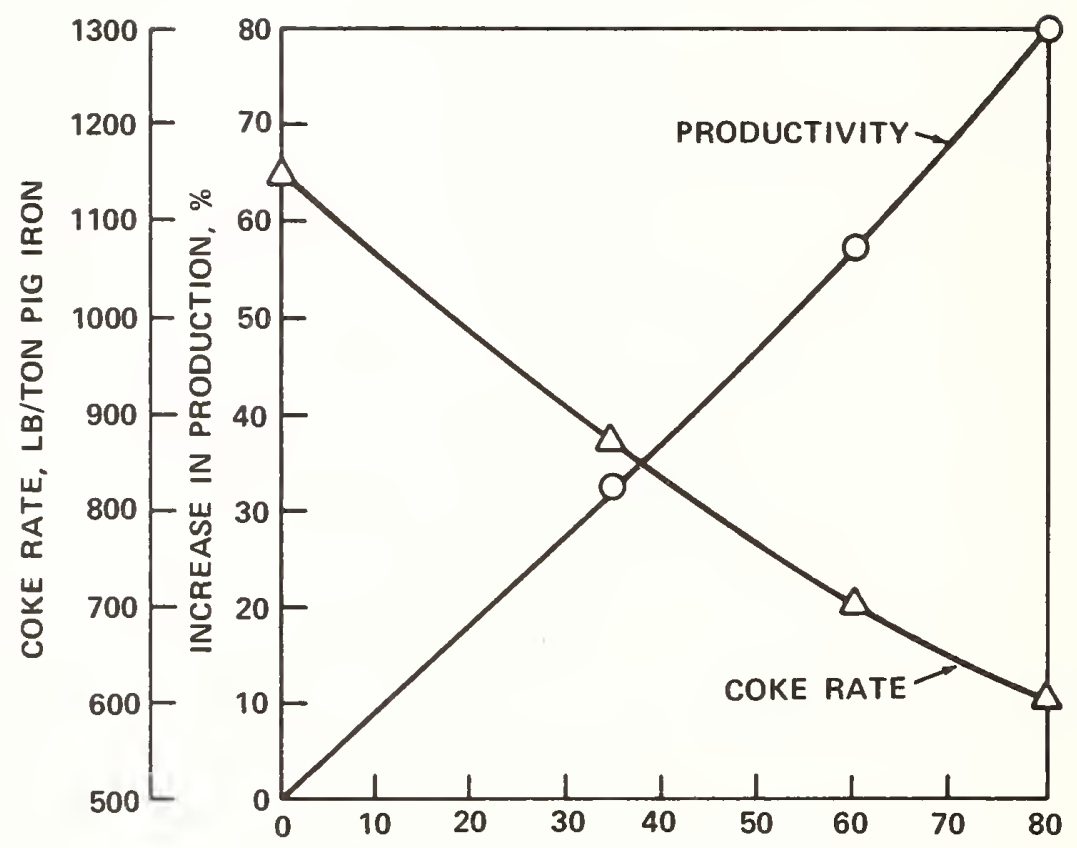


FIGURE 8 PROJECTION OF DECREASE IN COKE REQUIREMENT

PER TON OF PIG IRON PRODUCED

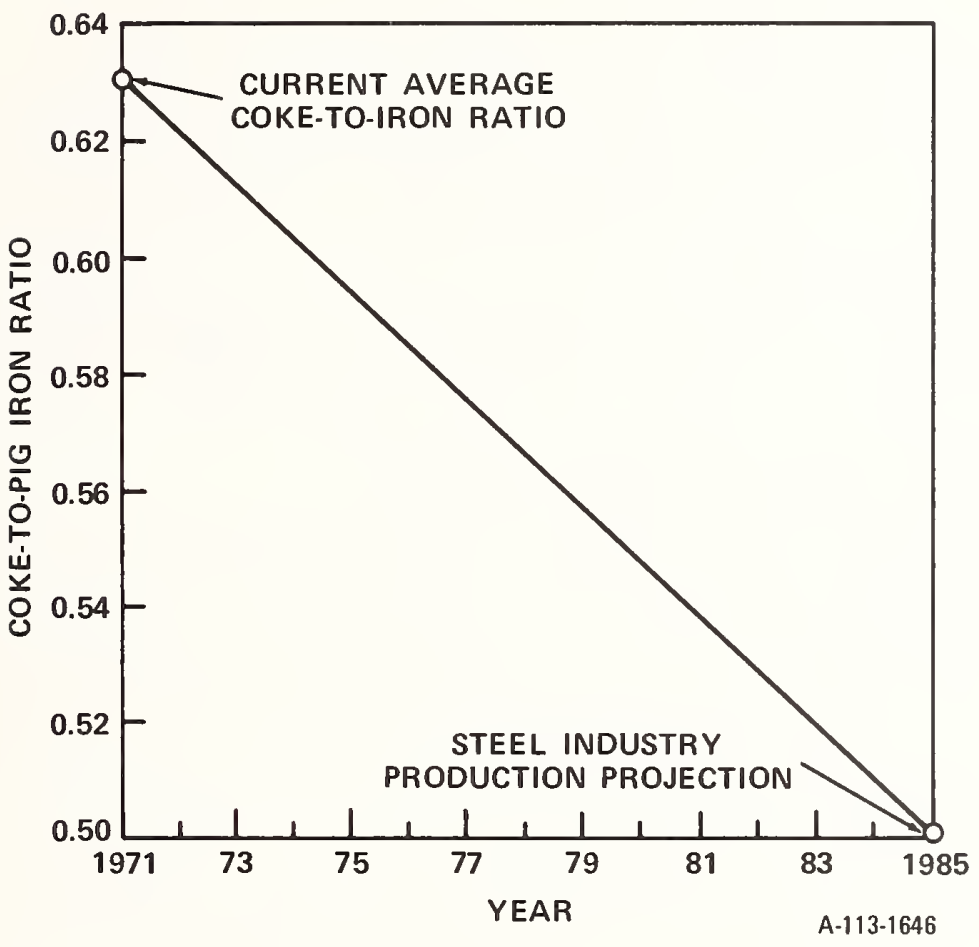

FIGURE 9 PROJECTION OF REQUIRED COKE PRODUCTION FROM 1971 TO 1985

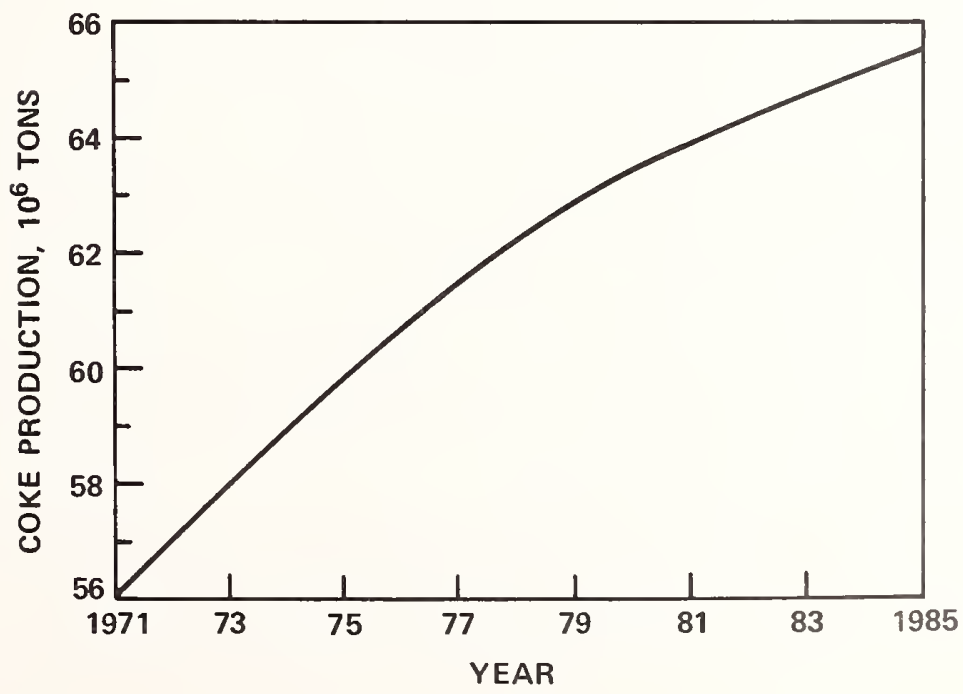


past 8 years. Much of this decline has been caused by pollution control regulations and the costs of transporting untreated ore to the plane. Concurrently, pelletizing has shown a steady increase. The pelletizing operation can be used at the mine mouth, so the tons of iron oxide transported per unit cost increase. The trends toward less sintering and more pelletizing were projected to 1985 (Figure 3) in terms of the percentage of total demand for ore. These data then were converted into the production rate of ore from the three methods of crushing, pelletizing, and sintering (Figure 4).

The energy requirements for sintering and pelletizing are fairly well fixed at $1.6 \mathrm{million}$ BTU/ton for sintering and $0.6 \mathrm{million}$ BTU/ton for pelletizing. By using these data together with those in Figure 3 , the total projected energy requirements for ore treatment can be calculated. In this case, the change in treatment method almost stabilizes energy consumption between 1971 and 1985, while production grows from 150 to 220 million tons/ year, as shown in Figure 5 .

Pelletizing currently uses natural gas as heating energy almost exclusively. However, fuel oil can be substituted for this application.

Historically, sintering uses $50 \%$ natural gas or oil and $50 \%$ in-plant gases (Figure 5).

Effect of Changes in Blast-Furnace Operation

The primary source of energy in blast-furnace operations is coke. During the last 10 years, the amount of coke required to produce 1 ton of iron has been decreasing steadily, as shown in Figure 6. In 1961, 0.72 ton of coke was required to produce 1 ton of pig iron. By 1971, coke consumption had decreased approximate $1 y 14 \%$ to 0.625 ton of coke per ton of pig iron. The single most important reason for this decrease probably is the increased use of pelletized ore, which increases production without increasing coke consumption per charge. The correlation between ore treatment and coke rate is shown in Figure 7 .

The steel industry predicts that coke requirements will decrease to on $1 y 0.5$ ton/ton of pig iron by 1985. This further decrease is based on the increased use of oxygen injection, hydrocarbon injection, and higher blast-air temperatures, al1 of which reduce coke requirements. For the purpose of this projection, a linear decline between 1971 and 1985 was assumed, as shown in Figure 8 .

The rate of decrease in the coke rate per ton of pig iron was combined with the projected production of pig iron (Figure 2) to estimate the demand for coking-grade coal between 1971 and 1985 (Figure 9). With current practices, about 1.44 tons of coking coal is required per ton of coke produced. Because no major change is expected in coking practices, the energy demand for coking coal is expected to increase from about 2020 trillion BTU in 1971 to about 2360 trillion BTU in 1985. (See Figure 10.)

Although the coke rate per ton of pig iron is projected to decline, this occurs at the expense of using additional quantities of other fuels. Hydrocarbon injection, oxygen injection, and higher blast-air temperatures all require additional fossil fuel or energy.

Hydrocarbon injection is a rapidly growing trend because it increases blast-furnace production. Hydrocarbon injection increases the hydrogen available to reduce iron oxides faster than conventional carbon monoxide from coke. Between 1967 and 1971, the amount of fuel oil used in blast furnaces increased threefold, from 67 to 194 million gal/year. The use of natural gas remained about constant.

Figure 11 shows that between 1967 and 1971 the percentage of iron produced by using hydrocarbon injection increased linearly. This trend was projected to saturation at $100 \%$, which occurs about 1980 . The percentage increase in the use of hydrocarbon injection was coupled with the projection of pig iron production (Figure 2) to obtain the estimated amounts of iron produced, based on about 1.5 million BTU of injected hydrocarbons per ton of pig iron. Figure 12 shows the total amount of energy estimated to be consumed in hydrocarbon injection. 
FIGURE 10 PROJECTION OF TOTAL PURCHASED COKING COAL

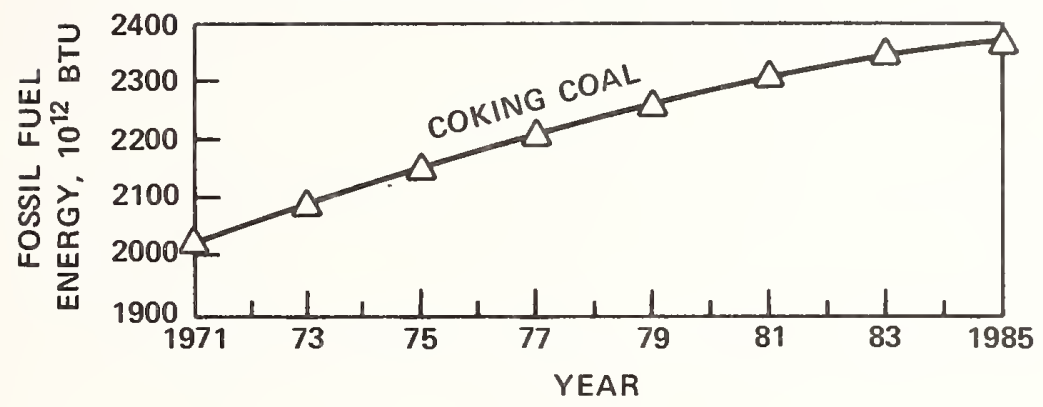

FIGURE 11

PROJECTION OF PERCENTAGE OF IRON MANUFACTURED BY USING HYDROCARBON INJECTION INTO THE BLAST FURNACE

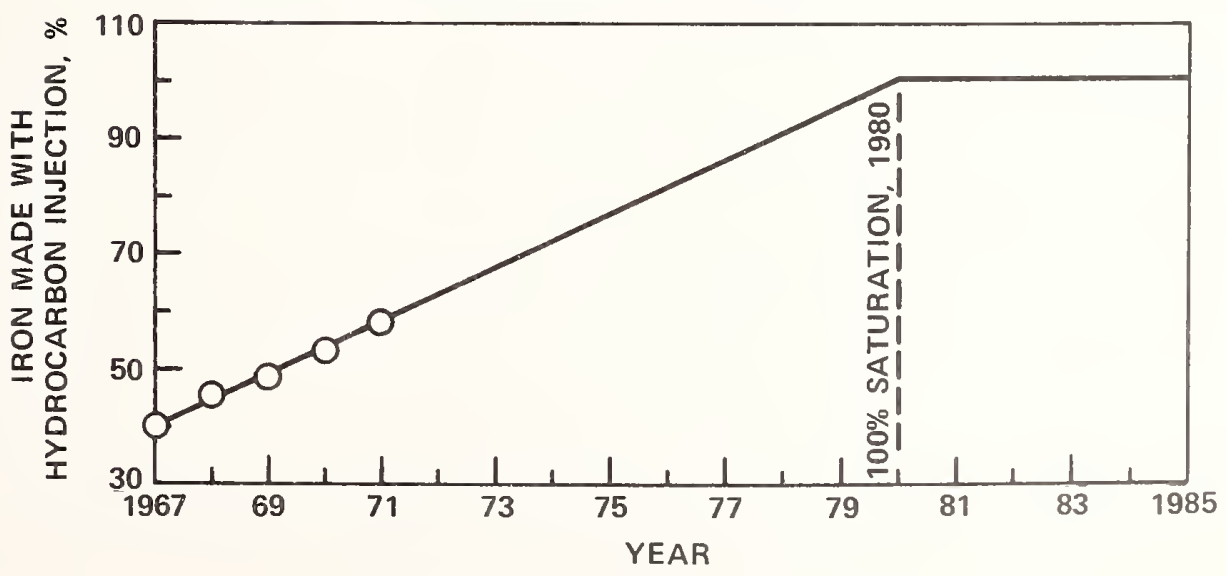


Increasing the blast-air temperature to decrease the coke rate also requires additional energy. Prior to 1950 , blast-air temperatures were usually below $1200^{\circ} \mathrm{F}$, but current blast temperatures are between $1300^{\circ} \mathrm{F}$ and $1400^{\circ} \mathrm{F}$. Typically, the efficiency of a blast-air stove is about $75 \%$. However, as the desired blast temperature increases, the efficiency decreases because of increased heat losses in the form of higher flue-gas temperatures. For a $1300^{\circ} \mathrm{F}$ blast-air temperature, about $2.25 \mathrm{mil1ion}$ BTU of energy is needed per ton of pig iron produced. Further major changes toward higher air temperatures are not expected before 1985 because such changes would require major capital expenses for new equipment. Figure 13 shows the projected energy consumption by blast-air stoves. Historically, about $90 \%$ in-plant gases and $10 \%$ purchased fuels are used to fire blast-air stoves. The anticipated split between in-plant and purchased fuels also is shown in Figure 13 .

A change to lower coke rates also will have the effect of decreasing the availability of blast-furnace gases. This decrease will force an increased demand for purchased fossil fuels. Decreasing the coke rate from 0.65 to 0.5 ton of coke per ton of pig iron is estimated to reduce blastfurnace-gas production from 5.2 to about $3.6 \mathrm{million}$ BTU/ton of pig iron. This change was coupled with the rate of change in the coke rate (Figure 8) and the projected production of pig iron (Figure 2) to determine the production of blast-furnace gas between 1971 and 1985 , as shown in Figure 14.

Effect of Changes in Coke-Oven Operation

The major effect of the decreased rate of coke production, as shown in Figure 9, will be a decreased rate of growth in the production of coke-oven gas. The manufacturing of 1 ton of coke produces approximately 14,000 cubic feet of coke-oven gas, or roughly 7 million BTU. Based on these data and on the projected production of coke (Figure 9), we calculated the projected supply of coke-oven gas shown in Figure 15.

While the amount of coke-oven gas available for other plant uses will increase gradual1y, the growth in the amount of other fuels required for firing the coke ovens will moderate. Typically, energy consumption for this process is about $2.0 \mathrm{million}$ BTU/ton of coke. Based on these data, we projected that the fuel demand for coke-oven underfiring will grow from only 112 to 132 trillion BTU/year. Almost all this energy is supplied by reburning the coke-oven gas. The demand for coke-oven gas for underfiring is shown in Figure 16.

Effect of Changes in Steelmaking Processes

The three basic steelmaking processes are 1) the open-hearth process, 2) the BOF process, and 3) the electric-arc-furnace process. The openhearth process essentially is a regenerative, reverberatory furnace in which a long, relatively shallow bath is heated by radiation from a luminous flame. After 1960, the amount of steel produced by the open-hearth process declined in favor of the BOF and electric-arc processes.

For this study, the growth and decline trends of the three processes were projected. (See Figure 17.) The BOF and electric-arc processes were projected linearly. The decline of open hearths was based on a $9 \%$ phaseout of old furnaces per year. The sum of the projections for each process agrees well with the steel industry's projection of a total production of $185 \mathrm{million}$ tons in 1985 .

An examination of the energy required by each process showed that the quantities are fairly well-known and fixed. Therefore, a projection of future energy demand can be derived by multiplying the energy demand per unit of steel by the projected production of steel by each process. Table 2 shows the energy requirements for each process. Note that considerable energy goes into producing the oxygen for the BOF process and the electricity for the electric-arc-furnace process; these energy demands are considered later in this section. 


\section{FIGURE 12}

PROJECTION OF ENERGY CONSUMPTION BY HYDROCARBON BLAST-FURNACE IGNITION

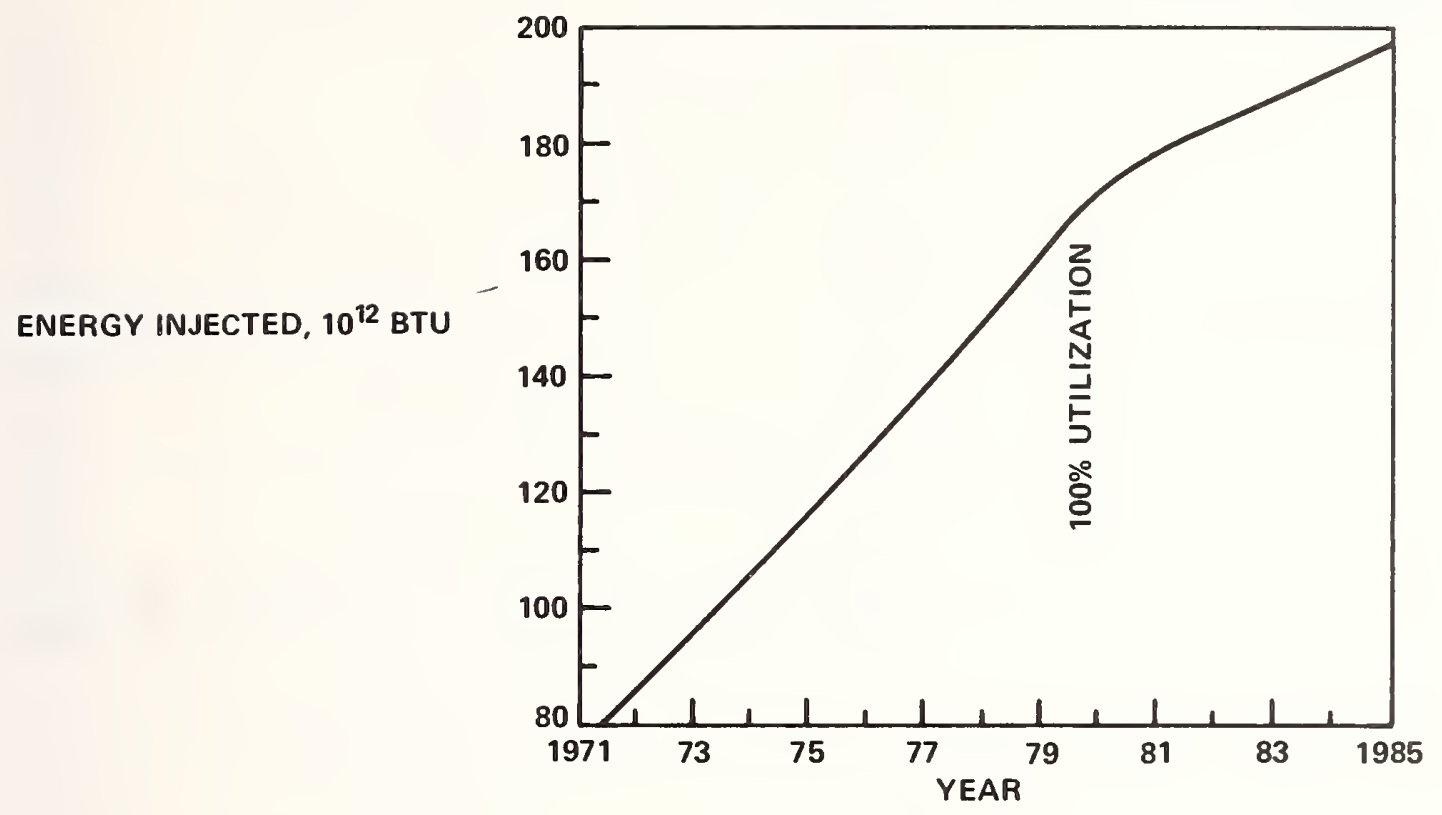

FIGURE 13

ENERGY CONSUMPTION IN BLAST-AIR STOVES

ENERGY CONSUMPTION, $10^{12}$ BTU

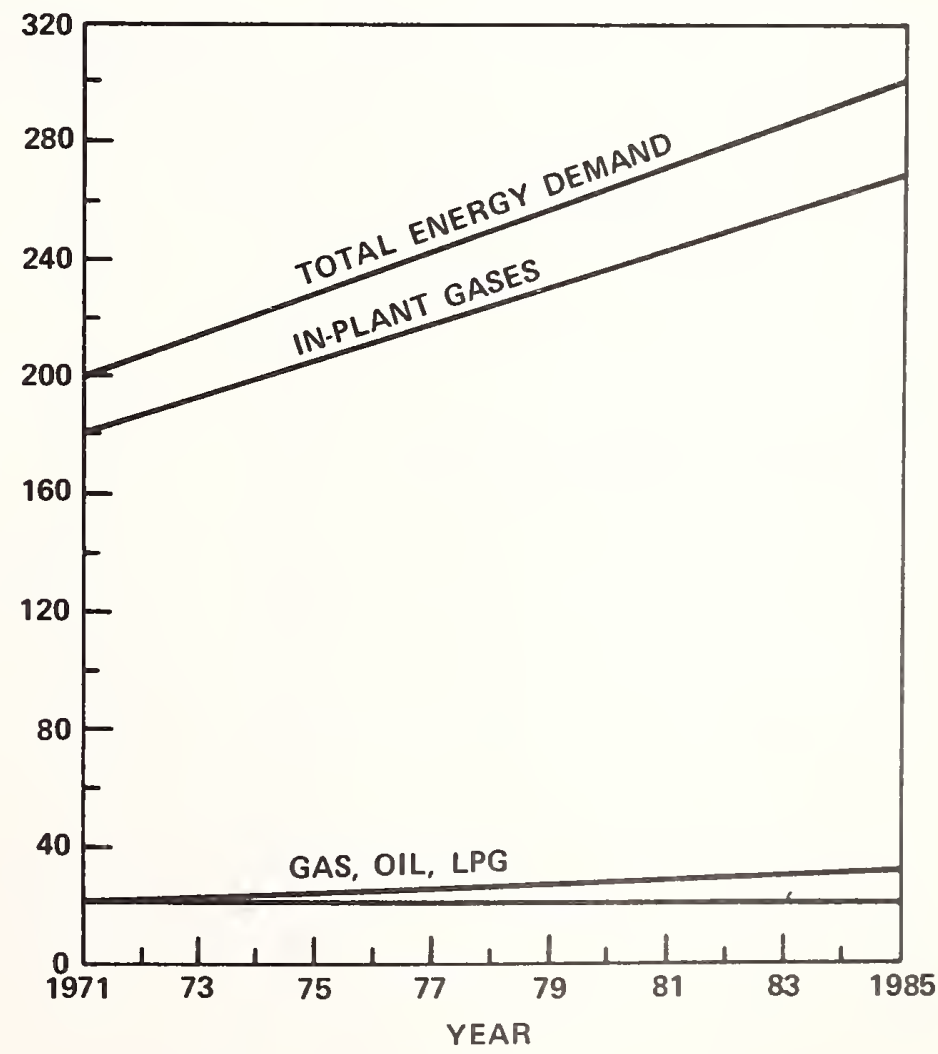


ENERGY PRODUCTION, $10^{12}$ BTU

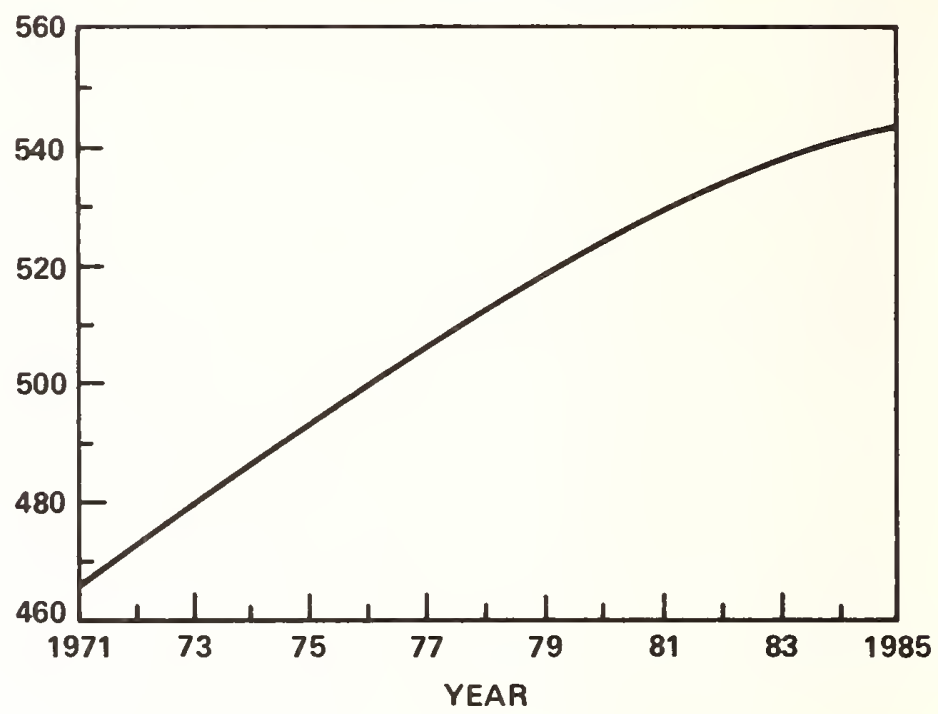

FIGURE 15 PROJECTED PRODUCTION OF COKE-OVEN-GAS ENERGY BASED ON REQUIRED COKE PRODUCTION

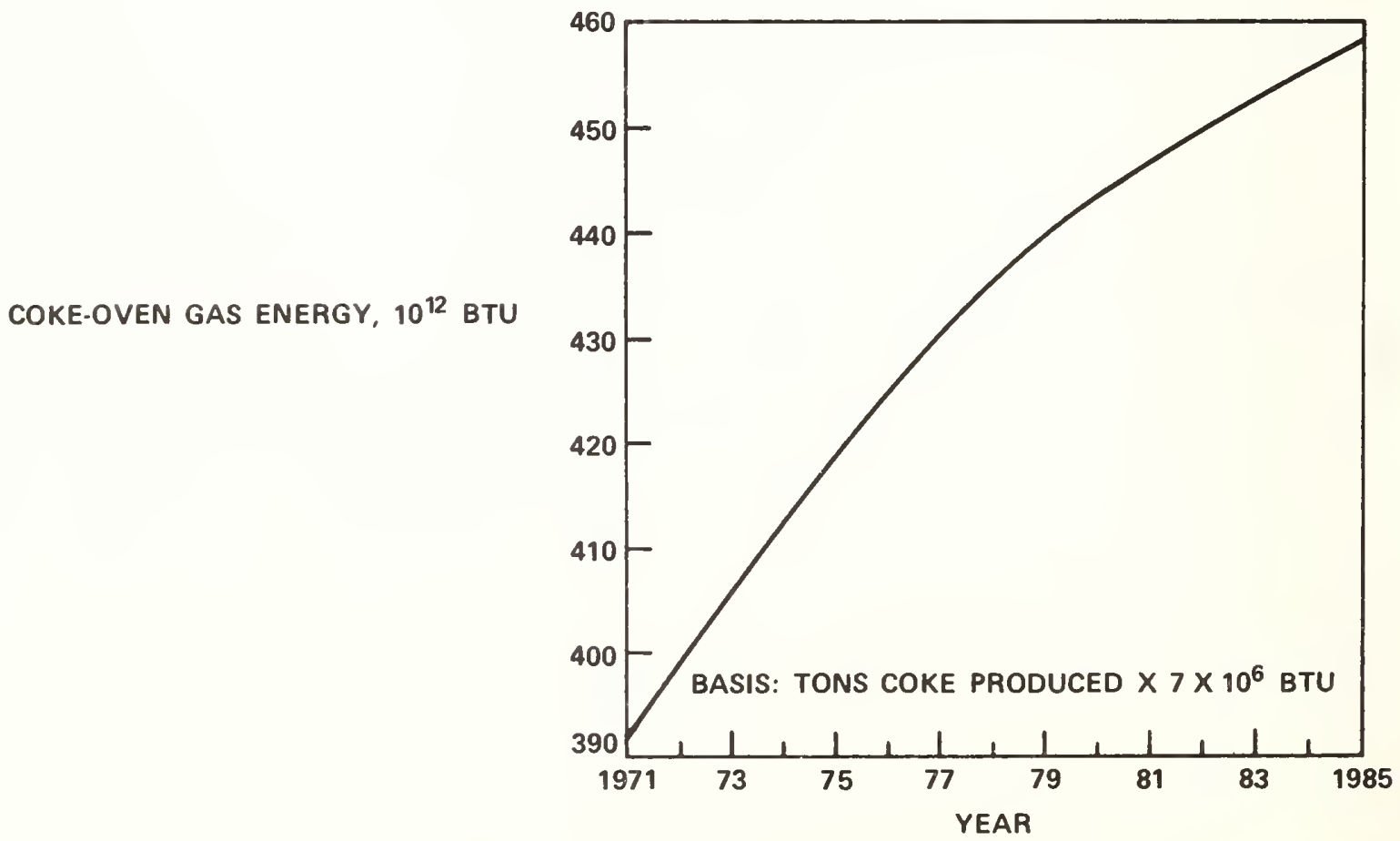


FIGURE 16

\section{PROJECTED DEMAND FOR INPLANT-GAS ENERGY FOR UNDERFIRING COKE OVENS}

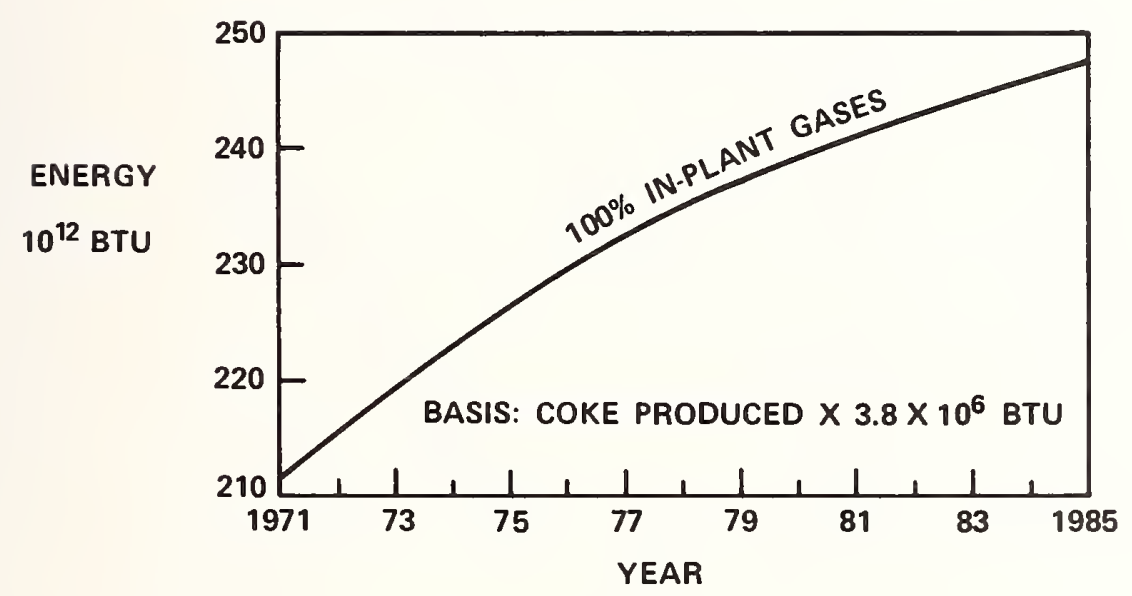




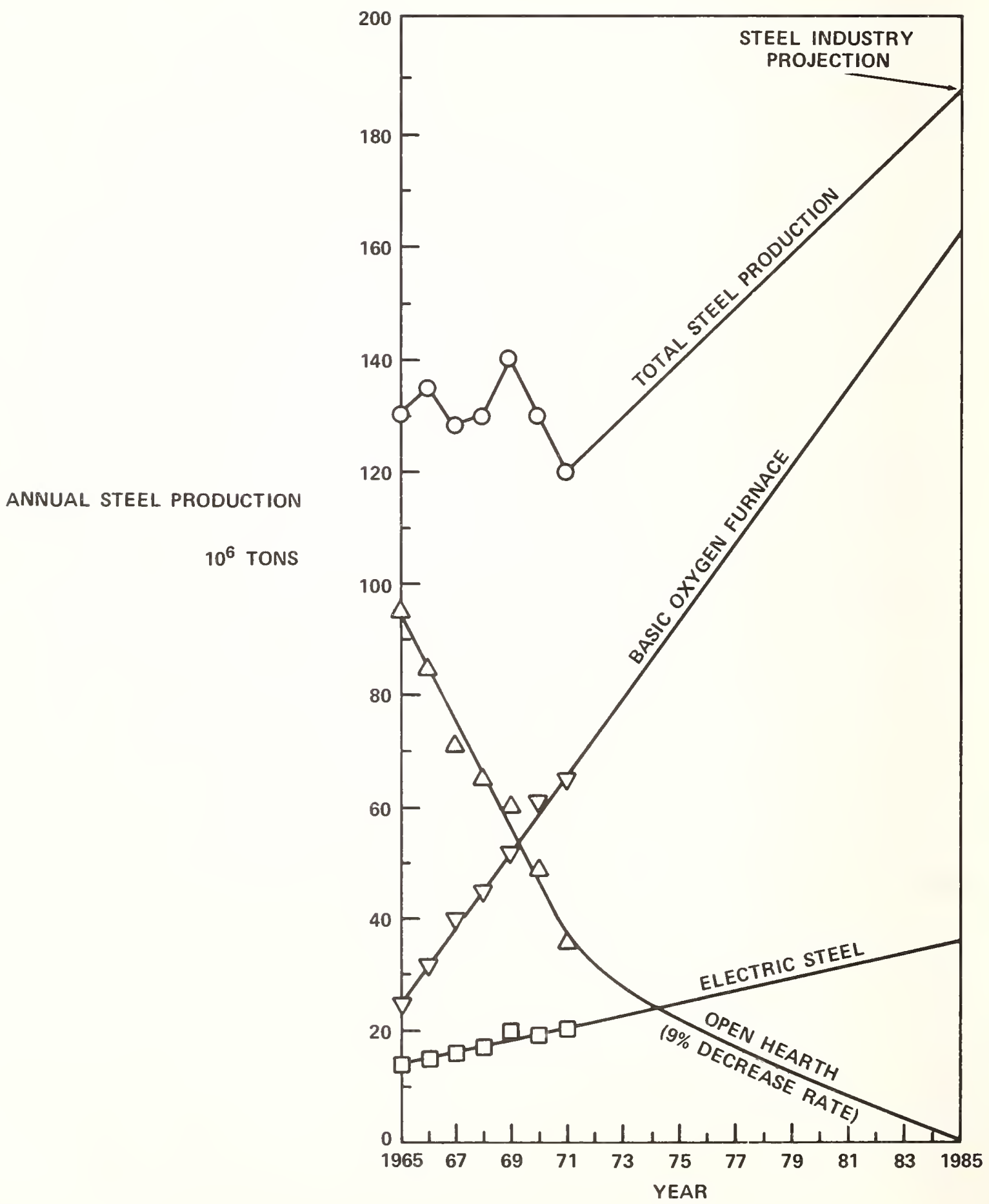




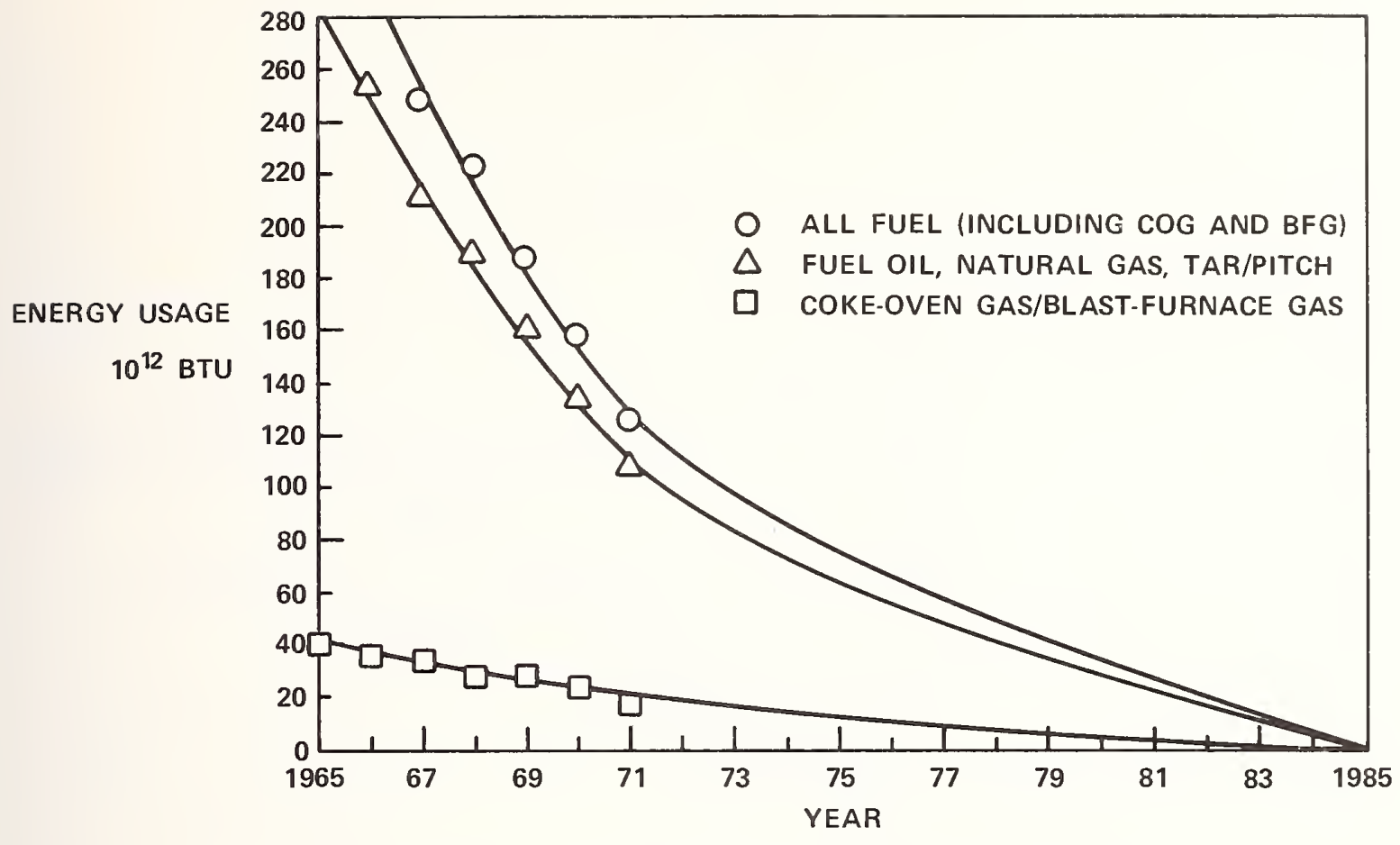

PROJECTED DECLINE OF ENERGY USE IN OPEN-HEARTH STEEL-MELTING FURNACES

FIGURE 19

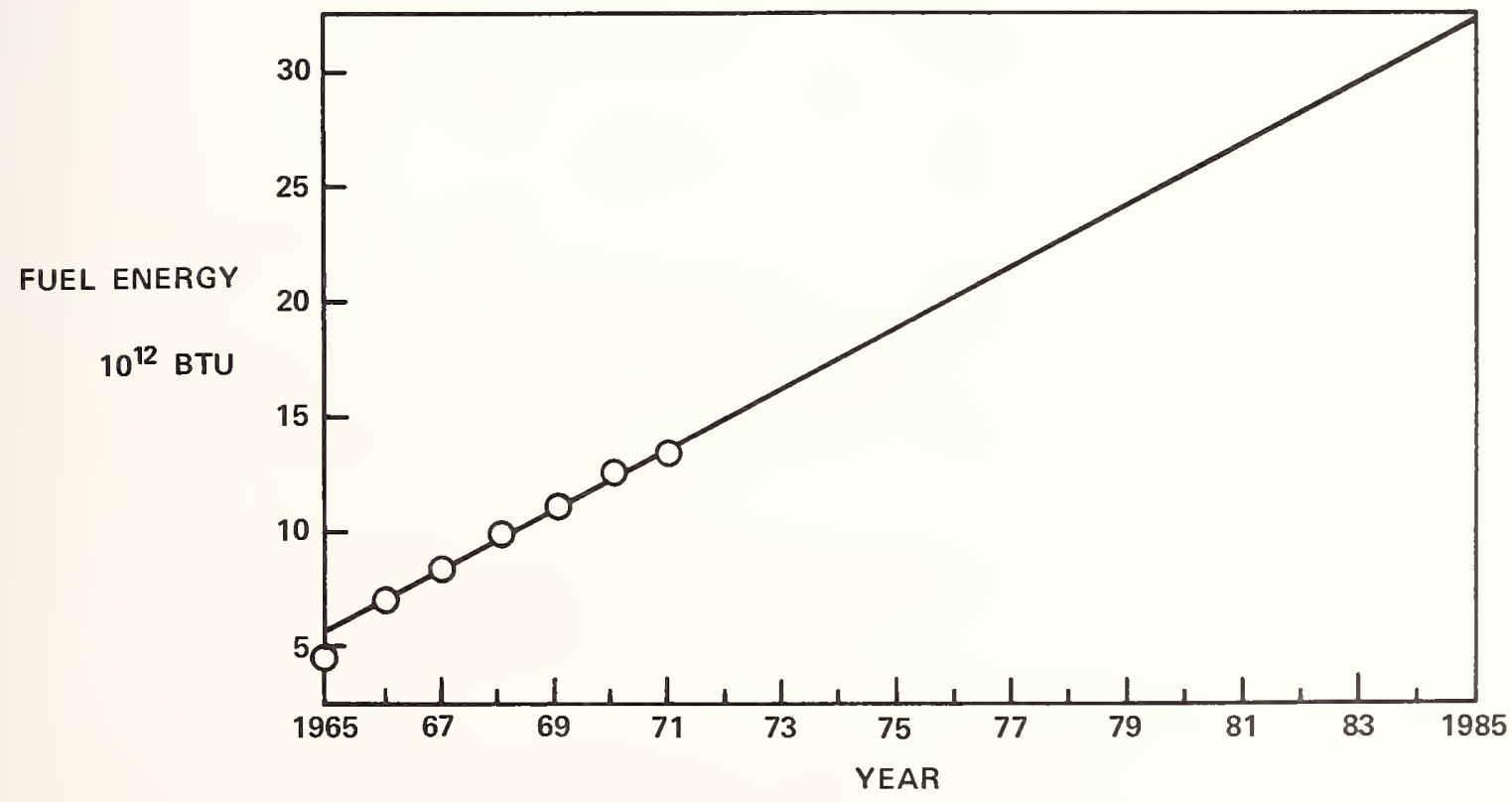

PROJECTED ENERGY CONSUMPTION OF FOSSIL FUELS IN PRODUCTION OF STEEL BY THE BOF PROCESS

(Primarily Heat Used Between Charges) 
FIGURE 20

STEEL PRODUCTION

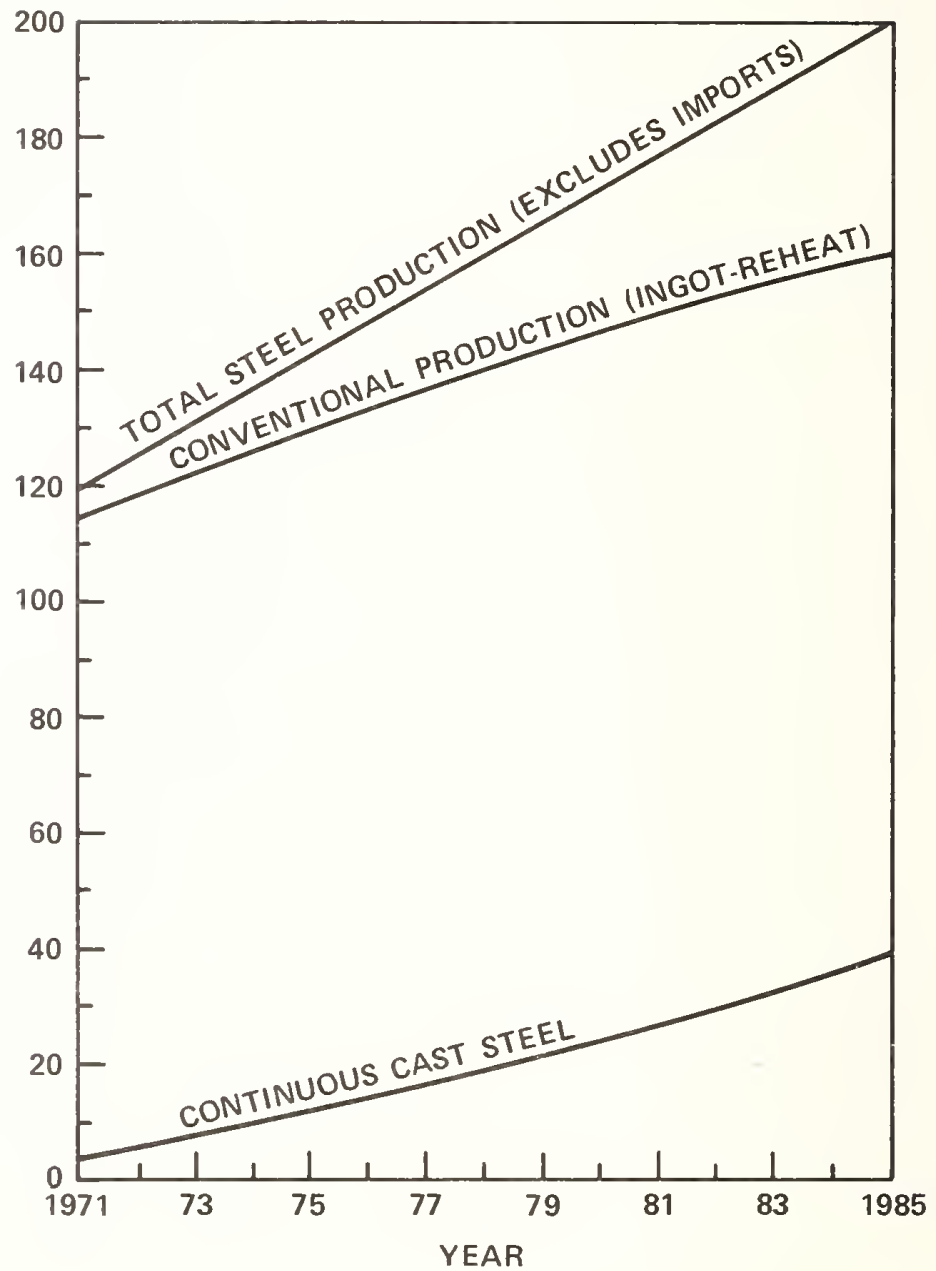

PROJECTED GROWTH OF CONTINUOUS CASTING AND CONVENTIONAL PRODUCTION OF STEEL 
PROJECTED FUEL ENERGY REQUIREMENT FOR

STEEL REHEATING AND CONTINUOUS CASTING

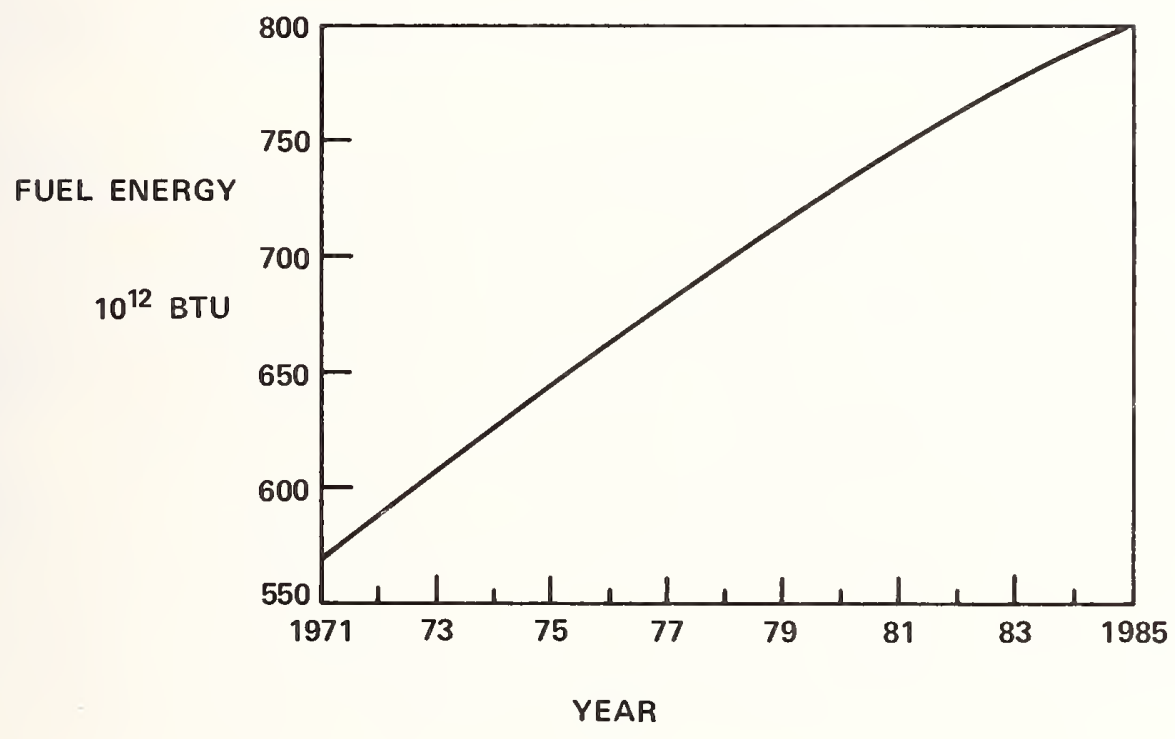

FIGURE 21 
Open-Hearth Furnace

BOF

Electric-Arc Furnace

Fossil Fuel $\begin{aligned} & \text { Requirements, } \\ & \text { BTU/ton }\end{aligned}$
\[ \begin{array}{c}3.5 \\ 0.2 \\ \text { None }\end{array} \]

Based on the above data, Figure 18 shows the projected energy demand for open-hearth steel production. Most of this energy will be supplied by fuel oil, natural gas, or tar and pitch. The amount of in-plant gases used is very small.

Most of the fossil-fuel energy for the BOF process is supplied by natural gas. This energy is used primarily to maintain the vessel temperature between charges. The use of energy for this process is very linear between 1965 and 1971 , as shown in Figure 19.

An extrapolation of these data agrees with the energy consumption per ton of steel multiplied by the projected BOF steel production. The energy used to produce the oxygen for the BOF process is considered 1ater in this report.

Energy Consumption for Continuous Cast Stee1s

Much of the steel produced by the above processes is cast into ingots, allowed to cool, and then reheated in soaking pits for further finishing into a product. However, some of the steel is directly and continuously cast into a product. The amount of steel handled in this way is relatively small, but projections show that this process will produce up to $20 \%$ of all finished products by 1985 . The amount of energy consumed by continuous casting is sma11, but worthy of inclusion in the overall analysis. Continuous casting consumes only about $0.25 \mathrm{million}$ BTU/ton of steel. All this energy is used for preheating the equipment and maintaining the temperature of the stee 1 throughout the process.

Based on the current production of about 5 million tons of continuously cast stee1, or $4 \%$ of tota 1 stee 1 production, and on the industry's projection of $20 \%$ of total production by 1985 , the amount of continuously cast steel by year was calculated. (See Figure 20.) Subtracting continuously cast steel production from total projected steel production (Figure 17) yields the steel produced by the conventional ingot-reheat process.

The data of Figure 20 together with the energy consumption data for continuous casting yield the energy demand projection for continuous casting shown in Figure 21 .

Energy Consumption for Oxygen Production

The major uses of oxygen in an integrated steel mill are for the Bof process, the open-hearth furnaces, blast-furnace injection, electric-arc melter injection, and general steel-cutting with gas-oxygen torches. A great deal of fossil-fuel energy is required to produce the electric power that, in turn, is used to produce the oxygen. The production of oxygen in a large plant requires a total of about 340 kwhr of electric power per ton of oxygen.

Based on a study of the oxygen requirements of each of the above processes, a projection of oxygen demand was prepared for the years between 1971 and 1985. Figure 22 shows that the bulk of this oxygen is used in the BOF process. The demand for oxygen from open-hearth furnaces will decline with the phasing out of the process. The demand from other processes will grow in proportion to the production growth of each process. The amount of oxygen required for general plant usage was derived from consumption data for 1966 to 1971. Published data for general plant oxygen usage divided by steel production in each year showed that 0.0095 * 0.0003 ton of oxygen is required for each ton of steel produced. Summing the individual oxygen requirements of each process yields the total oxygen 
FIGURE 22

PROJECTED STEEL INDUSTRY DEMAND FOR OXYGEN AS A FUNCTION OF PROCESS TYPE

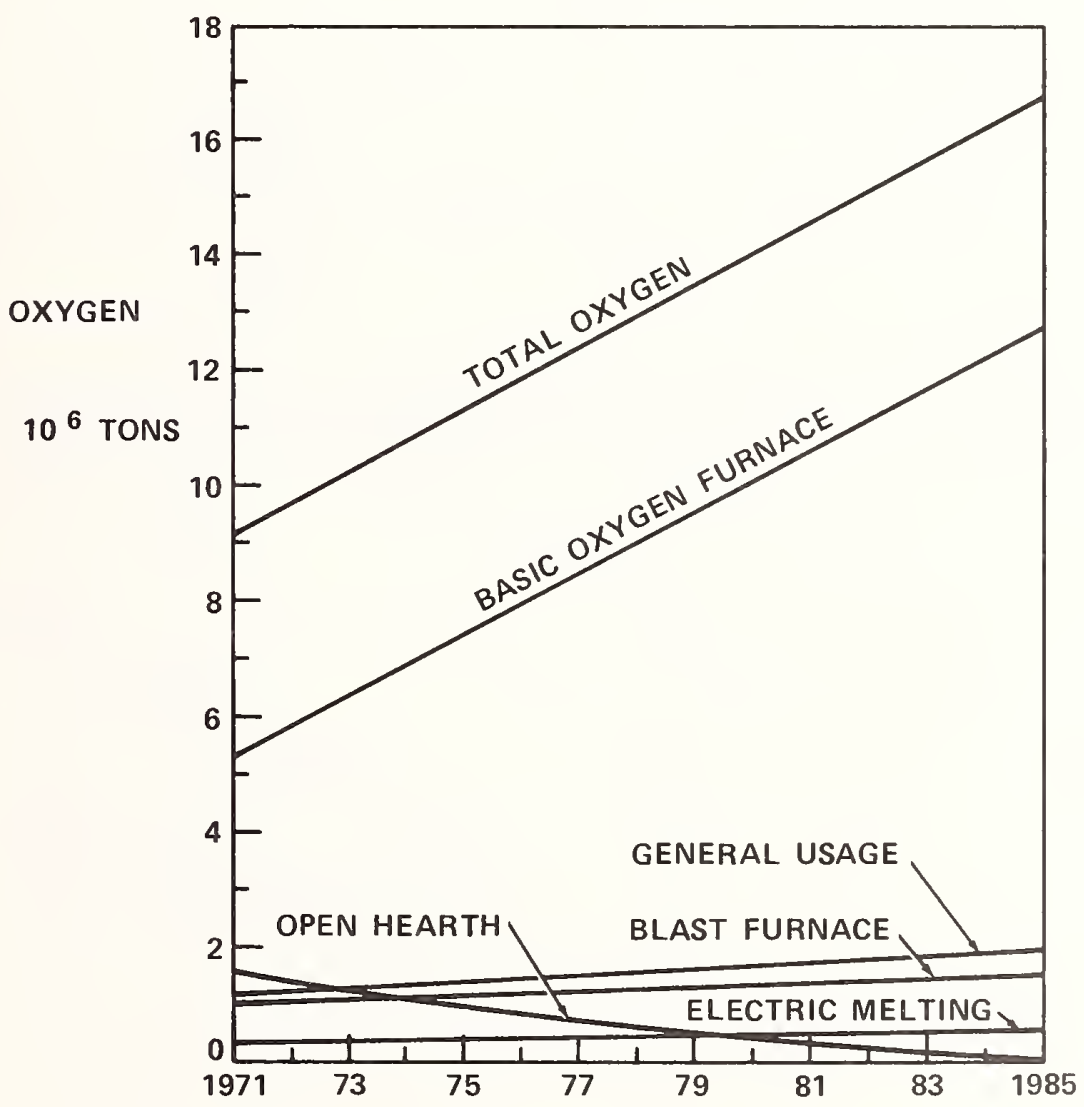

YEAR 
FIGURE 23 PROJECTED PERCENTAGE OF OXYGEN PRODUCED BY STEEL

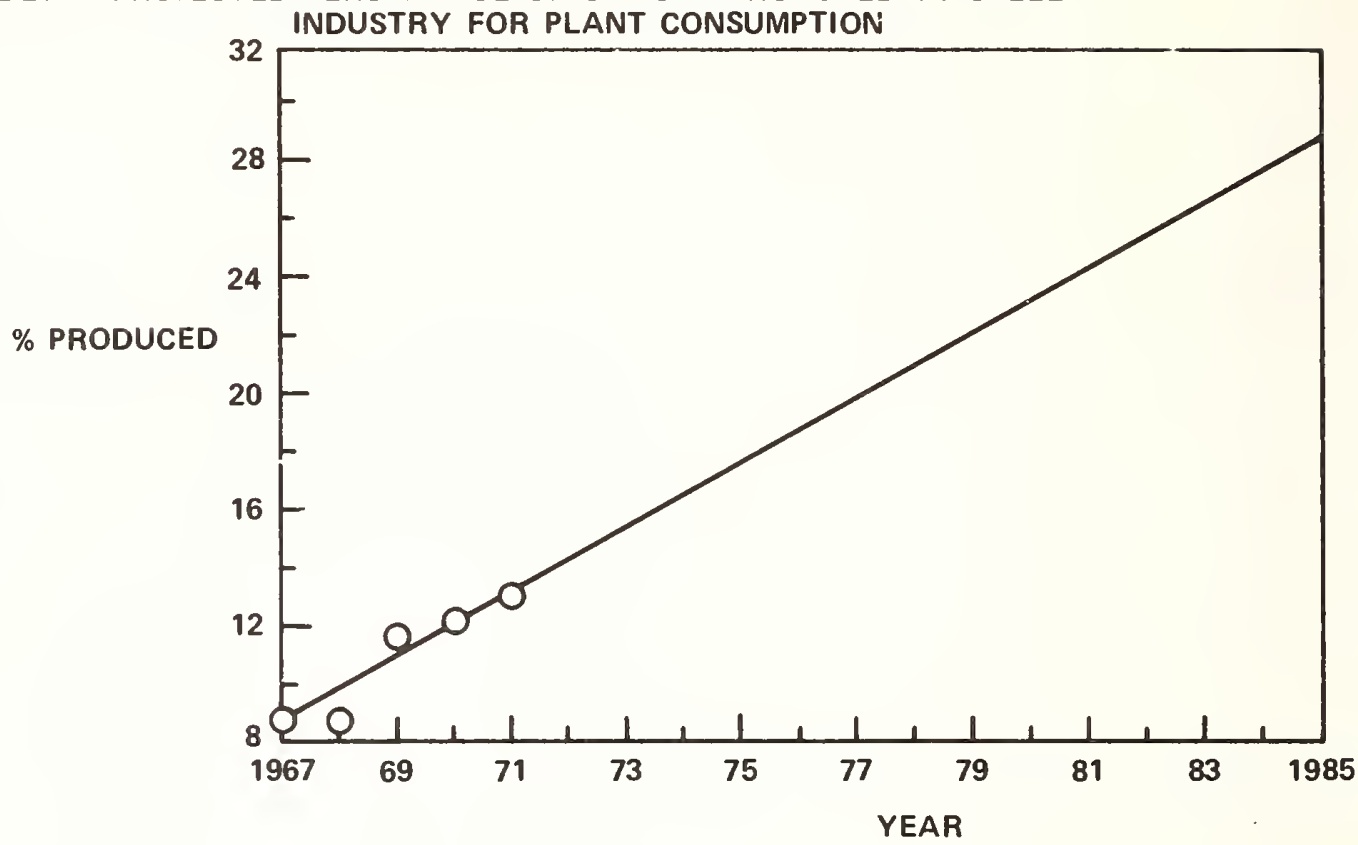

FIGLIRE 24 PROJECTED OXYGEN REQUIREMENT WITH RELATIVE AMOUNTS OF PURCHASED AND SELF-PRODUCED OXYGEN

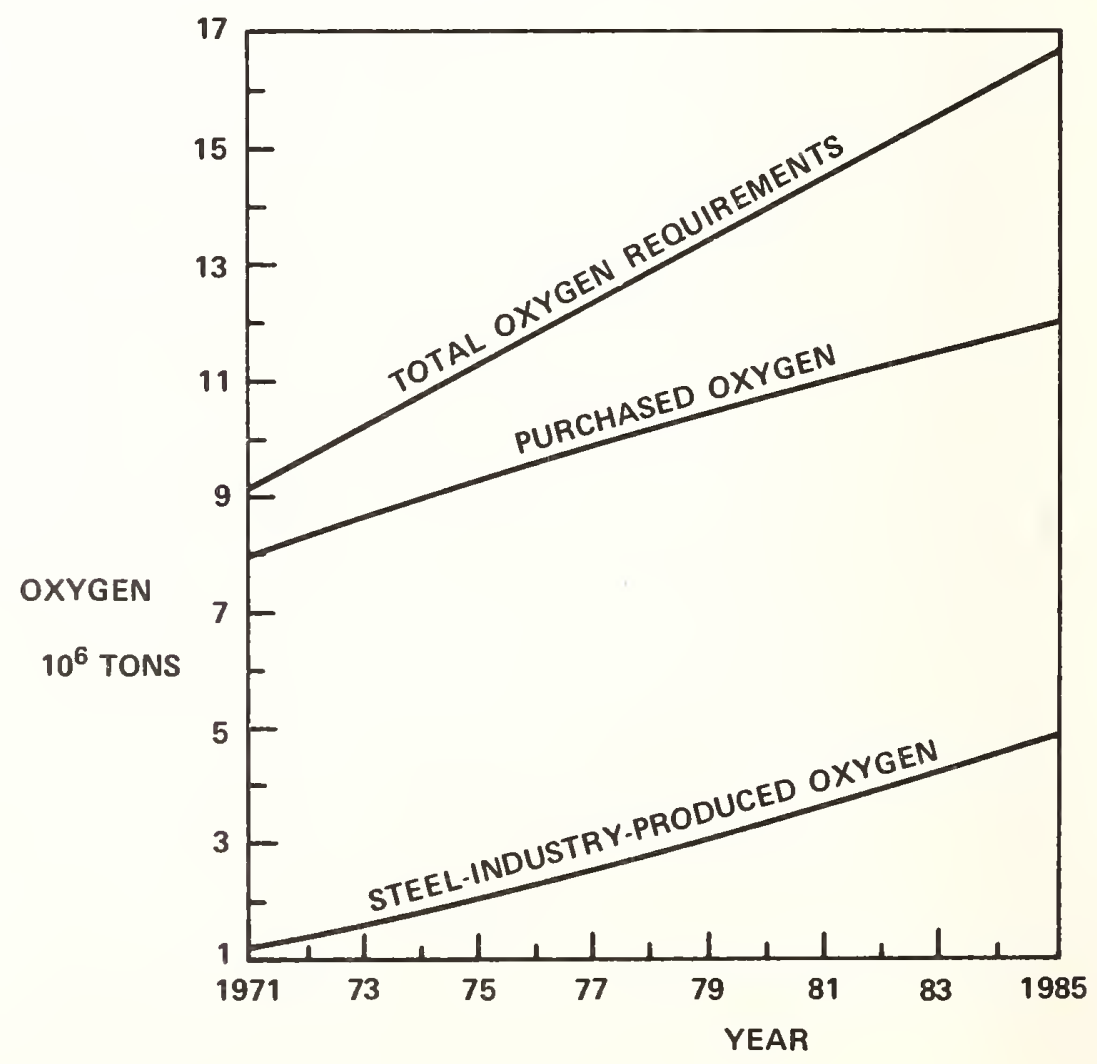


FIGURE 25

PROJECTION OF ELECTRIC POWER REQUIREMENTS FOR

PRODUCING OXYGEN REQUIRED BY STEEL INDUSTRY

ELECTRIC POWER

ELECTRIC POWER

REOD FOR

OXYGEN

REQD FOR

OXYGEN

PURCHASED

SELF-MFG

$10^{12}$ BTU

$10^{12}$ BTU

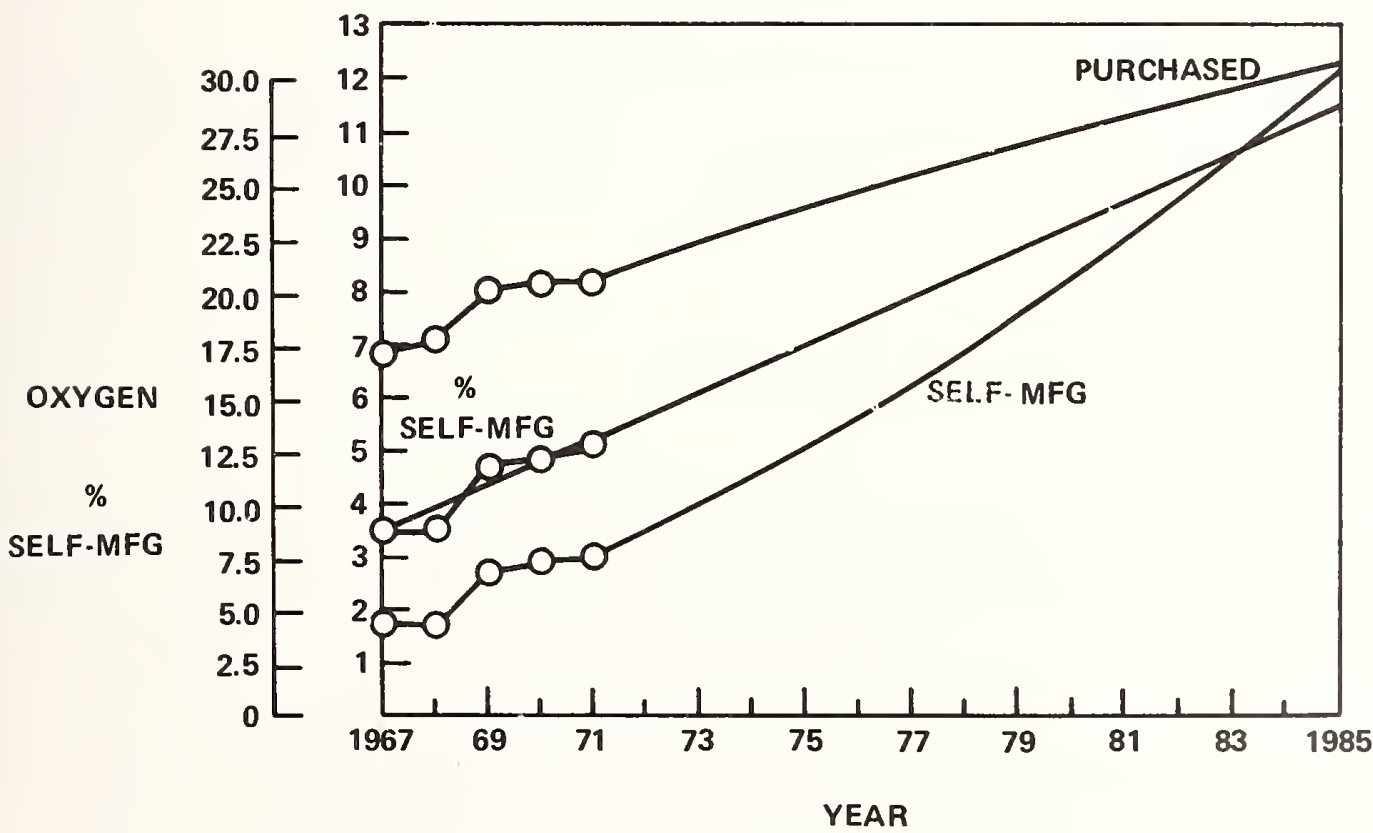

30.0
-27.5
-25.0
22.5
20.0
-17.5
-15.0
12.5
100
7.5
5.0
2.5
0 
demand of the steel industry (Figure 22).

Only a small portion of the oxygen used by the steel industry is produced in oxygen plants owned by the steel plant. In 1967, this so-called "self-produced" oxygen accounted for only about $8.8 \%$ of the total amount used. However, the steel industry is building an increasing amount of oxygen plants. Figure 23 projects the increase in self-produced oxygen in terms of the percentage of total demand from an extrapolation of data for 1967 to 1971. With this projection, the oxygen that will be self-produced and the amount to be purchased can be calculated (Figure 24). From this information, we could calculate the electric power necessary to produce the oxygen to be made by the steel industry (Figure 25). These data are used later in calculating the amounts of fossil fuels required by the boilers used to generate electric power in the steel plants.

Energy Consumption for Electric Power Production

We have just shown that a considerable amount of electric power is required to produce oxygen for the various iron- and steelmaking processes. In addition, large quantities of electric power are consumed for electric melting and general plant functions, such as electric motors.

The literature indicates that the electric-arc process uses about 1.7 million BTU of energy (electrical) per ton of steel produced. Based on these data and the projection of steel to be produced by the electric-arc process (Figure 17), the energy needs for this process were projected to 1985, as shown in Table 3. The amounts of fossil fuel needed to produce this amount of electric power are shown later and typical boiler efficiencies are considered.

Table 3. PROJECTED ELECTRIC POWER REQUIREMENTS FOR ELECTRIC FURNACE OPERATION FROM 1973-1985

$\begin{array}{lrr}\text { Year } & \begin{array}{c}\text { Projected Steel } \\ \text { Production, } 10^{6} \text { tons/yr }\end{array} & \begin{array}{c}\text { Projected Poired, } 10^{1} \\ \text { Required }\end{array} \\ 1973 & 24 & 40.8 \\ 1975 & 26 & 44.2 \\ 1977 & 29 & 49.3 \\ 1979 & 31 & 52.7 \\ 1981 & 34 & 57.8 \\ 1983 & 37 & 62.9 \\ 1985 & 40 & 68.0\end{array}$

The electric power demand for general plant use was derived from literature data for 1962 to 1971 , which show that electric consumption for general plant use (excluding electric melting and oxygen productions) correlates closely with steel production. These data show that 0.98-1.09 million BTU of electric power is used per ton of steel produced. Based on an average mean consumption of $1.06 \mathrm{million}$ BTU per ton of steel and our earlier projection of steel production, general plant electric power needs were calculated. (See Figure 26.) The electric power demands for oxygen production, electric melting, and general plant use were summed to obtain total electric demand (Figure 26.) This analysis showed that electric power consumption will grow from about 164 trillion BTU in 1971 to about 292 trillion BTU in 1985.

Electric power is much like oxygen production; that is, a portion of the demand is satisfied by in-house production and a portion is purchased. From 1967 to 1971, the percentage of electric power that was self-produced declined about $6 \%$ and very linearly. These data were extrapolated to estimate the further decline of self-produced electric power. This projection indicates all the electric needs of the steel industry will be met with purchased power by about 1984 or 1985 (Figure 27). 
FIGURE 26 PROJECTED REQUIREMENTS FOR ELECTRIC POWER

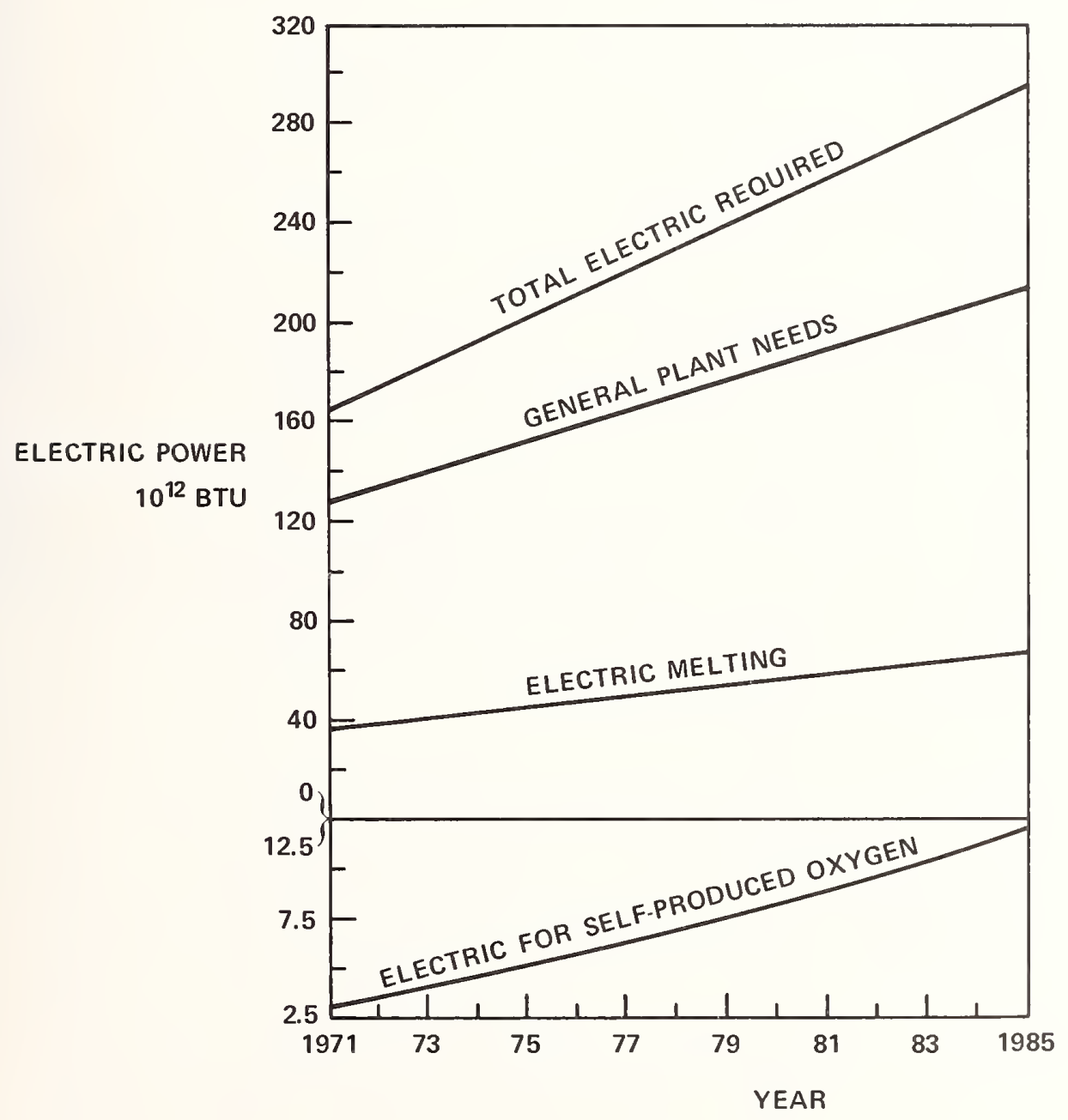


FIGURE 27 RATE OF DECLINE (Linear Projection) OF STEEL-INDUSTRY-

GENERATED ELECTRIC POWER

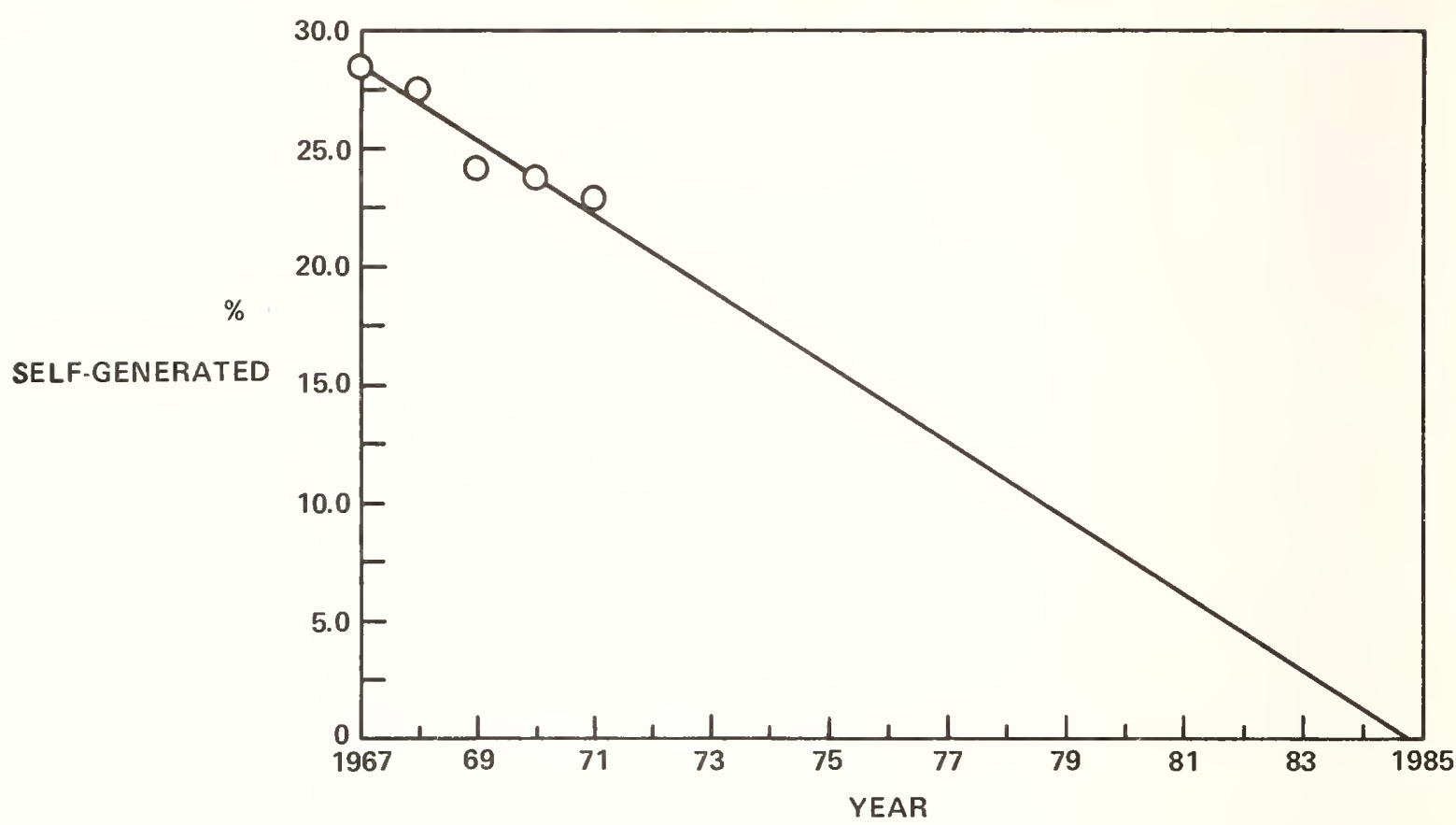

FIGURE 28 ENERGY REQUIREMENTS FOR BOILERS TO PRODUCE ELECTRIC POWER FOR THE IRON AND STEEL INDUSTRY

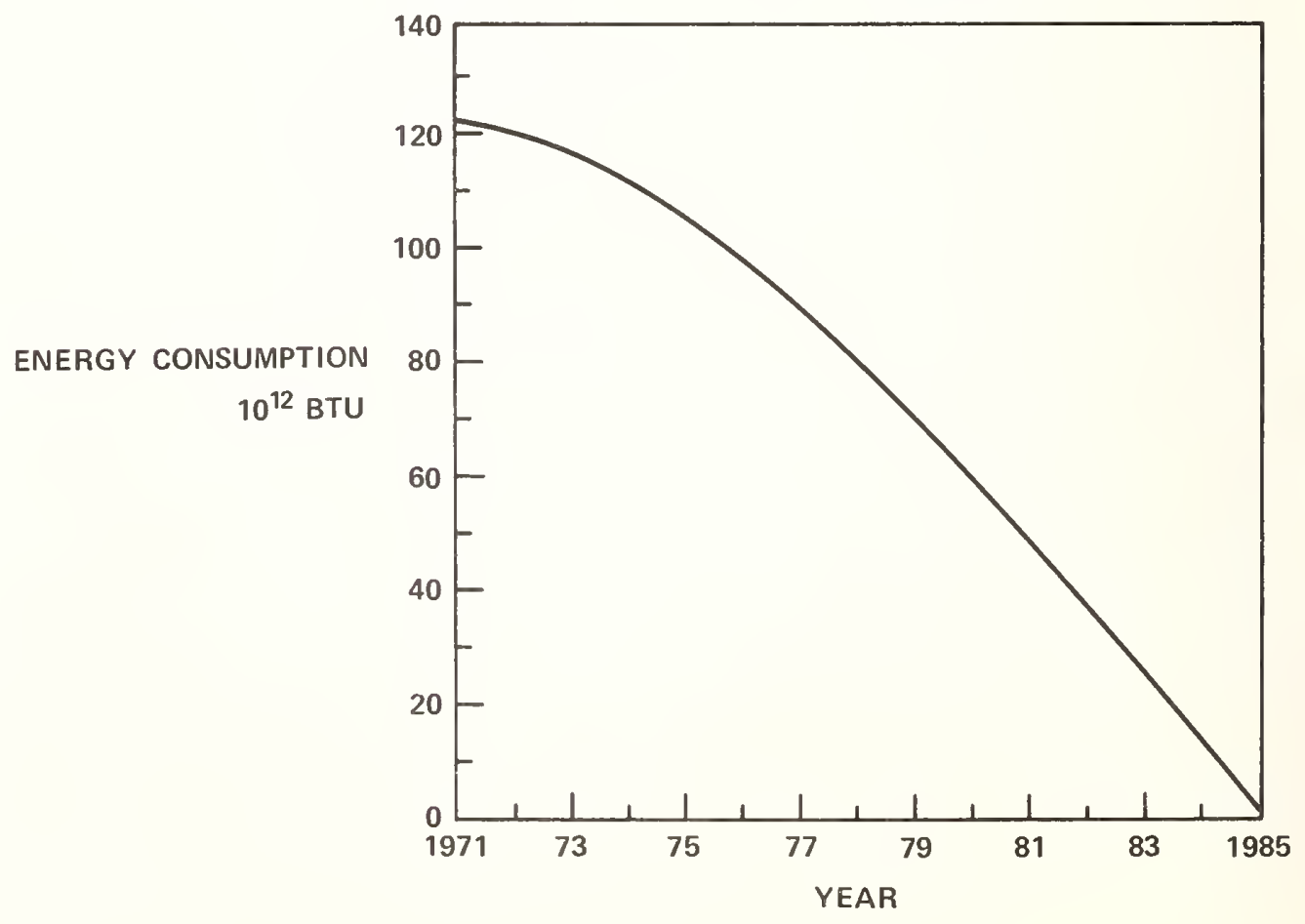


FIGURE 29

ENERGY REQUIREMENTS FOR BOILERS TO PRODUCE PROCESS STEAM FOR THE IRON AND STEEL INDUSTRY

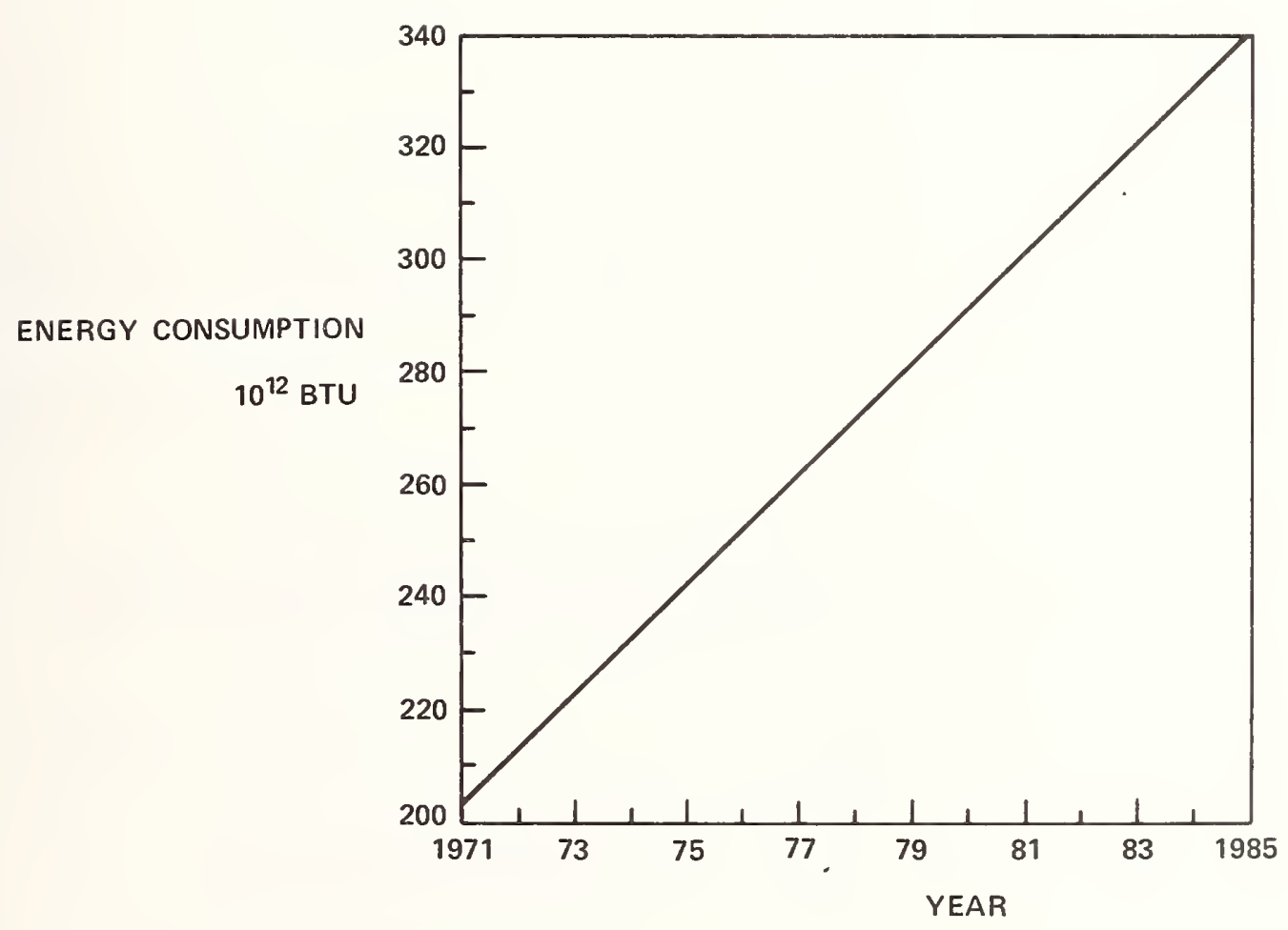


ENERGY CONSUMPTION $10^{12}$ BTU

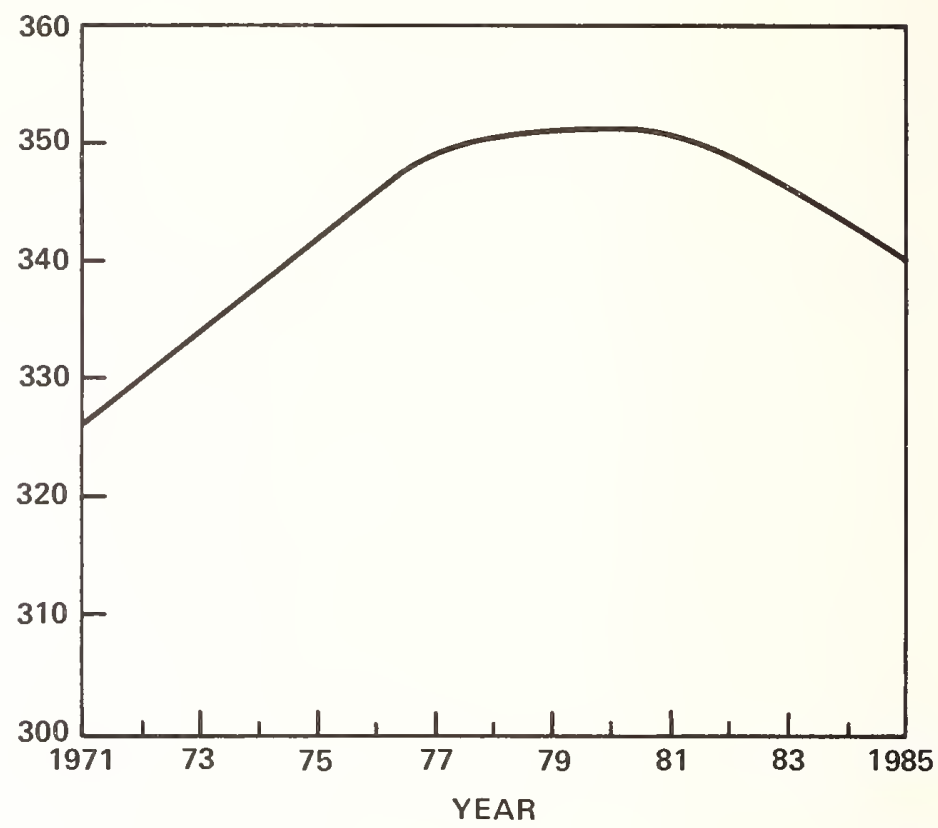

FIGURE 31

BREAKDOWN OF IN-PLANT-GAS USE FOR STEELMAKING TO FINISHED PRODUCT PROCESSES AND FOR USE TO GENERATE STEAM, ELECTRIC POWER, AND MISCELLANEOUS PROCESS HEAT

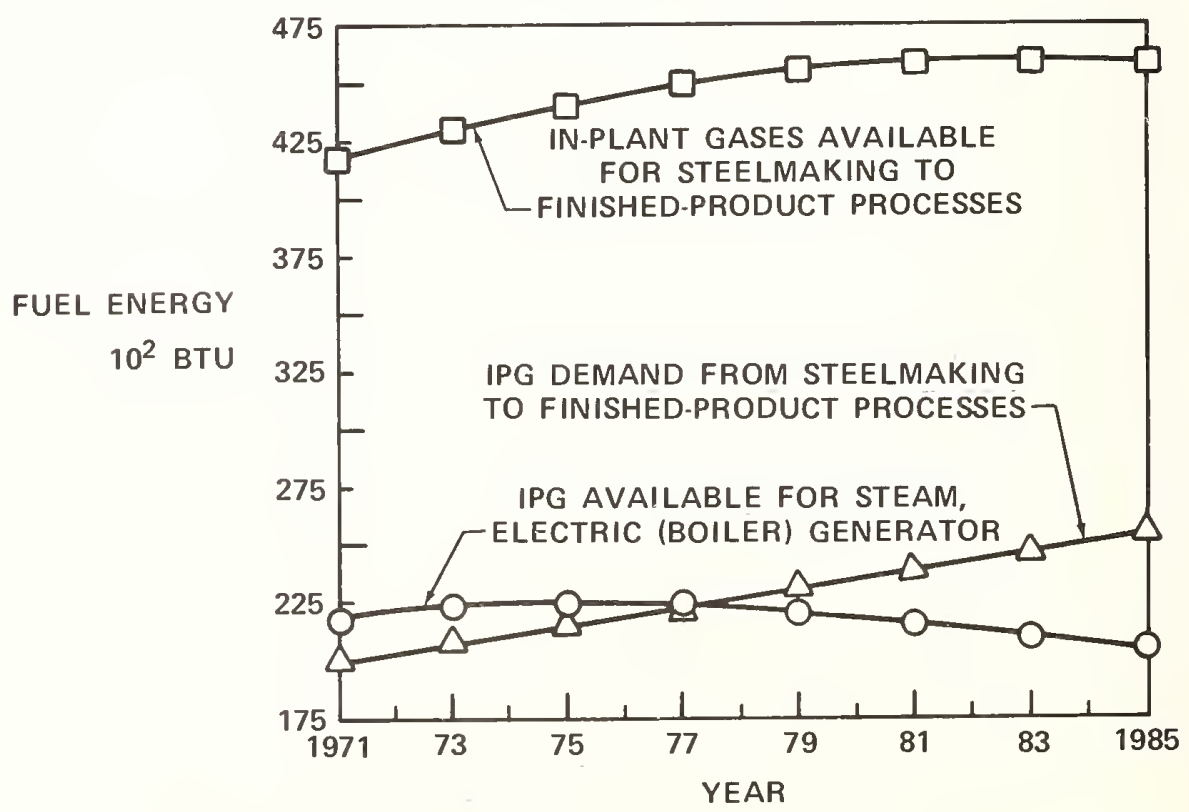


FIGURE 32

PROJECTION OF COAL ENERGY DEMAND FOR OPERATING STEEL INDUSTRY BOILERS

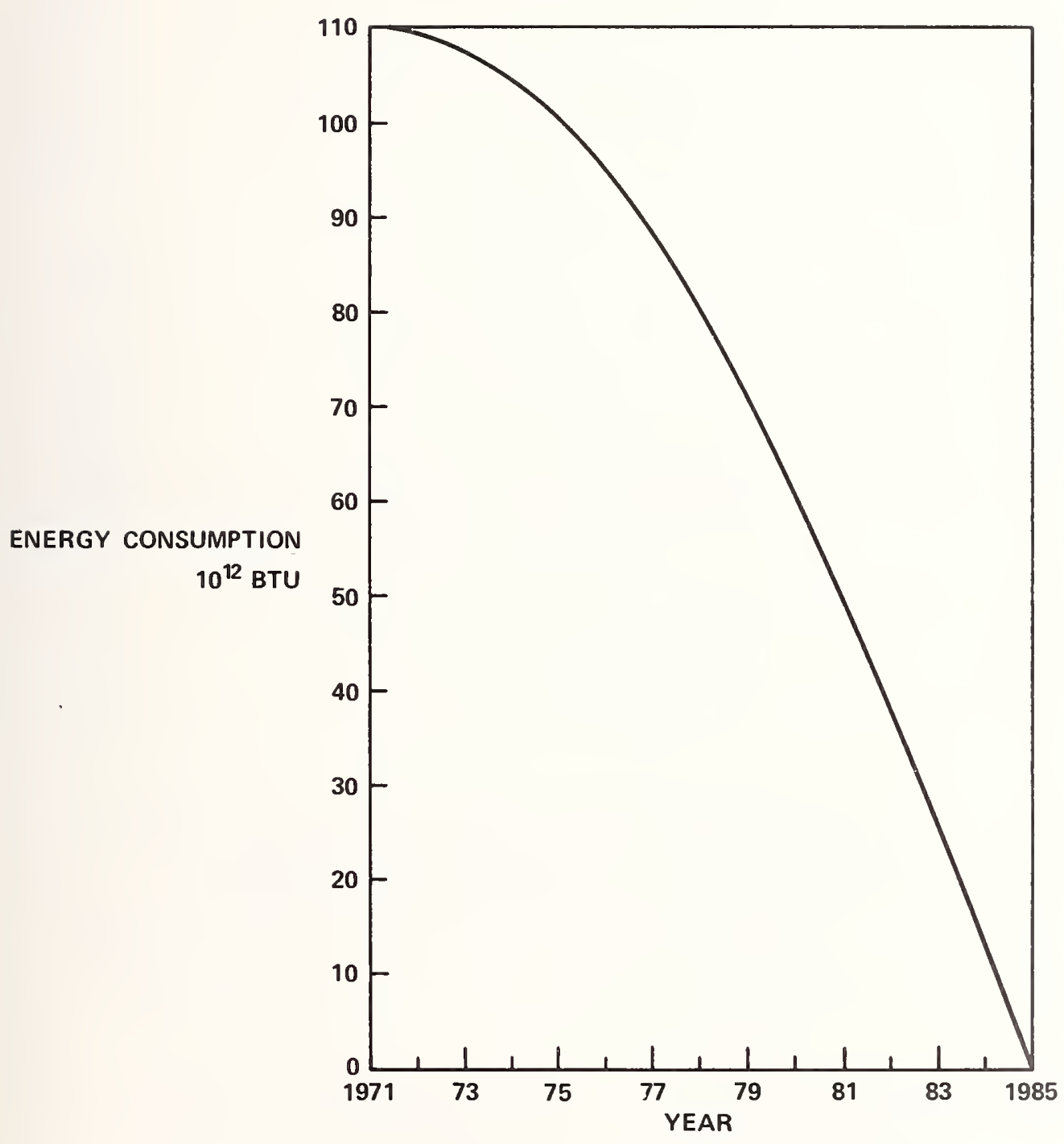




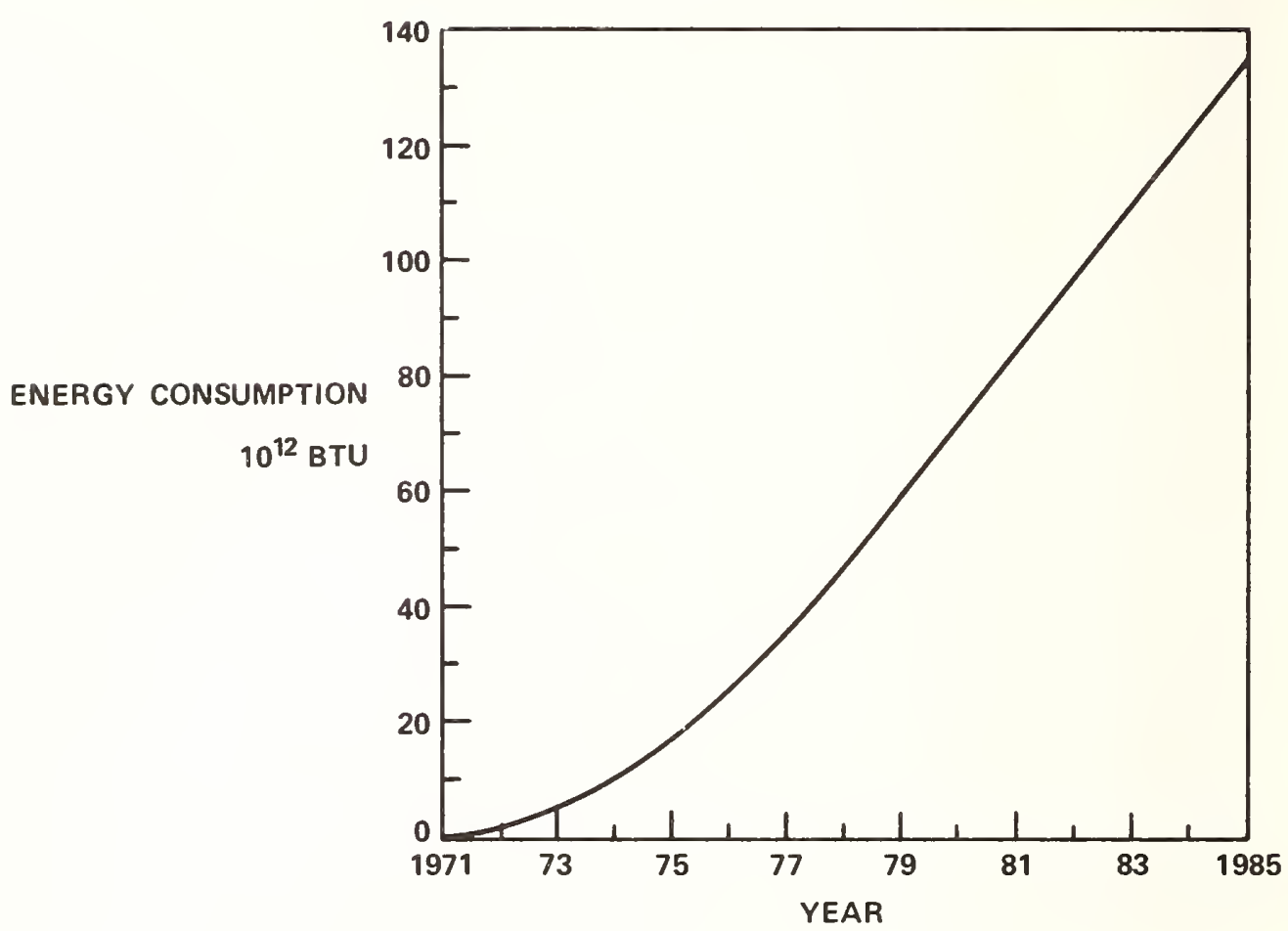

FIGURE 34 PROJECTED DEMAND FOR HYDROCARBON FUELS FOR "OTHER" PLANT USES

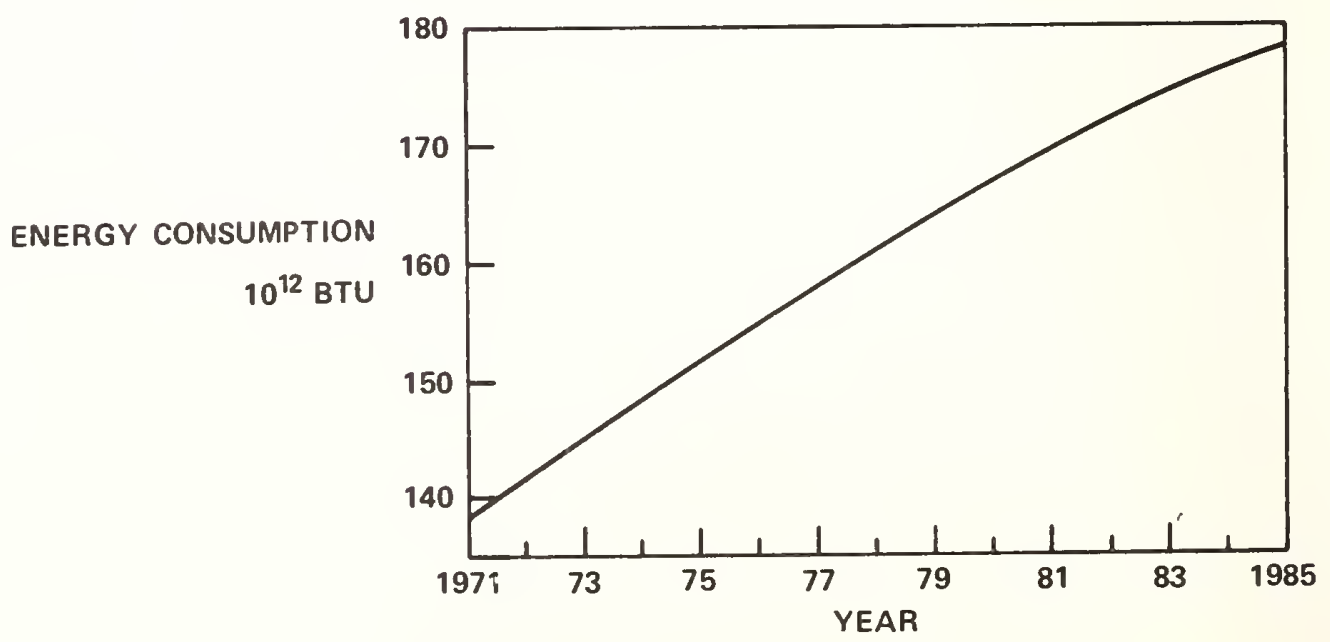


By assuming (from 1iterature data) that about 3.23 BTU of fossil-fue 1 energy is needed to produce 1.0 BTU of electric power, the consumption of fossil-fuel energy for electric power generation is projected to decline from about 123 trillion BTU in 1971 to near 0.0 in 1985 (Figure 28).

Energy Consumption for Process Steam Production

In addition to producing steam to run turbines for electric power generation, the steel industry boilers produce steam for direct process applications, such as forge hammers. Historically, the energy required to produce enough steam for plant operations has amounted to about $1.7 \mathrm{million}$ BTU/ton of steel produced. This average was distilled from data relating steam generation in millions of pounds per year to boiler efficiencies and steel production rates. Based on the projected steel production (Figure 17) and the energy required for steam as shown above, a projection (Figure 29) of fossil-fuel energy demand from 1971 to 1985 was prepared. This analysis shows that energy consumption for steam production will increase some 140 trillion BTU/year over the next 12 years.

The result of a decreasing demand for steam for self-generated electric power together with an increase in demand for direct process steam (Figure 30) will be an increase in fossil-fuel consumption until about 1978 and then a decrease from 1978 to 1985 .

The steel industry boiler can readily operate using in-plant gases, natural gas, oil, or boiler-grade coal. Typically, any excess in-plant gases are burned in the boilers, and purchased fuels make up the differences between total demand for energy and availability of in-plant gases. We summed the demands for in-plant gases by all other processes described earlier and then subtracted this sum from the total available in plant gas supply (Figures 14 and 15). This analysis showed that the availability of in-plant gases for boilers will increase slightly from 1973 to 1977 and then decline from 1977 to 1985 (Figure 31).

As a result, purchases of other fossil fuels will be increased. The sure-to-come increased demand for purchased fuels for boilers can be satisfied by coal, oil, or natural gas. We cannot be certain what fuel split will result from the current energy situation. An historical analysis would indicate that coal firing will decline rapidly (Figure 32) and be replaced by oil and natural gas (Figure 33). However, shortages of oil and gas may change the historical trend very significantly.

Demand for Energy for General Plant Uses

The iron and steel industry uses significant quantities of energy for such things as flame-cutting of steel and direct-fired space heating. The uses are too numerous to project energy consumption on an individual basis. However, the total consumption of energy for these general applications is equivalent to about $10.5 \%$ of all other process energy, excluding coal for coking. A summation of energy demands by all other processes multiplied by 0.105 shows that the consumption of energy for al1 "other" uses will rise steadily from about 138 trillion BTU in 1971 to about 175 trillion BTU in 1985. See Figure 34.

Aggregation of Detailed Analysis

In order to determine the demand for energy in the form of fossil fuels by the steel industry, all the fore-going information was integrated into an overall industry energy balance. This resulted in the data shown in Figure 1, which is a projection of the demand for all purchased fossil fuels between 1973 and 1985. In addition to the direct demand for fossil fuels, the steel industry will purchase fuels indirectly in the form of electric power and oxygen. This result also is derived from the foregoing discussion and the energy balance and is shown in Figure 35. 
FIGURE 35

PROJECTION OF TOTAL PURCHASED ELECTRIC

POWER, BOILER-GRADE COAL, AND PURCHASED

OXYGEN (Energy Equivalent) ENERGY

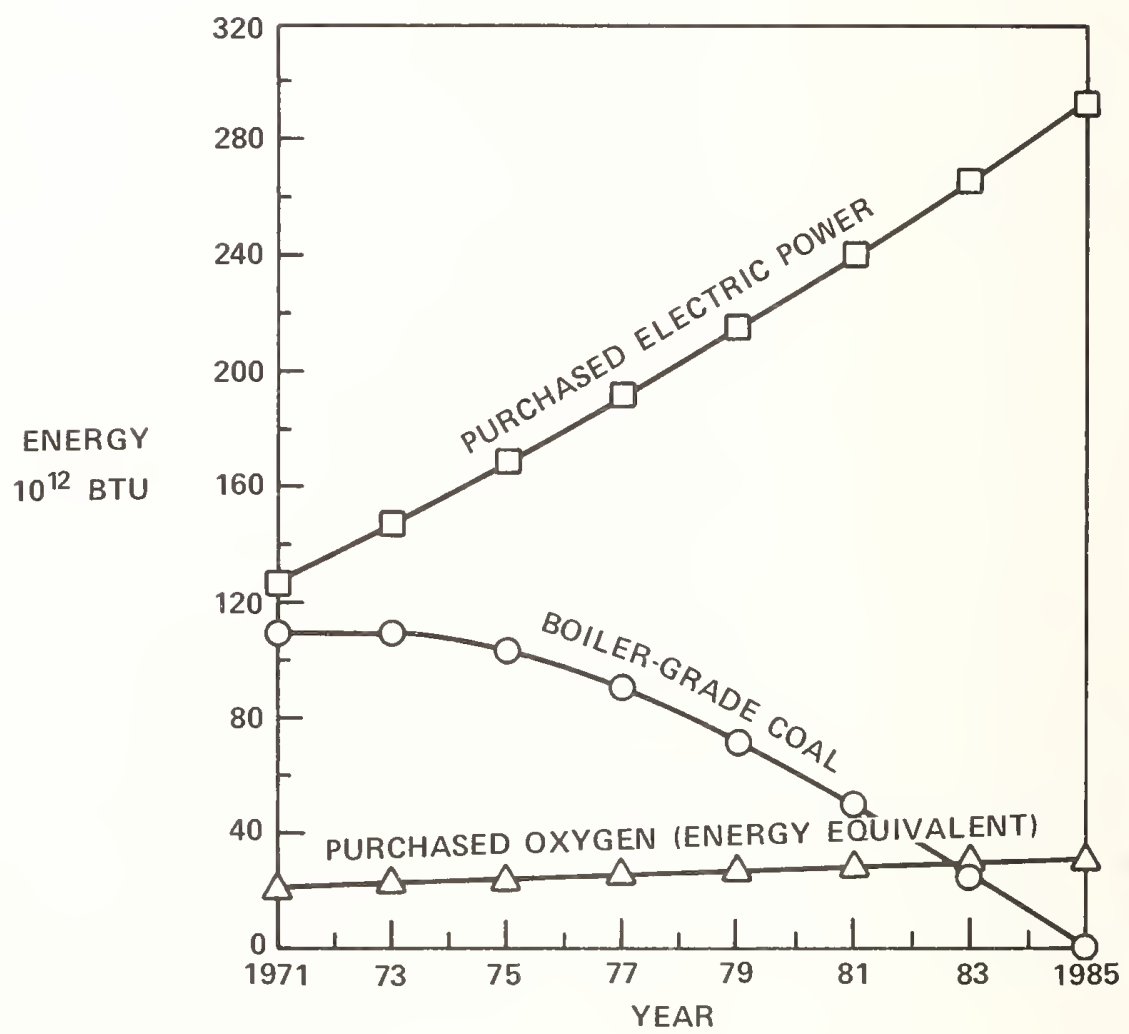


National Bureau of Standards Special Publication 403

Proceedings of 1973 Engineering Foundation Conference

(Issued June 1976)

POTENTIAL ENERGY SAVINGS IN

THE FORMING OF PAPER

by

T. Speidel, Thermo Electron Corp.

P. 0. Box 269

Sword Street

Auburn, Massachusetts 01501

D. Kallmes, $M / K$ Systens

\begin{abstract}
The United States produced 59 million tons of paper and paper products in 1972 requiring $320 \times 10^{12}$ BTU exclusive of the energy required to produce the necessary wood pulp. The conventional paper forming process is described in brief. A new method of forming paper is described having the potential of saving $40 \%$ of the energy conventionally required to form paper. The new method can make high quality paper utilizing up to $2 \%$ suspended wood pulp. A helical mixer with a high shear component in the jet permits a $35 \%$ decrease in the heat required during the process. This process is particularly attractive where fuel oil or fuel gas is used to supply the heat rather than waste bark and black liquor.
\end{abstract}

Key Words: Energy; industrial; paper

$\underline{\text { Summary }}$

In 1972, the United States produced 59 million tons of paper and paper products. This paper production required $320 \times 10^{12}$ BTU, exclusive of the energy required for first producing the necessary wood pulp. The conventional paper forming process is described in brief. A new method of forming paper, as developed by Thermo Llectron Corporation's Lodding Engineering Division, has the potential of saving $40 \%$ of the energy conventionally required to form paper. This new method, as embodied in the Lodding K-Former, and the energy saving potential are described in detail.

Conventional Paper Forming Process

Today, most wood pulp that is made into paper is formed on a machine whose basic principle was invented in 1799. This machine is called a Fourdrinier after its inventors. Figure 1 shows a schematic of such a machine. The pulp rixture, or stock (199 1bs. of water per $1 \mathrm{lb}$. of wood fiber), is pumped into a head box which feeds the water-pulp mixture from the slice opening, as a jet, onto an endless, rapidly-moving screen known as the Fourdrinier wire. The large water to fiber ratio $(0.5 \%$ solids content; termed $0.5 \%$ consistency of the stock) is presently required to assure a uniform dispersion of the fiber free from fiber flocculation.

As the stock nixture is deposited onto the wire, the excess water is drained through the wire by the forming board, foils, and flat boxes. By the time the wire reaches the couch roll where the web is transferred from the Fourdrinier wire to the press felts, a thin, wet web, now $4 \mathrm{lbs}$. of water per $1 \mathrm{lb}$. of fiber ( $20 \%$ consistency), is formed. The press felts (endless belts of heavy cloth) carry the weak paper web through the successive sets of press rolls. These rolls remove further water in much the same manner as huge wringers. The web now begins to resemble paper and can support its own weight. After the web of paper goes through the presses there is $1.5 \mathrm{lbs}$. of water per $1 \mathrm{lb}$. of fiber, or a $40 \%$ consistency. 


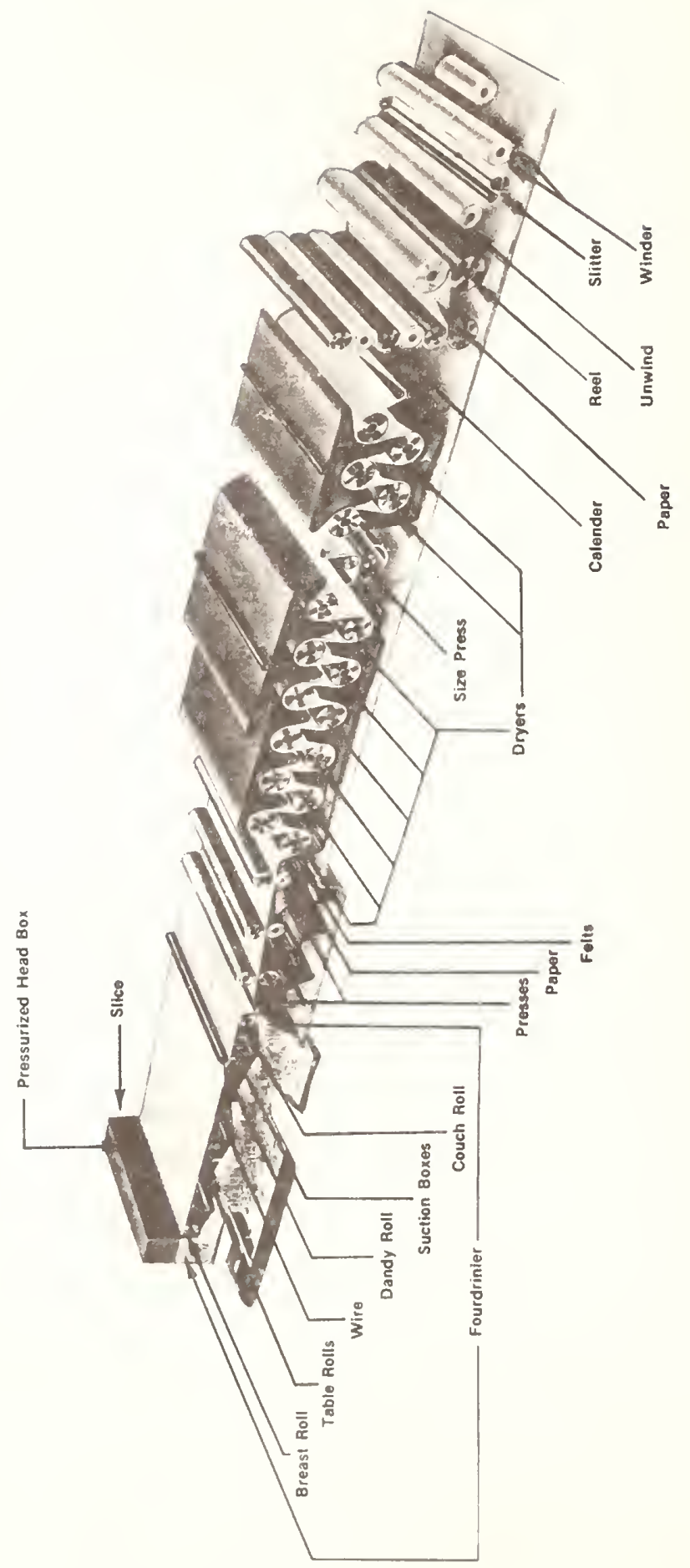

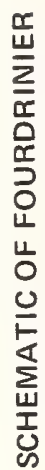

$\frac{5}{\frac{1}{5}}$ 
Fron the presses the web of paper moves into the dryers, a series of rotating cylinders continually fed with high pressure steam. The web is alternately wrapped around top and bottom dryer cylinders so that the remaining water is evenly evaporated from both sides of the web. The dried paper web contains 0.05 to $0.07 \mathrm{lbs}$. of water per pound of fiber. This small amount is necessary to prevent brittleness. As a final step, the paper is passed through a series of heavy revolving steel rollers, known as calenders. The calenders give the sheet of paper the finished surface. The paper is wound into jumbo rolls, 8 feet in diameter. These rolls are moved to winding machines where they are cut into smaller rolls of various widths and diameters as required by the users.

Thus, the present forming of $1 \mathrm{lb}$. of paper starts with stock of $1 \mathrm{lb}$. of fiber and 199 1bs. of water, from which $195 \mathrm{lbs}$. of water is drained on the Fourdrinier wire, $2.51 \mathrm{bs}$. of water is mechanically removed in the presses, and $1.5 \mathrm{lbs}$. of water is evaporated in the dryers.

Problems with Present Day Headboxes

As every papermaker knows only too well, pulp fibers flocculate extremely rapidly and the flocs are difficult to break up. The rate at which a suspension flocculates is a function of several characteristics, in particular the length of its fibers, their concentration or consistency, and the amount of microturbulence which the suspension contains. By microturbulence, we mean energy supplied over extremely small distances, of the order of millimeters or less. This energy is best supplied by creating pressure drops, changing the direction of flow, etc.

It has only recently been demonstrated that following the removal of energy input, microturbulence dissipates and excessive flocculation (i.e., over and above the amount in a random suspension) sets in within a matter of milliseconds. Table I shows the order-ofmagnitude of the times required for incipient flocculation at various consistencies.

TABLE I

\begin{tabular}{|c|c|}
\hline & TIME REQUIRED FOR MICROTURBULENCE \\
CONSISTENCY & TO DISSIPATE, SECONDS \\
\hline $0.5 \%$ & ABOUT 0.5 \\
$1.0 \%$ & ABOUT 0.1 \\
$2.0 \%$ & 0.04 \\
$3.0 \%$ & 0.01 \\
$4.0 \%$ & 0.001 \\
\hline
\end{tabular}

It should be evident that microturbulence must be supplied to the stock throughout its passage through the headbox, or the stock residence time must be kept well below a second. Every headbox that has essentially a box-like structure meets neither of tinese requirements, i.e., none of them supply any true microturbulence, and the residence time in them is three seconds or over. Thus, it is impossible for a headbox to deliver anything but a flocculated suspension to a wire, which has to be redispersed on the Fourdrinier before it can be formed into a saleable sheet.

Conventional headboxes even out the inconing, flows by providing a cavernous volume, or dead space, in which they intermingle. Throughout most of its passage through the headbox, the flow of the stock is laminar. A very snall anount of low energy, large scale (i.e., operating over a large distance) turbulence is introduced by the slowly turning rectifier rolls. The low level and the large scale of this turbulence is dranatized by the "holey" 


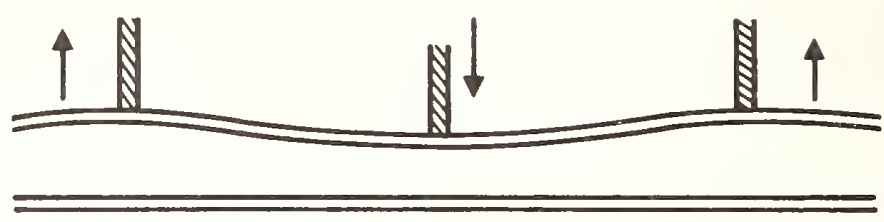

Downward Motion of Center Screw Causes Upward

Deflection of Slice Lip Beyond Neighboring Screws

FIGURE 3 K-FORMER

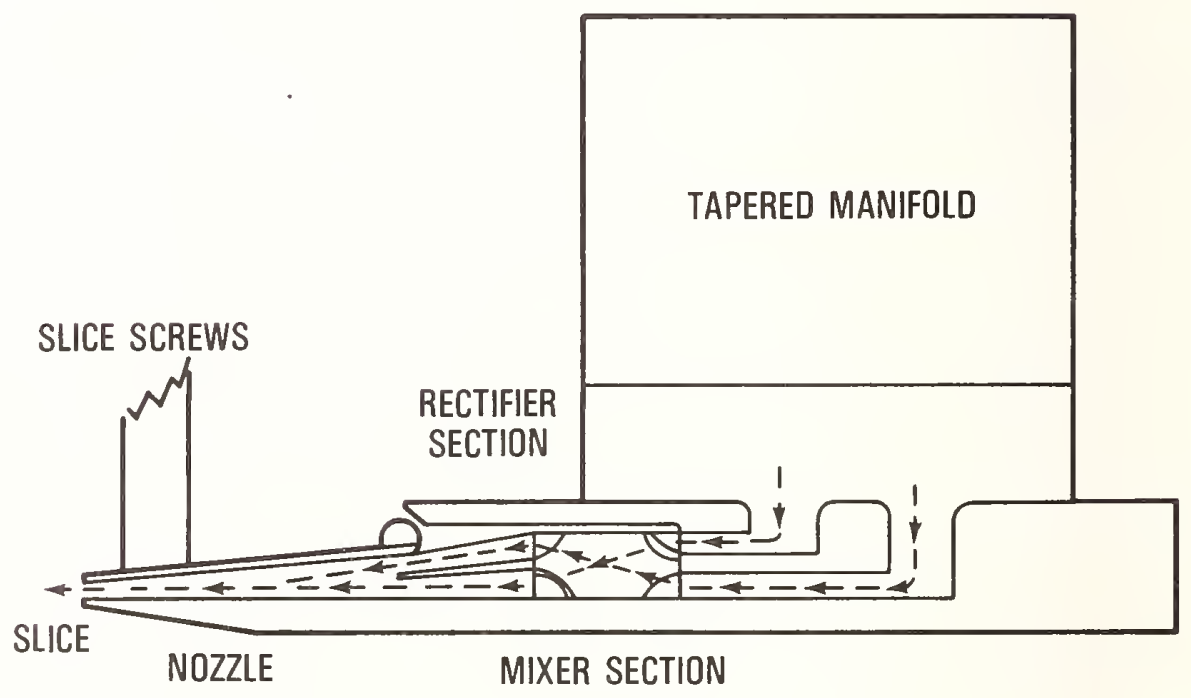

FIGURE 4 SCHEMATIC REPRESENTATION OF FLOWS OUT OF END OF MIXERS

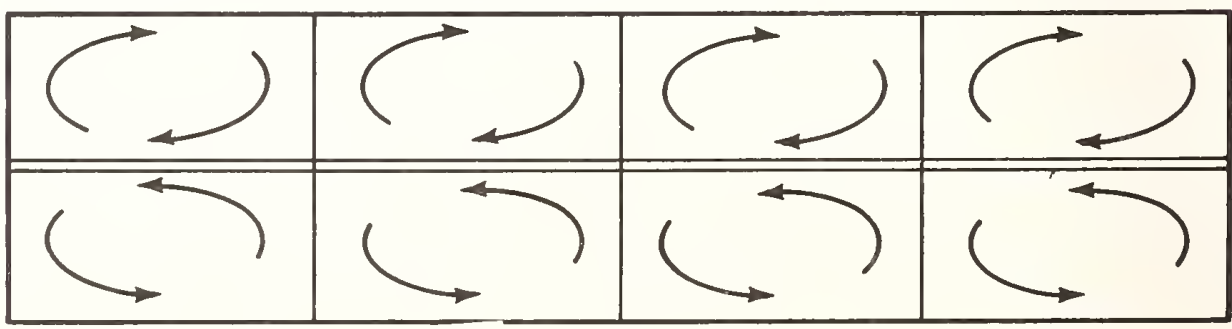


roll" pattern which often appears in a sheet. In fact, we believe that the only contribution which a rectifier roll can make to deflocculation is to break up extrenely large flocs into intermediate or smaller sized ones. It is impossible for a rectifier roll to break up flocs into individual fibers.

The major difference among headboxes lies in the uniformity of the badly flocculated flows which they deliver to the wire. Headboxes with well-designed manifolds operating within their design specifications produce much more uniform flows than those with an unequal cross-direction feed. If a manifold is designed or operated in such a manner that it tends to deliver a non-uniform flow to a headbox, the headbox per se is virtually powerless to correct it because its resistance to flow is negligible. A higher flow (per unit width) coming in on one side of a headbox virtually passes straight through it and can only be partially slowed down by closing down of the slice opening. In other words, a headbox is a zero-resistance systen or a short-circuit. If it contained resistances across its width which were relatively large compared to that of the manifold and its laterals, then the headbox rather than the manifold would govern the delivery of stock to the slice.

In order to compensate for all of their shortconings, individually and in combination (i.e., non-uniform flows, variable consistency, headbox deflections, lateral stock motion on the wire, etc.), headboxes are equipped with slice screws. A slice screw is basically a crude and inaccurate valve. Cutting the flow in one zone of the slice by adjusting one screw causes the flow to increase slightly in the two adjacent areas (see Figure 2). Obviously, any change in the flow to the back of a headbox (due to a speed or basic weight change, etc.) will cause a change in the flow at the slice which, in turn, will negate some or all of the corrections due to the previously-made slice screw settings. Clearly, there is no way in which the slice screw settings can permanently correct the deficiencies of a headbox.

Recognizing the shortcomings of corrections made by slice screws, the paper industry has resorted to computerizing the slice screws rather than correcting the basic hydraulic inadequacy of headboxes: their virtually total lack of resistance to flow.

Construction of the Lodding K-Former

Three years ago, Lodding first recognized the underlying shortcomings of conventional headboxes. We set out to find a device capable of transporting the stock from the manifold to the slice in such a way that it delivers a jet that is ultra-uniform in its dimensions and velocity, that simultaneously maintains or even enhances the uniformity of dispersion of its fibers, and that has high intensity micro-turbulence. The result is the Lodding K-Former.

The underlyine principle of the K-Former is that when a fluid or stock is spun sharply around an axis, a tremendous amount of mixing, shear, or microturbulence is created. However, a spin or vortex in a stock delivered to a Fourdrinier wire must be avoided at all costs in order to prevent terrible streaking or worming. Ilence, the second part of the problen was to find a means of rectifying and evening out the flow of individual spinning stock flows in a mininum of time before their nicroturbulence dies out.

The $\mathrm{k}$-Former employs a bank of parallel single blades making a $180^{\circ}$ twist in $2-1 / 4^{\prime \prime}$ long, one-inch square ducts to create the desired nicroturbulence. A $100^{\prime \prime}$ machine would have 100 of these mixers set side by side, and a 200" machine would have 200 mixers. The mixers are fed from the manifold by a special connecting section which eliminates all possible chances of fiber hangup, plugging, etc., as shown in Figure 3.

The feed and discharge edges of the twisted blades are set parallel to the plane of the sheet. Thus, the stock which enters the top chamber of each mixer leaves via the bottom one, and vice versa.

All the twisted blades have the same sense of rotation; it is irrelevant whether it is clockwise or counterclockwise. When viewed from the discharge end, the flows, out of the top chambers of a clockwise twisting unit, tend to spiral downward and to the right; those out of the botton, upward and to the left. These spirals are eliminated in the rectifier chamber which directly follows the mixer section. 
The rectifier chamber is a short section (1"- $3^{\prime \prime}$ in length, depending on the application), the same height as the turbulator ducts or with a linear taper. It is empty except for a rigid, thin, horizontal rectifier blade in its center the length of the chamber, butted up against the trailing edge of the twisted blades (see Figure 3).

The rectifier blade eliminates most of the spiral component of the flows discharged from the top chambers simply by preventing then from making their downward and to the right movement, and by allowing mixing of adjacent flows. The flows from the bottom chambers are treated similarly. When the two flows are combined at the end of the rectifier chamber, any residual spirals as well as any tendency of the top flow to twist to the right, or the bottom to veer to the left, are eliminated as shown in Figure 4.

Wakes which might be created by the vertical walls separating the ducts are eliminated by the transverse component of the stock flows, as well as by its high level of microturbulence. The rapid elimination of potential wakes allows for the use of extremely short slicenozzles in which the residence time of the stock is too short for the microturbulence to dissipate significantly.

The rectifier chamber is usually tapered, over a length of $1^{\prime \prime}$ to $3^{\prime \prime}$, from one inch down to the maximum height of the slice opening for two reasons. Firstly, it minimizes the residence time of the stock in this section. Secondly, the small acceleration given the stock helps to maintain microturbulence.

The flow from the rectifier chamber is delivered to the wire by means of a short nozzle ( $3^{\prime \prime}-6^{\prime \prime}$ in length). 'This nozzle has a variable taper so that the slice opening can be adjusted to the desired value.

Because of the intense microturbulence generated by the Lodding K-Fomer stock delivery system, and the very short residence times, the utilization of high consistency stocks is allowed on the Fourdrinier wire without the danger of flocculation. Thereas a conventional headbox operates in the range of 0.5 to $1.0 \%$ consistency (199 1bs. to 99 lbs. of water per $1 \mathrm{lb}$. of fiber); the Loddins, K-Former can operate at $1.0,2.0$ or $3.0 \%$ consistency (99, 49 , or $32 \mathrm{lbs}$. of water per $1 \mathrm{lb}$. of fiber) and make acceptable paper.

\section{Lodding li-Former Operating Experience}

The first Lodding $\mathrm{K}$-liormer has been operating continuously in a tissue mill since larch 15, 1973. The machine previously produced a hand towel product at 0.4 to $0.5 \%$ headbox consistency. After replacing the headbox with the Lodding [-Former, the same hand towel sheet is now made at consistencies of 0.8 to $1.4 \%$. In addition, operating with the $\ddot{H}$-Former, the same machine is now able to produce a lap-pulp sheet from de-inked waste paper at headbox consistencies up to $2.3 \%$

\section{Energy Considerations}

It should be apparent that the use of higher consistency stocks in the 1-2\% range with the K-Former and the ability to press wet webs to much higher solids contents should result in a very considerable reduction in the amount of energy required to drive a paper machine and to dry the paper. This section shows approximately what these energy savings might be in a typical situation.

A specific example for this calculation was used because it is impossible to obtain detailed information on an average paper machine; it simply does not exist. Every paper machine is unique, and its drive requirements differ from that of every other machine. Furthermore, one item - the energy to dry the sheet - predominates, and a very detailed picture of the drive requirements would be somewhat meaningless. Therefore, an energy analysis was taken for a typical newsprint machine for which the best data were available.

Two sets of calculations are presented. First, the energy consumption of a typical conventional machine is calculated, prinarily using data from TAPPI Data Sheet 014.07, Power kequirements of Fourdrinier iachines. Second, the energy consumption was estinated for a hypothetical paper machine consisting of a K-Former and a reduced number of drier cans. 
It has been shown that the saturation point of fibers is $65-70 \%$ solids. In other words, If all of the water were removed from the inter-fiber pores of a web, but the fibers remained saturated, the web would have a solids content of $65-70 \%$. This range then represents the theoretical maximum solids content which can be achieved in pressing. Higher values could only be achieved by crushing and damaging the fibers.

A web formed from high consistency stock is more porous; therefore, water and molsture are more readily removed by pressing than a conventionally formed sheet. In tests using a single press with a loading of only 190 pounds per lineal inch, pli (normal multiple press loadings are on the order of $1000 \mathrm{pli}$ ), a newsprint sheet formed by the K-Former has been pressed to a solids consistency of $47 \%$.

We believe that $\mathrm{K}$-iormed sheets could be pressed by modern presses to somewhere in the 50-55\% range. As can be seen from Table II, an increase in the solids content of the web entering the drier section from $40 \%$, which is about the value now achieved on the average, up to $50 \%$ represents more than a one-third reduction in the amount of steam required for drying: going to 55\%, almost a halving. These savings can, of course, be passed directly back to fuel savings. Thus, K-Forming opens up the possibility for tremendous savings in the fuel consumption of a paper mill.

TABLE II

\begin{tabular}{|c|c|c|}
\hline $\begin{array}{l}\text { PER CENT } \\
\text { SOLIDS }\end{array}$ & $\begin{array}{l}\text { POUNDS OF WATER } \\
\text { WHICH HAVE TO BE } \\
\text { REMOVED BY DRYING ONE } \\
\text { POUND OF PAPER TO } 93 \%\end{array}$ & $\begin{array}{c}\text { PER CENT } \\
\text { REDUCTION IN } \\
\text { STEAM CONSUMPTION } \\
\text { OVER } 40 \% \text { SOLIDS }\end{array}$ \\
\hline 35 & 1.78 & -- \\
\hline 40 & 1.42 & -- \\
\hline 45 & 1.14 & 20 \\
\hline 50 & 0.92 & 35 \\
\hline 55 & 0.74 & 48 \\
\hline 60 & 0.59 & 58 \\
\hline
\end{tabular}

Table III compares the operating conditions and normal running loads of the major units of a typical conventional newsprint machine to those of a hypothetical K-Former machine producing the same tonnage. Table IV gives the calculated power consumptions for the same two machines. 
TABLE III

OPERATING CONDITIONS

\begin{tabular}{lcc}
\hline & $\begin{array}{c}\text { CONVENTINAL } \\
\text { MACHINE }\end{array}$ & $\begin{array}{c}\text { LODDING } \\
\text { K-FORiER }\end{array}$ \\
\hline Machine Width, in. & 250 & 250 \\
Machine Speed, fpm & 2500 & 2500 \\
Basis Weight, lb/3000 ft ${ }^{2}$ & 32 & 32 \\
Daily Production, tpd & 400 & 400 \\
Headbox Consistency, $\%$ & 0.6 & 2.0 \\
Jet Speed & 2500 & 85 \\
Wire Retention, \% & 66.7 & 4000 \\
Fan Pump Flow, gpn & 17000 & 55 \\
Fan Pump Pressure, psi & 60 & 50 \\
Solids Content Entering Dryer, & 40 & \\
\hline
\end{tabular}

TABLE IV

PONER CONSUIPTION PER TON OF PAPER

FOR 400 TONS/DAY PAPER MACHINE

\begin{tabular}{|c|c|c|}
\hline & $\begin{array}{l}\text { CONVENTIONAL } \\
\text { :LACIIINE }\end{array}$ & $\begin{array}{r}\text { LODDING } \\
\text { K-FORIER }\end{array}$ \\
\hline ELECTRICAL REQUIREMENTS & $k w-h r$ & $k w-h r$ \\
\hline Stock Feed System & 102 & 35 \\
\hline Fourdrinier & 9 & 5 \\
\hline Presses & 18 & 10 \\
\hline Dryers & 20 & 12 \\
\hline Calender \& Reel & 10 & 10 \\
\hline TOTAL KW-IIRS/TON & 159 & 72 \\
\hline THERIAL REQUIIRELENTS & Btu/ton & Btu/ton \\
\hline Dryers & $3.7 \times 10^{6}$ & $2.4 \times 10^{6}$ \\
\hline
\end{tabular}


Even though these calculations are of an approximate nature, and are nade for only one specific example, several general conclusions can be drawn.

1. The dryer section is by far the largest single user of energy in a paper mill. Even after assuming that the total energy consumption of this example mill is $50 \% 1$ arger than the value we calculated (we omitted refiners), the energy required at present to dry the sheet from $40 \%$ to $93 \%$ solids still represents $80 \%$ of the total consumed.

2. The ability to form a sheet which can be pressed mechanically up to $50 \%$ solids instead of $40 \%$ reduces the energy requirements of this phase of the operation only by just over a third $(152 / 435=0.35)$. If a sheet could be pressed to $55 \%$, which is not altogether out of the question, the energy required would be almost halved. Clearly, the largest potential savings in energy reside in the dryer section by virtue of what might be accomplished in the press section.

3. Using higher consistency stocks, i.e., $1-1 / 2-2-1 / 2 \%$ instead of $1 / 2-1 \%$, will result in a substantial reduction in the power required to drive the fan pumps. This power savings is even larger than that which can be gained by the complete elinination of the Fourdrinier section.

4. For the specific example employed, the energy savings resulting from going to a higher consistency and the elimination of the Fourdrinier section are still only about $1 / 6$ and $1 / 12$ of those which can be nade by increasing the solids content of the wet web in the press to $50 \%$ instead of $40 \%$.

5. While the specific energy savings which can be achieved on every paper machine will differ from those calculated above, we are confident that the relative orders-of-magnitude of the savings will be the same. Therefore, from the standpoint of energy considerations, we have no doubt that the major effort of the paper industry should be geared toward producing saleable papers which can be mechanically dewatered to $50 \%$ solids or higher. From the work done to date, it appears that this is feasible by forming relatively bulky wet webs. 

National Bureau of Standards Special Publication 403

Proceedings of 1973 Engineering Foundation Conference

(Issued June 1976)

POTENTIAL FOR ENERGY CONSERVATION IN HEATING, VENTILATING, AND AIR-CONDITIONING EQUIPMENT FOR BUILDINGS

by

G. Kelly, T. Kusuda, and J. Hill

Thermal Engineering Systems Section

Center for Building Technology

National Bureau of Standards

Washington, D. C. 20234

\begin{abstract}
Approximately one-third of the Nation's energy use is presently used in residential and commercial buildings. Over seventy percent of the energy is being used for heating, cooling, and providing hot water. The potential for energy conservation through proper design and use of heating, ventilating, and air conditioning equipment within or in the proximity of buildings is discussed. The topics presented include a discussion of the positive and negative features of both unitary and central HVAC equipment, a description of typical all-air and air-water HVAC systems, the heat pump and how it can be combined with other equipment to conserve energy, and the recovery of energy from the building exhaust air. A brief description is given of total energy systems, modular integrated utility systems, and the utilization of waste heat from incineration plants. Considerable savings could be obtained from judicious choice of standard equipment based on energy conservation considerations. The use of life cycle costing rather than lowest possible first cost would vastly upgrade the present standards of practice.
\end{abstract}

Key words: Conservation; cooling; cost; energy; heating

$\underline{\text { Introduction }}$

Although it has been well recognized that the energy consumption for heating and air conditioning in buildings can be reduced considerably by adding more insulation, reducing air leakage, and decreasing the window area, little attention has been paid to the energy waste taking place in the heating, ventilation, air conditioning (HVAC) systems. Among buildings of similar construction with respect to type, insulation and window area, and having similar occupancy, the annual energy consumption could easily vary by a factor of six, depending upon a number of factors, including the type of HVAC system employed. Figure 1 shows a histogram, taken from data published by the Elegctric Heating Association, of the annual average rate of energy consumption expressed in watt/ft. of floor area of 29 all-electric buildings. The normalized annual average rate of energy consumption varies from 2.0 for an energy conserving building to 8.0 for buildings that use resistance heating and conventional cooling. This points out the potential significance of HVAC systems on energy conservation in buildings.

This potential for energy conservation through the proper design and use of conventional HVAC equipment is addressed in the first part of this paper. Consideration is given to the use of both individual unitary equipment and large central systems. Since central systems are usually employed in large buildings, several typical all-air and air-water systems are discussed from the standpoint of energy conservation. This is followed by a section on heat pumps which deals with the specific application of both vapor compression and absorption heat pumps in HVAC systems. The final section on standard equipment used in the heating and cooling of buildings concerns itself with the recovery of "waste"energy from exhaust air. Run-around coils, thermal wheels and the use of heat pipes are also discussed.

The second part of the paper deals with several systems which have a significant potential for conserving energy, but are not presently in common use. The special systems which are discussed are total energy systems, modular integrated utility systems, incinerator plants where the "waste" heat is recovered, and systems which employ solar energy in the keating and cooling of buildings. 


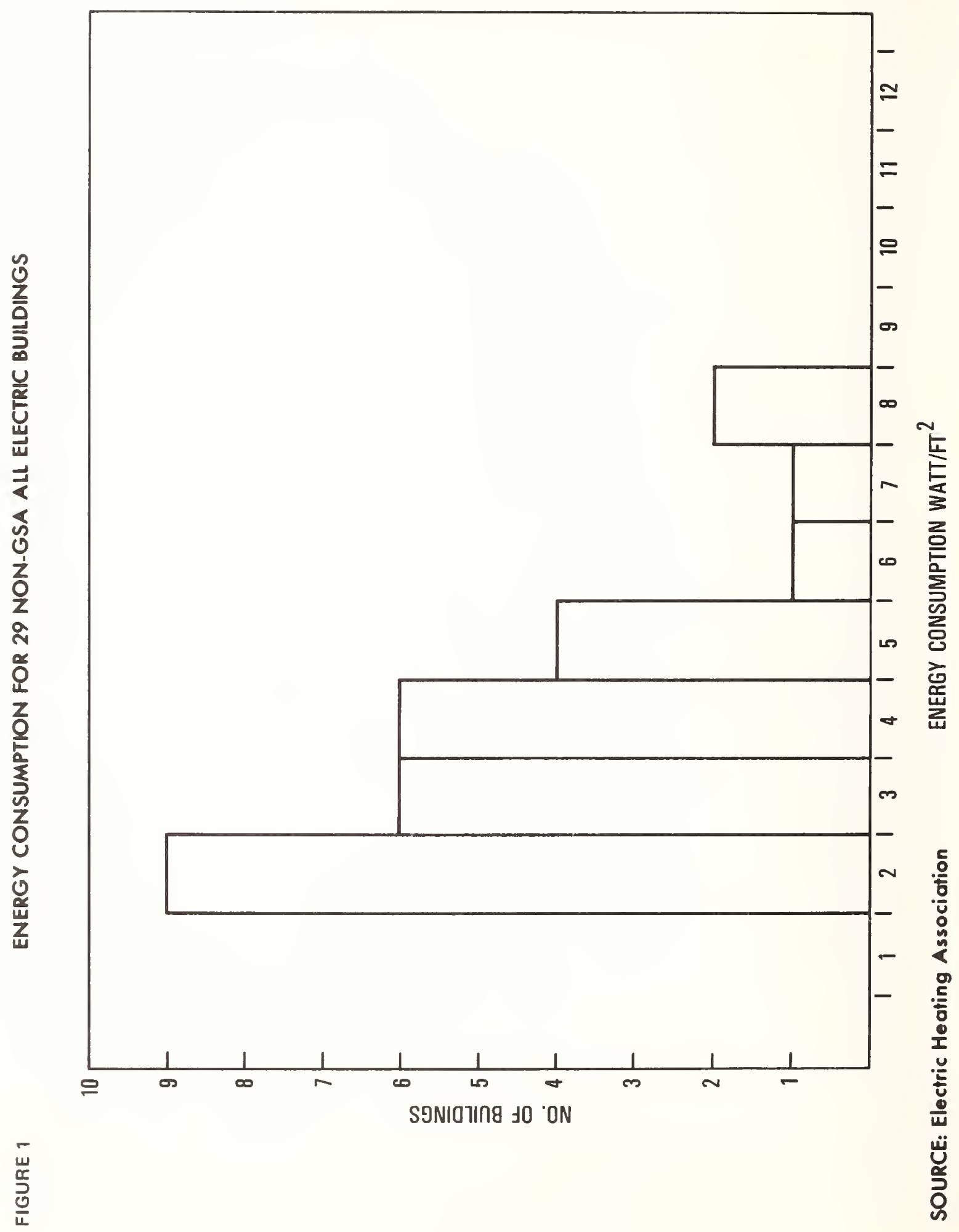


Unitary. Equipment Versus Central HVAC Systems

When technical options for energy conservation in HVAC equipment are discussed, one must give separate consideration to individual package type unitary HVAC equipment and large central systems because there are major differences in their operation and control. The individual unitary equipment is usually installed within the space to be heated or cooled, and its heating or cooling operation can be controlled strictly according to the need of that space. The central unit, on the other hand, serves many spaces, each having different heating and cooling requirements at any given time. For example, on an October day the area on the south side of a building may need cooling while the rest of the building requires heating. The central system in this case is expected to provide chilled air or water, depending upon the system, to the south facing zone, and simultaneously heated air or water to the rest of the building.

The energy saving options to be considered for the individualized unitary system are strictly related to improving the mechanical components and the manner in which they are assembled and maintained. Efforts are being made to improve the performance of this HVAC equipment through a labeling program. The manufacturers of the window type air conditioners are, for example, being asked to label the Btu/watt-hr value on their units. With respect to maintenance, an optimum schedule should be established for adjustments, changing of filters, tightening of fan belts, lubrication of moving parts, checking of refrigerant charge, etc .

For central systems, the above options for the unitary package are still valid. Additional consideration must be given, however, to the manner in which the heating and cooling effects produced at the central plant are distributed throughout the building .

The ideal HVAC system should be able to provide comfort to occupants in the conditioned space irrespective of the outdoor weather and the changes in the usage requirement of the space. Environmental parameters that have the most effect on comfort and are controllable by the HVAC system are the following: 1) air quality, cleanliness, and odor, 2) temperature, 3) humidity, 4) air velocity, 5) mean radiant temperature, and 6) noise. Most HVAC systems are designed to provide a satisfactory level of these parameters under a given set of design conditions which specify the outdoor temperature, humidity, wind condition, solar radiation, lighting level, occupant diversity and activity level, and the equipment and appliance usage schedule.

On actual installations however, the specified design conditions seldom, if ever, occur. Moreover, the conditions under which the system must operate are always changing. The greatest energy waste in HVAC equipment usually occurs when the system cannot cope with these changing requirements. In many cases the occupants in a large building find the space overcooled during the summer, overheated during winter, heated during the summer or cooled during the winter.

These types of system malfunctions can be readily corrected for small buildings having individual HVAC unitary equipment. Heaters and/or coolers can be regulated manually to satisfy the occupants' need at a specific time under specific conditions. If the individual home owner is paying his own gas and/or electricity bill, the energy waste can be made a minimum simply by adjusting the thermostat or shutting off the unit completely when heating and/or cooling are not needed. The overheating, overcooling, summer heating, or winter cooling problems are usually found with the large central systems, which are typically located in an unoccupied area of the building.

Although its ability to meet the changing demand of each individual space is limited, the central system is found in large buildings more often than the decentralized individual unitary system for the following reasons:

1. Energy efficiencies of boilers, pumps, fans, and refrigeration equipment are usually higher for larger central units than for small individual unitary equipment.

2. Centralized location of the major equipment consolidates operation and maintenance and permits the maximum choice of air filtration systems, odor and noise control systems, and high quality durable equipment.

3. The central system is readily adaptable for heat recovery or heat reclaim operation. The heat recovery system uses heat exchangers between the building exhaust air and outdoor makeup air whereas the heat reclaim system picks up the heat from lighting or other forms of heat generated within the interior zones of the building.

4. Air distribution and draft control is easily accomplished in the central system. 


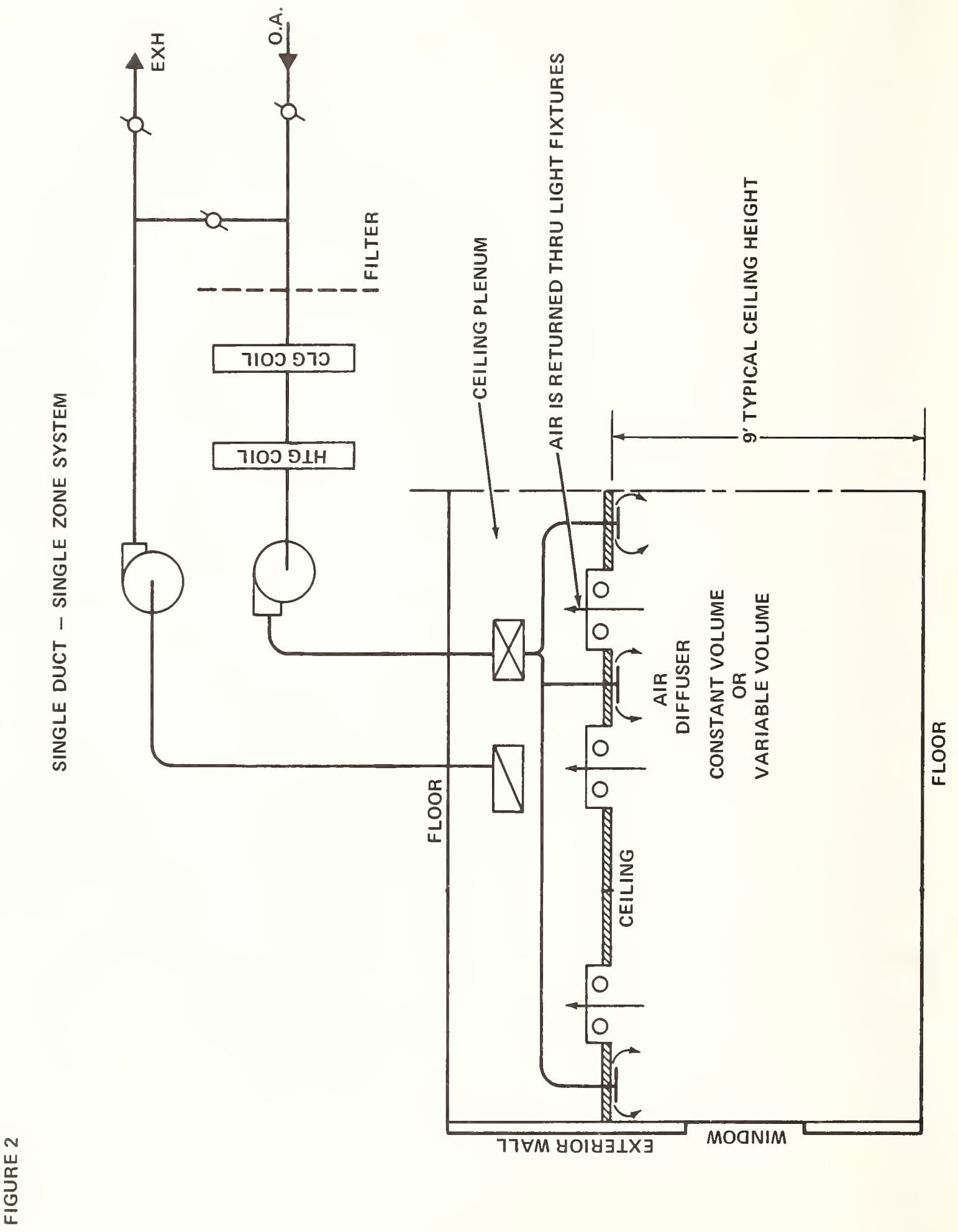




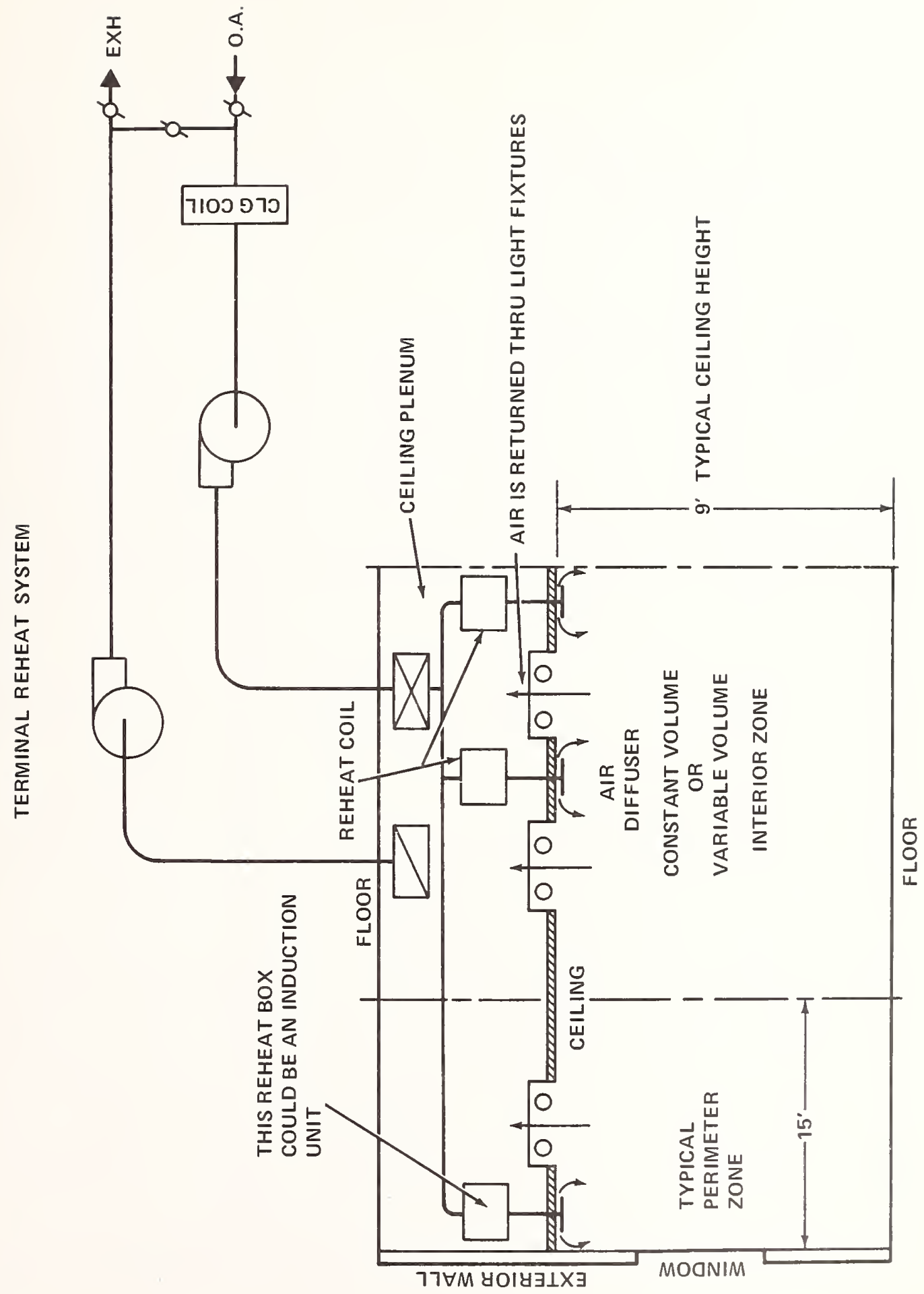

$m$
$\frac{n}{0}$
$\frac{0}{\square}$ 


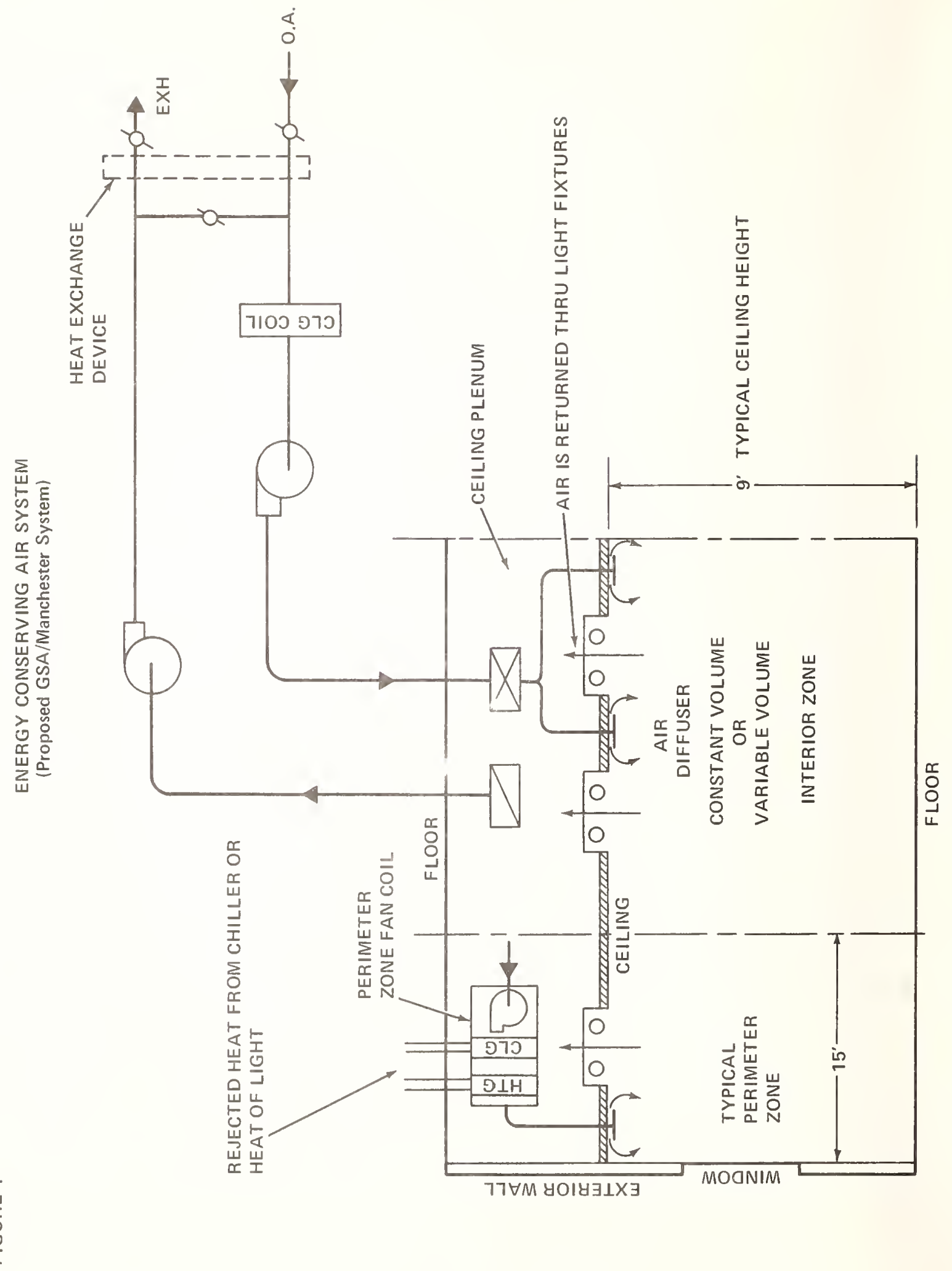


5. Hazards due to heavy electrochemical equipment in the occupied space are avoided.

6. The central system is adaptable to automatic controls.

\section{Typical Central HVAC Systems}

The most commonly used central HVAC systems are all-air systems or air-water systems. These systems include: single duct, constant volume; single duct, variable volume; single duct, reheat; double duct; multizone; two-pipe changeover; three pipe; four pipe; and induction. Details of these systems are given in the 1973 Systems Volume of the ASHRAE Handbook (1).

Although it is not the intention of this paper to describe all of these central systems, some typical ones will be discussed in the context of energy conservation.

\section{a. Single Duct Constant and Variable Volume Systems}

Figure 2 depicts a schematic of a single duct-single zone system which could be either constant volume or variable air volume (VAV), depending upon the air outlet unit in the room's ceiling. In order to respond to the changing space load, the constant volume system regulates its heat delivering capacity by changing the supply air temperature. This is accomplished by regulating the heating coil temperature during the heating season or cooling coil temperature during the cooling season. The variable volume or VAV system on the other hand maintains a constant coil temperature during each season, but regulates the supply air flow rate to meet the changing load. This can be done by either a damper in the VAV box at the ceiling or by dumping part of the supply air into the ceiling plenum space. The air supplied to the space exchanges heat with the air in the space. The space air is then returned to the central plant through the return air duct. Since the occupants of the space that is being conditioned generate excess carbon dioxide, odor, and smoke, these contaminants are diluted by mixing them with outside air. This is the reason that a part of the return air is exhausted and replaced by make-up outdoor air as indicated in Figure 2 .

On many days during spring and autumn, the space heat loss could be exactly matched by the heat given off by the lights, equipment, and occupants; no net heating or cooling is required. The single VAV duct systems have difficulty in meeting this zero load condition since the supply air flow cannot be made zero. A minimum of supply air must be fed into the space regardless of the thermal load in order to satisfy the space ventilation requirement.

\section{b. Single Duct Reheat System}

It is not difficult to control the supply air temperature by regulating the heating or cooling coil temperature if a single duct system is connected to a single zone such as shown in Figure 2. In actual practice however, the system supplies air to more than one space. Particularly during the intermediate seasons, it frequently happens that one space calls for heating while others require cooling. It is impossible to satisfy these different space requirements in the single duct systems described above. A common practice employed is to cool the central supply air to the lowest likely required temperature and modulate it up to the desired supply air temperature for the other spaces by the reheat coil such as shown in Figure 3 .

It is obvious that the reheating of the air which is once cooled by refrigeration causes a double expenditure of energy. The energy waste is greater in the constant volume system than the VAV system because the latter system requires heating of a smaller quantity of air. In addition, the VAV system that dumps a part of the supply air into the ceiling plenum obviously is not as conserving of energy as the VAV system where the volume control is done with dampers.

Figure 3 shows that the air conditioned space is divided by fictitious dashed line into a perimeter zone and an interior zone. While the heating/cooling requirement for the perimeter zone is constantly affected by the outdoor climate conditions, the interior zone load is usually constant, requiring continuous cooling during the occupied hours. Figure 4 shows how the single zone reheat system can be used in an energy conserving way to meet the requirements of these two different zones. The system has been recommended by the New York consulting firm of Dubin, Mindell, Bloome and Associates for a new federal office building to be built in Manchester, New Hampshire. In this system, the interior zone is supplied with cooled air through VAV boxes, while the perimeter zone has independent fan-coil units which contain separate circuits for the heating coil and the cooling coil. Since two pipes are connected to each coil at the fan-coil unit, this may be considered a four-pipe system. When the space requires cooling, the cooling coil is activated. If heating is required, the heating coil is activated. These two coils will never be activated simultaneously in the same unit, although the unit in one space could be heating while 


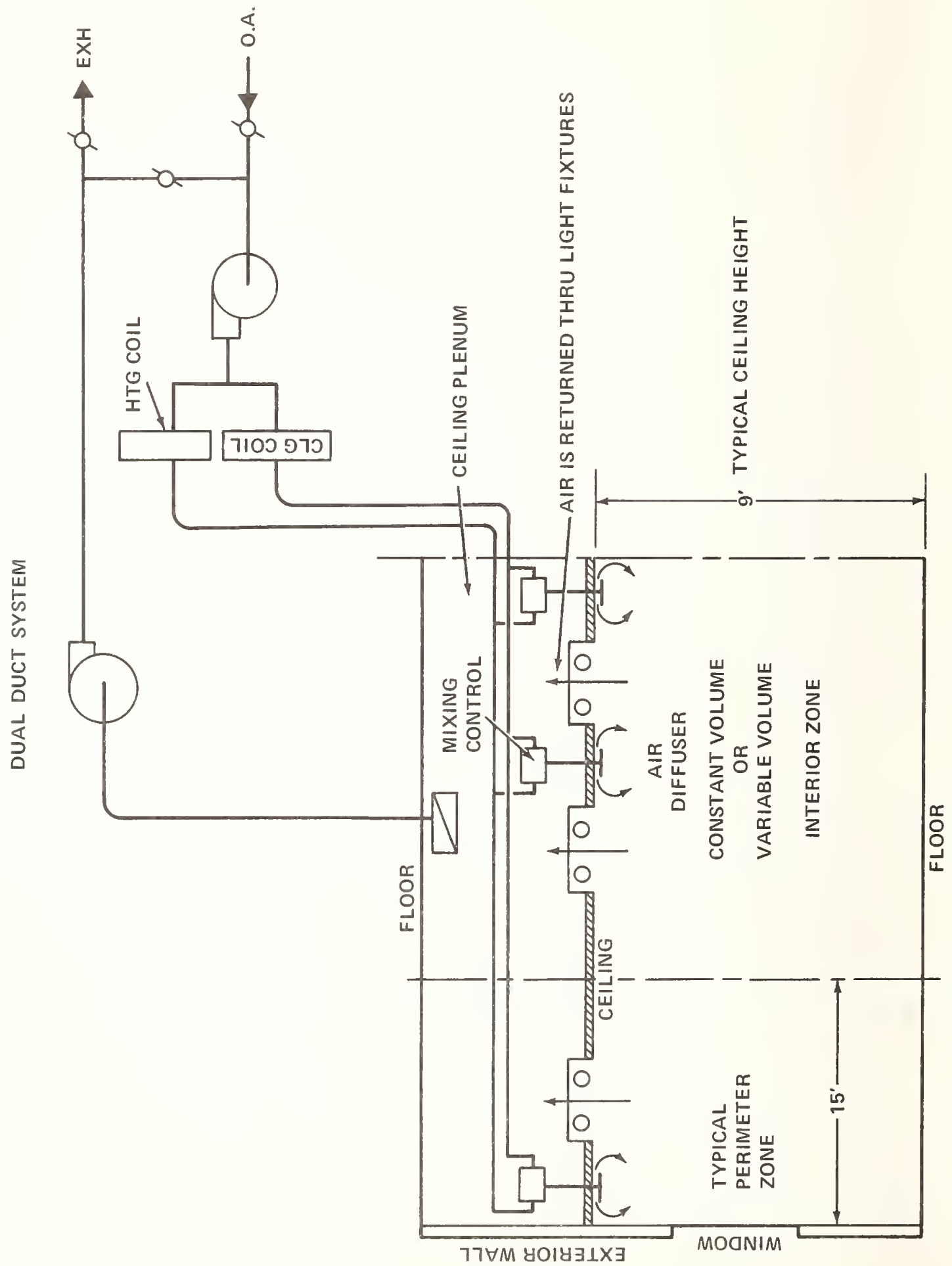

10
$\frac{0}{0}$
$\frac{0}{4}$ 


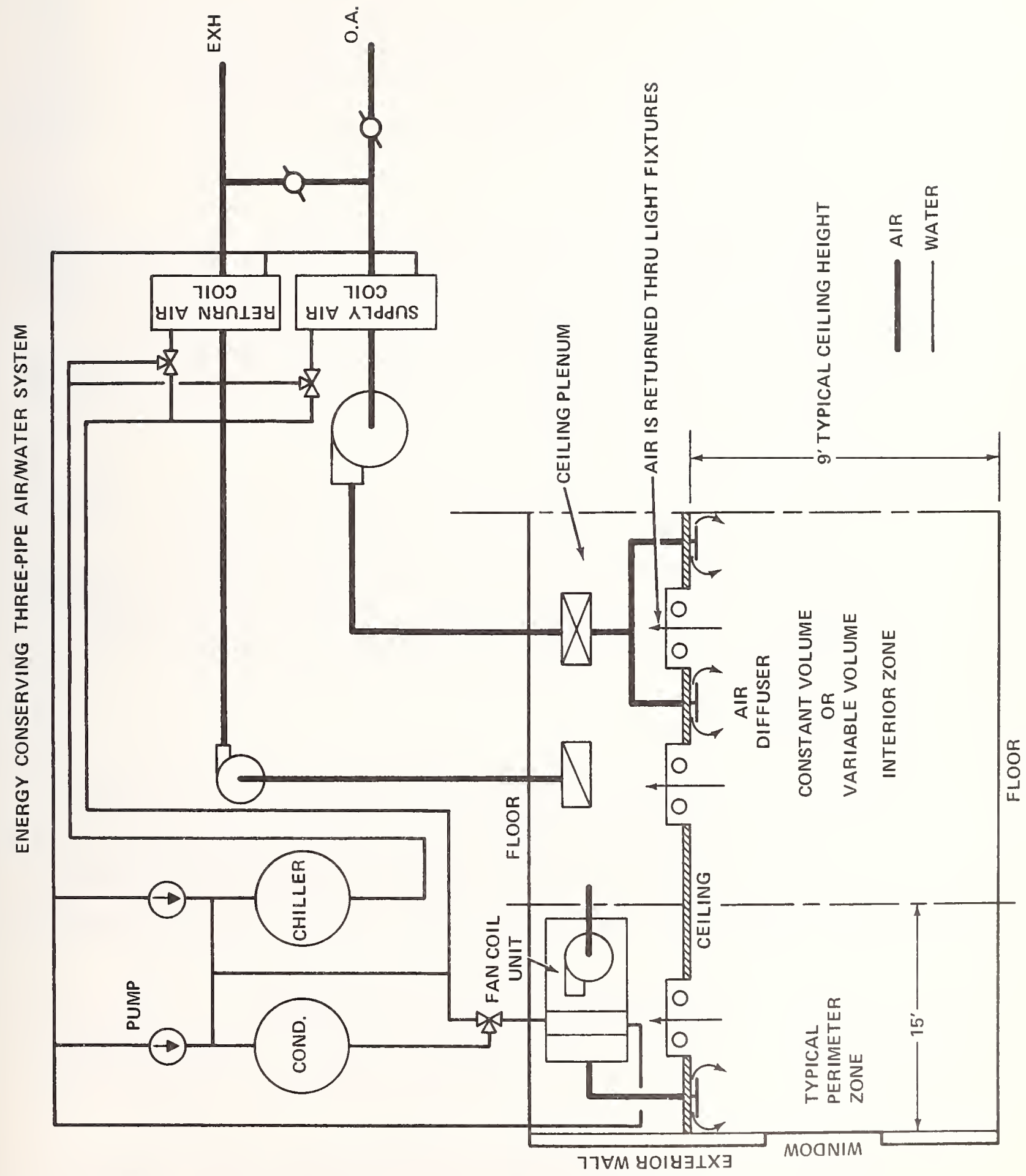

$\infty$
崩
$\frac{0}{4}$ 
others are cooling. The four-pipe system requires that hot water as well as chilled water be available throughout the year in the central plant. A unique feature of the federal office building that will use this system is that the hot water will be provided not by the burning of fossil fuels but rather by reclaiming the heat from the condenser of the water chilling unit. This energy is ordinarily rejected to outdoor air. On many days throughout the year, the hot water generated in the condenser of this water chiller, which is used to satisfy the cooling need of the interior zone, is more than enough to satisfy the heating requirements of the perimeter zone. It is customary, however, to install a conventional hot water heater to supplement the deficient heating capacity of the condenser water during a few extremely cold days.

\section{c. Dual Duct System}

Another commonly used central all-air system is the dual-duct system which is illustrated in Figure 5. In this system, both heated air and cooled air are provided in two separate supply ducts to all the spaces to be air conditioned. At the ceiling plenum above the space, mixing boxes are used to yield a desired supply air temperature which meets the heating or cooling load at a specific instant and at a specific location. Although the total air flow of the dual duct system after mixing usually remains constant, it could also be varied by a VAV box. The dual duct system is definitely not energy conserving because it requires mixing of heated air with chilled air to obtain the proper degree of heating or cooling. The system could be made energy conserving, however, if the heating coil was provided with hot water from the chilling machine's condenser or reclaimed heat from the lighting fixtures.

\section{d. Three-Pipe System}

One of the most interesting energy conservation HVAC central systems is the McFarland 3 -pipe system (2) which is depicted in Figure 6. In this system the air coils in the central plant, as well as in the individual spaces are fed with two supply pipes and one return pipe.

The coils in the supply and return air ducts are fed with chilled water from the chiller and room temperature water from the run-around loop. These are mixed to provide the desired coil temperatures. The perimeter reheat coils are supplied with the hot condenser water and the room temperature run-around water. With a delicate balancing and mixing of the chilled water, run-around water and condenser water, it is possible to attain a very high degree of energy conservation. Details of this system are given in reference (1).

\section{e. Economizer Cycle}

When the outdoor temperature and humidity conditions are favorable, it is possible to shut off the cooling plant and use the cool outdoor air to cool the interior zone. This operation is called using an economizer cycle. The dampers indicated in Figures 2 through 6 for the outdoor air intake, the return air duct and the exhaust air duct are controlled to regulate the mixing rate of outdoor and return air to achieve economizer cycle operation. The economizer cycle can obviously be a very energy conserving feature of a HVAC system and its use should be very much encouraged. Ross F. Meriwether used a computer simulation ( 3 ) to predict the energy savings by the use of an economizer cycle with a dual duct and VAV system for an office building in San Francisco. The results were as follows:

TABLE 1
Predicted Annual Cooling Energy Consumption for a San Francisco Office Building (Ton-Hour)

$$
\text { No Economizer Cycle }
$$

Dual Duct

VAV
Economizer Cycle

825,393

745,531

As can be seen from this table, the energy savings resulting from employing the economizer cycle are significant indeed. 
A heat pump is a device which utilizes work to extract heat from a source at one temperature and reject this heat plus the heat equivalent of the work done to a higher temperature sink. It may provide a heating function by extracting heat from an outside source and delivering heat to the inside space or it may provide for the cooling of the space by removing heat from it and rejecting it to the surroundings. Simultaneous heating and cooling can be done if the space is both the source and sink of all or part of the heat transferred.

There are two types of heat pumps in common use today. One type uses the vapor compression refrigeration cycle and the other uses the absorption refrigeration cycle. The basic components of the vapor compression machines are a condenser, a throttling valve, an evaporator, and a compressor. As illustrated in Figure 7, high pressure liquid refrigerant undergoes a constant enthalpy expansion through the throttling valve and is then fed in to the evaporator where it picks up heat. It leaves the evaporator as either a saturated vapor or a slightly superheated vapor and passes on to the compressor where it is compressed to the condenser pressure. In the condenser it gives up heat and leaves as a high pressure liquid to complete the cycle.

The four major components of an absorption machine are a generator, a condenser, an evaporator and an absorber. In the generator, heat is applied to a solution of refrigerant and absorbent. The refrigerant is driven out of solution by this heat and passes into the condenser while the absorbent travels to the absorber. In the condenser the refrigerant vapor becomes a liquid by giving up its heat of condensation. The liquid refrigerant then undergoes a reduction in pressure and flows into the evaporator where it absorbs heat and evaporates. The resulting vapor continues on to the absorber where it dissolves in the absorbent. The solution is then returned to the generator, completing the cycle as shown in Figure 8.

\section{a. The Vapor Compression Refrigeration Cycle}

The vapor compression heat pumps are classified according to the type of compressor employed. The compressor may be either the positive displacement type, including the reciprocating, rotary and helical rotary (screw) compressors or the centrifugal type (4). While the different compressors have different operating characteristics, in general the positive displacement compressors tend to be capable of operating over a wide range of temperature lifts or heads, while the centrifugal compressors do not have a high lift capability with low volumes of gas during part load operation $(4,5)$. On the other hand, the centrifugal compressors have a greater volumetric capacity, size for size. This makes the positive displacement compressor more suitable for handling small heating loads and the centrifugal compressor more suitable for large cooling loads. In applications involving both large heating and cooling loads, the practice appears to be to use either a centrifugal compressor with a higher compressor speed and/or larger impeller or to use a cascade system employing two or more centrifugal compressors (6). The compressors may be driven with either an electric motor or an engine. Although a heat engine would probably be the most suitable engine drive if a reliable one was available, the most common types in use are the gas engine, the diesel engine and the gas turbine.

The potential of the heat pump for energy conservation can be illustrated by considering the coefficient of performance, COP for a small, unitary, electric driven, air-source heat pump operated in a heating mode. The COP, which in this case is defined as the ratio of heat delivered to the work done, is presented in Table 2 for a typical unit.*

It can be seen from this table that a typical COP will vary from about 3.9 to 1.4 as the outside temperature ranges from $60^{\circ} \mathrm{F}$ to $-10 \mathrm{~F}$. Thus, at $45^{\circ} \mathrm{F}$, this heat pump will deliver 2.9 units of heat for each heat equivalent unit of work done. While this might at first seem a tremendously efficient way of heating a building, the picture is less bright when one takes into account the fact that only about $30^{\circ} * *$ of the heat energy of the fuel burned at the power plant in making electricity will reach the heat pump. Thus what will be called in this paper the effective COP (EFF. COP) of the power plant-heat pump combination is really $(2.9 \mathrm{x} .3)$ or .87 at an outside temperature of $45 \mathrm{~F}$. Other values of the EFF. COP at different outside temperatures are given

\footnotetext{
* The COP's in Table 2 are taken from Carrier Catalog \#38AC and are for a unit having an instantaneous heating of $112,000 \mathrm{Btu}$ per hour at an outdoor air temperature of $40^{\circ} \mathrm{F}$.

** $30 \%$ is intended to be representative of the efficiency of converting fuel into electricity and distributing it to the point of use.
} 


\section{FIGURE 7}

VAPOR COMPRESSION REFRIGERATION CYCLE

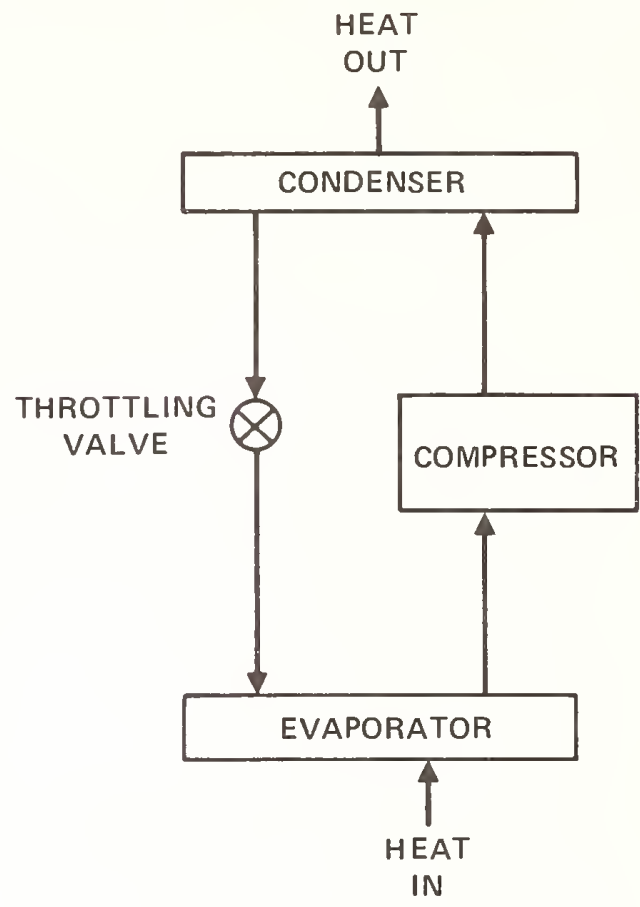

FIGURE 8

ABSORPTION REFRIGERATION CYCLE

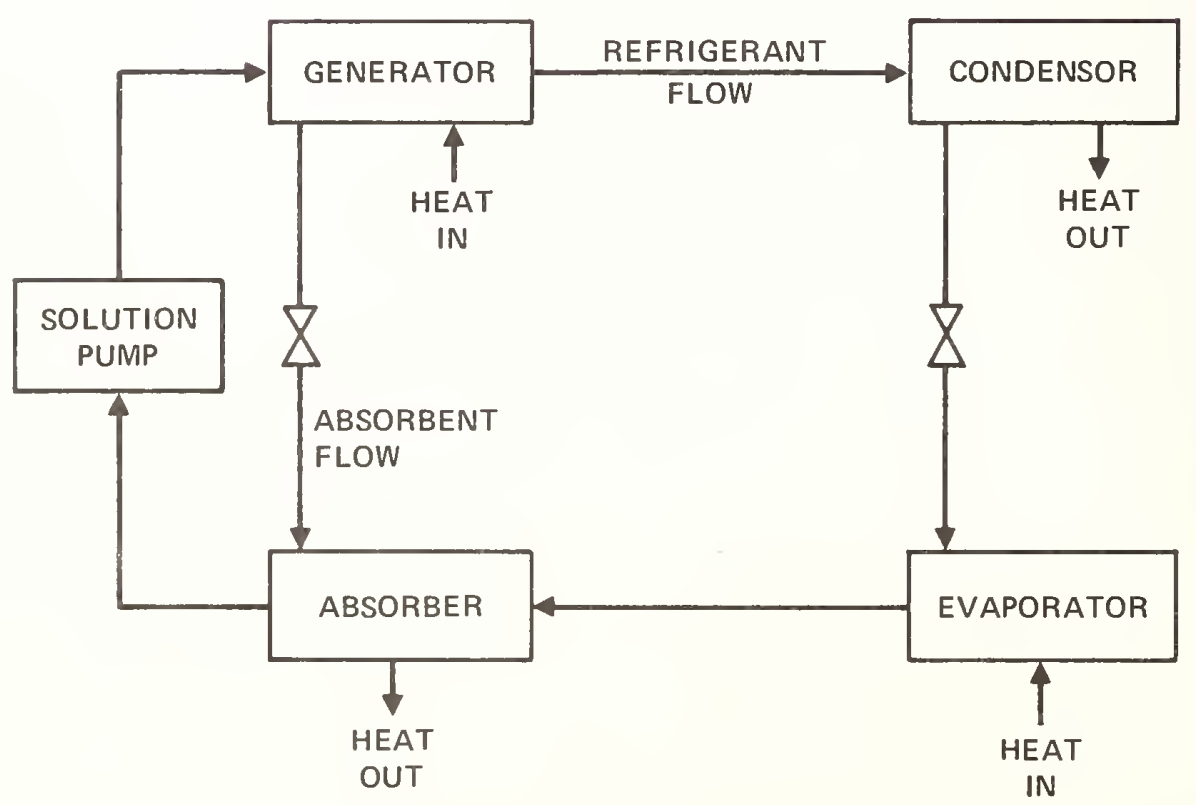


in Table 2. While this downgrading of the COP due to power plant inefficiency and transmission losses is unfortunate, the electrically driven heat pump is far more efficient than resistance heating, which would have an EFF. COP of .3. It is also better, during a large part of the heating season, than a gas or oil fired boiler which would have an efficiency between $75 \%$ and $80 \%$ with continuous operation at its maximum heating capacity .

\section{TABLE 2}

Typical Values of COP and EFF. COP for an Electric Motor Driven Air-Source Heat Pump (for Resistance Heating: $\mathrm{COP}=1, \mathrm{EFF}$. $\mathrm{COP}=.3$ )

Outside Temperature $\left({ }^{\mathrm{O}} \mathrm{F}\right)$

$-10$

0

20

40

45

60

$\mathrm{COP}$ *

(Saturated Suction Temperature $=110^{\circ} \mathrm{F}$ )

1.41 .8

2.3

2.8

2.9

3.9

$\mathrm{EFF} . \mathrm{COP}=(.30) \mathrm{COP}$

(Saturated Suction Temperature $=110^{\circ} \mathrm{F}$ )

$.42 \quad .54$

.69

.84

1.2

Takes into account defrost cycles and outdoor fan.

The heat pump with engine drive has seen only very limited use in the past because of its high first cost, high level of maintenance and poor record of reliability of the engine. This picture has, however, changed considerably in the last few years. New materials development and higher rotating speeds with lower piston speeds (shorter stroke) have resulted in engines with longer lives, increased brake horsepower and lower cost (7). While these improvements have not brought the cost of buying and maintaining an engine driven heat pump down to the level of an electrically driven one, these costs are much more than offset by the reduced operating cost if use is made of the heat recovered from the jacket, manifold and exhaust gas of the engine.

The smaller operating cost of the engine driven heat pump is due to its high EFF. COP and thus more efficient use of fuel. As an illustration, Table 3 gives the heat equivalent of fuel input per bhp output and the amount of heat recoverable for a particular naturally aspirated gas engine (8). The heat recovery system is an ebullient cooling type which takes advantage of the heat of vaporization of the jacket water by allowing steam to be generated in the jacket itself.

TABLE 3

Heat Recovery Rate for a Naturally Aspirated Gas Engine

Fuel Input

(Btu/bhp-hr)

8400
Heat Recovered

Manifold \& Jacket

(Btu/bhp-hr)

2350
Heat Recovered

Exhaust Gas

(Btu/bhp-hr)

1250

\author{
Total \\ Heat \\ (Btu/bhp-hr) \\ 3600
}

Using the information in this table and assuming that the COP of the engine driven heat pump is the same as the COP of the heat pump discussed above with electric drive*t(See Table 2), we find the EFF. COP of the engine driven system as follows:

$$
\text { EFF. COP }=\frac{(\mathrm{COP})(2544)+\text { Total Heat Recovered }}{\text { Fuel Input }}
$$

where use is made of the fact that $1 \mathrm{HP}=2544 \mathrm{Btu} /$ hour. This results in the EFF. COPs shown in Table 4.

\footnotetext{
* Âctually the COP for the engine driven heat pump will be slightly higher because an electric motor is only 85 to 90 percent efficient.
} 
The EFF. COP of a Air-Source Heat Pump Employing a

Naturally Aspirated Gas Engine Drive

Outside Temperature $\left({ }^{\mathrm{O}} \mathrm{F}\right)$

EFF. COP

$$
-10
$$

.85
0

.95
20

1.1
40

1.3
45

60

$1.3 \quad 1.6$

A naturally aspirated gas engine driven heat pump will thus have an EFF. COP in the temperature range $60^{\circ} \mathrm{F}$ to $-10 \mathrm{~F}$, between 1.6 and .85 as opposed to an EFF. COP between 1.2 and .42 for an electrically driven heat pump. Put another way, at $45 \mathrm{~F}$ the electric motor driven heat pump will use almost $50 \%$ more fuel than the heat pump with gas engine drive for each unit of heat produced, while at $-10^{0} \mathrm{~F}$ this figure increases to $100 \%$ more fuel consumed.

The above analysis and the results presented in Tables 2 through 4 indicate that an engine driven heat pump is the most effective device available today for heating from the standpoint of energy conservation. This analysis does not, however, take into account non-steady operation of either the engine driven or motor driven heat pump because the required information is not available. In addition, the discussion was limited to the direct use of the recovered heat from an engine driven heat pump for heating purposes. This recovered heat can also be used to drive an absorption heat pump to provide either heating or cooling. This will be discussed further in the section on the Absorption Refrigeration Cycle.

The electric driven or engine driven heat pump can utilize either outside or inside heat sources and sinks (9). The most commonly used outside source-sink is air which is universally available and free. This medium is used almost exclusively on residential installations for this reason. Water from well, lakes and rivers is also an excellent source-sink. Unfortunately the cost of drilling wells or owning a lake makes these source-sinks prohibitive to almost all residential and small commercial installations. In addition, extensive heating up and cooling down of lakes and rivers can have a detrimental effect on their ecology. The earth can also be used as a source-sink of heat although it has not been found in the past to be very practical and dependable. The use of solar collectors as a heat source for heat pumps is still in the research stage. The idea, however, has considerable appeal because of the heat pump's ability to absorb the solar heat at a relatively low collector temperature (9). In addition, operating at low collector temperatures reduces the heat losses of the collector and consequently increases its efficiency .

When the space inside the building is both a source and sink of heat, the heat pump acts as a heat transfer system. The transfer cycle involves taking heat from areas of the building where cooling is required and making it available where heating is needed. This is sometimes also referred to as bootstrap heating or heat reclaim (10). The transfer cycle has application in many office buildings where the interior areas require cooling all year long during occupied hours (10). This is due to the numerous sources of heat, such as lights, people. computers, cafeterias, elevators, transformers, motors, etc. (11). In addition, heat can be salvaged when needed from the building exhaust air, the lavatory exhaust air, and sewage system. This heat is then available for space heating, reheat for humidity control, preheating domestic hot water, etc.

The advantages of the transfer system are that heating and cooling are provided at the same time, the heat pump operates at a relatively high COP, and the wasteful bucking of mechanical cooling equipment and fossil fuel heating equipment against each other is eliminated. The disadvantage of the transfer system is that, unless some means of heat storage is provided, heat is only available when a cooling load exists. When more heat is being lost from the building than is being generated by internal sources, which may be the case when the building is unoccupied and/ or the outside temperature is low, an additional source of heat must be provided. This can be done by using the heat pump system to extract heat from an external source, such as the outside air, or by employing additional conventional heating equipment, such as resistance heaters or gas or oil fired boilers.

To illustrate this method of heat reclaim, Iet us consider some of the heat transfer cycles which are presently being used in many buildings. Figure 9 shows a water-to-water heat pump employing a double bundle condenser (12). The condenser contains two entirely separate water circuits; one going to the building heating coils and the other to a cooling tower. This allows part of the heat rejected by the compressor consisting of the cooling load plus the horsepower input, to be used in heating, while the remainder is rejected to the cooling tower without contaminating the house water circuits. 
COOLING TOWER

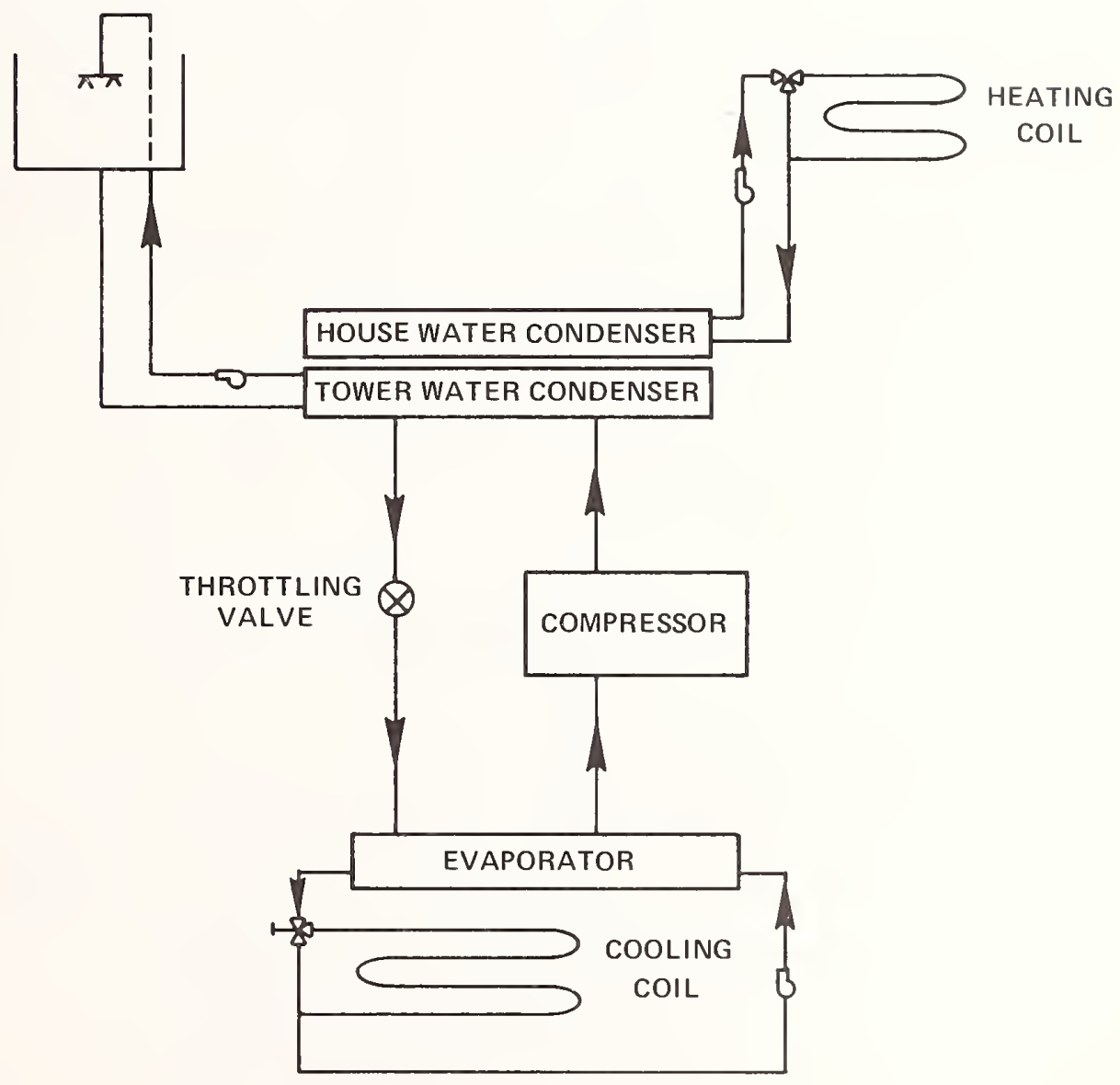




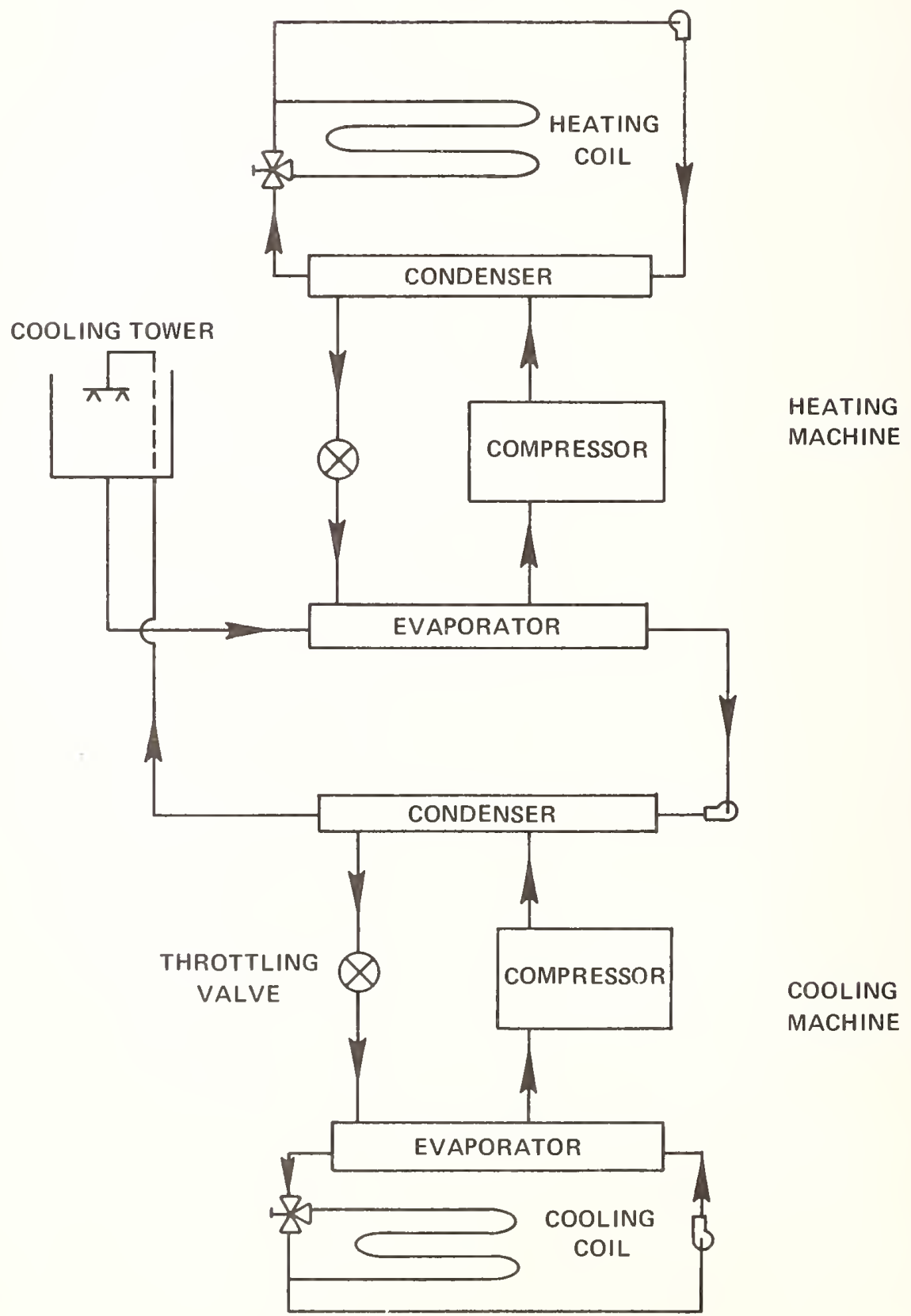




\section{CASCADE REFRIGERATION SYSTEM}

FIGURE 11

WITH OUTSIDE HEAT SOURCE

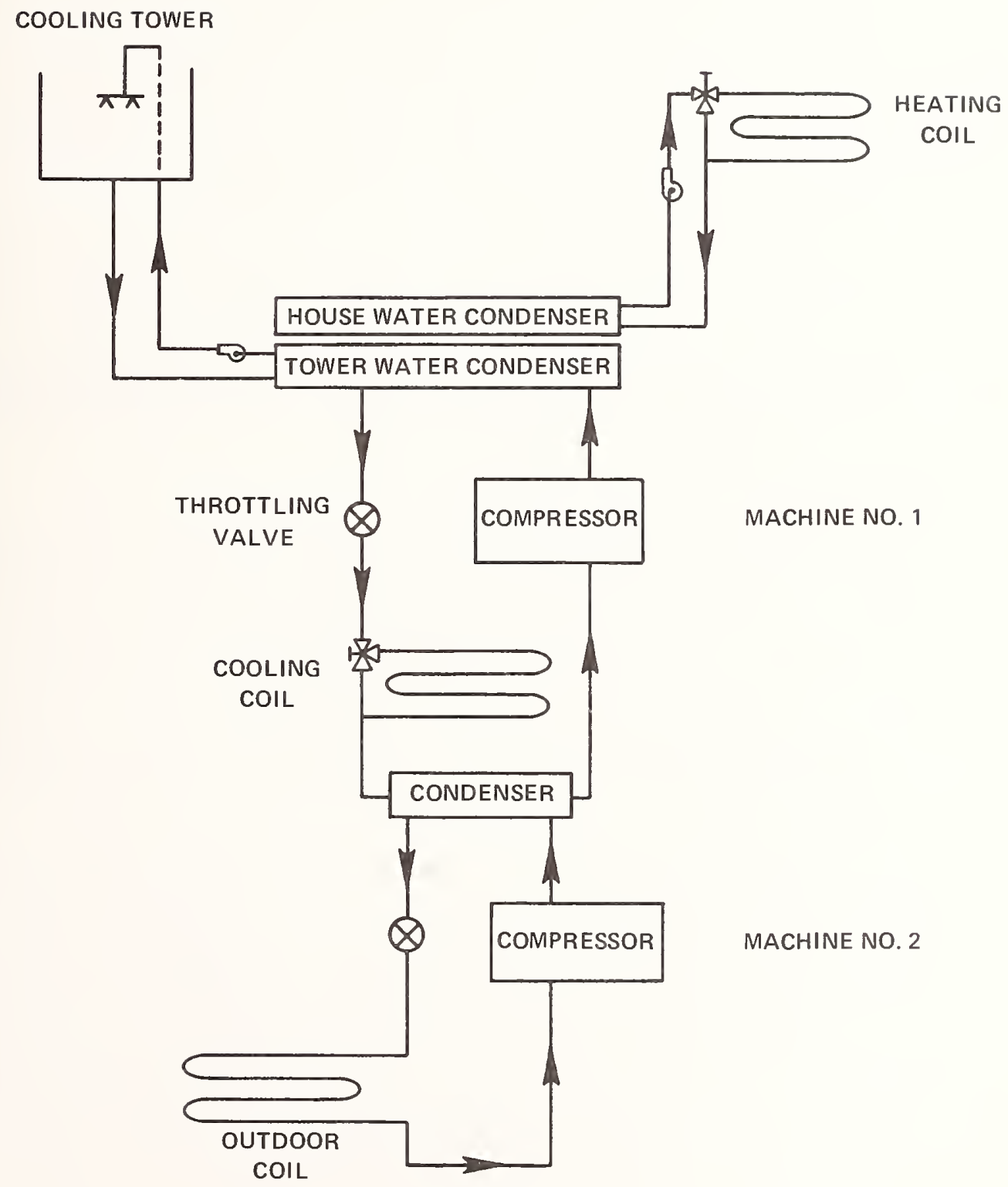


A cascade transfer cycle is shown in Figure 10 in which the cascading is accomplished by water (12). It uses two heat pumps, one of which can be called the cooling machine and the other the heating machine. Assuming that the heating machine is off the line, the cooling machine behaves in a completely conventional manner, rejecting heat from the compressor to the cooling tower. When the two machines are cascaded, higher than normal heating water can be obtained since the evaporator of the heating machine has as its heat source the hot water leaving the condenser of the cooling machine. In addition to providing moderately high temperature water, another advantage of this system is that only the heat required for heating will be delivered at the high condensing temperature of the heating machine. Any heat that is not needed will be rejected to the cooling tower at the lower condensing temperature of the cooling machine (13).

The disadvantage of the two systems shown in Figures 9 and 10 is that heat is only available as a by-product of cooling. As stated earlier, when more heat is required than can be provided by simple transfer, an additional source of heat must be provided. Figure 11 illustrates a method of handling this problem. Figure 11 (12) shows a cascade system in which refrigerant is used to accomplish the cascading. When machine \#2 is not in operation, the system behaves like a simple transfer system, extracting heat from areas where cooling is required and rejecting it where heating is needed. During the severe part of the winter when an additional source of heat is necessary, machine \#2 extracts heat from an outdoor source, e.g. , air or water, and delivers it to its condenser. This heat along with the heat from the cooling load is then used by machine \#1 in heating the building.

Storage units can also be used with systems employing heat pumps. During the day, heat can be extracted from the outside air, a solar collector or the interior of the building and stored in the storage tank at a high temperature. At night, when the outside air temperature is low or the collector is no longer operating, this heat can then be used directly for space heating . This will result in a higher system COP than if the heat pump were operated both day and night. During the summer, the process can be reversed with the heat pump operating at night to store cool water in the storage tank. In the day this cool water can then be used directly for cooling, again resulting in a high COP for the system.

\section{b. The Absorption Refrigeration Cycle}

Although many combinations have been tried, only the ammonia-water and water-lithium bromide cycles remain in common use in absorption refrigeration equipment (14). In the ammoniawater heat pump, ammonia is the refrigerant, water is the absorbent and the condenser is almost always air cooled. In the water-lithium bromide system, water is the refrigerant and lithium bromide is the absorbent. This last type of heat pump is available with either a single-stage generator or with a two-stage or double-effect generator. In the double-effect cycle, the firsteffect generator receives the external heat which drives the refrigerant from the absorbent. This hot refrigerant vapor goes to the second generator where it is partially or fully condensed and its heat used to generate low temperature, low pressure refrigerant vapor from a solution which has flowed from the first generator and has been cooled by passing through an economizer cycle. Water-lithium bromide heat pumps, with either a single- or double-effect generator, usually employ water-cooled condensers .

In determining its ideal or Carnot efficiency, an absorption refrigeration cycle may be replaced by a combined heat engine cycle and a vapor compression cycle (15). The heat engine takes a quantity of heat, at a temperature $T_{1}$, converts part of the energy to work $W$ and rejects the remainder to a sink at temperature $T_{2}$. The refrigerating machine takes the work $W$, absorbs a quantity of heat at a temperature $\mathrm{T}_{3}$ and rejects an amount of heat to a sink at temperature $\mathrm{T}_{2}$. Assuming typical values (16) of $\mathrm{T}_{1}, \mathrm{~T}_{2}, \mathrm{~T}_{3}$, for an ammonia-water absorption machine, a singleeffect water-lithium bromide absorption machine and a double-effect water-lithium bromide absorption machine, we find the Carnot cooling and heating COPs given in Table 5 . This table also gives the typical cooling and heating COPs that would normally be obtained by each type of machine (15). These typical COPs assume that the generator of each machine is direct-fired and that the flue gas loss and heat loss from the hot parts of the machine itself constitute $30 \%$ of the total heat input, $Q_{1}$. From the information in Table 5 , it can be seen that the cooling COP typically obtained from an ammonia-water absorption machine is only $24 \%$ of the Carnot cooling COP. This rather poor COP is partially due to losses from the rectifier, which is used in ammonia-water absorption machines to remove water vapor (absorbent) from the ammonia vapor (refrigerant) leaving the generator (15, 18). The typical single-stage water-lithium bromide absorption machine is thermodynamically very good as can be seen from the small difference between the actual cooling COP and the Carnot cooling COP. The problem, however, with this type of machine is that the Carnot COP is very low due to the low temperature of the generator. This can be rectified by going to a double-effect 
generator which raises the Carnot cooling COP to 2.4. This doubles the cooling COP which is typically obtained with a single stage generator and results in a value which is slightly over unity.

\section{TABLE 5}

Ideal and Real COPs for Absorption Refrigeration Machines

Type of Absorption Machine,

$\mathrm{T}_{1}, \mathrm{~T}_{2}, \mathrm{~T}_{3}$

Ammonia-water (air coled condenser), $\mathrm{T}_{1}=390^{\circ} \mathrm{F}, \mathrm{T}_{2}=125^{\circ} \mathrm{F}, \mathrm{T}_{3}=38^{\circ} \mathrm{F}$

Single stage water-lithium bromide (water cooled condenser) ,

$\mathrm{T}_{1}=176^{\mathrm{O}} \mathrm{F}, \mathrm{T}_{2}=105^{\mathrm{F}, \mathrm{T}_{3}}=45^{\circ} \mathrm{F}$

Double effect water-lithium bromide $\mathrm{T}_{1}=325{ }^{\mathrm{O}} \mathrm{F}, \mathrm{T}_{2}=105^{\mathrm{F}}, \mathrm{T}_{3}=45^{\mathrm{O}} \mathrm{F}$

Carnot
Cooling
COP

1.8

2.4

\author{
Cooling \\ COP \\ Typically \\ Obtained
}

.43

.55

1.93

Carnot

Heating

COP

2.8

1.25

Heatings

COP

Typically

Obtained

1.13

3.4

1.8

Large motor driven centrifugal heat pumps, operating over the temperature ranges used in the above examples, usually have a cooling COP in the neighborhood of 3 . This makes for an effective cooling COP of about .9, assuming that only $30 \%$ of the heating energy of the fuel burned at the power plant in making electricity reaches the heat pump. Because of this, the ammoniawater absorption machine and the single-stage water-lithium bromide machine, which have cooling COPs around . 43 and .55 , respectively, are not commonly used unless there is a cheap source of heat available. Two such sources of cheap heat might be steam produced as a result of some industrial processes or waste heat from engines. If the engines are used to drive vapor compression heat pumps, absorption machines are often run off the waste heat to provide additional cooling. In this case, the heat rejected by the absorption machine is usually not recovered since extra heating is usually not necessary when additional cooling is being provided.

The double-effect water-lithium bromide machine has a cooling COP comparable to, if not slightly better than, the effective cooling COP of the typical vapor compression heat pump. Because of this, it should definitely be considered as an alternative to a motor driven vapor compression heat pump. It may be either direct fired or used with waste steam or waste heat from an engine. In the latter case, if the engine is being used to drive a vapor compression heat pump. a very high cooling COP for the total system can be obtained. The double effect machine may also be combined with steam turbine driven centrifugal compressors (16). Steam from the noncondensing turbine is used to provide the heat for the absorption machine.

The ammonia-water and single effect water-lithium bromide absorption heat pumps have heating COPs comparable to a motor driven heat pump, while the heating COP of the double-effect water-lithium bromide absorption machine is comparable to an engine driven heat pump. Unfortunately, with the absorption machines in existence today, the heating COP drops very rapidly as one tries to increase the temperature of the condenser or decrease the temperature of the evaporator. This means that if one wishes to use the heat from the absorption machine at a reasonable heating COP, one cannot use the outside air as a heat source, but must employ a transfer cycle and use very large heating coils located in the space or zone to be heated. This last condition greatly increases the total cost of the system.

Another reason water-lithium bromide absorption machines have not been used extensively in the past for heating is that it was necessary to control the condenser water temperature to within $-5 \mathrm{~F}$ degrees of the design temperature to avoid the problem of crystallization. A new advance in the state-of-the art has now removed this constraint, allowing this type of absorption machine to operate with an uncontrolled condenser temperature (17).

A proposed system for the GSA Manchester Building utilizes the absorption heat pump in a transfer cyclc for both heating and cooling. This system will be described in the section entitled Solid Waste Utilization. If this turns out to be an effective use of an absorption machine, consideration should be given in the future to employing such a transfer system as a means of conserving energy. In the meantime, additional research is urgently needed which will result 
in improved designs (like the double-effect generator) and new working fluids (15), that will increase the COP of the absorption heat pump and allow it to operate adequately over a wide range of evaporator and condenser temperatures.

Heat Recovery Systems

A heat exchanger that transfers energy from make-up air to exhaust air in a central ventilation system can be considered another type of energy conservation system. These exchangers are usually one of the following three types: 1) run-around coil, 2) thermal wheel, and 3) heat pipe exchanger.

The run-around system shown in Figure 12 employs standard finned tube coils, both in the entering make-up air stream and exhaust air stream. Liquid is circulated, either by pump or by natural convection, through these two coils, which are connected in series. The heat from one duct is then picked up and delivered to another duct. The usual heat recovery effectiveness (19) of the system is approximately $60 \%$.

Thermal wheel type heat exchangers employ a rotating wheel 16 to 22 inches thick, (see Figure 13), which is packed with a heat absorbing material such as aluminum or stainless steel shavings. Exhaust air is drawn through one side of the wheel, warming the media. The wheel turns, is continuously warmed by the exhaust air stream, and rejects this heat to the incoming make-up air. Contamination is kept to a minimum ( $1 \%$ or less) by using a purging device, which returns the first makeup air that passes through the heat wheel back to the exhaust stream. Although heat recovery effectiveness is very high (on the order of $80 \%$ ), extra energy is required to turn the wheel and to pass the air through the wheel.

For summer operation, a total heat wheel may be used. This device is packed with lithium chloride-impregnated corrugated asbestos instead of metal shavings. The lithium chloride is a dessicant which absorbs moisture as well as heat. The heat recovery effectiveness of the total heat wheel can go as high as $90 \%$. The power consumption required to operate the total heat wheel is usually smaller than for the metal one because a smaller pressure drop usually occurs.

The application of the type of heat pipe heat exchanger shown in Figure $14 *$ to HVAC systems is relatively new. The pipe is usually a finned metal tube, the inside of which is filled with refrigerant 12 or water and a capillary wick lining material. The refrigerant evaporates as it is heated in the exhaust air stream (winter operation) and the vapor travels through the center of the pipe to the make-up air duct side and condenses. The condensed liquid flows through the wick along the interior surface of the pipe to the warm exhaust air side by capillary pumping action. The he at recovery effectiveness of this device is on the order of $60 \%$. An important consideration for using the heat pipe, however, is that it is a completely passive exchanger requiring no additional source of energy .

\section{Special Systems}

In this section consideration is given to systems which, although not commonly employed in the heating and cooling of today's buildings, have a significant potential for energy conservation.

\section{a. Total Energy and Modular Integrated Utility Systems}

The total energy (TE) system is a central system that generates electric power on site and utilizes the waste heat from the power generating process for the generation of domestic hot water and for space heating. The engine waste heat is also frequently used as the energy source for an absorption machine, thus providing space cooling.

The total energy system is said to consume approximately 20 to 50 percent less fossil fuel than a conventional system to deliver the same amount of enerev. A typical energy plant is located at or very near the user's site and the electric power is supplied by generators which are driven by gas turbines, gas engines, diesel engines, steam turbines, steam engines, or heat engines. The majority of existing systems, however, use either gas engines or diesel engines. Heat from the engine's jacket and hot exhaust gases are used to generate hot water or low pressure steam.

\footnotetext{
* This diagram was adapted from the promotional literature of Q-Dot Corporation,
} 4219 Sigma Road, Dallas, Texas 75240. 


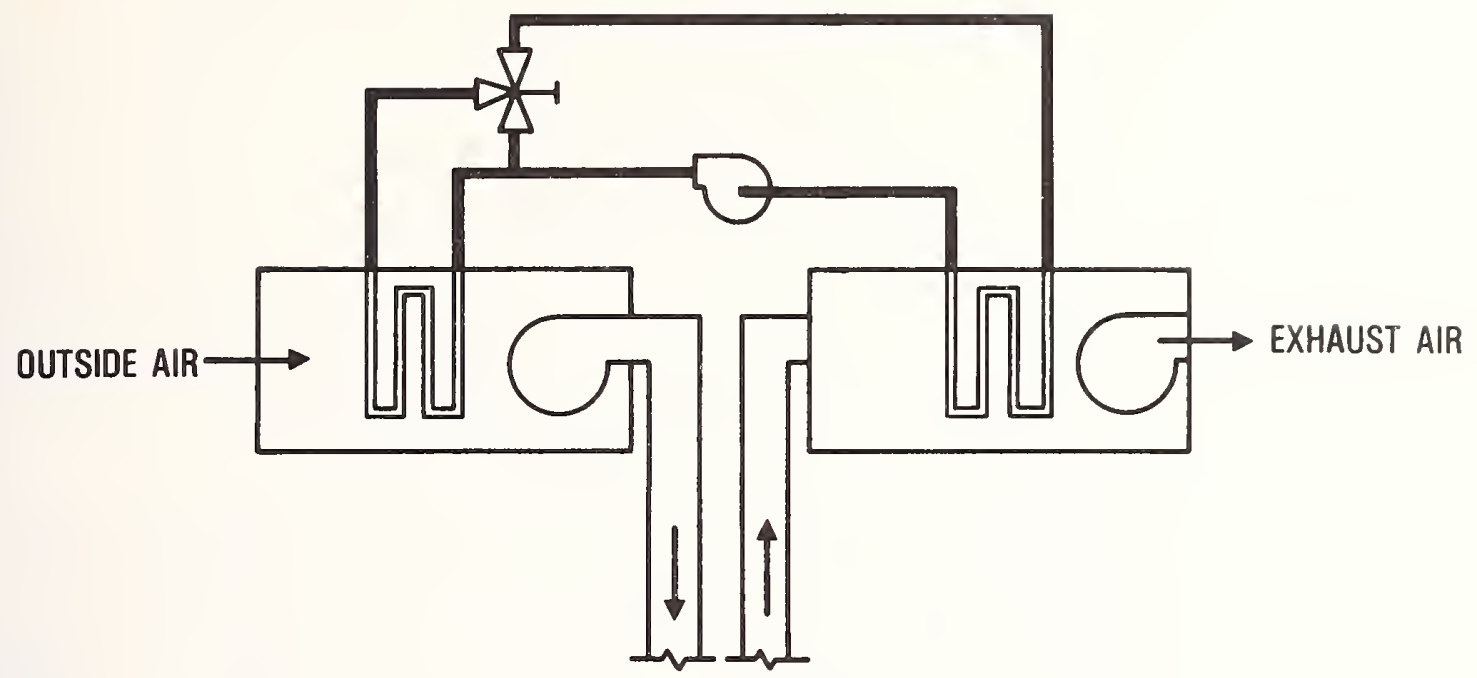

FIGURE 13

THERMAL WHEEL HEAT EXCHANGER

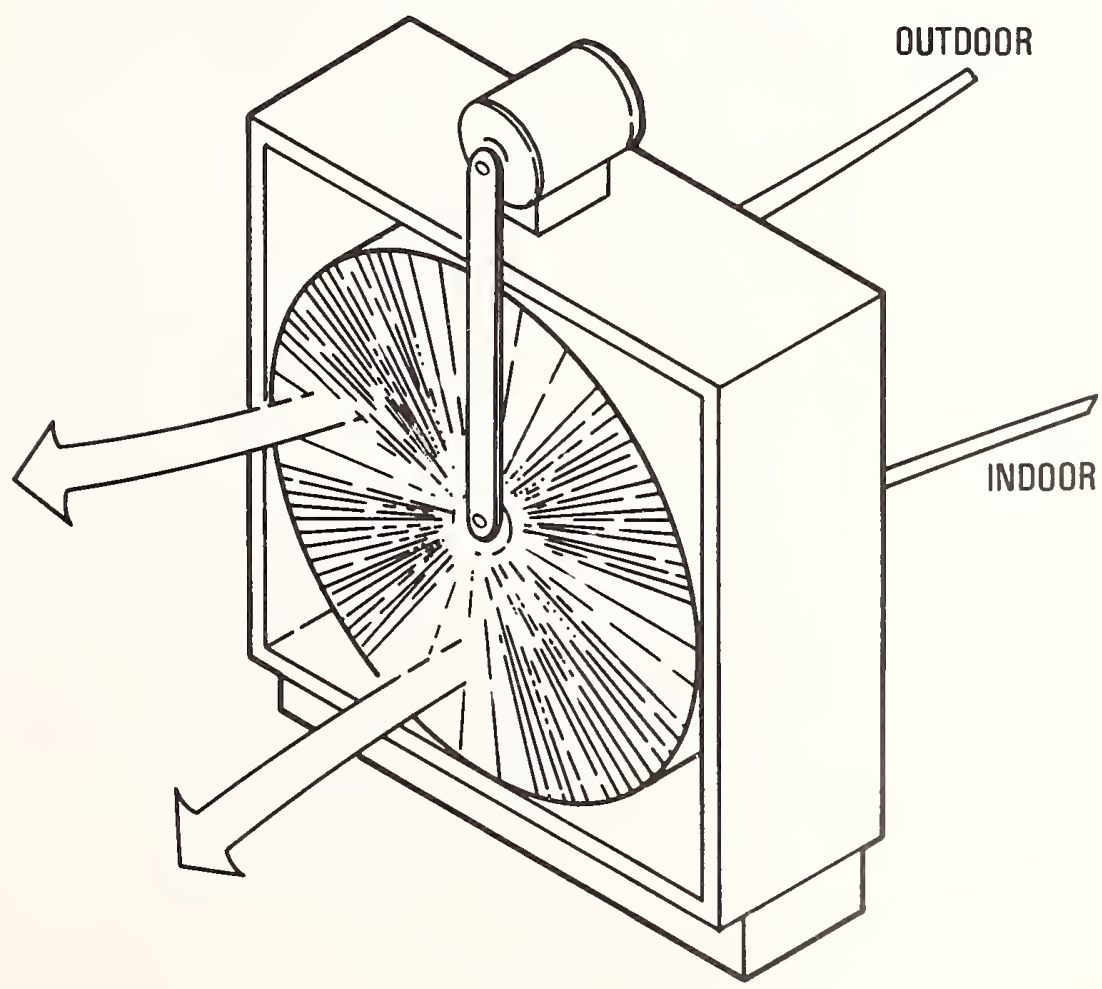




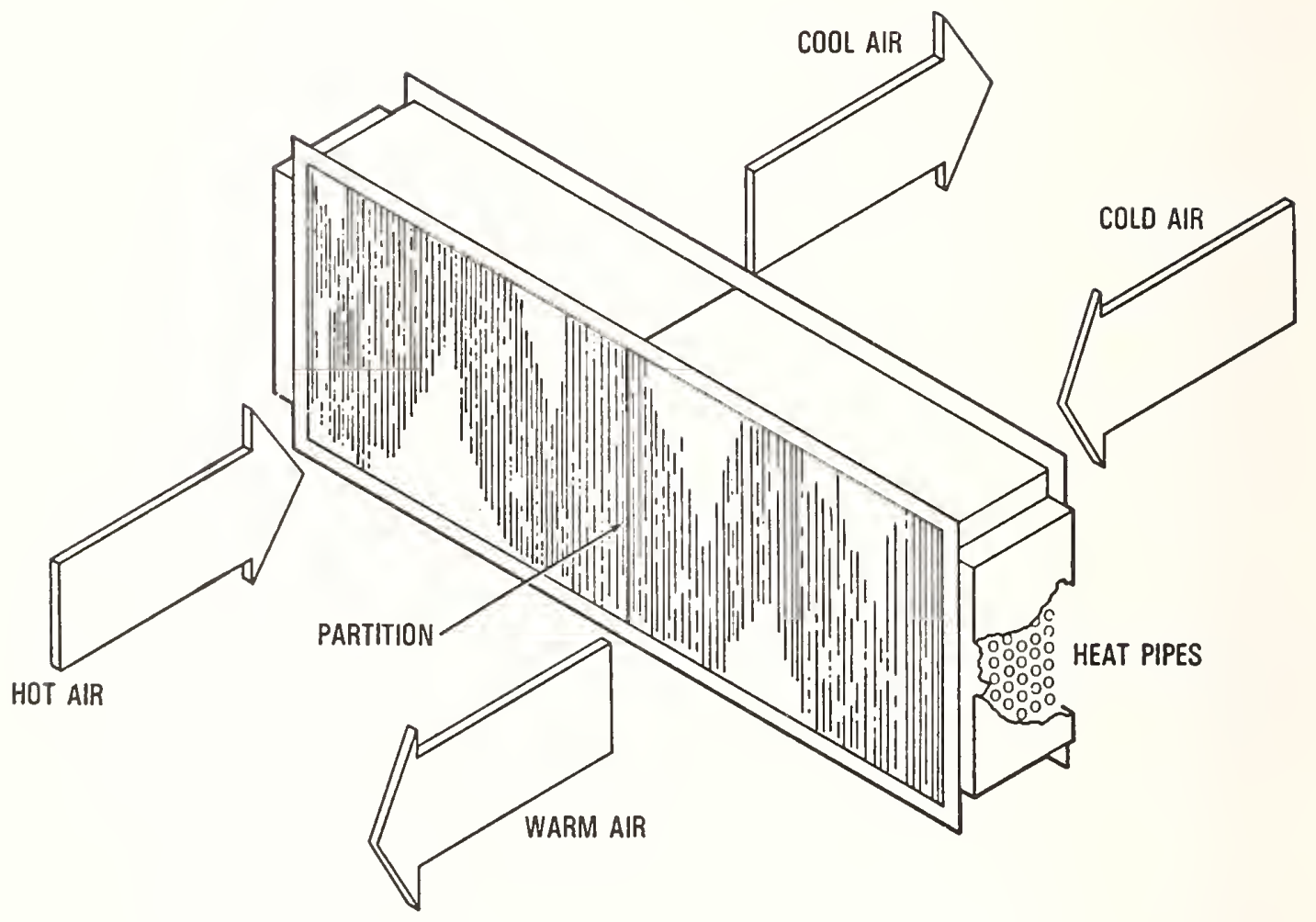


FIGURE 15

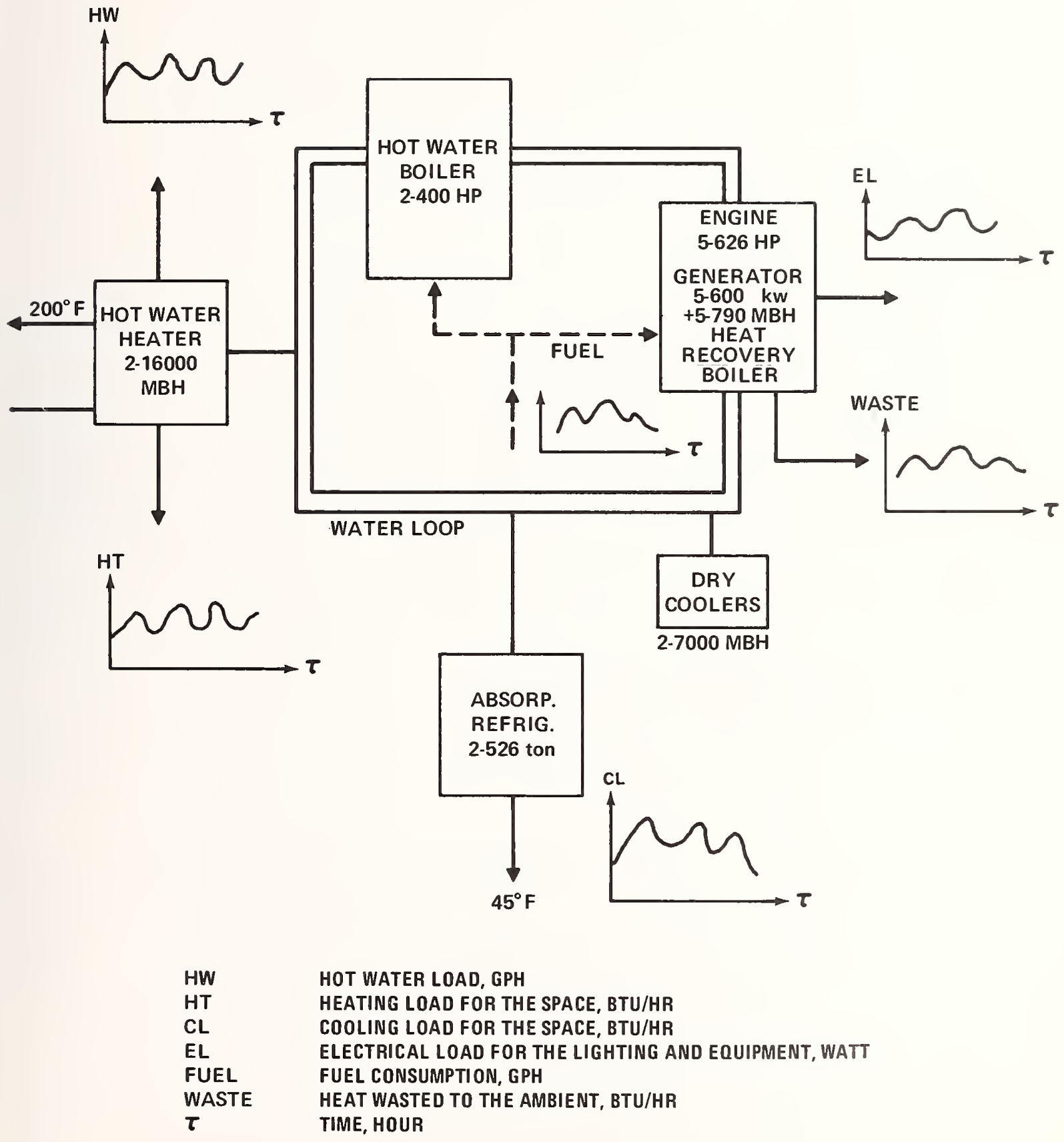




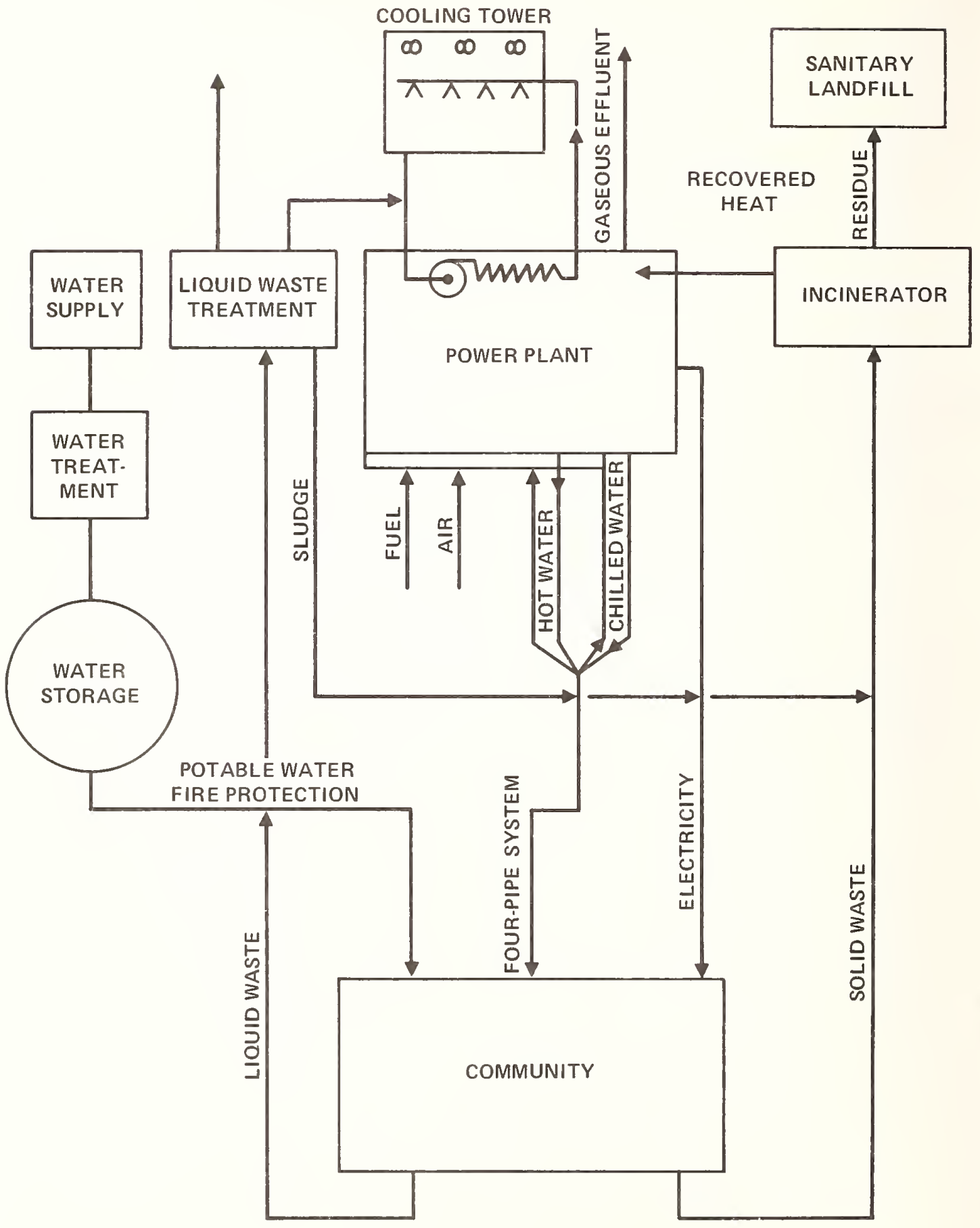


Approximately 500 total energy plants have been installed throughout the United States since 1960, mostly under the auspices of the gas supply industry. The primary application of the TE system has been to motels, schools, shopping centers, planned communities, and hospitals Well publicized examples include the 5080 unit Rochdale Village in New York, the $3600 \mathrm{KW}$ systems in the TWA facility of the Kansas City International Airport and a shopping center in King County , New York. A complete listing of the total energy installations is available in reference $(20)$.

Past experiences have shown that the total energy system is not usually feasible unless the following conditions are satisfied.

1. The supply of engine waste heat matches the heat demand. If this is not possible, a means must be provided to store the excess heat for use at other times.

2. Maintenance for the power generating facilities, which is an extra burden for most HVAC operators, is available at an acceptable cost.

3. A long range fuel supply is assured.

4. Efficient engines which operate on gas as well as oil are used.

5. Noise and air pollution problems are accounted for and adequately solved.

The National Bureau of Standards is currently working with the Department of Housing and Urban Development to evaluate the Total Energy System's potential for decreasing the amount of fuel required to provide the utility services to an apartment complex of 500 units and for obtaining better control of noise and air pollution problems (21). The installation is being made at a site in Jersey City, New Jersey as a part of the HUD Operation BREAKTHROUGH program. Figure 15 depicts a schematic layout of the total system that consists of diesel engine driven generators, supplementary hot water boilers, absorption chillers, hot water heaters, and a dry-cooling tower. This equipment is all located in a single water loop. Hot water $(200 \mathrm{~F})$ generated at the hot water heater and chilled water $\left(45^{\circ} \mathrm{F}\right)$ produced by the absorption chiller will be sent to six apartment buildings, one commercial building, two schools and one indoor swimming pool.

The Jersey City TE plant is being extensively instrumented to determine its thermal efficiency, the daily and seasonal load patterns, the reliability of the utility services, the success of noise pollution control, the maintenance and repair requirements, the owning and operating costs and the occupants' response to this system. The Jersey City site is almost completed at present and the field measurements are expected to start in July 1974.

The Atomic Energy Commission's Oak Ridge National Laboratory recently made a study for extending the total energy concept to a city the size of Philadelphia (22). Considered in their analysis were steam turbine-driven power generators that utilize heat from nuclear reactors, conventional as well as fast breeder type. On a project of this magnitude, the total energy plant could provide heat for many applications other than space heating/cooling and hot water generation. Other uses could be industrial processing, sewage plants, snow melting systems, drying facilities, and greenhouses.

Perhaps the most interesting application of the total energy concept is in the MIUS program of the Department of Housing and Urban Development (23). The acronym MIUS stands for Modular Integrated Utility Systems and combines energy, water, solid waste disposal and sanitation services into a single utility, such as shown in Figure 16 . The goal of the HUD project is to achieve a $50 \%$ reduction in energy waste in electric power generation, an $80 \%$ reduction in liquid waste disposal and $85 \%$ reduction in solid waste disposal by appropriate recycling procedures. The National Aeronautics and Space Administration has been participating in the project because of their experience in the development of life supporting systems for spacecraft. Other federal agencies, such as AEC, the Environmental Protection Agency, and NBS are also participating in setting up a prototype installation to evaluate the concept. The final selection of the various utility subsystems of the demonstration MIUS installation will depend upon climatic factors, population density, total population, consumer mix, local geology and local resources such as water, natural gas, and land. A preliminary study made by the Oak Ridge National Laboratory recommended internal combustion engines as prime movers for the MIUS and indicated that the best choice for the heat recovery system would be $240^{\circ} \mathrm{F}$ to $250^{\circ} \mathrm{F}$ system suitable for use with a single-stage absorption chiller. The final heat rejection may be by means of a cooling tower or a cooling pond. The pond, in addition to serving as a heat rejection system, could be used as source of water for fire protection, to hold run-off storm water and to serve to improve the appearance of the MIUS site. 
FIGURE 17

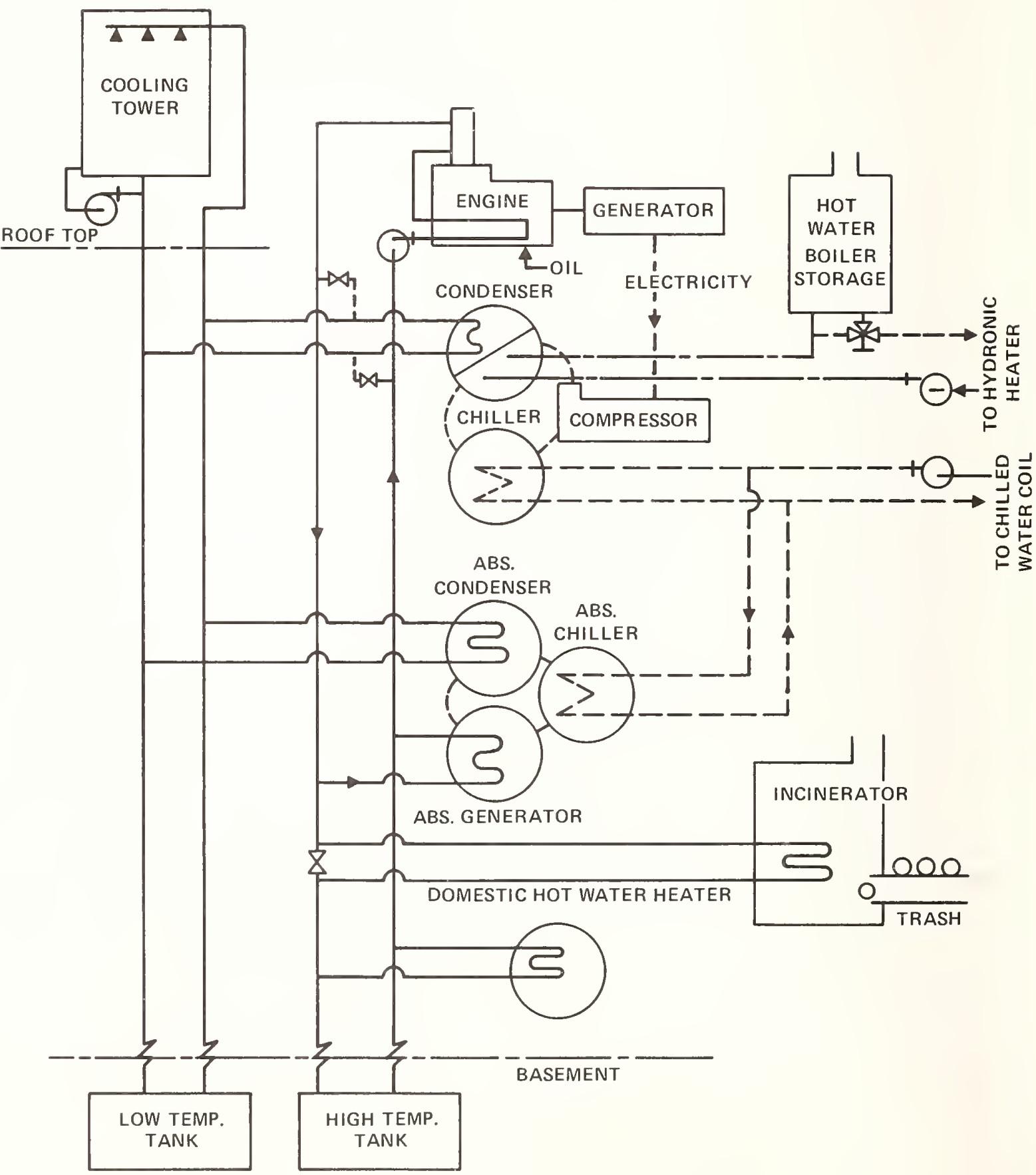


An average American produces 7.2 pounds of solid waste per day (24). Assuming that the heating value of city refuse is approximately $1 / 4$ that of coal, the total solid waste in the U. S. would be equivalent to $1.653 \times 10^{15} \mathrm{BTU}$ per year or equivalent to approximately $2.5 \%$ of the annual energy consumption if all this waste could be converted to energy. The solid waste can be used as a fuel to generate steam, which in turn drives turbine generators, heats hot water and operates absorption chillers. The idea of recovering heat from solid waste incinerators is not new. One of the most famous installations is the TIRU plant in Issy Le Moulineaus, on the outskirts of Paris (25). The plant processes Paris city trash at a rate of 27 tons/hour and feeds it into the incinerator-boiler that generates 1800 tons of steam a day at 930 psig. The high pressure steam is used to generate $24 \mathrm{MW}$ of electricity during the summer and to provide hot water and space heating for various dwelling units, schools, hospitals, and commercial buildings in Paris at a rate of 285,000 lbs. of steam per hour during the winter. Except for large installations, such as the U. S. Naval station facilities at Norfolk, Virginia (600 tons/day) and the City of Chicago's plant (1200 tons/day), the use of heat recovery incinerators has been limited in the United States.

The City of Nashville, Tennessee is currently planning a central steam and chilled water distribution system for 27 downtown buildings which will be serviced by the heat from the incinerator-boiler. The boiler plant will produce $215,000 \mathrm{lbs}$. per hour of 400 psig steam. This steam will be used for cooling as well as heating with the use of steam driven gentrifugal refrigeration water chillers having 13,500 tons of capacity. The chilled water at $45 \mathrm{~F}$ and steam at 125 psig will be sent through an underground heat distribution system.

A small scale experimental facility for opeating a 15 ton absorption water chiller with a trash incinerator is being considered for the GSA Manchester Building, which was mentioned earlier. Figure 17 shows a schematic diagram of the building's system. The incinerator-boiler is connected to the high temperature water loop, which picks up additional heat from the engine driven generator and provides hot water to operate an absorption chiller. The electricity generated by the engine driven generator in this system will be used to run the electric motordriven centrifugal chiller with a double bundle condenser. The heated water at the double bundle condenser is in turn available for space heating through the use of terminal reheat coils which were discussed earlier.

\section{c. Solar Energy}

The potential for conserving energy in building environmental equipment through the use of solar energy as a supplementary source appears to be very significant.

Buildings can be heated, cooled, and/or have their hot water supply generated with solar energy by the use of some type of solar receiver or collector in which a fluid such as water or air is heated. The heated fluid is then passed into the building for use directly in a heating system, domestic hot water system, as a heat source for an air conditioning unit, or to be put into storage for later use.

There have been approximately 20 to 30 experimental solar heating systems constructed in houses and laboratories during the past 25 years with a half dozen or more of them still in use. Reference 26 gives a good summary of most of them, showing the kinds of collectors , thermal storage material and transfer fluids used. One-half of the solar buildings have been residential, two were small office buildings and the remainder consisted of laboratories. Eighteen were erected in the continental United States.

The concept of solar air conditioning is intriguing but has not been carried forward nearly as fast as heating. Solar energy has been successfully used to drive absorption refrigeration systems at the Universities of Florida (27) and Wisconsin (28). Recently a study has been reported where a complete house in Brisbane, Australia was air conditioned by such a system (29).

The major emphasis to date on solar energy utilization in buildings has been for residences. It is expected that more and more emphasis will be given to using solar energy in commercial buildings for several reasons.

1. Commercial buildings usually have simultaneous heating and cooling requirements over long periods of the year which would result in a much fuller utilization of the energy than in residences. 
2. Most energy conserving designs for these buildings already include thermal storage, thus not adding this cost to the incremental cost of the addition of a solar energy system.

3. Many systems will require a much smaller thermal storage system (relatively speaking) than in residences since most of the energy collected can almost always be used immediately .

4. Absorption cooling equipment is available in the 100-ton range which can use the relatively low water temperatures available from simple flat plate collectors. This equipment is directly applicable for use with many commercial buildings which have cooling requirements. Absorption units, on the other hand, are much more expensive than electric compression systems in residences.

$\underline{\text { Conclusion }}$

This paper has considered the potential options for energy conservation in buildings resulting from the application of both conventional HVAC equipment and special systems. It has not dealt with the entire HVAC field, but has instead considered specific examples which are illustrative of the state-of-the-art in the designing and use of building environmental systems for energy conservation.

\section{References}

1. ASHRAE Handbook and Product Directory - 1973 Systems, American Society of Heating, Refrigerating and Air-Conditioning Engineers, 345 East 47th Street, New York, N.Y. 10017

2. McFarland, A. L. . "Three-Pipe Systems: Concepts and Controls," ASHRAE Journal, pp. 37-41, August 1967.

3. Meriwether, R. F., "Computer Programs for Energy System Analyses," APEC Journal, July 1971.

4. ASHRAE Guide and Data Book - Equipment 1972, Chapter 12, ASHRAE, New York.

5. ASHRAE Guide and Data Book - Equipment 1972, Chapter 18, ASHRAE, New York.

6. O'Neil, J. F. "The Economics of the Heat Pump," Engineering Journal, p. 42, November 1965 .

7. Barrangon, M., "The Gas Engine," ASHRAE Journal, pp. 50-53, February 1970.

8. Fleming, W., "Total Energy Concepts for Refrigeration and Air Conditioning Engineers," ASHRAE Journal, pp. 32-39, December 1970.

9. Ambrose, E. R., Heat Pumps and Electric Heating, John Wiley and Sons, New York, 1966.

10. Szabo, B. S., "Internal-Source Heat Pump Systems, " Air-Conditioning, Heating, and Ventilating, p. 51, June 1966.

11. Tambyn, R. T., "Bootstrap Heating for Commercial Office Buildings," presented at the ASHRAE Semiannual Meeting, New York, February 11-14, 1963.

12. Japhet, R. A. . "Considering Heat Reclamation? Here are Your Options," Heating, Piping, and Air Conditioning, pp. 89-95, April 1969.

13. Ostrander, W. S., "Centrifugal Compressor Heat Reclaim Systems - Where Now?," Building Systems Design, pp. 23-27, May 1972. 
14. ASHRAE Guide and Data Book - Equipment 1972, p. 135, ASHRAE, New York.

15. Whitlow, E. P., "Trends of Efficiencies in Absorption Refrigeration Machines," ASHRAE Journal, p. 44, December 1966.

16. ASHRAE Handbook and Product Directory - Systems 1973, p. 29, ASHRAE New York.

17. Archie, John L., "Absorption Refrigeration Systems - 1971," ASHRAE Journal, p. 41 , September 1971 .

18. ASHRAE Guide and Data Book - Equipment 1972, p. 139, ASHRAE, , New York.

19. ASHRAE Handbook of Fundamentals 1972, p. 34, ASHRAE, New York.

20. "Total Energy," Total Energy Publishing Company, 522 Briar Oak Lane, San Antonio, Texas.

21. Achenbach, P. R., and J. B. Coble, "The Application of Total Energy Systems to Housing Developments," NBS Special Publication 361, Vol. 1,

Performance Concept in Buildings, 1972.

22. Miller, A. J., "Use of Steam-Electric Power Plants to Provide Thermal Energy to Urban Areas, "ORNL-HUD-14, NTIS

23. Samuels, G., and W. J. Boegley, Jr., "Preliminary Concept Recommendations for Near-Term MIUS," Oak Ridge National Laboratory Report, 1973.

24. Cohan, L. J. , and J. H. Fernandis, "The Heat Value for Refuse," Mechanical Engineering, September 1968 .

25. Beader, R. J., "Incineration Plant-Plus," Power, January 1967, pp. 62-64.

26. "Conservation and Better Utilization of Electric Power by Means of Thermal Energy Storage and Solar Water Heating, "Phase I Summary Report, the University of Pennsylvania (NSF Grant No. GI 27976), October 1, 1971.

27. Farber, E. A., "Design and Performance of a Compact Solar Refrigeration System," ASME Paper 70-WA/Sol-4, 1970.

28. Duffie, J. A., R. Chung, and G. O. G. Lof, "A Study of a Solar Air Conditioner," Mechanical Engineering, August 1963.

29. Sheridan, N. R. , "Performance of the Brisbane Solar House," Solar Energy, Vol. 13, pp. 395-401, 1972 .

30. Dubin, Fred S., Statement to the Subcommittee on Energy of the House Science and Astronautice Committee, June 12, 1973. 
National Bureau of Standards Special Publication 403

Proceedings of 1973 Engineering Foundation Conference (Issued June 1976)

\title{
ASHRAE AND ENERGY CONSERVATION
}

\author{
by \\ Preston E. McNa11, Jr. \\ Johnson Service Company \\ and \\ Chairman, ASHRAE Research and Technical \\ Committee
}

\begin{abstract}
ASHRAE is concerned with all aspects of environmental control for people, as well as for plants and animals as the latter relate to food production and processing. The ASHRAE Guide is discussed and its excellent treatment on thermal comfort in buildings is emphasized. The need for better energy management and the importance of first cost to the building industry in speculative type investments is discussed. The utility of reheat HVAC systems is emphasized since they are easy to maintain and have low initial costs. ASHRAE has considerable know-how which is not optimally used at present because of inadequate incentive. Labor is no substitute for energy since a man is worth only $10 \$$ per day in energy expended.
\end{abstract}

Key words: Energy; environment; food

I am pleased to be able to address you today, but I am sorry I could not have more time to prepare, since I am filling in for another speaker who suddenly became ill.

ASHRAE (The American Society of Heating, Refrigerating and Air-Conditioning Engineers) is a technical society, not a trade association, as some people assume. It is concerned with all aspects of environmental control for people, as well as for plants and animals as the latter relate to food production and processing. Although mechanical engineers are the largest group of members, other technologies are also well represented, such as chemistry, material science, medicine, physiology and psychology.

ASHRAE is unique in many ways, but of importance here is its research program. It is the only society which funds and conducts a sustained research program. A portion of each of its 25,000 plus members' dues is allocated for research. Industry and individual contributions and the income from its annual equipment exposition are also used for research. Currently, the annual effort is about $\$ 300,000$. This is not large by Federal standards, but it is precious to ASHRAE. Its Research and Technical Committee allocates it to various projects. The results must be non-proprietary and in the public domain.

This research effort, started in the early 1920's, has been reduced to practice in the ASHRAE Handbook, now a 4 volume, 6-1/2" thick set. Over 800 technical experts, serving on over 80 separate committees (including energy utilization and energy conservation) aid its preparation. Energy conservation is no newcomer to ASHRAE, whose first research was concerned with measuring and predicting heat flow through walls and other building components. follows:

ASHRAE's responsibility in the current U.S. energy situation is as

1. Approximately $20 \%$ of U.S. energy is used in the heating and cooling of spaces occupied by people (homes, factories, offices, schools, etc.).

This is primarily gas and oil, with some electricity.

2. Approximately 5\% of U.S. energy is used in refrigeration associated with foods, from proceessing plants, storage, transportation, etc., to the household refrigerator. This is primarily electric, with some gas and oil. 
Therefore, $25 \%$ of the U.S. energy is used in the equipment and systems designed, built and installed with ASHRAE knowledge. This is a significant amount and therefore, significant savings are probable.

If ASHRAE is as knowledgeable as I have claimed, why haven't we already designed and built optimum energy systems? There are many reasons, but two significant ones have to do with our past "free ride", so far as energy cost was concerned, and our business practices with speculative builders. Recent studies have shown that for a typical commercial building, on $1 y$ 10-15\% of the annual cost is energy related. Another 10-15\% is for maintenance and the lions share remaining $(70-80 \%)$ is for capital cost. Economics dictates that first cost and interest rates are far more important than energy. The speculative builder will sacrifice a "quality" job and sell out to the ultimate owner, leaving him with a "low dollar" energy wasting system. Even the non-speculative builder would tend to make similar decisions until he sees the "energy crisis" clearly coming. This explains the many existing energy-wasting systems, such as the reheat system, which cools all the system air to, say, $55^{\circ} \mathrm{F}$ and then heats it up as needed, with double energy costs in some cases. Past economics approved such systems, which do give very good comfort performance. A tenant paying $\$ 7$ - $\$ 10$ per sq. ft. per year demands comfort.

Significant energy savings can be made in the short-range by modest investments in "tuning-up" or adding to existing systems, with existing hardware and technology. ASHRAE members can do this now.

There are also many computerized control systems in use which could be considered for some larger existing systems. This relatively new technology, applied to heating and air-conditioning systems, allows a much more efficient operation by providing almost instantaneous data for the operator to use in controlling the system. Even more sophistication, already available, provides preprogramming the computer with control strategies so that operating efficiencies can be even further increased, past man's capability to continuously react to all his decision variables. A large water chiller, for example, could have a significant increase in efficiency if the chilled water could satisfy the load and be $1^{\circ} \mathrm{F}$ warmer.

The President's goal of 5\% should be easy to attain by the above means, without drastic measures.

One of those "easy" suggestions is changing thermostat settings. It is true that considerable savings could be realized with lower winter and higher summer control points, and this could be done today, for a short-range saving. However, before we implement this, we should consider the consequences. ASHRAE has sponsored comfort research for 50 years. Our present data shows the following. Lightly clothed people in an office or residential environment prefer $75^{\circ} \mathrm{F}$. This seems to be true, winter and summer, regardless of national origin or weather climate around the world. Quality of life is largely dependent on our environment. If we remove the stress caused by people fighting their environment, we release more energy for man's higher pursuits. If we lower winter thermostats, we must encourage people to wear heavier clothing. In the summer, though, the limits of decency on clothing have perhaps been reached.

As an aside, it may have occurred to some that we might save energy by limiting or controlling "labor saving" appliances or machines. Let's put this in perspective. A healthy young male, who is doing heavy physical labor, (ditch-digging, for example) can produce equivalent watt-hours of energy in an 8 hour day of less than $10 \$$ worth of electrical energy. Clearly, increased reliance on manual labor is no practical answer.

Over the last 25 years, ASHRAE has documented energy saving systems which have been built, in some cases as demonstration projects. These involve heat pumps, heat recovery systems, solar heating and cooling systems, etc. Much of this information is now being used in some systems built in recent years and some now being designed and built by a few enlightened owners. Many will take advantage of such existing knowledge and will benefit in the future. Savings in energy use of up to $30 \%$ should easily be possible in new construction, without resorting to exotic or yet-to-be-developed 
hardware.

Why don't we do it? In my opinion, the main deterrent to employing our extensive existing know-how to energy conservation is a lack of incentive for the people who are in the decision-making positions - the present building owners-- (homeowners to those owners of large building complexes). I believe, with proper incentives, present and near-future savings could approach 20-30\% easily, without a significant effect on living standard or comfort.

There are many long-range possibilities. Twenty percent of our energy is used to heat and cool people. But a person metabolizes at the rate of only about $400 \mathrm{BTU} / \mathrm{hr}$. on the average. This is a relatively small amount. A family of 4 could heat and cool themselves with about \$15 worth of natural gas per year if it were $100 \%$ efficient! Recent research at Kansas State University has indicated that a liquid or air-cooled hood, covering the head and neck, can effectively cool a person working in a hot environment. At the same time, it allows good freedom of movement and permits the rest of the body to sweat efficiently, which entire body cooling with air jets or liquidcooled suits tends to inhibit. The energy could be provided with a small refrigeration system, similar to that of a household refrigerator. The energy savings of such a future "people oriented" system could be dramatic. There are countless other examples.

In summary, ASHRAE has know-how available today to make a great impact in energy conservation. However, a building system is a complex system, including:

Architectural and structural details

Weather-climate environment

Building usage - (hotel, office, etc.)

Heating and cooling systems

Control methods and strategy

Available energy sources, rates, etc.

There are thousands of combinations of the above six variables. An optimum energy conservation system is difficult to design. It is not a game for amateurs, it is not a game for "quick-draw" solutions, like "don't heat with electricity", nor is it a game for "instant experts" who leap on the energy bandwagon. It needs to be done by professionals who understand the total concept of these complex systems.

To conclude, ASHRAE has considerable know-how which is not optimally used at present because of inadequate incentives. For the future, ASHRAE's organization of experts can provide some of the nation's best stewardship for the massive research effort needed in this important area. 

V. INSTITUTIONALACONSIDERATIONSA FOR ENERGY C O N S E R V A T I O N 
FACTORS CONTROLLING THE MANUFACTURE AND MARKETING OF ENERGY CONSERVING PRODUCTS

by

J. B. Com1y and C. M. Huggins

General Electric Corporate $\mathrm{R}$ \& D

P.0. Box 43

Schenectady, New York 12301

The complex of factors relating to decisions to manufacture and market new or improved products is discussed, with examples taken from consumer equipment of importance in conservation of energy at the point of utilization. The heat pump and the incandescent light bulb are used as specific examples. Premature marketing of the heat pump as a heating system impaired its degree of acceptance. The tradeoff between energy efficiency and replacement cost of the incandescent light bulb illustrates the optimization of these two factors in a product. Technological development alone does not assure immediate implementation of energy efficient systems. The prospect of commercial success of a product should be evaluated well before that product is brought to market.

Key words: Costs; energy; heating; manufacturing; marketing

The rapidly growing awareness of the possibilities for conservation of energy which lie in more effective utilization of energy at the point of use is indicated by the proliferating proposals for improvements in equipments which use energy. Many of these ideas are novel - for example, the use of solar energy to heat or cool buildings, or the use of heat pipes to speed up the cement conversion process; others represent modifications in the design or applications of equipment which is already widely in use. For example, improving the efficiency of air conditioners, making more efficient light bulbs, or improving the performance of heat pumps, furnaces, refrigerators, or ovens.

It is tempting to technical people like us to zero in on an interesting and innovative technical idea and to push it to the point of demonstrating full scale technical feasibility. We then assume implicitly that the idea should have a large impact on society simply because of its technical merits. However, the "technology" which is required to serve a large consumer market is much broader than the simple engineering feasibility of a new idea. A specific product configuration must be defined in concrete form; designs must be prepared which allow the product to be manufactured, to be reliable in operation over many years, and to be serviceable and maintainable.

Technical information and trained people must be available in the field to assure that the product can be properly specified and installed, and service for it must be available. Various costs must be considered and addressed at the design stage, including engineering, tooling, capital equipment, plant, start-up, materials, and labor. The risk of failure of the product either technically or in the market place must be addressed and compared with the payoff possibilities, and alternate uses for the resources needed for the job must bc explored.

Factors in the market place must also be reviewed. The idea must serve a need felt directly by the prospective purchaser, and its first cost must not be prohibitive to him. He must have sufficient knowledge of the product 


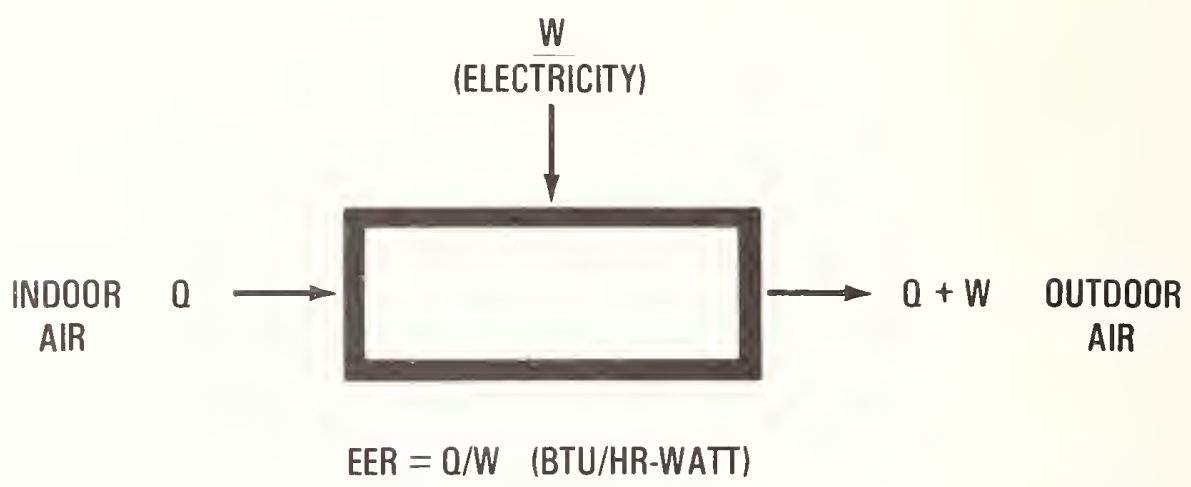

FIGURE 1a

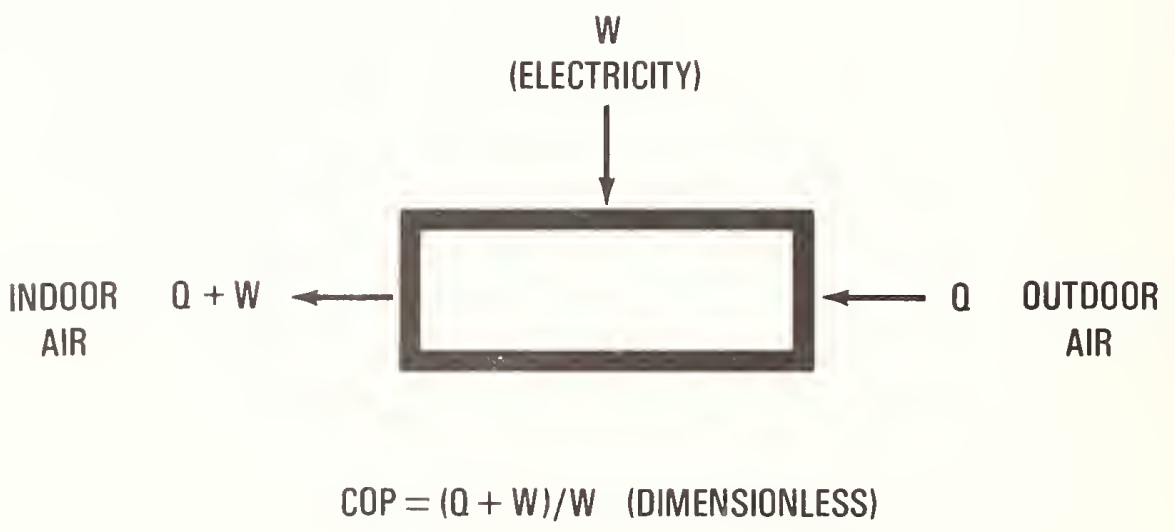

FIGURE 1b 
so that he can judge its overall value to him, the special features it may have of interest to him, the ease with which he can use the product, how easy it will be for him to service it during its lifetime, and whether that lifetime seems to be acceptable to him.

In this paper some of these factors will be illustrated by discussing two examples of consumer products which relate to energy conservation: the heat pump, and the life, cost, and efficiency of light bulbs.

\section{Heat Pumps}

Heat pumps and central air conditioners are very closely related. Both are refrigeration machines employing an evaporation/condensation cycle, with a compressor to effect the required pressure changes. Figure la shows a highly simplified version of the energy flows for air conditioners. The work input $W$ is made by an electric motor, assumed to be $100 \%$ efficient. The indoor air heat exchanger picks up heat $Q$ and delivers it, along with the work input to the outside air. The Energy Efficiency Ratio (EER) which is used to describe the unit's efficiency is the ratio of the heat removed from indoors, $Q$, to the electricity used, $W$, and is generally expressed in mixed energy units, BTU/hr-watt. The EER for air conditioners ranges from about 4.4 to 11.5 at design conditions.

A heat pump (Fig. 1b) operating in the heating mode is simply an air conditioner operating in reverse, using input work $W$ to collect heat $Q$ from the outdoor air and delivering the sum $Q+W$, indoors to heat the house. The Coefficient of Performance (COP) is the ratio of heat delivered to the house, $Q+W$, to the work input, $W$, and is generally expressed in dimensionless units. Typical instantaneous operating COP's range from 1.25 to 3 , depending on the outdoor temperature and other factors.

The heat pump operating in the heating mode as shown in Fig. 1b delivers from 1.25 to 3 times as much heat (i.e., the COP) to the house as it uses from the electrical lines. The heat pump is thus an important energy conserving product. Its history and present design illustrate the tradeoffs which must be made in engineering, manufacturing, and marketing such products.

The heat pump principle was first discussed by Lord Kelvin in 1853.* Practical demonstrations began in the $1930^{\prime} \mathrm{s}$ with the development of hermetically sealed compressors. GE's history includes experimental office building systems installed in the $1930^{\prime} \mathrm{s}$ with utility companies in ohio and in New Jersey, three more units sold through normal sales channels in 1947 in Connecticut, Alabama, and Ohio, and another three units sold in 1949 in various locations.

The market really opened up after 100 pilot models were sold in 1953 through central air conditioning distribution systems. Other manufacturers moved in 1952-1953 to market packaged unitary heat pumps to the residential market.

Growing at the average rate of $15 \%$, the market reached 50,000 units in 1960 , with about $15 \%$ of al1 central air conditioning (unitary) applications for residences being supplied by heat pumps. Figure 2 shows the growth of the heat pump market from its beginning to 1972 .

During the $1950^{\prime} \mathrm{s}$ the heat pump performed we11 in areas where its primary function was cooling; however, major field problems arose where heating was important. A11 manufacturers found they had insufficient knowledge of the stresses on compressors caused by the high pressure ratios experienced with very low outdoor temperatures, and the field failure rate grew to unacceptable proportions. In $1962 \mathrm{GE}$ withdrew its heat pump from northern markets, and began a major study on reliability of compressors and on the field problems which the industry faced.

The reliability problem was solved by the mid $60^{\prime} \mathrm{s}$, but the damage done to the heat pump's reputation was severe; the sales growth rate was much smaller during the next decade, about $7 \%$ per year on average. At present

* William Thomson, "The Power Required for the Thermodynamic Heating of Buildings", Cambridge \& Dublin Math. J., Nov. 1853, p. 124. 


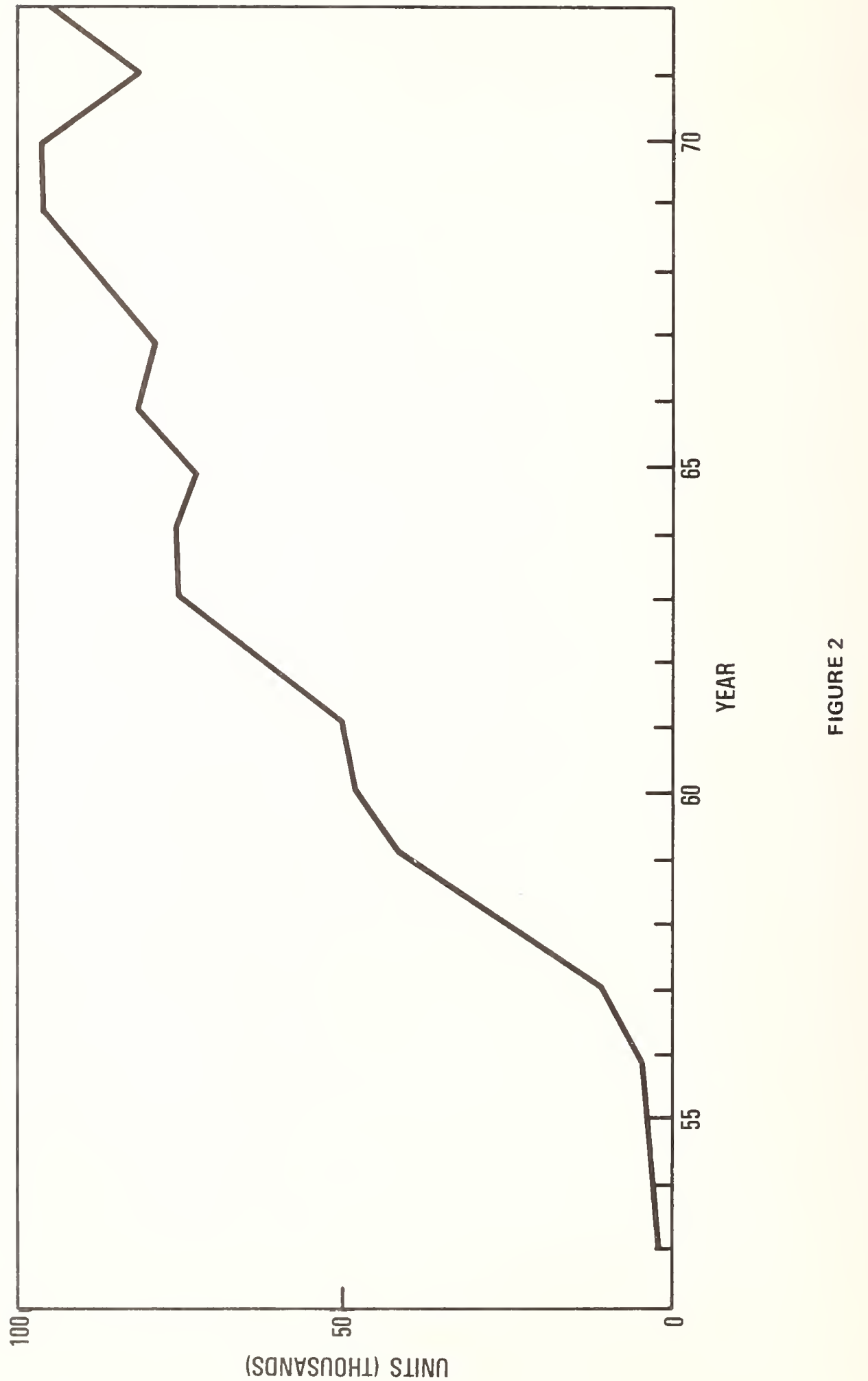


only $4 \%$ of all unitary applications (central air conditioners) are heat pumps. The program which GE mounted resulted in dozens of reports in our corporate laboratories, and possibly hundreds in the operating department. The GE Climatuf ${ }^{R}$ compressor now in use is the result of a large number of improvements including current and temperature cutouts, internal pressure relief valves, designs for stresses in shipping, noise reduction, carefully tailored starting torque, improved and more reliable heat exchangers, reduced refrigerant charge requirements, faster condensor defrosting, more reliable outdoor fans, and designs for directing what noise there is away from where people are most likely to be. great.

The importance of reliability in this kind of equipment is clearly very

The Seasonal Performance Factor (SPF), or seasonal average COP of a heat pump installation results from a number of factors, both in how it is designed and in the weather conditions it faces. Table 1 shows how the COP depends on outdoor temperature in a typical heat pump.

\section{TABLE 1}

5 ton Heat Pump COP vs. Outdoor Temperature

\begin{tabular}{|c|c|c|c|c|}
\hline $\mathrm{T}$ indoor & $\mathrm{T}$ outdoor & $\begin{array}{l}\text { Power in } \\
\text { (BTU) }\end{array}$ & $\begin{array}{l}\text { Heat out } \\
\text { (BTU) }\end{array}$ & COP \\
\hline $\begin{array}{ll}70 & \mathrm{~F} \\
70 & \mathrm{~F} \\
70 & \mathrm{~F}\end{array}$ & $\begin{array}{ll}45 & F \\
20 & F \\
10 & F\end{array}$ & $\begin{array}{ll}23 & 600 \\
18 & 100 \\
16 & 600\end{array}$ & $\begin{array}{ll}60 & 000 \\
35 & 000 \\
29 & 000\end{array}$ & $\begin{array}{l}2.5 \\
1.9 \\
1.75\end{array}$ \\
\hline
\end{tabular}

The decrease in COP at lower outdoor temperatures is a result of higher compression ratio due to lower suction pressure and the lower density of the gas being circulated.

Heat pump installations are sized to meet the summer cooling load rather than the winter heating load. This is necessary because an oversized cooling installation gives poor humidity control. The fraction of time an over-sized cooling unit runs to keep the air cool is too small to allow a large fraction of incoming air to flow over low temperature coils and thus condense out the moisture in the air. Since this sizing approach generally results in an installation which has insufficient capacity to handle the heaviest heating loads in the winter, supplemental electric resistance heating is provided for peak heating needs. To derive the SPF one must include this use of electricity at an effective COP of 1.0 . The resulting use of electrical energy and SPF is illustrated in Table 2.

Although the percentage saving is higher in milder climates, the actual energy saved is greater in colder climates, because of the larger annual heat loss.

Another interesting comparison is that of the use of energy by the heat pump with other systems, when energy usage is evaluated back through to the utility generating or supply plant. In an analysis done for the New York area, the heat pump, with SPF of 1.7 , used $59 \%$ as much fuel as straight electric resistance heating, as shown on Figure $3 \mathrm{~A}$. The figure also shows that the heat pump used about the same fuel energy as a typical gas fired furnace and somewhat less than an oil furnace. The solid bars on the chart refer to the same equivalent house for each heating system. The dotted portions of the bars refer to additional air infiltration which will normally occur when combustion furnaces are used. Another interesting point is that in practice electric baseboard heating equipment tends to use somewhat less energy than an electric furnace simply due to individual room thermostat controls. Finally, the fuel used by the power plant is often heavy crude oil, coal, nuclear, or hydro power instead of gas or light distillate fuel oil, so that if this factor were also considered, the comparison to use of the 


\section{Table 2}

$\underline{\text { Residential Energy Usage (Heating Season) }}$

(For 4-bedroom, 2-story house with standard insulation for electrical heating)

\begin{tabular}{|c|c|c|c|c|c|c|}
\hline Location & $\begin{array}{l}\text { Heat in } \\
\text { Below } \\
65^{\circ} \mathrm{F} \\
\end{array}$ & $\begin{array}{l}\text { Hours } \\
\text { Below } \\
20^{\circ} \mathrm{F} \\
\end{array}$ & $\begin{array}{l}\text { Energy for } \\
\text { Electric } \\
\text { Furnace } \\
\end{array}$ & $\begin{array}{l}\text { Energy for } \\
\text { Heat } \\
\text { Pump }\end{array}$ & $\begin{array}{l}\text { Energy } \\
\text { Saved by } \\
\text { H.P. }\end{array}$ & $\begin{array}{l}\text { OSavings } \\
\text { by Use } \\
\text { of H.P. }\end{array}$ \\
\hline Chicago & 6,380 & 589 & 18,890 & 11,970 & 6,920 & 36.6 \\
\hline St. Louis & 5,329 & 348 & 14,440 & 8,430 & 6,010 & 41.6 \\
\hline Ft. Worth & 3,833 & 71 & 7,460 & 3,470 & 3,990 & 53.4 \\
\hline
\end{tabular}




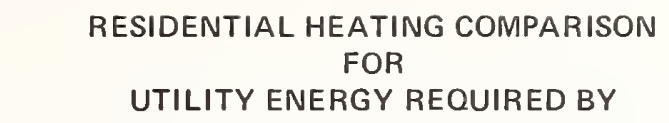

VARIOUS HEATING SYSTEMS (NEW YORK AREA)

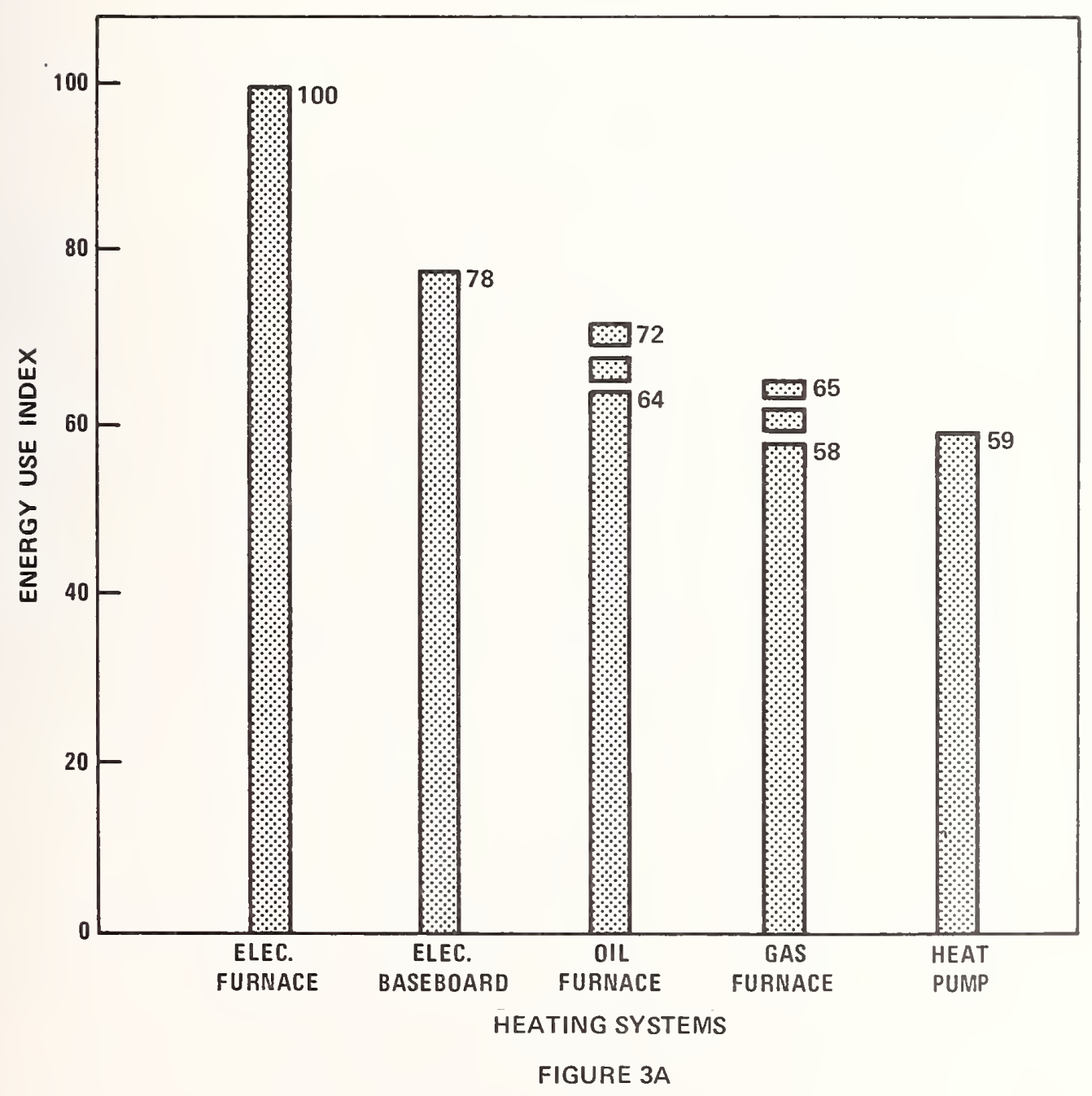


more precious gas or oil fuels would become even more favorable to the heat pump.

The extra energy saving that would result from even higher CoP in heat pumps seems attractive. To explore this possibility, lets look first at the factors that degrade COP.*

Figure 3 shows how the COP goes from a theoretical maximum (Carnot)

COP of 21.2 , down to approximately 2.5 which is actually obtained.

These factors are explained as follows:

Carnot-- The theoretical maximum $\mathrm{COP}=\mathrm{T}_{2} /\left(\mathrm{T}_{2}-\mathrm{T}_{1}\right)$

Air Flow--The air moved to move heat indoors must

be hotter than indoor temperatures, say $100^{\circ} \mathrm{F}$, and

similarly for outdoor air.

Heat Exchanger--Temperature drop must occur across

the heat exchange surfaces.

Fans--Fan power to move air is used for the indoor

section, but outdoor fan power goes to waste.

Pipes and Valves--Pressure drops within the heat

pump refrigerant loop decrease efficiency.

Rankine Cycle--Difference between the actual con-

densing cycle and the ideal.

Compressor Cooling--Hermetic compressors put motor

losses into the refrigerant before compression as a

matter of operating convenience and to reduce costs.

Miscellaneous--Other small losses in the system.

Large cost increases have been found to accompany any substantial changes in these elements of heat pump design.

Value to the customer is a key consideration in designing this kind of equipment. Consider a 2-1/2 ton cooling system using either an electric furnace or a heat pump installation. We assume a $1600 \mathrm{sq}$. ft. residence in Ashland, Ky., with normal electric-heating insulation. The heat pump saves about $40 \%$ of the heating season electricity with a consequent saving in the users electrical bill of $\$ 84$. The cost spread between an electric furnace installation and a heat pump in this case is on the order of $\$ 300$. Thus the customer saves his extra investment cost in about four years.

A $20 \%$ improvement in COP might be made by increasing heat exchanger area, along with some other modifications. However, with current technology we estimate that this might increase the cost of the heat pump equipment and installation by $50 \%$. The heat pump premium would then be $\$ 800$ and the annual fuel savings would be $\$ 105$, yielding a payback period of about 8 years, assuming no interest is imputed on the extra investment. Our belief is that the market for this improved heat pump would be 1 imited, so that making improvements using current technology would not pay off substantially.

Now suppose a major invention is made which seems to promise a major improvement in COP, large enough to promise a reasonable payback period for the customer ( $3-5$ years), if he made this extra $\$ 800$ investment in the equipment. Even if successful, the introduction costs for this new invention are also a challenge which must be met. Let's look at the risks the manufacturer takes if he converts his plant to the new design. We assume the product has been tested in prototype and we believe some units will sell, but we aren't entirely sure how many people will buy it at a premium in cost; and we feel some risk about how well it will perform over the long term in the field and the consequent warranty costs we might incur. The investment we have to make to supply between 50,000 and 200,000 units per year, the number we need to impact between $2.5 \%$ and $10 \%$ of the new housing starts each year, is about $\$ 25 \mathrm{million}$. This includes engineering, tooling, factory modification, start up, and equipment investment costs and in addition includes training of sales and service people over a two year period. The

* W. A. Spofford, "Heat Pump Performance for Packaged Air Source Units", ASHRAE J, , Apri1 1959. 


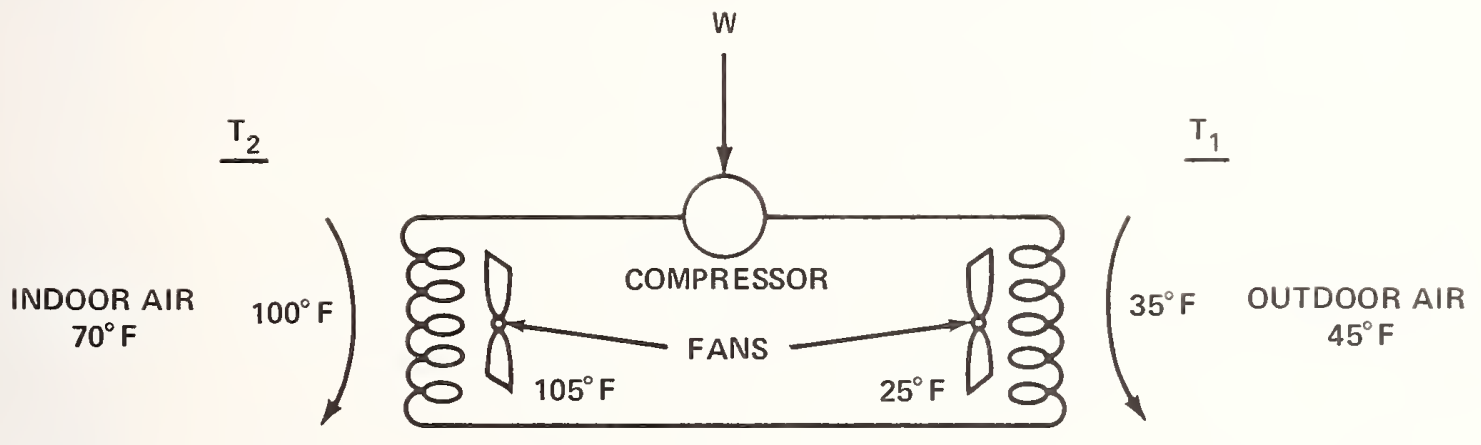

\begin{tabular}{|c|c|c|}
\hline FACTOR & $\underline{T_{2}}\left(^{\circ} \mathrm{F}\right)$ & $\underline{\mathrm{T}_{1}\left({ }^{\circ} \mathrm{F}\right)}$ \\
\hline IDEAL (CARNOT) & 70 & 45 \\
\hline AIR FLOW & 100 & 35 \\
\hline HEAT EXCHANGER & 105 & 25 \\
\hline FANS & FAN POWER & \\
\hline PIPES AND VALVES & PRESSURE DROP & \\
\hline RANKINE CYCLE & ( $80 \%$ OF IDEAL) & \\
\hline COMPRESSOR COOLING & & \\
\hline MISCELLANEOUS & & \\
\hline
\end{tabular}

FIGURE 3 
\$25 million investment would all have to take place before we got any significant income from the new product, and before we were sure that the new product would continue to sell and would perform we11 in the field. We would have to defer plans for other product changes, improvements, or expansions to provide the costs, and engineering and manufacturing manpower to be able to make this changeover.

In summary, continued search for technical breakthroughs in heat pump performance are desirable, but market and economic requirements are such that real hurdles must be overcome before even a reai breakthrough could be expressed in production.

Over the years many such new ideas have been investigated in great detail, only to find that the product will not go because of economic or other factors which may be unrelated to the technological feasibility of the idea. The path from a new technical idea, demonstrated in the laboratory, to a product with large enough market to have significant impact on a national problem like the energy crisis is complex and challenging. Major financial risks are associated with attempts to project such ideas into major markets. For this reason, product improvements tend to occur in evolutionary fashion rather than in single revolutionary solutions.

\section{Light Bulbs}

The complex tradeoff of customer value is illustrated very clearly by the light bulb industry, where lifetime cost of light and energy efficiency have been the ruling factors for decades. Figure 4 shows how the production of light in the USA has grown since the beginning of the electrical light industry, clearly an exponential-style behavior. Superimposed on the growth curve is a curve representing the electrical demand caused by this growth in lighting. If technology had stopped with the incandescent lamp, the electrical demand curve would have followed the lighting curve; however, because of the greatly increased efficiency of fluorescent lamps over incandescents, the curve is much flatter. The relative efficiency ranges for different lamp technologies is shown in Figure 5. There has been a steady progression of new, more efficient technologies over the years.

In fact the individual technologies have experienced efficiency improvements with time, too (Figure 6). The incandescent lamp saturated in the $1940^{\prime} \mathrm{s}$, following decades of increase. The fluorescent lamp is still rising, and promises to do so for many years to come.

Questions are often asked about incandescent light bulbs without recognizing that different effects are closely coupled. Such questions as "Why don't lamps last longer?", "Why do they cost so much?", and "Why can't they be made more efficient?" can only be answered together.

The tradeoff of 1 ife for efficiency is illustrated in Table 3 .

TABLE 3

$$
\text { Lamp Efficiency vs. Life (100 watt lamps) }
$$

\begin{tabular}{lcc} 
Service & Life (hrs) & Efficiency (L/W) \\
\cline { 2 - 3 } Rough & 1000 & 12.3 \\
Vibration & 1000 & 14.2 \\
General & 1000 & 16.8 \\
General & 750 & 17.5 \\
Photoflood & 50 & 19.8
\end{tabular}

To increase the efficiency of an incandescent lamp the filament must be run hotter. If the filament runs hotter, tungsten boils off at a greater rate and leads to earlier failure: a simple trade of life for efficiency. Figure 7 illustrates in schematic form how the cost of 1 ight varies with lamp design life. Lamps with very high efficiency have very short life, hence the cost of bulb replacement dominates and is high. Lamps with very long life operate at low efficiency, increasing the energy use per unit of 
EQUIVALENT ELECTRICAL DEMAND

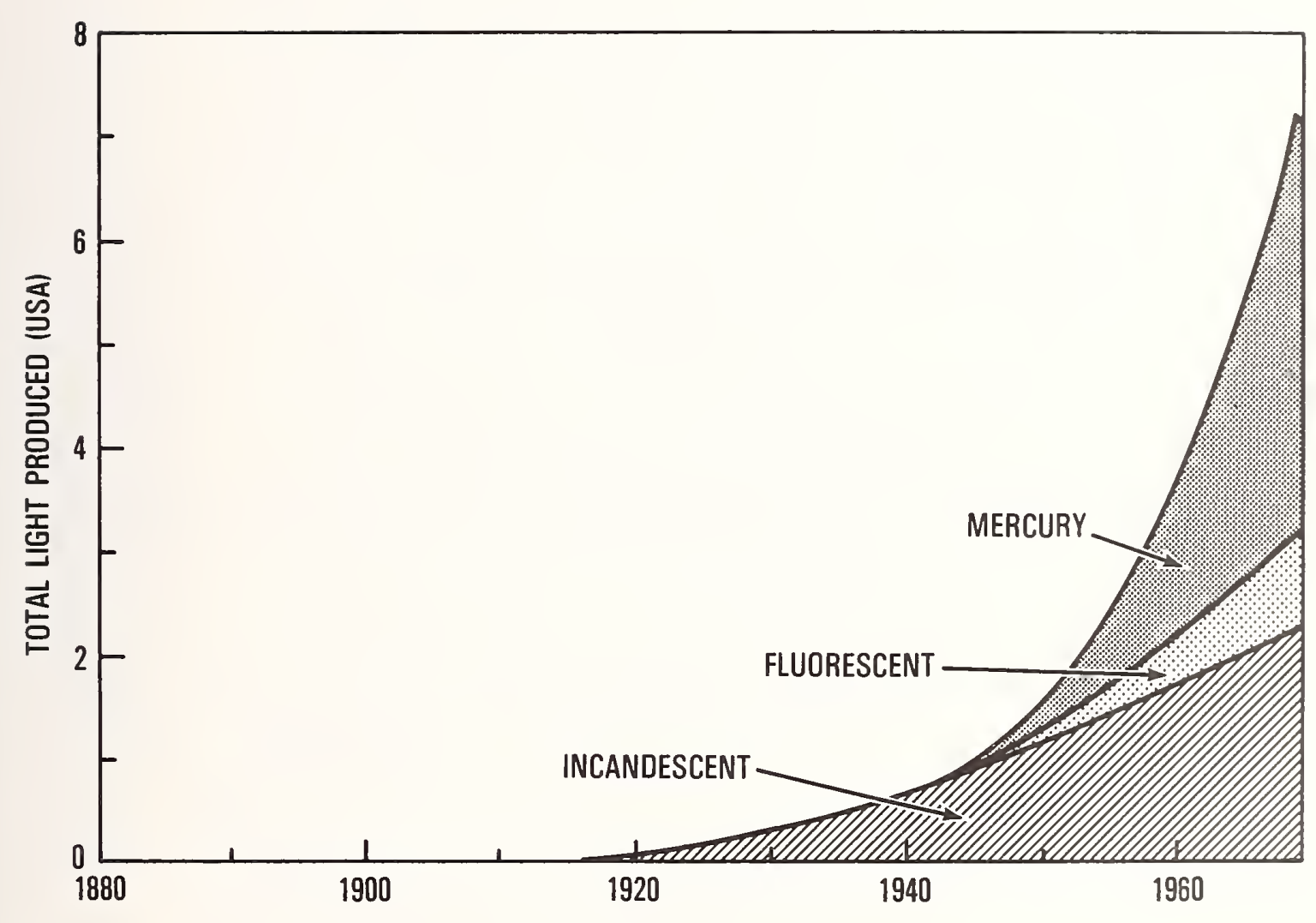

FIGURE 4 

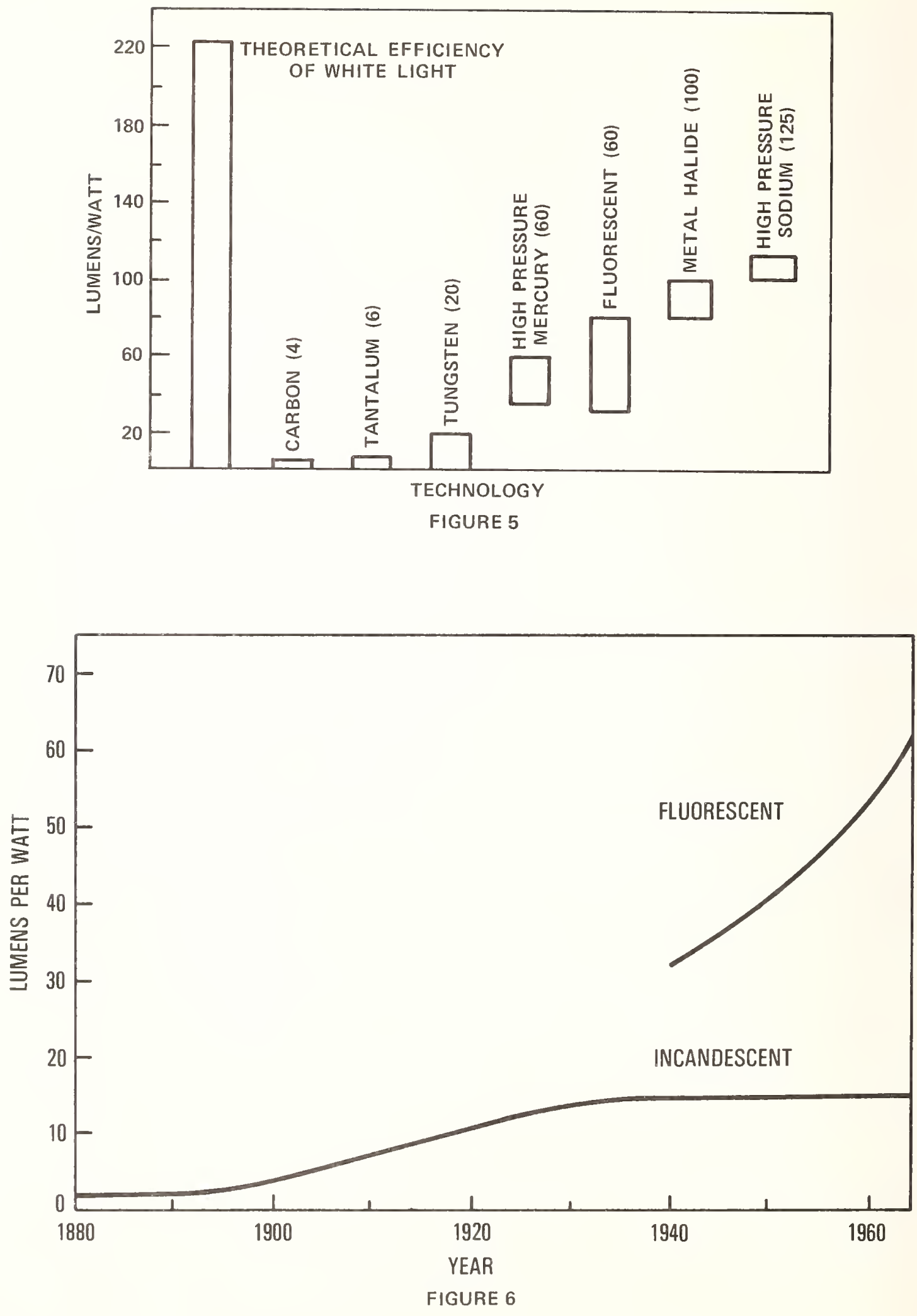


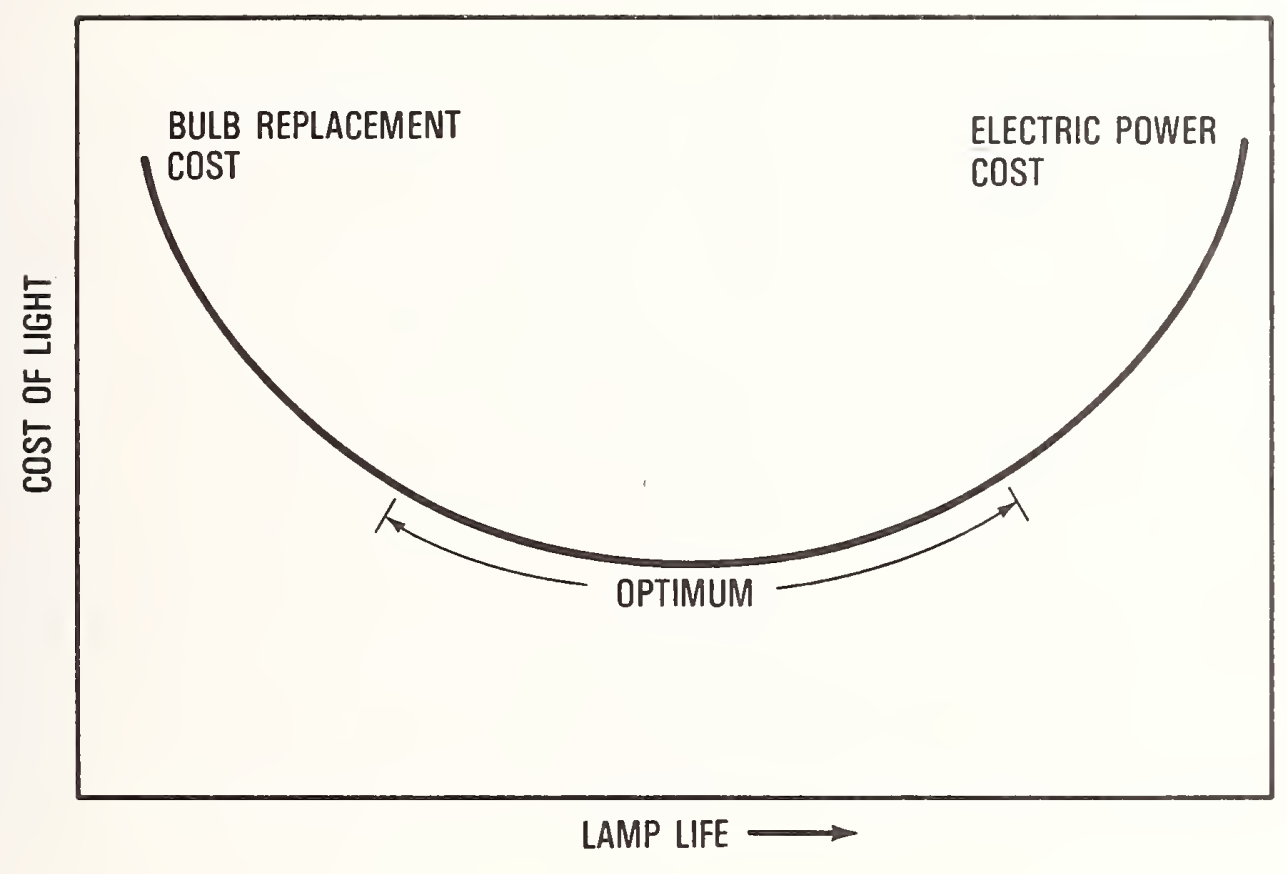

FIGURE 7 
output, over-compensating for the reduced rate of replacement of 1 ight bulbs. These longer-life bulbs are more expensive to make, and thus face the consumer's natural resistance to a higher priced product. There is an optimum in the lamp design, at which the cost of light is a minimum. It is at that optimum that most modern incandescent bulbs are designed.

Many factors beyond the control of the manufacturer, and even the homeowner, influence the life of light bulbs in the home. Figure 8 shows schematically how the light output and life of incandescent bulbs varies with under- and over-voltage. A house near the local distribution transformer might experience as much as $15 \%$ overvoltage in the evening when system line voltage is boosted to assure that customers further away get the full voltage expected. If that happens regularly when a particular set of lights is on in a house, the lifetime of those lamps may fal1 precipitously.

Summary

There are many opportunities to conserve energy using technology which already exists but which has not been fully applied in every day use. Heat pumps could be used economically in many more new housing installations, and in replacement of more old equipment than is now being done; a reasonable goal might be to use heat pumps in at least $15 \%$ of all new central air conditioning installations again, as was the case in the 1ate 1950's. Shifting from incandescent to fluorescent lamps would save energy for the nation and money for consumers.

The descriptions in this paper illustrate the complex of factors which must be considered when making manufacturing and marketing decisions on new products, or product improvements; energy conserving products are not different from others in this respect.

As good new ideas arise for new equipment or for ways to redesign existing equipment to operate more efficiently, they should be explored thoroughly. However, basically good ideas may be pursued in unproductive directions and be lost. Even at an early stage the complex process of technology transfer from the laboratory to operations must be begun, and a clear-headed business evaluation of the real commercial prospects for success must be made. Using this approach, many of the pitfalls which might arise as the idea nears commercialization may be anticipated, and successful solutions may be worked out early enough to avoid a major crisis as the idea moves to the prototype stage. 


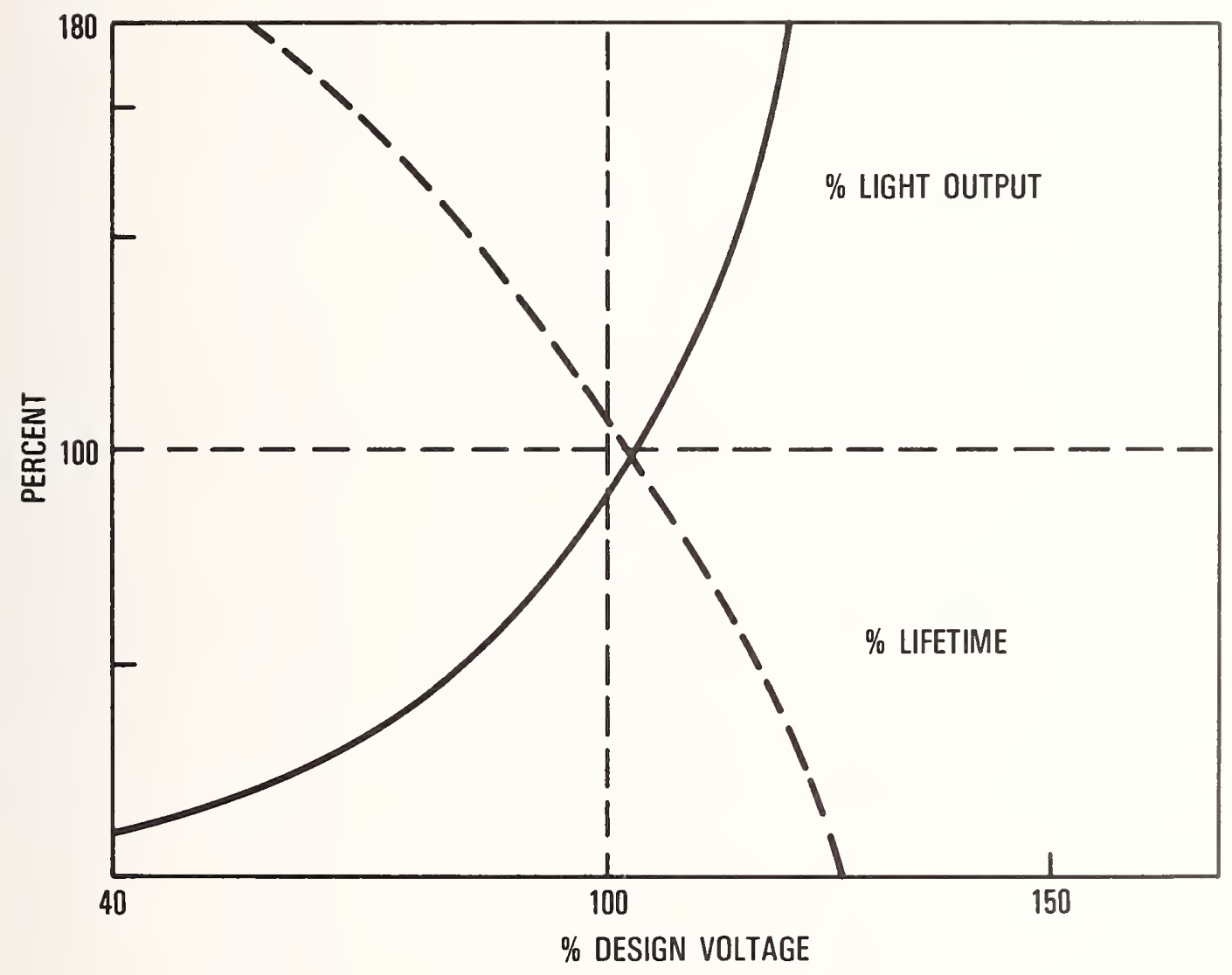

FIGURE 8 

National Bureau of Standards Special Publication 403

Proceedings of 1973 Engineering Foundation Conference

(Issued June 1976)

ECONOMIC, ENERGY, ENVIRONMENT TRADE-OFFS

by

Paul Swatek*

Environmental Affairs Coordinator

Massachusetts Audubon Society

Lincoln, Massachusetts 01773

The individual is a member of a community of interdependent parts. His instincts prompt him to compete for his place in the community, but his ethics prompt him also to cooperate. Believing that pecuniary motivation is high on the list of human priorities, freer market mechanisms than presently exist are urged. The market should be unshackled, both removing subsidies to the energy industry (oil depletion allowance) and having the producers internalize the now externalized socia] and environmental cost of their operations. Such measures are projected to be effective in all energy consuming sectors, await the development of no new technologies, require no legislation of rigid criteria and technical standards, require no bureaucracy, rely on the normal operation of the free market, do not depend on changes in basic motivation of consumers, and will work and produce an efficient allocation of resources.

Key words: Costs; economics; energy; environment

Introduction

"All ethics so far evolved rest upon a single premise: that the individual is a member of a community of interdependent parts. His instincts prompt him to compete for his place in the community, but his ethics prompt him also to cooperate (perhaps in order that there may be a place to compete for)."

"The land ethic simply enlarges the boundaries of the community to include soils, waters, plants, and animals, or collectively: the land." (Sand County Almanac)

I begin this discussion of economic, energy, environment trade-offs by quoting Aldo Leopold, because the fundamental truth that he enunciated a quarter of a century ago provides a philosophical underpinning to the conservation-become-environmental side of the frequently vigorous debate that is taking place today over allocation of the earth's resources. The earth and the community of plants and animals (including man) that are sustained by it and the energy of the sun are together parts of an elaborate ecological network. In the natural state, energy flows from the plants and plankton up through the herbivores and carnivores. Material wastes produced by one part of the system are utilized by other parts in such a way that nearly all matter is cycled and recycled.

The system is so interdependent that an alteration to one element inevitably is felt by other elements, and it is so complex that is has proven impossible for man to predict with much certainty all of the effects of his substantial tinkering with natural ecosystems.

As man-made environments and economic systems have approached the complexity of natural systems, man has also experienced failures to predict their behavior, with unfortunate consequences.

It is the escalation of these unplanned assaults on the land and natural ecosystems, and on the public health and social welfare, especially those associated with the extraction of fuels, their conversion to other energy forms, and their end use, that has brought the traditional conservationist 
and now the so-called "environmentalist" so strongly into the energy decision making picture.

Energy is the common element that ties Glen Canyon, the Grand Canyon, Alaska and Canada's western coast, the hills and streams of Appalachia, Maine's Penobscot Bay, the clean air regions of the West, and the nation's coastlines and continental shelf together in conservationists' minds, for it is in the search for energy sources that men have been willing to exchange the ecological integrity and long-term productivity of significant natural resources in order that our modern civilization can indulge its extravagant appetite for energy. This energy connection became clear to conservationists at the same time that society began to question the acceptability of the environmental and social impacts associated with mining coal, auto-based urban transportation systems, and the hazards of an imperfect nuclear technology.

Thus, in the last several years, environmentalists have paid increasing attention to some of the fundamental factors influencing energy use, convinced that they provide some of the best handles for tackling problems to those who would protect the land and preserve livable environments.

Existing Incentives for Energy Waste

Resources have traditionally been allocated according to the dictates of economic and technical, rather than environmental, factors. In this country, we have relied on a market system using the dollar as the primary measure of value. Energy decisions have been guided by the perceived needs and shortterm interests of individual components of the system more than by a plan conceived and coordinated to meet the long-term best interests of the whole.

The theory of our economic system is that the price of a good reflects its value to society and that the market will allocate goods and services in an optimal fashion. Yet we have allowed extraordinary-economic and political power to accumulate in the hands of some, especially the energy industries, and that power has been used to distort the market allocation of resources in very significant ways.

As examples, I would cite such direct subsidies as the oil depletion allowance, the write-off of "intangible drilling costs", the favorable tax treatment of royalty payments to foreign governments, and the limited liability provisions of the Price-Anderson Act (which exempts the utilities industry from assuming more than a small portion of the liability in the event of a major nuclear accident). In addition, it is the general taxpayer, not the coal industry or user, who now pays the cost (annual1y about $\$ 1.5$ billion) of payments to miners who are victims of black lung disease.

Until recently, industry has not been expected to assume the very substantial economic and non-economic costs associated with pollution it causes. Now that abatement of pollution is required, legislatures have apparently decided that special tax benefits to those who invest in add-on abatement equipment will be a preferred tool in cleaning up the environment.

In terms the economists use, we are not internalizing the costs of producing and using energy. The use of energy is cheap, even when the expense of producing it is great. The victim of pollution and the general taxpayer bear the costs instead of the user.

The effect of the low price is an inflated demand for energy at the low price and a distortion of resource-allocation priorities. Demand is inflated further by the practice still followed by most utilities of using a promotional rate structure, so that the more energy one uses the less per unit one pays for it.

The policy of low energy prices has contributed to high levels of material consumption and, by traditional measures, a higher "standard-ofliving". However, in the face of the consequences that we are now seeing from the exponential growth in resource consumption, the basic wisdom of the energy policies that I have outlined above must be called into question. A growing number of people have concluded that the high material standard-ofliving is not necessarily coincident with a high quality of life. 
Economic Incentives for Energy Conservation

The previous analysis invites an exploration of the benefits of reversing some of the above-mentioned policies. Most environmentalists feel that the results look quite promising and merit a try. Working through the pricing mechanism offers a number of distinct advantages:

1. It promises to be effective in a 11 energy-consuming sectors.

2. It awaits the development of no new technologies. Rather, it has the effect of stimulating innovation.

3. It avoids legislation of rigid criteria and technical standards.

4. It requires no bureaucracy for its implementation and administration.

5. It relies on normal operation of the free market system.

6. It expects no changes in the basic motivations of consumers and business managers.

7. Economists tel1 us that it will work, and that in the process it will produce an efficient allocation of resources.

A few examples illustrate how increases in the price of energy will work to dampen demand and improve supply.

In the domestic and commercial sectors, as the data becomes available and buyers learn how to interpret it, there will be strong incentives to purchase more energy-efficient equipment. This is especially true, for instance, of such home appliances as refrigerators, freezers, and air conditioners which use lots of energy and where energy-efficiencies per unit of performance vary by $50 \%$ and more. As energy prices escalate, the operating savings achieved by using more efficient equipment will also escalate and manufacturers will have a greater incentive to market energy-efficient equipment to compete for the more energy-conscious consumer dollar.

The effect of raising fuel costs on consumption by the automobile may be estimated by comparing European and American gasoline prices and car sizes. In Europe, gas prices are much higher, and car mass and fuel consumption are much lower. Because of the very large portion of energy used in the transportation sector, this effect alone will be very significant.

In similar ways, rising energy prices will make investment in insulation and other energy-conserving measures more economic. Increases in the prices of goods whose manufacture is energy-intensive will disfavor their use and result, in some cases, in the substitution of less energy-expensive materials to achieve the same function.

Even in situations in which direct energy input now accounts for only a small portion of the cost of producing a product, a boost in energy prices will sometimes be enough to tip the market balance to a new process or to a competitor. It has been one of the great strengths of the American free enterprise system to exploit such minor competitive advantages.

On the supply side of the supply-demand equation, increasing the mar ket prices for fuels will make it possible to exploit sources of energy that were uneconomic before, because the cost of obtaining them with an acceptably minimal environmental impact will no longer be too high.

Imperfections in a Strictly Economic Approach

I do not mean to ignore the disadvantages of an energy conservation strategy that relies primarily on internalizing the costs of energy production and the consequent increase in energy prices to bring supply and demand back into balance and to allocate resources wisely.

Such a strategy, for instance, would not be likely to reduce demand for energy by $5 \%$ this year, but if we are to believe the economists, it could in four or five years. There is a lag as the realization that prices of energy are on the way up sets in and as more energy-efficient equipment replaces older less-efficient equipment. This lag may be a serious liability, if quick results are needed. It is encouraging, however, to think that the turn around in electric power rates that has occurred in the past several years may already be working to lower demand. It will be interesting to note whether those utilities which three years ago first instituted price increases experience slower growth rates in the next few years. (Note: The long-term price elasticity of demand for energy, as reported by a number of economic studies recently published, appears to be in the range around -1.2 . 
This means that a one percent increase in energy price this year produces a decrease in demand several years later of more than one percent. Arguments that try to dismiss this long-term effect are specious - "Do you mean to tell me that you think that the American consumer will be willing to leave his car in the garage and walk to work!")

There is an additional disadvantage of the price mechanism in that the rise in price of energy will tend to have an immediately regressive social impact. Use of energy increases roughly $70 \%$ as rapidly as does family income. Thus, the energy bill for the poor family is likely to be a greater percentage of income than it will be for the more affluent family. Fortunately, fairly simple measures are available to reduce this impact, at least as far as domestic utility bills are concerned. Most environmentalists support proposals to set a lower unit price on a uniform basic allotment of energy for each domestic user with unit prices scaled up as total use increases.

While discussing the social impacts of reallocating our energy priorities, it would be a mistake not to mention some of the ways that our present system discriminates against the poor. As an example, I would cite transportation systems. A disproportionate share of federal assistance has flowed to highways and air travel, both energy-intensive modes of transport, at the same time that urban mass transportation, an efficient mode, has languished. Yet, the urban poor, especially the aged, the young, and the infirm, who benefit little from the investment in air and auto facilities, would benefit more from public transportation improvements. So would the energy picture.

In continuing to permit pollution from energy-related facilities, we have tended, also, to pass the externalized costs on to the poor, for it is the poor who tend to inhabit the more environmentally degraded neighborhoods. In many cities, the highway that brings the affluent suburban commuter to work runs through the bedroom of the poor, and the power plant that supplies the downtown high-rise office building emits its sulfurdioxide to damage the urban dweller's lungs and property. I mention this primarily to point out that an energy policy that increases prices to reduce pollution will also produce benefits, and that these benefits will accrue to the poor as well as the wealthy.

There is a third potential social impact to be derived by raising energy prices. As the price of energy has decreased and the price of human labor has gone up, it has been economic to substitute machines for man. A rise in energy costs should make this substitution less economic in the future with a resultant beneficial impact on the job picture (new energy-for-labor substitutions will lessen), at a time when unemployment is high.

By endorsing a fundamentally economic approach to energy conservation, I do not mean to imply that a purely economic approach will be either sufficient or politically easy to achieve.

One of the most fundamental flaws in our market system is its failure to protect common property resources. Traditionally, air and water have been considered free goods, allocated on a first-come first-served basis, to be used or abused pretty much at will. The consequences of this system have been aptly described by Garrett Hardin in his now wel1-known "Tragedy" of the Commons". Each member of the New England town had the right to use the common green space at the town center as a grazing place. With few cows and enough grass the system was in equilibrium, but as the size of the herd increased, the grass was unable to recover from the heavier use and the common was destroyed as pasture. At any point in this process, it was in the economic self interest of any member of the community to add a cow to the herd, because all benefits - milk and meat - belonged to the owner; to the extent that there was a cost to the rest of the herd or the pasture, it was shared by the entire community. This was true even as the carrying capacity of the common was approached and exceeded.

Hardin's suggestion is that what is needed is "mutual coersion, mutually agreed upon". Or put another way, when the market system fails, some sort of regulation is required. 
Regulation by federal statute has been necessary to protect air and water quality from pollution produced from energy fuels. By requiring compliance with federally established standards, externalized costs are

internalized and the market system's allocation-of-resources machinery operates, but now with reduced environmental degradation. What constitutes "excessive" degradation is determined, in a mechanistic sense, by the stand ards, which are established by the political process. More will be said about this later.

At this point I should mention the pollution tax, an alternative and perhaps complementary approach to solving the commons problem which has many backers these days, among them the Coalition to Tax Pollution, and the Administration. Basically, the idea is that a tax is assessed per unit of pollutant emitted. The current proposal for a sulfur tax would call for a levy of 20 cents per pound of sulfur emitted, a level at which it would be more economic to abate sulfur dioxide emissions as needed.

In a number of ways, this technique offers a better approach than the regulatory-standards approach. Only one standard - the price per unit of pollutant emitted - needs to be set. It applies uniformly across all industries and requires no assessment of "best available" technology. Enforcement machinery is replaced by a monitoring system and a tax collection apparatus. Industry, faced with an ever-present incentive to abate, is free to choose its approach to abatement.

The Trade-offs

With either the standards approach or the pollution tax, fundamental priority decisions are made, of course, when the numbers are set. If you accept the basic premise that price is the most influential factor (that we can control) which affects energy supply and demand, then these numbers are the key to how we determine what trade-offs there will be between environmental quality, energy quantity, and economics.

How should this balance be determined? If the data base were available to do it, one might suggest that the most rational procedure would assess the cost of damage from a given amount of pollutant, estimate the cost of abating the pollutant to various levels, choose that level of abatement whose cost (including energy cost) matches the cost of the damage at that level, and then to apply standards and/or a pollution tax designed to achieve the desired level of abatement. If we were able to carry out such a calculation to solve our energy, environment, economics trade-off decisions, we could, at least in theory, optimize the solution so as to avoid environmental1y damaging undercontrol and economically expensive overcontrol.

I hardly need to say that the decision-making system in use today is not the one I have described. In most cases we do not have the knowledge and data needed to solve the problem in the above manner. Instead, we substitute for this technical calculus a political calculus which performs the integration in the absence of the required technical input because it has to do it. It is the only method that we now have to make the difficult trade-off decisions. Presumably, as we learn more about the energy/ecosystem/economics/ abatement technology interactions, we will be able to introduce more quantitative information into our consideration of the alternatives. I would point out, however, that to be politically useful and effective, the source of the technical input must be credible to the public. Because of the wild oscillations in energy industry stances on issues recently, I suspect that it will take some time and perhaps some changes in standard operating procedures for industry credibility to be re-established in the political forum.

I never foresee a time, however, when the political calculus will cease to be the ultimate determinant of resource allocation decisions. This is because it will probably never be possible to quantify and reduce to common dollar units the value of all of the resources impacted by energy technology. How do you attach a dollar value, for example, to the clean air of the Four Corners area or the Big Sky country of Montana? One could analyze the number of kilowatt-hours of electricity that would be generated over the 
lifetime of the plants proposed to operate there and figure out how much more it would cost to generate that much power in a more acceptable way. But against what figure would you compare that? Economists have fun trying to establish such numbers by looking at public vacation expenditures to learn what people are willing to pay for the experience of visiting this beautiful country. I suppose one could try to extract relevant numbers from comparative real estate and salaries data, from questionnaires and the like. The comparison, however, eventual1y boils down to a value judgement; and each man's point of reference is his own. When the political calculus comes into play, the intangible factors weigh in with the technical factors.

Before leaving the question of value, I should mention the existence of some fascinating attempts to assign quantitative values to non-market natural resources. As an example, I would cite an interdisciplinary effort being conducted at the University of Massachusetts at Amherst under the overall direction of Dr. Joseph Larson which attempts to quantify the values of wetlands as water resource, wildife habitat, and cultural/aesthetic amenity. Also, a number of programs are underway throughout the United States to inventory and evaluate "natural areas", and federal land use legislation is pending which establishes criteria for areas of "critical environmental concern". One must mention the work of Luna Leopold who came up several years ago with a scheme to rate unique natural resources and the analysis of John Krutilla 2 which demonstrates that a truly unique and valuable natural resource (his example: Hell's Canyon on the Snake River) may have enormous present value, meriting preservation, if the demand to experience it in its natural state is increasing. This may be true even if there is not today a market for the experience (i.e., It is available at no charge.)

I mention these land use matters because land use impacts, in addition to emissions impacts, are among the most significant environmental factors that are influenced in a major way by energy decisions. Strip mining chews up the land, spitting it out either reclaimed or unreclaimed, but in either case profoundly altered. Energy facility siting brings changes to 1 andscapes by itself and plays an important role in shaping development patterns by its secondary effects.

Land, in this nation, has been treated as a commodity to be bought and sold according to the dictates of the market system. This basic concept is written into the Bill of Rights. A transformation is well under way, however. Certain rights in land will in the future be treated more as common property resources are. Exercise of these rights will be strictly regulated. The land ethic of Aldo Leopold is at work. A utility familiar with siting problems knows well that land use considerations now present significant constraints to its decision-making. This is as it must be.

In addition to the social and environmental factors that $I$ have already cited, there are obviously other considerations which weigh into the decision-making process. Balance of payments is an interesting case in point. As imports of petroleum grow, attempts are being made to even the trade balance by boosting exports - of scrap metals, enriched uranium, western forests, agricultural products, and other resources. There are environmental impacts associated with each of these commodities. This is testimony to the truth that the trade-offs are almost infinitely complex and that the wise choices are sometimes obscurely hidden.

The political process determines the trade-offs by balancing interests. many of which I have described. The success with which interests are balanced, however, depends on attitudes.

The consumer wants convenience and material affluence and a pleasant environment, all at the same time. The businessman wants a free hand to carry out his business, and we all tend to resist change, especially when it

${ }^{1}$ A Guide to Important Characteristics and Values of Freshwater Wetlands in the Northeast, edited by Joseph S. Larson, Publication \#31 of the Water Resources Research Center, Univ. of Mass., Amherst, Mass., July 1973.

2 To Conservation Reconsidered, by John Krutilla, American Economic Review, Vo1. 57, pp 777-786, Sept. 1967. 
assails our parochial, short-term self-interest. For these reasons it would be difficult to initiate measures, for example, that would create new jobs in one place at the expense of existing jobs, even if the net job impact is beneficial. In such situations it is sometimes necessary to forge ahead, despite objections. The political process has to make such decisions every day; if the solution is wise, the flak will be minimized.

Despite human desires, demand cannot indefinitely challenge supply. We know this from the law of conservation of matter. We know we cannot forever extrapolate the present into the future without unacceptable environmental and social disruptions. Of course, when we set new courses, we should seek those ways that minimize the necessary disruptions.

I suspect that we cannot really fully understand the nature of the trade-offs until we recognize the way in which material growth challenges personal freedom. It is helpful to me to think of the problem in the

following terms, by analogy with a chinese checkers board and a bag of marbles. When one places the first marble on the board, it has maximum freedom to move. Addition of the second imperceptibly restricts the freedom of the first, but the system is more interesting in the sense that one marble can now skip over the other. Ten marbles on the board enriches the system more, but restricts freedom to move very little. When the board is half filled, the average marble begins to notice that half the time the next space is occupied. When the board is completely full, all freedom of movement and nearly all of the richness of interaction is gone.

If you think that you will never be a marble on a completely filled chinese checkers board, you never have been in a traffic jam. The laws of thermodynamics work, and they work on humans. For an idea of what happens to individual freedom and liberty in a society that is operating somewhat nearer to the practical environmental limits than the United States now is, consider mainland China. Viewed from this perspective, one begins to realize that the trade-offs among economics, energy, and the environment also involve our personal freedom. This is why society needs the sort of ethical system that I mentioned at the outset.

\section{$\frac{\text { A Policy }}{\text { To }}$} ronment trade-offs I would offer the following example of how the principles that I have outlined can be applied. In January 1973, the Board of Directors of the Sierra Club adopted two brief energy policy statements relating to economic policy and energy conservation.

"Current and past economic policies with regard to energy are a major cause of the problems we face with respect to environmental impact and energy supply and demand. New economic policies can be a major factor in bringing about a more rational and less environmentally destructive pattern of energy development and use. The Sierra Club believes that the prices of all forms of energy should cover energy's true costs. This will favor those energy sources which have minimum environmental impact while penalizing those with the most serious impact. It should also blunt the growth in total energy demand.

"The Sierra Club specifically recommends:

(1) Rapid phasing out of all economic subsidies to energy industries. Examples include depletion allowances on the extraction of energy resources, which should be replaced by recovery of amortized investment costs only; the favorable tax treatment of imported oil; the tanker subsidy program; and the subsidy of hydro-electric projects by means of specious calculations of recreational and flood control benefits and the use of a discount rate less than the opportunity cost of capital.

(2) Removal of environmental and social subsidies by internalization of environmental and social costs. For example, emissions of pollutants should be taxed, and the industry, and ultimately the user, should be required to pay for the costs of pollution abatement, adherence to stringent regulations to protect the health and safety of workers, full compensation to the victims of occupational diseases and injuries such as black lung 
disease, etc. Pollution taxes must be set at a level high enough to assure that they will be effective in abating pollution. They should also be high enough to cover all direct and indirect costs to society of the polluting activity.

(3) Revision of rate structures to better assure that energy is priced at its full cost. This should follow the principle of marginal cost pricing, i.e., the settling of prices at that level which covers the full costs of new supplies of energy. Included in marginal cost pricing should be the charging of higher rates during periods of peak demand, to cover the higher costs of providing new capacity and to provide an incentive for reducing energy use. The possibility of windfall profits for energy companies from marginal cost pricing should be eliminated by imposing an energy tax to divert surplus revenue to the government.

(4) The imposition of severance taxes upon the extraction of nonrenewable energy resources should follow the rapid phasing out of subsidies.

(5) Termination of the fuel import quota systems. If some system for reducing the fuel imports is considered important for reasons of national policy, a tariff system should be substituted.

"The revenues from the above taxes could well be spent to cover the costs of government programs to develop less wasteful and environmentally damaging ways of producing and using energy, to pay for surface restoration of old mine workings, and to cover the costs of monitoring and effective regulation of health, safety, and environmental impact. However, a trust fund may not be desirable, since it may tend to circumvent rational budgetmaking and setting of priorities."

"Special efforts should be made to insure that those of low income do not suffer from the generally higher level of energy prices which can be expected to result from having the user of energy pay energy's true costs. Fortunately, the economic reforms which we advocate will have a far greater impact on the users of large quantities of energy than on the poor. However, until our society devises an effective program to address the economic needs of the poor, special provision must be built into the energy rate structure to assure all domestic users of minimum quantity of energy to meet basic needs at rates that will not adversely impact the poor."

"Energy conservation must be made a major national goal. We must establish federal, state, and local policies, as well as encourage personal attitudes, which will promote more efficient energy use and better conservation of energy resources. The following steps are some of many which should be pursued with vigor:

(1) Land use controls and urban designs to reduce transportation demands.

(2) Efficient and attractive public transportation systems and smaller, more efficient private vehicles.

(3) "Total energy" systems, which usefully employ "waste" heat.

(4) Energy-efficient buildings designed to lower requirements for artificial heating, cooling and lighting.

(5) The direct use of pipeline quality gas instead of electricity generated from such gas for heating, and the use of heat pumps where practical.

(6) Products with longer 1 ives, lower average energy demand, and greater efficiencies. These features should be specified on product labels.

(7) The recycling of materials and reuse of containers, and the elimination of unnecessary packaging.

(8) The use of renewable energy sources, such as solar energy, wind power, and geothermal power. cies."

(9) Improved energy conversion, storage, and transmission efficien-

This conference has demonstrated amply that energy conservation measures are available and technologically feasible. All that is needed are the incentives to motivate the decision-makers to act. The economic 
and regulatory measures that conservationists advocate will work, * we believe, and in a manner that will minimize adverse social and economic impacts.

* Note the large energy savings in the industraal sector, anticipated from actions to "raise energy prices by tax and/or regulation," that are projected in the Office of Emergency Preparedness report on "The Potential for Energy Conservation" published in October, 1972. 



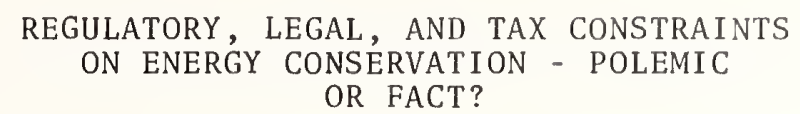

by

\author{
Honorable Charles Warren \\ Assemblyman, California State Assembly \\ State Capitol \\ Sacramento, California 95814
}

\begin{abstract}
Recognizing the vital role of power in society, an education and voluntary basis for balancing the different mechanisms in the market (such as the adjustment of electric rate structures) is urged. In the last analysis, if this approach is unsuccessful, regulation will be required drawing upon the power of the State. Regulatory enactments should be directed toward behavioral norms in the every day activities of people rather than adjudicating conflicts. The State would set standards for the building industry, controlling lighting and insulation, be prepared to establish allocations of energy, and prescribe levels of operating efficiency. Since the standards proposed are esentially performance criteria rather then product quality criteria, one could enforce conformity at the point of end use.
\end{abstract}

Key words: Energy; legal; regulatory; standards

"You mean you can't take less....it's very easy to take more than nothing." Mad Hatter.

"When I use a word....it means just what I choose it to mean - neither more nor less." Humpty Dumpty.

Introduction

My topic today is the legal, tax, and regulatory constraints in achieving energy conservation. I have divided the topic into several parts to more clearly set forth issues this topic suggests. After detailing our work, I shall point out the conservation elements in our system, their theoretical constraints, and some examples of how these constraints are brought to bear in the legislative arena.

I would emphasize that legal, tax and regulatory constraints do not equate with governmental constraints and that governmental constraints are the real issue.

Before discussing the variety of constraints to energy conservation in the legislative arena, let me first provide you with some background of the California State Assembly's initial involvement with the energy problem.

Initially, we were bombarded by the electrical utility industry with information concerning the need to eliminate delay, dissent, and deliberation in the process of siting thermal electric power plants. The industry contended it was not able to accommodate demand because of the existing siting procedures, and sought to reduce the many steps involved in that process to one. The characterizations by the utility industry of its problem, as well as the clearly one-sided arguments it provided the legislature, indicated to us that the issue was much bigger and more complex than we had been led to believe. Certainly the counter arguments of conservationists indicated this. (Incidentally, although they are not experts in energy, legislators develop the ability to perceive meritricious arguments and related presentations.)

Legislative leadership became convinced that an independent assessment of the problems was needed, as well as a framework to clarify the various issues presented by representatives of both the utility industry and con- 
servation organizations.

At that time, the policy options concerning siting were considered paramount, particularly from a public policy point of view, but overriding the primary considerations was the nagging intuition that perhaps the issue was so large that meeting all forms of demand was not possible. Therefore, an overall review of electrical conservation issues was also considered essential.

The California State Assembly commissioned, with the assistance of the Nationa1 Science Foundation, two studies from the Rand Corporation of Santa Monica: "Planning for Power Plant Siting" and "Slowing the Growth Rate". 1 It was our intention not to use the results as a form of some theoretical exercise, but to elucidate issues and to subject these issues to the review of both the "special" interests and the general public.

Although the reports and their methodology were directed to the electrical energy quandary, the investigation and subsequent recommendation mix was applicable to all forms of energy, fully recognizing the need to do further work in such forms.

The energy conservation report required analysis of depletion rates of all primary energy fuels, and necessarily impinged upon other forms of energy either as complements or substitutes for electrical energy.

Following the receipt of the Rand reports, and in order to develop a consensus, lengthy interrogatories were prepared and submitted to all California utilities, conservation groups and appropriate governmental agencies. All responded and their answers were reviewed, compared and collated. ${ }^{2}$ Thereafter, public hearings were held on those subjects on which the responses indicated disagreement. Expert and lay witnesses from throughout the United States appeared before our subcommittee, testified, and submitted additional written evidence.

Following the hearings, legislation was drafted which is believed to be without precedent in the United States - Assembly Bill 1575.

Problem Definition

We formulated the following issues for our Rand investigators: What is our current rate of growth in demand for electrical energy and what is the projected trend of such demand? Should the electricity growth rate be reduced? If so, how much could it be reduced? What would be the impact of reducing the electricity growth rate on the people, the economy, and the environment of California? What would be the impact if we did nothing?

Perhaps the most mind-boggling factor to a layman was the projected rapid rate of expansion of the electrical utility industry: capacity doubling approximately every 8 to 10 years, consumption in California in the year 2000 approximate1y 7 times what it was in 1970 , and a need for constructing up to 130 new generating units about 1200 megawatts in size. 3

1 - R. H. Ball, R. G. Salter, S. Dole, B. Frederick, M. Hammer, W. E. Mooz, R. Papetti, and G. Richards, California's Electricity Quandary: II. Planning for Power Plant Siting, R-1115-RF/CSA, Rand Corporation, September, 1972 .

R. D. Doctor, K. P. Anderson, M. B. Berman, S. H. Dole, M. J. Hammer, P. T. McClure and C. B. Smith: California's Electricity Quandary: III. Slowing the Growth Rate, R-1116-NSF/CSA, Rand Corporation, Sept., 1972.

The first volume in the series was a study done for the California State Resources Agency: W. E. Mooz and C. C. Mow, California's Electricity Quandary: I. Estimating Future Demand, R-10 $84-\mathrm{NSF} / \mathrm{CS} \overline{\mathrm{RA}}$, Rand Corporation, September 1972 .

2 - California State Assembly Planning and Land Use Committee; Subcommittee on State Energy Policy, Survey of Energy Problems and Programs. Sacramento, California, June, 1973.

3 - California Public Utilities Commission, Report on Ten-Year and TwentyYear Forecasts of Electrical Utilities' Loads and Resources, July, 1972. 
These parameters were taken together with the report's assessment of available resources which, although optimistic, is within tolerable limits. The results are somewhat start1ing:

1. If low rather than high estimates of ultimately recoverable resources are correct, then, including massive imports and synthetic fuel development, even coal will be exhausted in the mid $21 \mathrm{st}$ century.

2. If high estimates are not accurate, then we will not have time to develop alternatives.

3. Low priced uranium may in itself become a scarce resource.

I believe our subcommittee was impressed, particularly after our extensive hearings, to learn that in addition to the potential resource scarcity, nuclear development would be substantially slowed because of controversy over emergency core cooling systems, radioactive waste disposal, and inherent problems of internal sabotage or external assault.

I realize that in some circles this latter analysis is either "laughedoff" or relegated to a plot of "nongrowth" extremists, but I believe after hearing from the AEC's Deputy Director for Licensing, Mr. Edson Case, and Mr. Frank Pittman, Director of Waste Management and Transportation, that the concerns are real.

Coupling these concerns with other obvious problems, such as resource depletion, capital accumulation under present utility industry financing techniques, and the patent 1 and, water and air quality impacts of a sevenfold increase in the supply system for California, we reached the conclusion that a detailed understanding of electrical energy demand determinants or driving forces was essential and that positive loop reinforcement and exponential growth rates must ultimately attenuate either in a rational or understood manner or, if not, in an irrational and dislocative manner.

Perhaps the same argument can be made regarding all forms of energy, freeways, megalopolis, or even lemmings, but believe me, to laymen it was quite a shocking revelation. The conclusion was reinforced when the world's largest private utility was unable, after detailed questioning, to come to grips with the issue or provide any counter analysis of what was agreedupon hard data.

The approach of our legislation attempts to systematize the relationship among several factors. These factors include: 1) demand, 2) the expected pecuniary, nonpecuniary, and environmental impact of that demand, 3) specified minimal conservation actions to reduce further undesired consequences, 4) other verified supply needs and, 5) the capacity mix to support the supply needs.

\section{Conservation as a Parameter}

A1though l am an avowed layman when it comes to hardware, my level of expertise has increased with regard to legal, social and political aspects of the energy dilemma.

Certain definitions or choices of words of art have accelerated the debate. Because the Rand reports cite the control of growth as a necessary parameter, studies by Stanford Research Institute, 5 which were commissioned by the California Utilities in response to our hearings, raise the issues of correlation between per capita G.N.P. and per capita energy consumption.

I have seen additional studies by Borschani at U.C. Berkeley (who is now with the Ford Foundation Energy Policy Project) which raise some interesting aspects of this American axiom. For example, Great Britain and New Zealand have nearly identical per capita G.N.P., but New Zealand consumes only half the energy per capita that Britain does. It might be interesting

4 - R. D. Doctor, K. P. Anderson, et.al., California's Electricity Quandary: III. Slowing the Growth Rate, p. 17 .

5 - Stanford Research Institute, Meeting California's Energy Requirements, 1975-2000, Menlo Park, California, May 1973. 
to see some work which groups European common market countries and which reflects the recent dollar devaluation.

This type of argument, which may seem extraneous to those engaged in hard research and development, is crucial as a socio-political restraint on conservation when those opposed to articulated governmental energy policies attempt to paint conservation as necessarily growth-inhibiting.

Perhaps the major legal constraint on a macro scale is the ability or inability to "make your case". What I mean by this is that under regulatory power of the state, a wide variety of alternatives exist, but the degree of interference with private options or the interjection of active state governmental participation in the market place - (understanding that low visibility or inchoate policies have aided the entire energy industry as we11 as other special interests for decades) - must be explicitly justified.

However, one very practical consideration is that, even stipulating the need for conservation, no active constituency exists to push these types of programs through a long and cumbersome legislative process.

Some Conservation Options and Their Constraints

Although prudence and common sense might dictate that those sectors or uses which are the most inefficient, ranging from transportation at $25 \%$, electrical generation at $35 \%$, residential/commercial at $75 \%$, and industrial at $75 \%, 6$ should be regulated in that order, constraints, be they social or historical, are more easily applied in those areas which have a regulatory history.

In the abstract, options obviously available include:

1. Financial incentives or disincentives to induce technical innovation by tax deductions, credits and accelerated depreciation.

2. Regulation of inefficient uses directly through the police power by restrictions, specific methods, or standards.

3. Public education and persuasion.

4. Promotion by government of various technical options by demonstration projects.

Our consultants at Rand indicated that a mix was probably best and presented a series of policy options (See Appendix 1). They did recommend, however, that as the policies broadened from an educational and voluntary basis to more restrictive policies, they be brought on line in a slow ascending order to provide an economic indicator of the results on those potentially affected.

Again on a theoretical basis the constraints appear to break into several major categories:

1. Potential limitation by federal preemption under or in conflict with the Interstate Commerce Clause.

2. Conflicts with existing state level regulatory or line agencies whose missions have been extremely supply-oriented along with their clientele.

3. Conflicts with existing federal regulatory authorities and their originally enacted policies.

4. Equalization, sensitivity, due process and progressive requirements of tax policies.

5. Problems of retroactive regulation.

opponents of the bill and proponents of the status quo organize their arguments, and in fact "create" the legal and regulatory impediments, on a highly subjective basis. A legislative decision should be based on political acceptability or conversely public awareness, established technical know-how, and economic sensitivity.

6 - A. L. Austin, B. Rubin, and G. C. Werth, Energy: Uses, Sources, Issues AEC Document UCRL-51221, p. 1-19. 
Applied Conservation Policy

Because a conservation policy must be based on agglomeration, it is necessary to choose those areas where government may operate with a series of sustained effects rather than merely setting and mandating absolute targets to solve the abstract problems.

An example of quick and decisive legislative action, totally legal and regulatorily acceptable, with a variety of unforeseen results, is the clean Air Aet of 1970. While recognizing that the quantification of standards precluded bureaucratic foot dragging, it also mandated programs which impinge on a variety of other factors including energy and mass transit.

Some regulatory constraints are present because existing institutions have historical responsibilities for electrical energy. In California's case, the State Public Utilities Commission has specific responsibility for rate structure and site certification.

The first change in our legislation is the general responsibility for conducting on-going assessments and forecasts of the demand-supply curves for all forms of energy. We seek the balanced use of all forms of energy to meet the state's needs and to avoid possible undesirable consequences of reliance on a single source of energy.

Conservation responsibilities include the geduction of wasteful, inefficient, unnecessary or uneconomical uses by: ${ }^{7}$

(a) pricing of electrical and other forms of energy;

(b) improved housing design and insulation;

(c) restriction of promotional activities;

(d) improved appliance efficiency; and

(e) use of advanced power generation technology.

Based on their assessments, the commission established by our legis lation is to recommend to the legislature their proposals for state action to develop potential sources of energy and to reduce its wasteful and inefficient uses in other ways.

More specifically, within one year after the effective date of the bill, the commission is empowered to: ${ }^{8}$

(a) prescribe minimum standards for lighting, insulation, climate control systems and other building design aspects which are economically feasible.

(b) prescribe per unit energy requirement allotments based on square footage for various classes of buildings.

(c) prescribe minimum levels of operating efficiency for all appliances whose use requires significant amounts of electrical energy on a state-wide basis. In this connection, within six months following the date of such minimum levels, the sale of appliances which are not certified by the manufacturer to be in compliance with such minimum levels shall be prohibited.

(d) prescribe minimum standards of efficiency for construction and operation of any new facility which are technically and economically feasible.

It is hoped by these measures to reduce the annual rate of growth in the demand for electricity to more manageable proportions and thereby to reduce substantially the number of power generating facilities presently anticipated.

Frankly, this is the heart of the approach represented by my bill and represents the first time any governmental agency has recognized its responsibility to reduce the demand curve. It is important to note that no specific rate of growth is recommended or set forth, leaving to the commission itself such decisions after it has had opportunity to acquire the

7 - California State Assembly Bill 1575, 1973-74 Regular Session, Proposed Section 25401.

8 - California State Assembly Bill 1575, 1973-74 Regular Session, Proposed Section 25402 . 
detailed data provided in the planning and forecasting elements and requiring further legislative action.

For purposes of this paper, let us assume - a questionable assumption for some - that the methods themselves are entirely feasible, but their impacts are open to question.

The major legal objection to these types of duties is that direct legislative delegation has empowered the commission to affect the lives of our citizens and that perhaps such delegation is one which lacks exactitude. The imprecision, at least in an emotional sense if not truly legal sense, raises the constitutional problem of due process - something by the way which is not uncommon on a whole series of issues. I would suggest that the legislative mandate is clear. The very determinations, such as minimum levels of operating efficiencies on those appliances which require a significant amount of electrical energy on a state-wide basis, are precisely the type of over-view strategy to be worked out by a deliberative body which will hold public hearings to receive expert and lay testimony and expert staff evaluation.

Can we do each of the specific functions? We believe that each is feasible. However, some of the proposals may impinge upon the U. S. Constitution's commerce clause. Unless the Congress preempts the entire energy field under its almost plenary commerce powers, state legislation can be drafted which technically is not violative of federal mandate; however, many of these functions, if executed on the federal level, would provide a uniformity which would insure limited economic dislocation.

Many regulatory issues have been raised by those who are not enamored with governmental intervention. These are directed primarily, however, to the philosophy of such governmental activity. The Stanford Research Institute study provides, for example, that such actions are incremental and ineffective and that, as a theorem, governmental involvement will insure inadequate distribution of benefit and will cause market place distortion. Our most universal approach is tied to that portion of the bill which involves the pricing of electrical energy. We have had greatly conflicting evidence on the price elasticity of electricity, particularly between the Rand and S.R.I. studies. It is interesting to note, however, even S.R.I. suggests that on a macro scale the growth in demand for electrical energy is projected to decrease as prices increase naturally.

The commission is empowered to make recommendations concerning electrical energy pricing to the PUC and Board of Directors of publicly owned utilities in order to reduce wasteful, unnecessary or uneconomic energy consumption through differential rate structures. Also, to be considered as demand suppressant techniques are cost-of-service allocation, elimination as a business expense of advertising or promotional activity, peak load pricing, and other pricing measures.

These are to be accepted by the PUC or the Board of Directors, unless rejected as not feasible. The rejecting entity must communicate the reason for its decision to the legislature and Governor.

Because our growth in electrical energy demand is expanding most rapidly in the commercial sector, and because of the inherent requirement of technical know-how to deal with industrial processes, it was felt that the most leverage and greatest flexibility could be exercised by the pricing mechanism.

The economics of this approach are, of course, the subject of debate; however, again the major constraint is the existing regulatory scheme which has been developed to induce greater consumption.

One of the major options proposed by Rand (See Appendix 2) involves the substitution of gas for electricity as an end source. Various stastical data indicate there would be an overall energy saving if gas were burned as a direct end energy source rather than in electrical generating boilers.

We did not adopt this proposal, but even if we thought it extremely meritorious, somewhat one-sided decisions by the Federal Power Commission have negated this as an energy saving strategem. 
We fund our proposed operation by a $\$ .0002$ (2/10 of a mil) surcharge on electrical energy use in California, which assures an annual funding level of approximately $\$ 32 \mathrm{million.}$ This funding, along with pricing mechanism alterations, has been attacked for a variety of reasons which, a1though not constitutional in nature, are based on strong equity considerations.

Because our pricing and surcharging will be based on use, it will have the effect of making rate schedules less regressive. In addition, it is felt to be the least disruptive mechanism.

Although our legislation has centered on electrical energy, our system can be applied to all forms of energy and we now have a contract with Rand to explore overall energy policies.

In conclusion, my message to this body is that legal, regulatory, and tax constraints are illusory in that they hide the true nature of the opposition, which is political: the exercise of political persuasion in the development of public policy.

The true constraints are whether direct state/federal/local police powers will be brought to bear, whether the public understands the necessity for such action, and finally whether the effectiveness of such powers can be sustained while we seek alternatives through adequate research and development.

Appendix 1

POLICIES FOR SLOWING THE GROWTH RATE

FOUR TYPES OF POLICY OPTIONS

Policies that can be used to slow the rate of growth in electricity demand are of four basic types:

- Policies designed to elicit voluntary responses from consumers. Among these are (1) consumer education measures that would teach basic energy conservation practices, (2) a program of labeling electrical appliances with energy efficiency ratings or with average annual energy costs to use the appliance, and (3) provision of financial incentives for development and use of energy-conserving appliances and devices.

- Policies designed to change the user cost of electricity (for example, through sales or use taxes or through changes in utility rate schedules).

- Policies designed to change the purchase costs of electrical equipment. These include sales taxes, taxes based on the estimated average annual electricity use of the equipment, elimination of promotional rebates to builders and users, and tax relief for either users who install more efficient equipment or manufacturers who make such equipment.

- Proscriptive policies. These include changes in building code requirements, bans on the manufacture, sale, or installation of certain types of equipment, restrictions on the wattage or minimum efficiency of electrical equipment and appliances, restrictions on new building permits, and explicit rationing of electricity and other forms of energy. 


\begin{tabular}{|c|c|c|c|c|c|}
\hline & $\begin{array}{l}\text { Building Design } \\
\text { and Construction } \\
\text { Changes }\end{array}$ & $\begin{array}{l}\text { Advertising and } \\
\text { Promotion } \\
\text { Changes }\end{array}$ & $\begin{array}{l}\text { Electricity Use } \\
\text { Efficiency } \\
\text { Incentives }\end{array}$ & $\begin{array}{l}\text { Rate } \\
\text { Changes }\end{array}$ & $\begin{array}{c}\text { Rationing \& Kestrict- } \\
\text { ing Certain Uses or } \\
\text { Devices }\end{array}$ \\
\hline Problem & $\begin{array}{l}\text { Too much electric- } \\
\text { ity is used for } \\
\text { space condition- } \\
\text { ing }\end{array}$ & $\begin{array}{l}\text { Advertising and promo- } \\
\text { tions aimed at in- } \\
\text { creasing use of elec- } \\
\text { tricity }\end{array}$ & $\begin{array}{l}\text { Electrical devices } \\
\text { are inefficiently } \\
\text { designed and used }\end{array}$ & $\begin{array}{l}\text { Rate schedules give in- } \\
\text { centives for high volune } \\
\text { use }\end{array}$ & $\begin{array}{l}\text { Energy is provided } \\
\text { without regard for } \\
\text { need }\end{array}$ \\
\hline Policy & $\begin{array}{l}\text { Use design and } \\
\text { materials that } \\
\text { improve effi- } \\
\text { ciency }\end{array}$ & $\begin{array}{l}\text { Permit only ads and } \\
\text { promotions that en- } \\
\text { courage more effi- } \\
\text { cient use of elec- } \\
\text { tricity }\end{array}$ & $\begin{array}{l}\text { Provide incentives } \\
\text { for production and } \\
\text { use of more effi- } \\
\text { cient electrical } \\
\text { apparatus }\end{array}$ & $\begin{array}{l}\text { Adjust rates to dis- } \\
\text { courage or reschedule } \\
\text { use }\end{array}$ & $\begin{array}{l}\text { Restrict availability } \\
\text { of electricity or } \\
\text { certain electrical } \\
\text { devices }\end{array}$ \\
\hline Action & $\begin{array}{l}\text { Change the State } \\
\text { Housing Code or } \\
\text { the Uniform } \\
\text { Building Code } \\
\text { and local codes }\end{array}$ & $\begin{array}{l}\text { CPUC advertising and } \\
\text { promotion regulations }\end{array}$ & $\begin{array}{l}\text { Tax system changes } \\
\text { or subsidies or } \\
\text { bonuses; 1abeling }\end{array}$ & $\begin{array}{l}\text { Increase rates across } \\
\text { the board; raise unit } \\
\text { costs for high volume } \\
\text { use }\end{array}$ & $\begin{array}{l}\text { Schedule brownouts } \\
\text { or blackouts }\end{array}$ \\
\hline Variations & $\begin{array}{l}\text { Voluntary compli- } \\
\text { ance; standards } \\
\text { issued by lenders } \\
\text { or insurers }\end{array}$ & $\begin{array}{l}\text { Variations in strin- } \\
\text { gency and interpre- } \\
\text { tation }\end{array}$ & $\begin{array}{l}\text { Negative sanctions } \\
\text { for devices not } \\
\text { meeting efficiency } \\
\text { minimums }\end{array}$ & $\begin{array}{l}\text { Adjust rates for hour, } \\
\text { day or season; various } \\
\text { rate schedules }\end{array}$ & $\begin{array}{l}\text { Timers or governors } \\
\text { on devices; temporal, } \\
\text { seasonal or geographi- } \\
\text { cal restrictions }\end{array}$ \\
\hline $\begin{array}{l}\text { Parties in } \\
\text { the Decision } \\
\text { Process }\end{array}$ & $\begin{array}{l}\text { State legisla- } \\
\text { ture; ICBO and } \\
\text { local city } \\
\text { councils }\end{array}$ & $\begin{array}{l}\text { CPUC, utility compan- } \\
\text { ies, Legislature }\end{array}$ & Legislature & CPUC, utility companies & Legislature, CPUC \\
\hline $\begin{array}{l}\text { Parties } \\
\text { Affected }\end{array}$ & $\begin{array}{l}\text { Developers, } \\
\text { architects, hone } \\
\text { or commercial } \\
\text { building buyers }\end{array}$ & $\begin{array}{l}\text { Electrical manufac- } \\
\text { turers, utilities }\end{array}$ & $\begin{array}{l}\text { Manufacturers, ven- } \\
\text { dors, customers and } \\
\text { consumers }\end{array}$ & $\begin{array}{l}\text { Large users of electric- } \\
\text { ity, perhaps all users }\end{array}$ & $\begin{array}{l}\text { Utilities, manufac- } \\
\text { turers, consumers }\end{array}$ \\
\hline $\begin{array}{l}\text { Institutional } \\
\text { Effects }\end{array}$ & $\begin{array}{l}\text { Agencies alreacy } \\
\text { exist for both } \\
\text { adoption and } \\
\text { implementation }\end{array}$ & Nominal & $\begin{array}{l}\text { No existing organi- } \\
\text { zation to develop } \\
\text { and administer the } \\
\text { policy }\end{array}$ & Nomina1 & $\begin{array}{l}\text { No existing agency to } \\
\text { develop or monitor } \\
\text { restrictions }\end{array}$ \\
\hline $\begin{array}{l}\text { Problems \& } \\
\text { Bottlenecks }\end{array}$ & $\begin{array}{l}\text { Localized } \\
\text { requirements }\end{array}$ & $\begin{array}{l}\text { Citizen actions } \\
\text { against utilities; } \\
\text { interpretation of } \\
\text { the regulations }\end{array}$ & $\begin{array}{l}\text { Setting standards } \\
\text { and verifying per- } \\
\text { formance }\end{array}$ & $\begin{array}{l}\text { Developing equitable } \\
\text { and effective rates }\end{array}$ & $\begin{array}{l}\text { Identifying essential } \\
\text { uses and users }\end{array}$ \\
\hline $\begin{array}{l}\text { Timing: } \\
\text { Adoption } \varepsilon \\
\text { Effects }\end{array}$ & $\begin{array}{l}1 \text { to } 2 \text { years for } \\
\text { adoption; effects } \\
\text { would increase } \\
\text { over years }\end{array}$ & $\begin{array}{l}\text { Up to } 1 \text { year for } \\
\text { adoption; both im- } \\
\text { mediate and long-term } \\
\text { effects }\end{array}$ & $\begin{array}{l}3 \text { to } 4 \text { years for } \\
\text { adoption of a } \\
\text { thorough program; } \\
\text { effects would occur } \\
\text { over several years }\end{array}$ & $\begin{array}{l}\text { About } 1 \text { year for adop- } \\
\text { tion; both immediate } \xi \\
\text { long term effects }\end{array}$ & $\begin{array}{l}3 \text { or } 4 \text { years for adop- } \\
\text { tion of a thorough } \\
\text { program; effects will } \\
\text { begin immediately }\end{array}$ \\
\hline $\begin{array}{l}\text { Type of } \\
\text { Impact }\end{array}$ & $\begin{array}{l}\text { Direct, predict- } \\
\text { able }\end{array}$ & $\begin{array}{l}\text { Indirect, not very } \\
\text { predictable }\end{array}$ & $\begin{array}{l}\text { Indirect, not very } \\
\text { predictable }\end{array}$ & $\begin{array}{l}\text { Indirect, partially } \\
\text { predictable }\end{array}$ & Direct, predictable \\
\hline $\begin{array}{l}\text { Effects: } \\
\text { Economic, } \\
\text { Social है } \\
\text { Political }\end{array}$ & $\begin{array}{l}\text { Building may cost } \\
\text { more for design, } \\
\text { and possibly for } \\
\text { construction; } \\
\text { less operating } \\
\text { cost for elec- } \\
\text { tricity; HUD } \\
\text { may resist } \\
\text { increased home } \\
\text { purchase prices }\end{array}$ & $\begin{array}{l}\text { Lower utility bills; } \\
\text { fewer appliances or } \\
\text { features sold; dif- } \\
\text { ferent living habits, } \\
\text { status for decreasing } \\
\text { use of electricity: } \\
\text { some opposition by } \\
\text { electrical manu- } \\
\text { facturers }\end{array}$ & $\begin{array}{l}\text { Lower bills; direct } \\
\text { benefit to some } \\
\text { manufacturers; cer- } \\
\text { tain use patterns } \\
\text { might change }\end{array}$ & $\begin{array}{l}\text { New economics of scale, } \\
\text { some prices may rise; } \\
\text { opposition would } \\
\text { come from major users }\end{array}$ & $\begin{array}{l}\text { Some prices may rise; } \\
\text { work hours or days to } \\
\text { be rescheduled in some } \\
\text { cases; opposition } \\
\text { would come from those } \\
\text { most affected }\end{array}$ \\
\hline
\end{tabular}


Table A-1 summarizes the electricity savings expected over the long term from implementation of each of the policy objectives described in the text. The reader should use caution in combining results of two or more objectives, as they are not necessarily additive. For example, large savings can be expected either by increasing the insulation ( 1 ine 5 ) or by utilizing solar energy ( 1 ine 6 ). If both are done simultaneously (1ine 7), however, the reduction in electricity requirements is smaller than would be estirated by simply adding the savings from each effect.

The policy objectives shown in the table include the following:

Line 1: Average efficiencies of room air-conditioner units is increased by 50 percent above current practice.

Line 2: Residential lighting requirements are reduced by 50 percent.

Line 3: Residential electricity requirements are reduced by 10 percent through use of low energy designs for new buildings.

Line 4: Accelerated trend toward multi-family housing reduces projected residential electricity demand by 20 percent.

Line 5: Insulation of new homes is improved sufficiently to reduce heat losses and gains by 50 percent in gas-heated homes and by 40 percent in electrica11y heated homes.

Line 6: Solar heating systems supply 70 percent of residential heating, water heating, and cooling needs in new construction.

Line 8: Gas appliances replace electricity for space heating, water heating, cooking, and clothes drying.

Line 12: Gas appliances replace electricity for space heating, water heating, cooking, clothes drying, central air conditioning, and refrigeration.

Line 16: Gas replaces electrical systems for heating and air conditioning in the commercial sector.

Line 17: Lighting requirements in the commercial sector are reduced by one-third overall.

Residential electricity use is projected as 216 billion $\mathrm{kWh}$ and 138 billion kWh in the year 2000 for the CUP and RBCP, respectively. Total electricity use in California is projected as $848^{\prime}$ billion kWh and 679 billicn kWh for the CUP and RBCP, respectively. Capacity savings are calculated on the basis of 230 MWe per billion kWh consumed each year.

Charges in residential, electrical utility, and statewide gas consumption resulting from implementation of each policy objective are shown in Table A-2. The "25-percent basis" columns assume that 25 percent of the electricity demand saved would have been generated by burning gas, an assumption consistent ith current projections for the year 2000. Percent changes in total gas demand are based on projections of 5650 triliion Btu and 5190 trillion Btu for total gas demand in the year 2000 for the CUP and RBCP, respectively. 


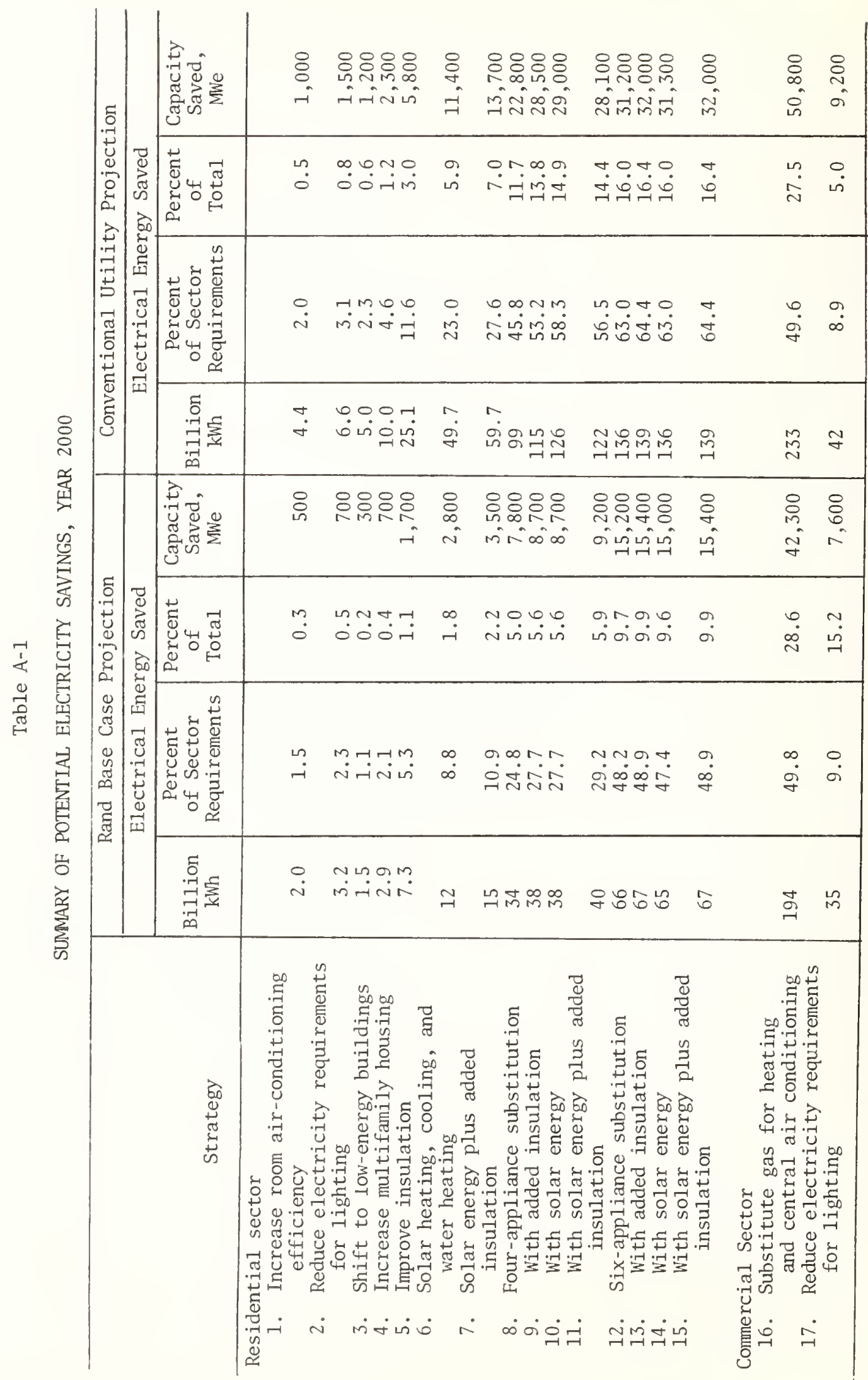




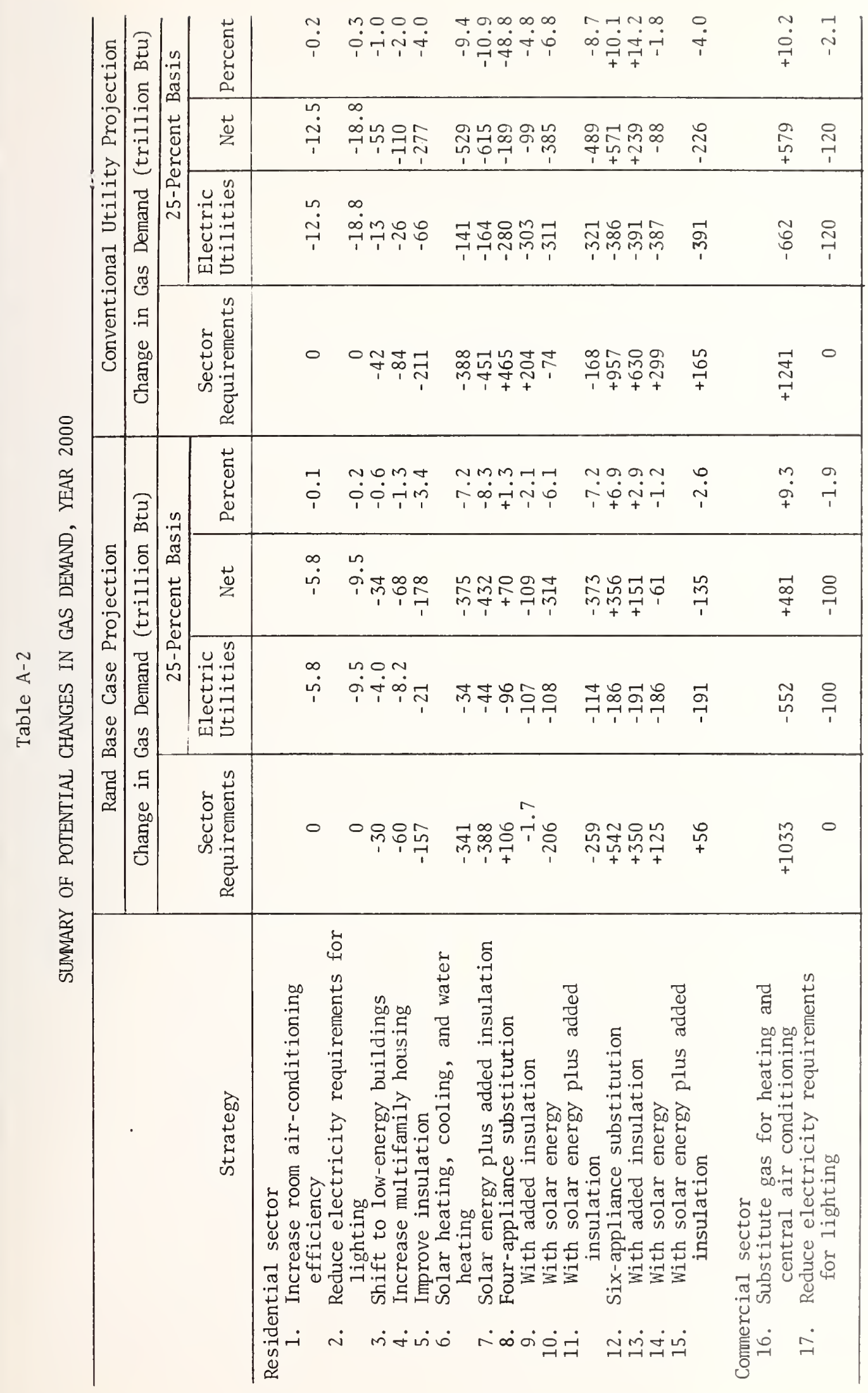



National Bureau of Standards Special Publication 403

Proceedings of 1973 Fngineering Foundation Conference

(Issued June 1976)

FINANCIAL FEASIBILITY OF ENERGY CONSERVATION

by

Sheldon Sixfin

Technical Director of Environmental Systems

Technical Service Department

The Chase Manhattan Bank

6 th Floor

One Chase Plaza

New York, New York 10015

\begin{abstract}
Energy availability is approached from a purely economic point of view. The technology to be used is determined by the rate of return on the investment. A sample cost feasibility analysis for a 100,000 square foot industrial plant is presented as an example. Besides price, the ultimate criterion for choosing an energy source is its availability. Where critical energy shortages are foreseen, incentives must be provided to encourage the flow of capital in the directions necessary to alleviate the shortages. Private investors should be compensated for the risk that they undertake in the location and development of energy resources.
\end{abstract}

Key words: Costs; energy; financial; resources; risk

At 11:00 on the night of July 25, 1956, the Italian liner, Andrea Doria, was traveling toward New York City in fog along the shipping lane off Nantucket Lightship. At the same instant, the Swedish passenger ship Stockholm was traveling away from New York on a parallel lane. Within moments they were destined to collide. The impact occurred at 11:09 p.m. and by dawn the Andrea Doria was down.

Today, as passengers on this "spaceship earth", we all face a crisis not unlike the events of July 25, 1956. On the one hand, we have a rapidly growing world population. On the other hand, our precious land and energy resources that must support future populations are being limited by our growing requirements and usage.

This collision of forces is inexorable unless we take immediate and substantial steps now by clearing away the fog that surrounds the subject of energy conservation. We still have time to change course and avert the disaster. What then are some of the specific problem areas that we must address? I will mention a few:

1. The need for industrial energy conservation.

2. The principal sources of energy in the U.S.

3 . The requirements for energy in the U.S.

4. The economics of investment in equipment which saves energy.

5. Criteria for determining financial feasibility of such investments.

6. Methods using the above criteria.

7. Projections of energy costs.

8. Capital requirements of the energy industry.

9. Proper allocations of capital resources.

10. Availability of supplies and of capital.

With respect to the need for industrial energy conservation, it is important to recognize that $2 / 3$ of energy use in the U.S. is for businessrelated purposes and on 1 y $1 / 3$ for private purposes.

If we consider the energy used for private purposes, approximately $33 \%$ of this is used in the household - for such requirements as electric lights and appliances; approximately $33 \%$ is used for household heating; the final third is used for transportation. If we consider that portion of transportation energy which moves people to and from work as a business-related use, then over $75 \%$ of the energy in the U.S. can be considered used for 
business-related purposes.

Although certain economies can be achieved in household use, in household heating, and in private automobile use, the extent of these economies is limited when one also considers the population growth of the U.S.

However, when we look at the industrial area, we find that there are vast fields in which energy conservation is possible. With more sophisticated use of heat exchanger technology and by the use of other energy conservation techniques, process changes can be implemented. These can achieve major fuel savings. It is in the area of business-related and industrialrelated uses where we can achieve the greatest energy economies.

The principal sources of energy in the United States are oil, natural gas, coal, water power, and nuclear energy. Oil is currently the largest source of primary energy and is expected to be so in 1985 because it is so versatile. Among the sources of primary energy, oil is the only one that is used in the five major markets for energy use - industrial, electric utility, transportation, residential and commercial; it is virtually the only source that can presently serve the transportation market's needs. Conceivably, coal might also be used as a fuel for transportation purposes, but it would have to be converted to a liquid first.

of the overall growth of the nation's needs between 1970 and 1985, oil alone is expected to accommodate half. To a significant degree, the exceptionally strong increase in the demand for oil reflects the rapidly developing shortage of natural gas. If there was no supply limitations, the potential demand for gas in 1985 would be far greater than is presently projected.

Natural gas is truly a premium fuel and is much preferred by a wide range of consumers, but under no realistic circumstances can the supply of gas be expected to be adequate for the full potential demand. Consumers, therefore, will be forced to substitute other sources of primary energy. The deficit in gas availability will have to be made up by oil or coal. One of the ways in which this deficit can be made up is through the gasification of these materials. Both oil and coal are likely to be converted into synthetic gas and burned in that form.

The requirements for energy in the U.S. can be split into the five major national markets noted above. The requirements can also be analyzed geographically by five major regions: the West, the Rocky Mountain states, the Gulf Coast, the North Central region and the East Coast. The latter two regions are deficit areas in respect to primary energy; that is, they both consume far more than they produce within their borders. As such they are realistically more vulnerable in the event of energy shortages. This is a fact that is increasingly apparent to consumers as time goes on. Reactions can well be expected.

Further details on the sources of energy, the demand for energy and the general outlook for energy in the United States to 1985 is provided in a booklet which is published by the Energy Economics Division of the Chase Manhattan Bank entitled "Outlook for Energy in the United States to 1985".

The economics of a given course of action relates to the profit or fiscal position of a respective consumer or purchaser. It may be favorable or unfavorable depending upon the prevailing conditions. Since a purchase of any kind of energy conserving equipment entails the investment of capital as well as the expenditure of money for operating costs, the economics associated with the venture are usually best expressed in some kind of language or terms which relates the ultimate gains, if any, to the capital investment. It is not sufficient to simply determine that an investment will make or save money - it is necessary to determine at what rate it will make money - what rate of return (interest) may be expected from the investment. This will permit a fair comparison of the prospective benefits from such an investment with the benefits offered by other available investment opportunities.

There are no simple short cuts for making a complete economic appraisal of any proposed business venture. There are also no mysteries about the procedure. The purchase of equipment, such as engines and turbines, should 
ordinarily be viewed as an investment made for the sole purpose of yielding an attractive return. However, the results of this analysis can be affected if questions of availability of supply come into play. This question of availability will be discussed later.

There are several easily identifiable factors which collectively determine the economics of any application. These criteria for determining

financial feasibility are as follows:

1. Capita1 Cost

2. Projected Operating Cost

3. Current Energy Cost

4. Projected Escalation of Energy Cost

5. Discount Rate (Current \& Projected)

6. Internal Rate of Return

7. Net Present Value

8. Discounted Cash Flow

9. Availability Considerations

These criteria must be applied to determine cost feasibility of any project. The Industrial Division of the Caterpillar Tractor Company has developed some specific methods for analyzing cost feasibility. The Caterpillar format achieves an analysis which defines the quantity of annual "net cash flow". This analysis is applied primarily to considerations of an onsite power system vs. a conventional utility system. The determination of "net cash flow" is a common procedure for comparing financial investments and is a real developed dollar amount which may be used as a basis for mathematical expressions relating to the amount of differential capital investment. A sample cost feasibility analysis for a 100,000 square foot industrial plant can be given as an example. (Tables 1 and 2).

This example and the associated print-out which further discusses the rate of return and the payout period is available on request from John 0. Henderson of the Caterpillar Tractor Company, Peoria, Illinois, who has graciously provided me with this information.

In order to perform an analysis such as this, it is important to obtain a proper projection of energy costs during the life of the project. The following table gives a projection of energy costs per million BTU in 1973 dollars for energy delivered at the Gulf Coast, U.S.:

$\begin{array}{lcc} & \frac{1980}{1985} & \frac{1985}{\$ 1.08} \\ \text { Coal (Low Sulfur Wyoming) } & \$ .87 & \\ \text { Natura1 Gas (New Sources or } & & 1.76 \\ \text { Oil (Low Sulfur Residual) } & 1.43 & 1.53\end{array}$

(These projections were provided through the courtesy of Robert Spencer.)

A few comments should be made at this point about the capital requirements of the energy industry and the proper allocation of capital resources. All of our analysis assumes that the energy industry will obtain all the capital it needs for expansion purposes. In a free capital market, this is true only if the rate of return on the investment of capital resources is equal to or better than the rate of return for similar risk investments elsewhere. Where critical energy shortages are foreseen, incentives must be provided to encourage the flow of capital in the directions necessary.

The private financial sector is well equipped for the task of allocations of capital resources. It is, however, of vital importance that the economic climate be such to permit private investors to be compensated for the risk that they undertake in the location and development of energy resources. 
In conclusion, I would like to stress the importance of energy supply availability. Our previous considerations provide a method to analyze the financial feasibility of an energy conservation project in terms of characteristic financial criteria.

However, such an analysis breaks down, if, for example, there is no availability of energy at the prices quoted. This condition holds true at the present time in the natural gas industry. Gas which is regulated in price and now sells for an average of approximately $\$ .22$ per million BTU at the well-head is under allocation and is not available at all times to all customers. Therefore, the customers must look to an alternative source of supply if possible; sometimes because of technical factors, such as a gas burning unit which cannot be easily converted to oil or coal, it is impossible to use such an alternative source. Under these conditions, our limiting factor becomes availability rather than cost considerations. This factor is the most important one facing us today. The likelihood of continuing availability of given fuel sources over the lifetime of the project may be the critical issue and our analyses must be subordinated to this consideration.

\section{TABLE 1 \\ Sample Cost Feasibility Analysis}

Industrial Plant, 100,000 square feet, Central United States operating five days per week.

Purchased electrical power, cost for year equals $\$ 62,525$.

Existing mechanical power consists of one diesel driven air compressor. On-site power plant will consist of 3-G398 electric sets and 1-G398 power unit to drive air compressor.

Maintenance Cost
G-398 electric set
G398 engine
$\$ .80$ per hr.
.65 per hr.

Fue1 Cost is $\$ .35$ per MCF.

The T/E system will be completely automatic.

Tax Rate

Federal - $\quad 48 \%$

State - $4 \%$

Property tax and insurance is $2 \%$

Usable heat is $65 \%$ of available engine system heat.

Differential investment is $\$ 195,000$ which is depreciated over 12 years.

Differential expense that is deductable before taxes is $\$ 25,000$.

Investment tax credit is $\$ 10,500$.

Borrowed capital is $\$ 85,000$ for 10 years at a simple interest rate of $8 \%$.

Cash flow period is 15 years with a salvage value at end of period of $\$ 35,000$. Load factor is not an imput item. This will be calculated by the computer. 


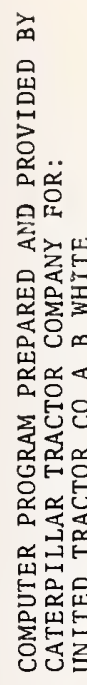

(1)

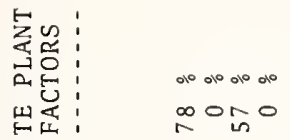

ज星

zo:

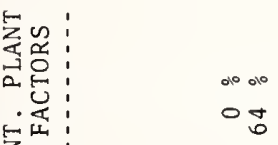

空

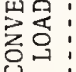

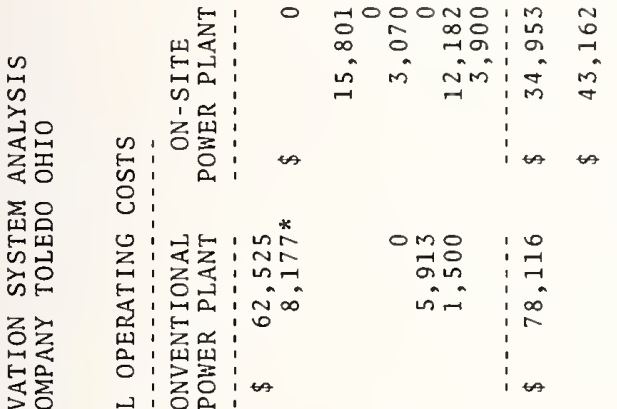

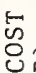

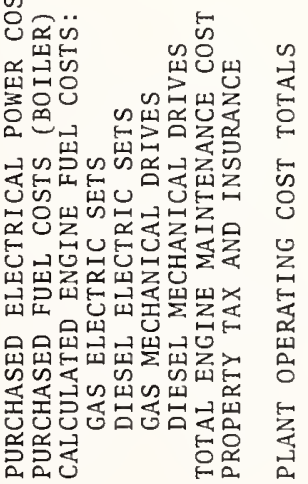

乎:

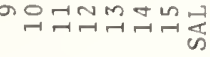

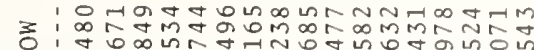

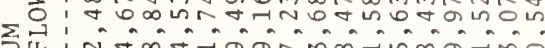

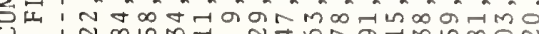

岁:

芆:

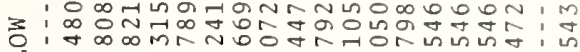
出:

$\mathbb{U}^{0}:$

$\infty$

$\infty$

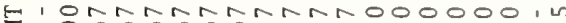

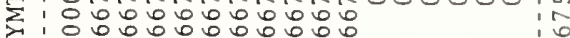

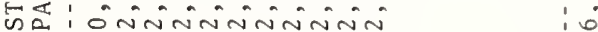

哂:

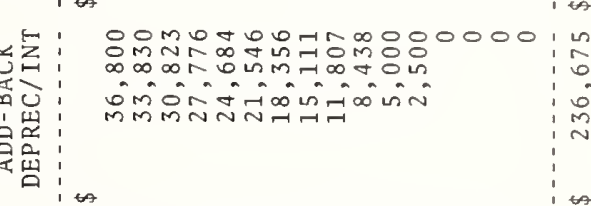

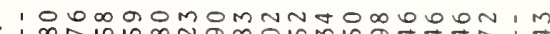

ব:

H

ڤ :

次:

考: 专

点

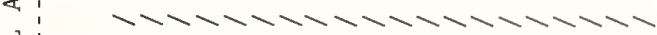

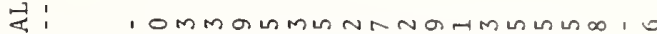

U:

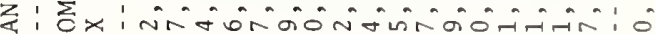

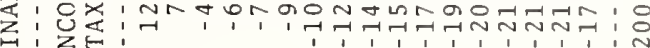

击:

帘

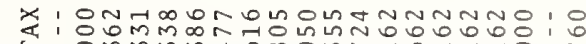

WE OMmMm

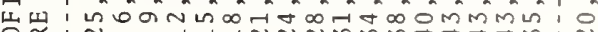

崖: ?

㟧

a

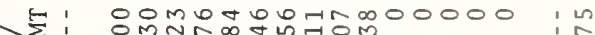

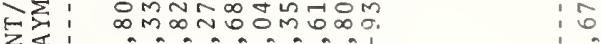

$\begin{array}{lll}1 & 1 \\ 1 & 1 & 1\end{array}$

$\sum \sqrt{\sigma}$

出:

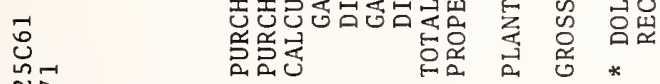

«임

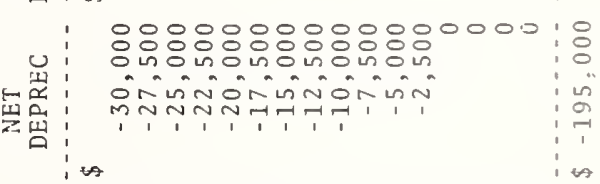

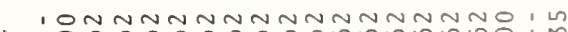

\&!

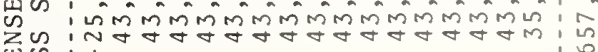

学思

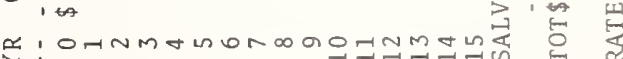


V I. $\quad S$ U M M A R Y A N D C R I T I Q U E 

NATIONAL CONTEXT FOR ENERGY CONSERVATION

by

\author{
Jesse C. Denton \\ University of Pennsylvania \\ Philadelphia, Pennsylvania
}

The general topic for the first day's papers was "The National Context for Energy Conservation". Dr. Charles Berg opened the conference with his paper, "Effective Utilization of Energy and Other National Resources". Dr. David C. White then presented "National Benefits of Energy Conservation", followed by Dr. Bruce Hannon's "Options for Energy Conservation". Dr. B. B. Hammel discussed "Measures of Thermal Energy Utilization". Dr. Jesse C. Denton spoke on "Economic and Environmental Implications of Effective Energy Utilization". Robert Shepherd, of the Department of Commerce, spoke on "Energy Conservation Goals and Methods".

Dr. Berg, from the National Bureau of Standards, stated that the term "energy crisis" was not a crisis of energy depletion but rather energy cost. He cited the United State's dependency on fuel imports to illustrate the problems that questionable reliability and increasing costs of fuel imports pose for American industry. Improving energy use efficiency would reduce energy consumption and, considering rising energy costs, may prove to be economically attractive to industry. Dr. Berg promoted a policy of rational life term costing of equipment, which includes energy costs of that equipment, rather than the present criterion of justification, which is based primarily on first costs. In conclusion, he advocated a rational economic method for achieving effective and balanced use of all natural resources, based on total life term costing.

David C. White, from MIT, spoke next. After indicating the correlation between a nation's gross national product and its energy consumption per capita, Dr. White pointed out the consequences of economic growth on the world's estimated energy resources. In the absence of new energy technologies or a reduction of energy consumption in relationship to the GNP, sustained high economic growth will be difficult and costly to achieve as our own resource base diminishes. The developing nations of the world will be competing for resources as their own GNP's increase, further exacerbating the resource depletion problem. Besides discussing the effect of petroleum imports on America's transportation sector, Dr. White envisioned potential international complications as the nations of the world compete for scarce resources.

Dr. Bruce Hannon, from the University of Illinois, presented an input/output model used to measure energy use efficiency of production processes and product uses. The model provides estimates of total energy and employment shifts as consequences of demand shifts in a variety of processes and products. He concluded that U.S. industries, in general, become energy-intensive as they grow. He recommended that impacts be thoroughly understood before policy shifts are initiated.

Dr. B. B. Hamme1, from Drexel University, presented a method of analysis useful in assessing modifications in an energy system. The concept of thermodynamic availability is used to determine maximum energy utilization efficiency. He demonstrated this method by evaluating the efficiencies of several water heating systems. 
Dr. Jesse Denton, of the National Center for Energy Management and Power, talked about the application of technology transform analysis as a basis for an input/output analysis which describes the interrelationships between energy, environmental, economic, and human factors. He used the example of an abbreviated, once-iterated analysis of the automobile industry to demonstrate the complexity of such an analysis and the pitfalls of drawing premature conclusions from an incomplete analysis. He cautioned that the first iteration of a projected modification of a system may be misleading.

Robert Shepherd, from the Office of Energy Programs in the Department of Commerce, concluded the day's presentations with his evening talk. He discussed the goals of the President's energy messages of early 1973 and the feasibility of the 1974 goal of a 5\% energy use reduction nationally. He also provided a view of the Federal government's organizational structure in terms of the energy situation. Mr. Shepherd urged voluntary energy conservation and a major educational program, among other measures, to solve the nation's energy problems. The panel discussions concluded the following:

1) We recommend that a national educational program be developed to encourage more efficient energy utilization. The promotion should be conducted by suppliers of energy and aimed at both the individual consumer and the top management of industry and commerce. It may be necessary to undertake field demonstration projects to show that energy conservation measures can be cost-effective. These projects, together with selected case studies, should be widely publicized, and accompanied with technical material.

2) We favor a voluntary approach to energy conservation. If that fails, we prefer incentives to regulations. Voluntary actions must be adequately publicized and funded; an accurate appraisal of their effectiveness is also necessary. Methods of energy conservation can be categorized as follows in terms of time horizons: 1) energy management, 2) use of present technology, and 3) use of new technology. The government must be willing to encourage conservation measures in all sectors of the economy.

3) Detailed strategies for implementation of conservation measures must be developed for specific energy end use sectors. Input/output analysis shows promise as a guide for future energy conservation decisions.

4) We recommend that a national program be developed to encourage improved maintenance of vehicles, industrial, and home equipment. The goal of such a program would be more efficient operation and longer useful life of the equipment.

5) We recommend that architects and engineers be encouraged to give full consideration to those features which would reduce the energy requirements of and minimize waste in building design and construction.

6) Conservation of energy is a worthwhile goal, but other factors should also be taken into account. For example, safety, durability, reliability, direct and indirect costs of technology and products should be considered.

7) Highest conservation priority should be given those fuels in short supply.

8) We need maximum process control of energy uses. Data collection and analysis is fundamental for resource planning.

9) Public officials need to be motivated as well as educated to adopt a resource conservation policy in their development of policies and regulations.

10) Lack of technology is not so much a barrier to energy conservation as is a lack of economic incentive. Cost-effective measures of energy conservation must be encouraged in all sectors of industry. 


\title{
ENERGY MANAGEMENT IN INDUSTRY
}

\author{
by \\ Robert R. Gatts \\ National Bureau of Standards \\ Washington, D.C. 20234
}

\section{Conference Inputs}

On Tuesday morning, four speakers presented some facts and perceptions from their experiences with energy management. Mr. Dilip Limaye from Decision Sciences Corporation spoke on "Industrial Energy Analysis and Forecasting", Mr. Allen Cook from the American Can Company discussed "Management's Role in Industrial Thermal Energy Utilization", Dr. Michael Noland from the Midwest Research Institute described "Plant Energy Policies in the Manufacturing and Processing Industries", and Professor William Rudoy of the University of Pittsburgh provided case histories of his experiences in "Effective Energy Utilization in Industry".

On Tuesday evening the several discussion groups reviewed the information and perceptions provided by the morning speakers, introduced other concepts and information, and drew general conclusions. Those conclusions, integrated with sumnaries from the Tuesday morning papers are presented herein. The resulting description of the situation is the perception developed by the total conference.

\section{The Problem}

With approximately $40 \%$ of the national use of energy going for industrial processing, (notably direct heat, process steam, and electrical drive) a situation has been developing in which many industrial firms have experienced fuel shortages in the recent past and expect shortages of either primary or back-up fuels or both during the next few years. Under these conditions energy will no longer be inexpensive.

Collective action is required by the industrial sector, the transportation sector, the agriculture sector, the government and the general public. This action must include a strenuous effort within industry to use fuels and electricity more effectively.

There is a high level of appreciation of this problem by top management of large U.S. corporations, but lower levels of operating management do not give energy conservation a high priority. An important factor in this priority is the relatively low total costs of energy (perhaps 2 to $3 \%$ ) in comparison to labor costs ( 30 to $40 \%$ ). Many firms believe that, individually, they are adequately addressing plant energy problems, but they have not initiated systematic energy planning and management programs.

In a considerable number of instances efforts to conserve energy within industrial plants have met with outstanding success, achieving savings of the order of 20 percent or more with changes in maintenance or operating practices or by investment in equipment modifications with pay back periods of two years or less from the cost savings on energy used.

These instances are numerous and the achievements demonstrated are convincing. However they do not represent a data base suitable for accurate prediction of the potential for energy conservation nor do they provide a basis for concisely generalizing energy management procedures. 
A systematic approach to energy management at the operational level cannot be developed to apply equally well to all industrial facilities. There is no systematic pattern discernable in companies in their approach to fuel conservation. The potential for energy conservation in industry is more difficult to characterize than in the transportation, commercial, or residential sectors.

Applications of energy to industrial processes are numerous and varied but aggregation of industry into major energy using sectors (usually by SIC code) aids in collecting data. Energy consumption patterns differ markedly from industrial sector to industrial sector and from plant to plant within an industrial sector.

Energy conservation must be achieved in elemental pieces by a myriad of different energy management practices applied to as many different situations. This is another way of saying that the conservation of energy in industry is an engineering function and must be approached with a significant and careful engineering effort which will custom-fit energy conservation policies to the needs of individual consumption centers.

An engineering manager, concerned because of perceived large energy price increases or because of softness in the security of his energy supply, lacks information on which to base engineering decisions. He is concerned but guessing as to the best measures to take. He may be held back by capital investment requirements for more effective process equipment, better fuel controls, thermal energy recovery systems, or material recovery and recycling systems.

He undoubtedly needs better information on future fuel regulations, pricing, distribution, and availability to facilitate his decisions. He will lack price elasticity information on an overall basis for his own operation and for his industry and region. He will lack methods and data by which he can predict technical and economic feasibility of improvements as a function of effort. Specific information as to the reduction of energy consumption in a given equipment or process as a consequence of specific modifications is not easily available but must be estimated by rather detailed engineering calculations, for which the necessary data may not be availab1:

\section{Internal Potential for Energy Conservation}

The very complexity of industrial processes which are responsible for difficulties in generalizing and predicting the resuits of efforts to conserve energy also provide a wide variety of opportunities for energy conservation if approached with appropriate understanding of energy balances, thermal process technology, and materials properties.

Opportunities for affecting energy use can be reached through:

- Process technology

- Equipment reliability

- Dependability of fue1

- Support of the equipment manufacturer and the energy commodity supplier

- Labor requirements and skills

- Space requirements

- Regulatory factors 
Methods of improving energy utilization include:

- Better utilization of equipment

- Better heat confinement

- Better maintenance

- Heat recovery

- Retrofitting and up-grading equipment

- New improved equipment and processes

- By-product material recovery and recycling

- New and better thermal process technology

The engineering manager considering the implementation of energy conserving equipment and practices can be encouraged by the many instances where outstanding success has been achieved and the virtually unknown instance where a reasonable engineering effort has failed to save energy.

A serious effort to conserve energy within an industrial firm should be based on a management plan. This may vary from a relatively simple plan for a small firm to a formal management plan for a larger corporation. Elements of such a formal plan would include the following as appropriate.

- A corporate team - responsible for energy management with authority to plan and implement policy.

- A statement of policy need and objectives prepared by the team.

- Outside counsel and assistance

- A thorough energy inventory of supply and use schedules, suppliers, historical data of supply and prices and of fuel shortages and power outages.

- Energy facilities inspection schedules.

- Review of technology related to principal equipment and processes.

- Cost of likely power or fuel shortages.

- Actions for energy economy.

- Actions for energy security.

External Forces for Energy Conservation

There are many forces for energy conservation in industry which can arise outside the individual firm but which can have major effects on conservation of energy within the firm, within an industry, or within several industries. 
1. Information in many forms can be important: case studies of successful programs illustrating opportunity. and demonstrating feasibility, basic data for engineering calculations, and lists of energy conservation methods for suggesting possibilities.

Such information could be complied and developed by industry associations, universities, or government laboratories and communicated through appropriate publications and seminars to individual firms.

2. Tax policy incentives by government can provide economic incentive for capital investment in energy saving equipment which would otherwise not be purchased.

3. Price rate structures could encourage lower energy consumption by imposing rates which increase with usage which is larger than a norm for the processes being used.

4. Shipping rate structures could encourage shipment of reclaimed materials for recycling to favor their use over new materials where resulting energy savings would occur.

5. Energy accounting systems and energy use norms could be provided by government supported research for smaller industrial firms to use in appraising their energy use rates.

6. Government supported research on fuel price elasticity and other aspects of energy availability models and supporting data bases could provide predictors as a basis for energy availability expectations.

7. Government supported research on technologies for reclaiming and recycling industrial wastes could result in processes which conserve energy and other natural resources.

8. University extension services could be used for educational programs and for cooperative research programs with industry and commerce.

9. State and federal regulations which encourage or require unnecessary use of energy could be reexamined and modified as appropriate.

10. All appropriate costs, including social costs, of energy utilization could be internalized to resolve conflicts between energy conservation management and economic energy management.

These opportunities for motivating or inducing energy conservation are listed as possibilities but it is the sense of the conference that these options be carefully considered for implementation in appropriate situations by appropriate agencies in and out of government. 


\author{
Kenneth G. Kreider \\ National Bureau of Standards \\ Washington, D.C. 20234
}

Presentations were made concerning energy conservation in industrial processes and equipment in the third morning session. They were Dr. George Kelly's presentation, "Potential Options for Energy Conservation in Heating, Ventilating, and Air-Conditioning Equipment for Buildings"; Dennis Larson's "A Projection of Energy Demand by the Iron and Steel Industry"; Thomas Speidel's presentation on Thermo Electron's paper-forming machine which utilizes higher consistency pulp; and Preston McNall's remarks on the American Society of Heating, Refrigerating, and Air Conditioning Engineers (ASHRAE) program on energy conservation. The subject of energy conservation in industrial processes and equipment was also discussed in the evening task groups and I will try to summarize the four presentations, the task group discussions, and articulate some of the conclusions and recommendations.

Dr. Kelly emphasized the large amounts of energy consumed in commercial buildings and discussed the potential for energy conservation through proper design and use of building equipment. He presented a discussion of the features of unitary and central heating, ventilating and air conditioning (HVAC) equipment. He described both al1-air and air-water HVAC systems and elaborated on the virtues and shortcomings of the heat pump. Engineering descriptions of both vapor compression and absorption type heat pumps were given together with discussions on how the heat pump can be combined with other equipment to save energy. Total energy systems, modular integrated utility systems, and the utilization of waste heat from incineration plants were also covered.

The paper considered in detail the potential options for energy conservation in buildings resulting from the applications of standard HVAC equipment and presently available special systems. It is evident that considerable savings could be obtained by judicious choice of standard equipment based on energy conservation considerations. The use of life cycle costing rather than lowest possible first cost would vastly upgrade the present standards of practice. In addition, the use of innovations such as heat pumps and improved heat recovery devices promise significant improvements in HVAC efficiencies.

Dennis Larson's paper discussed energy demand in the iron and steel industry. This industry is not only one of the larger consumers of energy $17.5 \%$ of the total U.S. energy in 1968)*, but it is a very complex industry. His paper considered the interrelationships between projected demand for the products and the amounts of fuels needed for manufacturing the products, and the trends that could change the amounts of fueis needed per unit of product.

He concluded that there would be a $65 \%$ increase in production and a $28 \%$ increase in energy consumption in this industry between 1971 and 1985 . However, the growth rate of energy consumption decreases with time and should almost level off by 7985 . The change in energy requirements per ton of finished product is primarily the result of technological changes. Therefore, trends that phase out obsolete inefficient equipment can accelerate this energy utilization efficiency improvement. Most of the improved efficiency is expected in the iron-making and steel-making processes and very little change is forecast in the reheating and finishing portion of the industry.

* "Patterns of Energy Consumption in the U.S..", Office of Science and Technology", 1972. 
Tom Speidel's presentation on paper forming from high consistency pulp emphasized the energy savings from this basic processing change. He reviewed the standard wire belt fourdrinier paper-making process which uses 200 pounds of water for one pound of wood pulp. The new processing equipment which is similar to the Swedish high consistency former (HCF) can make high quality paper utilizing up to $2 \%$ suspended wood pulp. A helical mixer with a high shear component in the jet permits a $35 \%$ decrease in the heat required during the process. This process would be particularly attractive where fuel oil or fuel gas are used to supply the heat rather than waste bark and black liquor.

Preston MCNall described the ASHRAE energy conservation program. He pointed out that labor is no substitute for energy since a man is worth only $10 \notin$ per day in energy expended. He described the ASHRAE Guide and pointed out the excellent work in it on thermal comfort in buildings. Also emphasized was the need for better energy management and the importance of first cost to the building industry in speculative type investments. $\mathrm{Mr}$. MCNal] noted the utility of reheat HVAC systems since they are easy to maintain and have low initial costs.

Some general conclusions can be drawn from the presentations and the panel discussions.

1. Proper application of existing technology and equipment can effect large energy savings.

2. Awareness of energy conservation possibilities could be improved. Government promoted demonstrations of good examples would be useful.

3. Utilizing waste heat from industrial processes and equipment can be significant for energy conservation.

4. Total energy systems offer important opportunities for energy conservation.

5. Although the steel industry is improving the basic steel-making and iron-making process efficiencies, the processes relating to finishing and reheating may require more attention.

6. New methods for utilizing low-grade fuels should be developed.

7. Technological improvements in heat pumps, solar collectors, and automatic burner ignition devices should be promoted and publicized.

8. Improved stack gas control developments should be sponsored.

9. Economic motivation must be provided if the standard of energy conservation practice is to be improved. Taxation and banking/financial policy may be the proper tools. If this approach has shortcomings, regulations related to energy conservation may be required.

This last recommendation appears to the author to have a message. If economic motivation or government regulation is required for the success of energy conservation programs, then $i t$ would seem that energy conservation programs will require complex rationale and close cooperation between government and industry. 


\title{
INSTITUTIONAL CONSIDERATIONS RESPECTING ENERGY CONSERVATION
}

\author{
by \\ Samuel Z. Klausner \\ University of Pennsylvania \\ Philadelphia, Pennsylvania
}

Four papers were presented at the fourth morning of the conference on the topic "Institutional Considerations of Energy Conservation". J. B. Comly presented "Factors Controlling the Manufacture and Marketing of Energy Conserving Products". Paul Swatek then presented his views in his paper, "Economic, Energy, Environment Trade-Offs". Charles Warren. Assemblyman from the California State Assembly, discussed "Regulatory, Legal, and Tax Constraints on Energy Conservation -- Polemic or Fact? Sheldon Sixfin concluded the day's presentations with "Financial Feasibility of Energy Conservation".

The solutions to "the energy problem" are determined by the manner in which the problem is conceived. The basic observation which sets the problem is the perceived imbalance between the rates of energy consumption and energy supply. Another conference might have turned to the question of supply (the more typical American response to any shortage) and sought improved ways of extracting fuels or of exploiting some exotic source. We have chosen, in the way of the Buddhist sage and of the Protestant reformer, to look at our habits of material consumption. We judge our patterns of consumption in the light of individual perfidy; for that we are suffering. Some modest part of the energy consumption enhances the quality of our existence, our health, our strength against adversaries, and our mastery over other gifts of nature.

J. B. Comly, of General Electric Corporate Research and Development, pointed out that technological development alone does not assure immediate implementation of energyefficient systems. He showed that premature marketing of the heat pump as a heating system impaired its degree of acceptance. The tradeoff between energy efficiency and replacement cost of the incandescent light bulb illustrated the optimization of these two factors in a product. Mr. Comly concluded that the prospect of commercial success of a product should be evaluated well before that product is brought to market.

Believing that pecuniary motivation is high on the list of human priorities, Paul Swatek of the Massachusetts Audubon Society puts his faith in mechanisms of a freer market than we have known for some decades. He is certainly not a partisan of the industries, for he would unshackle the market, both removing subsidies to the energy industry (such as the oil depletion allowance) and have the producers internalize the now externalized social and environmental cost of their operations. He is attracted by an apparent social simplicity of these and other production mechanisms. They are effective in all energy consuming sectors, await the development of no new technologies, require no legislation of rigid criteria and technical standards, require no bureaucracy, rely on the normal operation of the free market, do not depend on changes in basic motivations of consumers, and, most reassuring of all, economists maintain that it will work and produce an efficient allocation of resources. Anticipating an audience question about the failure of some economists to discover short-term price elasticity for electricity, he reported a long-term price elasticity of demand of about -1.2.

Mr. Warren, recognizing the role of power in society, says he is prepared to rely for market balance of mechanisms in the market (such as an adjustment of electric rate structures would produce) on an educational and voluntary basis, but in the last analysis he relies on regulation. Behind regulatory enactments is the police power of the state. He would bring this power to bear, not simply as a Locke or other early modern political theorist would in adjucating conflict, but in specifying behavorial norms in the every day activities of people. He would set standards for the building industry, controlling lighting and insulation, be prepared to establish allocations of energy, and to prescribe levels of operating efficiency. Since the standards which he proposes are essentially 
performance criteria rather than product quality criteria, he would presumably be able to police conformity at the point of end use.

Sheldon Sixfin, of the Chase Manhattan Bank, approached energy availability from a fiscal point of view. The technology to be used is determined by the rate of return on the investment. Besides price, the ultimate criterion for choosing an energy source is its availability. He suggested, "Where critical energy shortages are foreseen, incentives must be provided to encourage the flow of capital in the directions necessary.... Private investors (should) be compensated for the risk that they undertake in the location and development of energy resources."

The panels made the following recommendations:

1) Potential interruptions of gas and electric service should be expected and proper preparations made.

2) Streamline procedures for processing nuclear power plant plans.

3) Develop a national education program on energy conservation, in which both the government and utilities participate to disseminate educational material.

4) Identify and determine the effectiveness of industrial energy conservation methods. Identify institutional constraints on energy conservation.

5) Publicize case histories of successful energy-saving measures for industrial management.

6) Implement regulatory actions to encourage energy conservation. Among the possibilities are: tax write-offs for homeowners who make energy-conserving improvements, negative tax incentives, such as a gasoline or pollution tax, and building standards established by the FHA and VA to optimize conservation.

7) Initiate zoning reform of "shared-energy" systems.

8) Review policies for subsidizing various transportation modes. 


\section{ENERGY CONSERVATION THROUGH EFFECTIVE ENERGY UTILIZATION}

\section{Engineering Foundation Conference}

A conference on "Energy Conservation through Effective Energy Utilization", is scheduled at New England College, Henniker, New Hampshire, August 19-24, 1973 by the Engineering Foundation in cooperation with the National Bureau of Standards. Co-Chairman of the conference are $\mathrm{Dr}$. Jesse C. Denton, National Center for Energy Management and Power, and Dr. Robert R. Gatts, National Bureau of Standards.

The conference is being co-sponsored by the American Society of Heating, Refrigerating and Air Conditioning Engineers and the National Center for Energy Management and Power.

The conference will deal, on an interdisciplinary basis, with the opportunities and implications of more effective utilization of thermal energy. The conference will focus on effective utilization as a means of energy conservation to identify the areas in which research is needed and will have significant impact. In some instances, the conference may identify specific research tasks, but, in other cases, it is anticipated that the conference will identify vital research areas which will need to be amplified and elaborated in greater detail to provide a partial basis for a National program of energy conservation. The detailed substantive input to such a program could be derived from intensive workshops conducted subsequent to this conference.

The conference will focus on the thermal process technologies as applied in industrial processes, in industrial equipment, and in building HVAC equipment. This focus on thermal process technology will help to develop a national perspective on energy conservation in industrial processes and HVAC equipment comparable to the existing perspective on energy conservation in building design and construction.

The program will consist of four days of presentations and discussion sessions dealing with the elements of energy conservation and a summary session on the fifth day. A typical day will see a paper presentation and discussion period in the morning followed by afternoon or evening discussion sessions. The morning sessions will be common, but the discussion sessions wi11 be concurrent in groups of 15 to 20 . The papers presented at the conference and summary material from the discussion sessions will be published in the conference proceedings and distributed widely to persons who play decisive roles in energy conservation - government, industry, labor, academia, and public interest groups. 
Appendix A

PROGRAM

Monday August 20

9:00 - 12:30 p.m. National Context for Energy Conservation

National Benefits of Energy Conservation

Distribution of Potential Impact Across Sectors

Measures of Effectiveness of Thermal Energy

Utilization

Economic and Environmental Implications of

Effective Utilization of Thermal Energy

7:00 - 10:00 p.m. Discussion Sessions

Tuesday, August 21

9:00 - 12:30 p.m. Energy Management Practice

Effectiveness of Thermal Energy Utilization in

Industrial Processes

Options in Energv Manaqement for Industrial

Processes

7:00 - 10:00 p.m. Discussion Sessions

Wednesday, August 22

9:00 - 12:30 p.m. Applications of Thermal Process Technologies

Variations in Current Practice for Industrial Processes

Potential Options for Enerqy Conservation in Industrial Processes and Equipment

Potential Options for Enerqy Conservation in Building Equipment

7:00 - 10:00 p.m. Discussion Sessions

Thursday, August 23

9:00 - 12:30 p.m. Institutional Considerations of Energy Conservation

Design, Manufacture, Acquisition, Application Chain

for Industrial Equipment

Cost, Energy Environment Accounting

Regulatory, Tax, Legal Constraints

Financial Feasibility of Energy Conservation

2:00 - 5:00 p.m. Discussion Sessions

7:00 - 10:00 p.m. Preparation of Summaries 
Friday, August 24

9:00 - 12:00 Noon Summary Session and Critique

National Context for Energy Conservation

Energy Management Practice

Applications of Thermal Process Technologies

Institutional Considerations of Energy Conservation 
Appendix B

PARTICIPANTS IN ENGINEERING FOUNDATION CONFERENCE

ON

ENERGY CONSERVATION THROUGH EFFECTIVE ENERGY UTILIZATION

New England College, Henniker, N. H. August 19 - 24, 1973

Gifford H. Albright

Pennsylvania State University

101 Engineering Unit "A"

University Park, Pennsylvania 16802

J. Ben Austin

Bucknel1 University

Lewisburg, Pennsylvania 17837

M. Balasubramanian

University of Pennsylvania

Philadelphia, Pennsylvania 19174

W. R. Becraft

Space Division

General Electric Company

Valley Forge Space Center

P.0. Box 8555

Philadelphia, Pennsylvania 19101

Charles Berg

National Bureau of Standards

Washington, D.C. 20234

William A. Blecher

United Aircraft Research Laboratory

East Hartford, Connecticut 06108

Hal Bloomberg

38 Exter Street

Brooklyn, New York 11235

Robert S. Bostwick

Florida Power \& Light Company

P.0. Box 3100

Miami, Florida 33101

Harry Brown

Drexel University

Philadelphia, Pennsylvania 19174
Robert A. Clifton

Bureau of Mines

4105 Wilson Boulevard

Arlington, Virginia 22203

Dr. James B. Comly

General Electric Company

Schenectady, New York 12345

Allen Cook

American Can Company

Greenwich, Connecticut 06830

William T. Cox

Department of Agriculture

Washington, D.C. 20250

Paul Craig

National Science Foundation

1800 G. St., N.W.

Washington, D.C. 20550

Joseph F. Cuba

ASHRAE

United Engineering Center

345 East 47th Street

New York, New York 10017

Charlotte Cuba

ASHRAE

345 East 47 th Street

New York, New York 10017

James Curl in

Library of Congress

10 First Street, S.E.

Washington, D.C. 20540

Jesse Denton

University of Pennsylvania

264 Towne Building

Philadelphia, Pennsylvania 19174 
Dave Didion

National Bureau of Standards

Washington, D.C. 20234

Eldon G. Ehlers

American Gas Association

1515 Wilson Boulevard

Arlington, Virginia 22109

Robert R. Gatts

National Bureau of Standards

A152 Technology Building

Washington, D.C. 20234

Leon Glickman

Massachusetts Institute of Technology

Boston, Massachusetts 02139

Bernard Hamel

Drexel University

Philadelphia, Pennsylvania 19104

Howard Harrenstien

University of Miami

Coral Gables, Florida 33124

Saul Hoch

General Electric Company

777 14th Street, N.W.

Washington, D.C. 20005

Harold Hollister

U.S. Atomic Energy Commission

1717 H. Street, N.W.

Washington, D.C. 20426

James $H$. Inglis

Federal Power Commission

825 North Capitol Avenue, N.E.

Washington, D.C. 20426

R. Gerald Irvine

NYS Public Service Commission

44 Holland Avenue

Albany, New York 12208

Neldon L. Jensen

Bureau of Mines

1800 C. Street, N.W.

Washington, D.C. 20240

William J. Jones

Energy Laboratories

Massachusetts Institute of Technology

Building 26-145

Cambridge, Massachusetts 02139
R. A. Kelly

Flinn \& Dreffein Engineering Company

3504 Commercial Avenue

Northbrook, Illinois 60062

Glen Kendal1

Environmental Protection Agency

Room 1019, Waterside Ma11, West Tower

401 M. Street, S.W.

Washington, D.C. 20460

W. B. Kirk

American Gas Association, Laboratories

8501 East Pleasant Valley Road

Cleveland, Ohio 44131

Samuel Klausmer

University of Pennsylvania

4025 Chestnut Street

Philadelphia, Pennsylvania 19174

G. Lamb

University of Pennsylvania

Room 716 Maloney Building

Philadelphia, Pennsylvania 19174

Dennis Larsen

Institute of Gas Technology

3424 South State Street

Chicago, I1linois 60616

Dilip Limaye

Decision Sciences Corporation

Jenkintown, Pennsylvania 19046

Quentin Looney

Department of Commerce

Washington, D.C. 20230

Oscar Manly

Visdyne Corporation

Burlington, Massachusetts 01803

Robert G. Massey

National Bureau of Standards

A124 Technology Building

Washington, D.C. 20234

Preston E. McNall

Johnson Service Company

507 East Michigan

Milwaukee, Wiscons in 53201

F. McQuade

University of Pennsylvania

Philadelphia, Pennsylvania 19174 
Patricia J. McWethy

National Science Foundation

1800 G. Street, N.W. K700

Washington, D.C. 20550

John Mockoviak

Grumman Aerospace

Bethpage, Long Island, New York 11714

R. B. Mose 1y

She 11 Oil Company

P.0. Box 2463

Houston, Texas 77001

A. Dwayne Nelson

3 M Company

3 M Center Building 230-2

St. Paul, Minnesota 55101

Mike Noland

Midwest Research Institute

Kansas City, Missouri 64112

John Patterson

Esso Research \& Engineering Company

P.0. Box 215

Linden, New Jersey 07016

Anton Roeger

Texas Eastern Transmission, Incorporated Box 1612

Shreveport, Louisiana 71130

Donald A. Reppert

Monsanto Company

800 N. Lindberg

St. Louis, Missouri 63166

Barry Riordan

Council on Environmental Quality

722 Jackson Place, N.W.

Washington, D.C. 20006

Peter Romano

Grumman Aerospace

Bethpage, Long Is land, New York 11714

William Rudoy

University of Pittsburgh

Pittsburgh, Pennsylvania

15213

Maxine Savitz

National Science Foundation

1800 G. Street, N.W.

Washington, D.C. 20590

Loren C. Schmid

Batelle - N.W.

Richland, Washington 99352
George Schrenk

University of Pennsylvania

Towne School

Philadelphia, Pennsylvania 19174

Robert E. Shephard

Department of Commerce

Office of Energy Programs

Washington, D.C. 20230

Karl Sittel

Reentry \& Environment Systems Division

General Electric Valley Forge

Technology Center

Philadelphia, Pennsylvania 19101

Sheldon Sixfin

Chase Manhattan Bank

New York, New York 10015

Emerson W. Smith

Postal Service

475 L'Enfant Plaza West, S.W.

Washington, D.C. 20260

Richard T. Smith

Southwest Research Institute

Box 28510

San Antonia, Texas 78284

Philip Snyder

Westinghouse Fluid Systems Laboratory

1291 Cumberland Avenue

West Lafayette, Indiana 47906

Thomas Spiedel

Thermo-Electron Corporation

Auburn, Massachusetts 01501

P. Swatek

Massachusetts Audubon Society

South Grate Road

Lincoln, Massachusetts 01773

Arthur Takata

IIT Research Institute

10 west 35th Street

Chicago, Illinois 60616

Theodore Teichmann

KMS Fusion Incorporated

3941 Research Park Drive

Ann Arbor, Michigan 48170

E. M. Sparrow

University of Minnesota

Department of Mechanical Engineering

Minneapolis, Minnesota 55455 
Table of Conversion Factors to Metric (S I ) Units

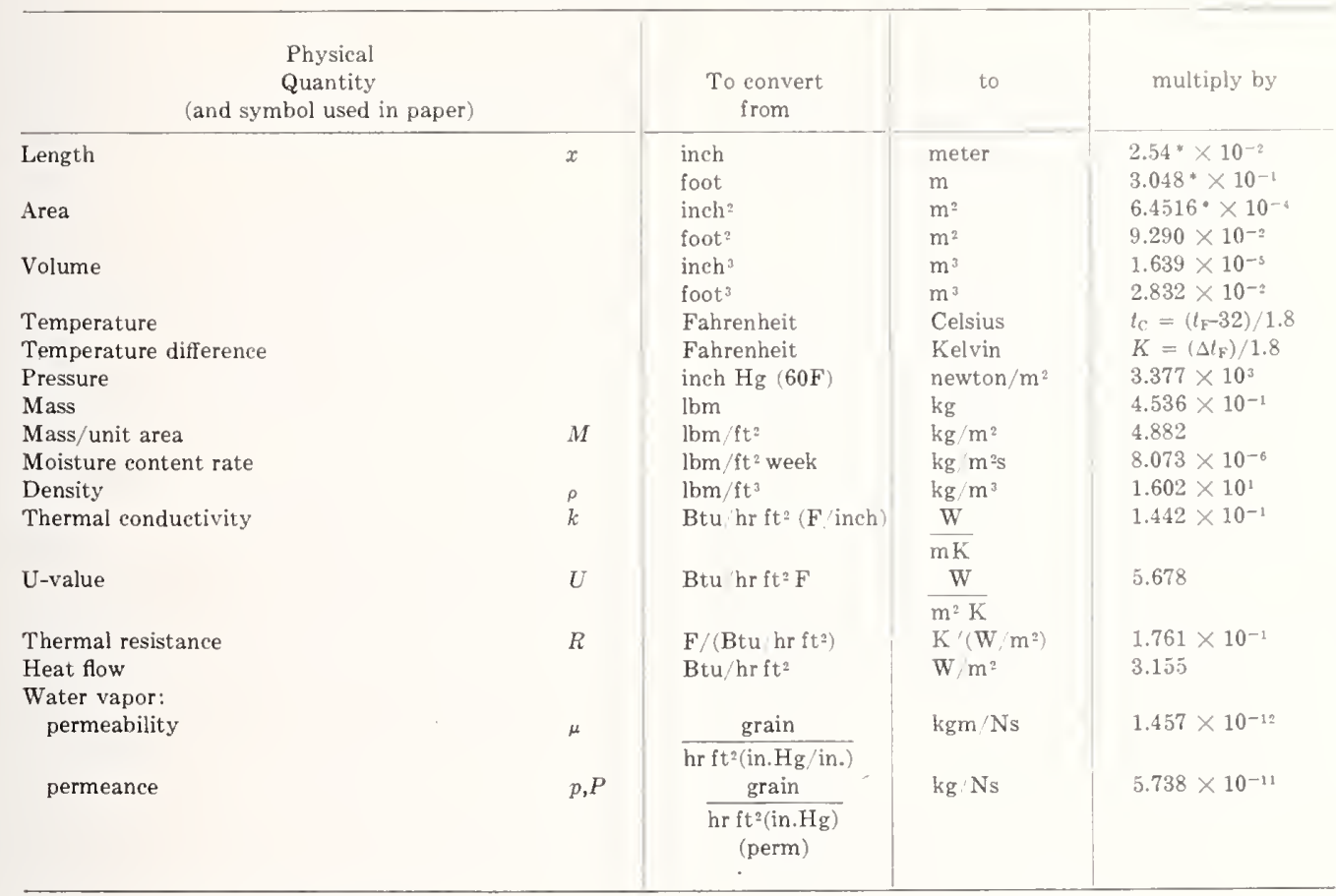

Exact value; others are rounded to fourth place.

In view of present practice in thermal process technology, the common units of measurement used by the various speakers are retained in this publication.

However, in recognition of the United States as a signatory to the General Conference on Weights and Measures, which gave official status to the metric (SI) system of units in 1960, many useful conversion factors are provided in the table above.

Readers interested in making further use of the uniform nomenclature that metric units offer are encouraged to refer to:

The International System of Units (SI), NBS Spec. Pub. 330, 1974 edition. Superintendent of Documents, U.S. Govt. Printing Office, Wash., D.C. 20402. SD Cat. No. C $13.10: 330 / 3$. Price 65 cents.

The Standard Metric Practice Guide American Society for Testing and Materials, 1916 Race Street, Philadelphia, Pa. 19103. E 380-72. Price \$1.75. Also available from the American National Standards Institute, 1430 Broadway, New York, N.Y. 10018. ANSI Z 210.1 Price $\$ 1.75$.

SI Units and Recommendations for Use of Their Multiples. American National Standards Institute. ISO International Standdard 1000, 1973 edition. Price $\$ 1.50$. 
MBS-114A (REV. 7.73)

\begin{tabular}{|c|c|c|c|}
\hline $\begin{array}{l}\text { U.S. DEPT. OF COMM. } \\
\text { BIBLIOGRAPHIC DATA } \\
\text { SHEET }\end{array}$ & $\begin{array}{l}\text { 1. PUBLICATION OR REPORT NO. } \\
\text { NBS Spec. Pub. No. } 403\end{array}$ & $\begin{array}{l}\text { 2. Gov't Accession } \\
\text { No. }\end{array}$ & 3. Recipient's Accession No. \\
\hline 4. TITLE AND SUBTITLE & 4. TITLE AND SUBTITLE & & $\begin{array}{r}\text { 5. Publication Date } \\
\text { June } 1976\end{array}$ \\
\hline \multicolumn{3}{|c|}{ ENERGY CONSERVATION THROUGH EFFECTIVE ENERGY UTILIZATION } & 6. Performing Organization Code \\
\hline 7. AUTHOR(S) & \multicolumn{2}{|c|}{ J.C. Denton, S. Webber, and J. Moriarty } & 8. Performing Organ. Report No. \\
\hline \multicolumn{3}{|c|}{$\begin{array}{l}\text { 9. PERFORMING ORGANIZATION NAME AND ADDRESS } \\
\text { NATIONAL BUREAU OF STANDARDS } \\
\text { DEPARTMENT OF COMMERCE } \\
\text { WASHINGTON, D.C. } 20234\end{array}$} & 10. Project/Task/Work Unit No. \\
\hline \multirow{2}{*}{\multicolumn{3}{|c|}{$\begin{array}{l}\text { 12. Sponsoring Organization Name and Complete Address (Street, City, State, ZIP) } \\
\text { National Bureau of Standards } \\
\text { National Science Foundation } \\
\text { Engineering Foundation }\end{array}$}} & $\begin{array}{l}\text { 13. Type of Report \& Period } \\
\text { Covered }\end{array}$ \\
\hline & & & 14. Sponsoring Agency Code \\
\hline
\end{tabular}

15. SUPPLEMENTARY NOTES

\section{Library of Congress Catalog Card Number: 76-18680}

16. ABSTRACT (A 200-word or less factual summary of most significant information. If document includes a significant bibliography or literature survey, mention it here.)

These proceedings of the 1973 Engineering Foundation Conference focus on effective utilization of thermal energy as a means of energy conservation. It is hoped publication will help stimulate the national dialogue toward a balanced national program for more energy conservation.

The varied professional backgrounds of the participants provided an interdisciplinary approach for action steps to be taken in areas where research is needed and will provide a significant impact. For example, the development of better stack controls was recommended as a specific research task, and the improvement of energy accounting systems and energy use norms was recommended as a useful research area. Broad agreement was reached that there is much left to be accomplished in thermal process technology as used in industrial processes, in industrial equipment, and in heating, ventilating, and air conditioning (HVAC) equipment for buildings.

A clear conclusion of the conference is that while new technology is important the

introduction of much technology that is already available is equally, if not more, important. Institutional barriers relating to economics, management, finance, and national policy keep avallable technology standing in the wings. The conference papers and discussions show that engineering design, when it can be rigorously applied, does result in striking reductions in energy use in the thermal process technologies.

17. KEY WORDS (six to twelve entries; alphabetical order; capitalize only the first letter of the first key word unless a proper name; separated by semicolons)

Automobile; break-even analysis; conservation; cooling; economics; energy; environment; fuel; heating; industry; imports; management; manufacturing; paper; petroleum; resources; standards; stee: ; thermal; thermodynamics.

18. AVAILABILITY $\mathrm{X}$ Unlimited

For Official Distribution. Do Not Release to NTIS

$x$ Order From Sup. of Doc., U.S. Government Pfinting Office Washington, D.C. 20402, SD Cat.No.C13.10:403

Order From National Technical Information Service (NTIS) Springfield, Virginia 22151

\begin{tabular}{|l|c|}
\hline $\begin{array}{l}\text { 19. SECURITY CLASS } \\
\text { (THIS REPURT) }\end{array}$ & 21. NO. OF PAGES \\
UNCL ASSIFIED & 251 \\
\hline $\begin{array}{l}\text { 20. SECURITY CLASS } \\
\text { (THIS PAGE) } \\
\text { UNCLASSIFIED }\end{array}$ & 22 . Price \\
$\$ 3.30$
\end{tabular}




\section{PERIODICALS}

JOURNAL OF RESEARCH reports National Bureau of Standards research and development in physics, mathematics, and chemistry. It is published in two sections, available separately:

\section{- Physics and Chemistry (Section A)}

Papers of interest primarily to scientists working in these fields. This section covers a broad range of physical and chemical research, with major emphasis on standards of physical measurement, fundamental constants, and properties of matter. Issued six times a year. Annual subscription: Domestic, $\$ 17.00$; Foreign, $\$ 21.25$.

\section{- Mathematical Sciences (Section B)}

Studies and compilations designed mainly for the mathematician and theoretical physicist. Topics in mathematical statistics, theory of experiment design, numerical analysis, theoretical physics and chemistry, logical design and programming of computers and computer systems. Short numerical tables. Issued quarterly. Annual subscription: Domestic, $\$ 9.00$; Foreign, $\$ 11.25$.

DIMENSIONS/NBS (formerly Technical News Bulletin)-This monthly magazine is published to inform scientists, engineers, businessmen, industry, teachers, students, and consumers of the latest advances in science and technology, with primary emphasis on the work at NBS. The magazine highlights and reviews such issues as energy research, fire protection, building technology, metric conversion, pollution abatement, health and safety, and consumer product performance. In addition, it reports the results of Bureau programs in measurement standards and techniques, properties of matter and materials, engineering standards and services, instrumentation, and automatic data processing.

Annual subscription: Domestic, $\$ 9.45$; Foreign, $\$ 11.85$.

\section{NONPERIODICALS}

Monographs-Major contributions to the technical literature on various subjects related to the Bureau's scientific and technical activities.

Handbooks-Recommended codes of engineering and industrial practice (including safety codes) developed in cooperation with interested industries, professional organizations, and regulatory bodies.

Special Publications-Include proceedings of conferences sponsored by NBS, NBS annual reports, and other special publications appropriate to this grouping such as wall charts, pocket cards, and bibliographies.

Applied Mathematics Series-Mathematical tables, manuals, and studies of special interest to physicists, engineers, chemists, biologists, mathematicians, computer programmers, and others engaged in scientific and technical work.

National Standard Reference Dats Series-Provides quantitative data on the physical and chemical properties of materials, compiled from the world's literature and critically evaluated. Developed under a world-wide program coordinated by NBS. Program under authority of National Standard Data Act (Public Law 90-396).

NOTE: At present the principal publication outlet for these data is the Journal of Physical and Chemical Reference Data (JPCRD) published quarterly for NBS by the American Chemical Society (ACS) and the American Institute of Physics (AIP). Subscriptions, reprints, and supplements available from ACS, 1155 Sixteenth St. N. W., Wash. D. C. 20056.

Building Science Series-Disseminates technical information developed at the Bureau on building materials, components, systems, and whole structures. The series presents research results, test methods, and performance criteria related to the structural and environmental functions and the durability and safety characteristics of building elements and systems.

Technical Notes-Studies or reports which are complete in themselves but restrictive in their treatment of a subject. Analogous to monographs but not so comprehensive in scope or definitive in treatment of the subject area. Often serve as a vehicle for final reports of work performed at NBS under the sponsorship of other government agencies.

Voluntary Product Standards-Developed under procedures published by the Department of Commerce in Part 10, Title 15, of the Code of Federal Regulations. The purpose of the standards is to establish nationally recognized requirements for products, and to provide all concerned interests with a basis for common understanding of the characteristics of the products. NBS administers this program as a supplement to the activities of the private sector standardizing organizations.

Federal Information Processing Standards Publications (FIPS PUBS)-Publications in this series collectively constitute the Federal Information Processing Standards Register. Register serves as the official source of information in the Federal Government regarding standards issued by NBS pursuant to the Federal Property and Administrative Services Act of 1949 as amended, Public Law 89-306 (79 Stat. 1127), and as implemented by Executive Order 11717 ( 38 FR 12315, dated May 11, 1973) and Part 6 of Title 15 CFR (Code of Federal Regulations).

Consumer Information Series-Practical information, based on NBS research and experience, covering areas of interest to the consumer. Easily understandable language and illustrations provide useful background knowledge for shopping in today's technological marketplace.

NBS Interagency Reports (NBSIR)-A special series of interim or final reports on work performed by NBS for outside sponsors (both government and non-government). In general, initial distribution is handled by the sponsor; public distribution is by the National Technical Information Service (Springfield, Va. 22161) in paper copy or microfiche form.

Order NBS publications (except NBSIR's and Bibliographic Subscription Services) from: Superintendent of Documents, Government Printing Office, Washington, D.C. 20402 .

\section{BIBLIOGRAPHIC SUBSCRIPTION SERVICES}

The following current-awareness and literature-survey bibliographies are issued periodically by the Bureau: Cryogenic Data Center Current Awareneas Service

A literature survey issued biweekly. Annual subscription: Domestic, $\$ 20.00$; foreign, $\$ 25.00$.

Liquefied Natural Gas. A literature survey issued quarterly. Annual subscription: $\$ 20.00$.

Superconducting Devices and Materials. A literature survey issued quarterly. Annual subscription: $\$ 20.00$. Send subscription orders and remittances for the preceding bibliographic services to National Bureau of Standards, Cryogenic Data Center (275.02) Boulder, Colorado 80302.

Electromagnetic Metrology Current Awareness Service Issued monthly. Annual subscription: \$24.00. Send subscription order and remittance to Electromagnetics Division, National Bureau of Standards, Boulder, Colo. 80302 . 
U.S. DEPARTMENT OF COMMERCE National Bureau of Standards

Washington. D.C. 20234

DFFICIAL BUSINESS

U.S. DEPARTMENT OF COMMERCE

Penalty for Private Use, $\$ 300$
POSTAGE AND FEES PAID

$C O M-215$

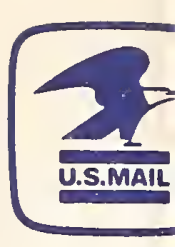

SPECIAL FOURTH-CLASS RATE BOOK 